\title{
Phylogeny and systematic revision of the helicarionid semislugs of eastern Queensland (Stylommatophora, Helicarionidae)
}

\author{
Isabel T. Hyman \\ Australian Museum, 1 William St, Sydney NSW 2010, Australia \\ Isabel.Hyman@austmus.gov.au \\ Frank Köhler \\ Australian Museum, 1 William St, Sydney NSW 2010, Australia
}

\begin{abstract}
The helicarionid fauna of southeastern to mid-eastern Queensland is dominated by a group of semislugs with moderately reduced shells belonging to genera Fastosarion, Eungarion, Stanisicarion, Dimidarion, Macularion and Hymanarion. We comprehensively revise their systematic classification using comparative morpho-anatomy and mitochondrial phylogenetics, and demonstrate that these genera combined form a well-differentiated and monophyletic radiation. In our mitochondrial phylogeny, this radiation is divided into three main clades that are statistically well supported. One clade is also well defined in terms of diagnostic morpho-anatomical characters, but we could not identify diagnostic characters for the other two clades due to considerable levels of morpho-anatomical variation. We propose accepting only two genera, Fastosarion (with junior synonyms Eungarion, Dimidarion, and Hymanarion) and Stanisicarion (with junior synonym Macularion). Both genera represent mutually monophleytic sister taxa that can consistently be distinguished by the presence or absence of a penial verge that is fused to the penial wall and by egg shape. We also synonymise Fastosarion ameyi with F. aquavitae, F. schelli with F. helenkingae, Dimidarion peterbrocki and D. slatyeri with $F$. alyssa, Stanisicarion virens with $S$. freycineti. Revised species descriptions are presented for Fastosarion alyssa, F. aquavitae, F. brazieri, F. comerfordae, F. griseolus, F. hannianus, F. helenkingae, F. mcdonaldi, F. minerva, F. paluma, F. papillosus, F. pustulosus, F. superbus, Stanisicarion aquila and S. freycineti. Nine new species, Fastosarion deensis, F. ephelis, F. insularis, F. katatonos, F. longimentula, F. rowani, F. sarina, F. tuljun and Stanisicarion wolvi are described, bringing the total number of accepted species to 24 .
\end{abstract}

\section{Keywords}

comparative anatomy - morphology - mitochondrial DNA - systematics - taxonomy

(C) HYMAN \& KÖHLER, 2019 | DOI:10.1163/18759866-20191416

This is an open access article distributed under the terms of the CC-BY 4.o License. 


\section{Introduction}

The Helicarionidae are a family comprising not only snails, but also semislugs, which are species that have undergone such a degree of shell reduction that they cannot fully retract into their shells. This group is well-represented in Australia with over 100 accepted species (Stanisic et al., 2010), as well as in Southeast Asia, islands of the Pacific, Madagascar and the Mascarene Islands and parts of continental Africa (Bank, 2017). In Australia, the centre of the diversity of this group is along the eastern coast, particularly in Queensland (Qld). While most of the New South Wales (NSW) fauna have recently been revised in detail (Hyman et al., 2017; Hyman \& Köhler, 2018a, b, 2019), the Qld fauna are at present poorly known.

Helicarionids in Qld can be grouped into three main morphological types: (1) snails with a complete shell of 5-6 whorls (e.g., Expocystis Iredale, 1937), (2) semislugs with moderately reduced shells of $3-4.5$ whorls (e.g., Fastosarion Iredale, 1933), and (3) semislugs with extremely reduced shells of fewer than three whorls (e.g., Parmacochlea Smith, 1884). There is evidence to suggest that shell reduction has evolved multiple times among the Australian Helicarionidae (Hyman et al., 2007), and some radiations contain both snails and semislugs, such as the helicarionid clade in southeastern Australia (Hyman et al., 2017) and the helicarionid radiation on Lord Howe Island (Hyman et al., 2007; Hyman \& Ponder, 2016; Hyman and Köhler, 2018a). These studies have also highlighted the systematic significance of certain reproductive characters in the delimitation of broad groups within Helicarionidae: the presence or absence of a vagina and of the penial accessory organs the caecum and flagellum, and if present, the shape of these organs, and the position of attachment of the penial retractor muscle.
Using these characters and the limited anatomical data available (Stanisic, 1993a; Scott, 1995; Hyman and Ponder, 2010), it has been our working hypothesis that the moderate semislugs of Qld form a single radiation. All species can be distinguished from other Australian semislugs by the presence of a long vagina, a long, slender flagellum without internal cryptae, and an epiphallic caecum with the penial retractor muscle attaching to its base or middle. Some of these character states are shared by the snail Expocystis rusticus (Pfeiffer, 1852), but it differs in lacking a vagina.

These moderate semislugs of Qld are currently classified into six different genera: Fastosarion, Eungarion Stanisic, 1993, Dimidarion Stanisic, 2010, Macularion Stanisic, 2010, Stanisicarion Hyman \& Ponder, 2010, and Hymanarion Stanisic, 2010. Some other semislug genera from southern Qld (e.g., Mysticarion Iredale, 1941, Cucullarion Stanisic, 1998, Ubiquitarion Hyman, Lamborena \& Köhler, 2017) have already been shown to belong to a different radiation (Hyman et al., 2017) and therefore are included only as outgroups in the present study.

Parmacochlea, Thularion Stanisic, 1993 and Antiquarion Stanisic, 2010 from northern Qld and Fenestrarion Stanisic, 2010 from southern Qld all have a greater degree of shell reduction. Parmacochlea and Thularion differ substantially in anatomy from Fastosarion and related groups (Stanisic, 1993b; Hyman \& Ponder, 2010); however, Fenestrarion and Antiquarion are known only by their shells, as is the moderately reduced semislug genus Colmanarion Stanisic, 2010 from northern Qld (Stanisic et al., 2010).

The present study is a continuation of our complete revision of Australian Helicarionidae (Hyman \& Ponder, 2016; Hyman \& Köhler, 2017: Hyman et al., 2017; Hyman \& Köhler, 2018a, b, 2019). Herein we revise the moderate semislugs of Qld using comparative 
morphology and by sequencing mitochondrial markers cytochrome $c$ oxidase subunit I (COI) and the large ribosomal subunit 16S.

\section{Materials and methods}

\section{Material}

This study is based on the examination of ethanol-preserved specimens and supplementary dry material from the Australian Museum, Sydney (AM), the Queensland $\mathrm{Mu}-$ seum, Brisbane (QM), the Museum of Tropical Queensland, Townsville (MTQ), Museums Victoria, Melbourne (NMV), and the Naturhistoriska Riksmuseet, Stockholm, Sweden (NHRM), including freshly collected material from northeastern NSW and southeastern Qld (table 1). In additional, photographs of type specimens from the Natural History Museum, London, UK(NHMUK) were made available for comparison.

\section{Molecular studies and phylogenetic analyses}

DNA was extracted from small pieces of foot muscle by use of a QIAGEN DNA extraction kit for animal tissue (Qiagen, Hilden) following the standard procedure of the manual. An approximately 900 base pair long fragment of the $16 \mathrm{~S}$ gene was amplified by PCR using the primers $16 \mathrm{~S}_{3} \mathrm{~F}$ and ${ }_{16 \mathrm{~S}} 4 \mathrm{Ra}$ (Hyman et al., 2007). Whenever we failed to amplify the whole fragment due to DNA fragmentation as typically encountered in extracts from older museum specimens, we amplified two overlapping shorter fragments or even performed nested PCRs by using the internal primers $16 \mathrm{~S}_{3} \mathrm{R}$ and ${ }_{16 S} 4 \mathrm{~F}$ (Hyman et al., 2007). In addition, an 823 base pair long fragment of the COI gene was amplified by using the primers LCOH1940 (Folmer et al., 1994) and COI-H865 (Hyman et al., 2017). For samples with highly fragmented DNA we performed a nested PCR using the primers LCOH149o and HCOI2198 (Folmer et al., 1994) to amplify a 655 base pair long fragment. Reactions were performed using standard protocols with annealing temperatures/elongation times of $55^{\circ} \mathrm{C} / 90 \mathrm{~s}$ for $16 \mathrm{~S}$ and $60 \mathrm{~s} 50^{\circ} \mathrm{C} / 6$ o s for COI, respectively. Both strands of PCR fragments were purified and cycle sequenced by use of the PCR primers. Electropherograms were corrected for misreads and forward and reverse strands were merged into one sequence file using CodonCode Aligner v. 3.6.1 (CodonCode Corp., Dedham, MA). Sequences of previous helicarionid studies (Hyman et al., 2007; Hyman et al., 2017) were retrieved from Genbank and included in our dataset while all newly produced sequences have been deposited in GenBank under the accession numbers MNo73529-MNo73784.

The $16 \mathrm{~S}$ sequences were aligned using the online version of MAFFT (version 7) available at www. http://mafft.cbrc.jp/alignment/ server/ by employing the iterative refinement method E-INS-i suitable for sequences with multiple conserved domains and long gaps (Katoh et al., 2002). Uncorrected p-distances between sequences were calculated by using the phylogenetic software MEGA7 (Kumar et al., 2016) under the option 'pair-wise deletion of gaps'. We used Guidancez (Sela et al., 2015) to identify and remove unreliable alignment regions in the $16 \mathrm{~S}$ alignment by employing default settings. The final sequence alignments of $16 \mathrm{~S}$ and COI were concatenated into one partitioned data set. Four partitions were designated: The entire $16 \mathrm{~S}$ fragment plus each of the three codon positions of the COI fragment. The best-fit model of nucleotide substitution was identified for each sequence partition separately by means of the corrected Akaike Information Criterion ('AICc') using the software Partitionfinder 2.1.1 (Lanfear et al., 2012). Phylogenetic relationships were estimated by employing a Maximum Likelihoodbased method of tree reconstruction as well 

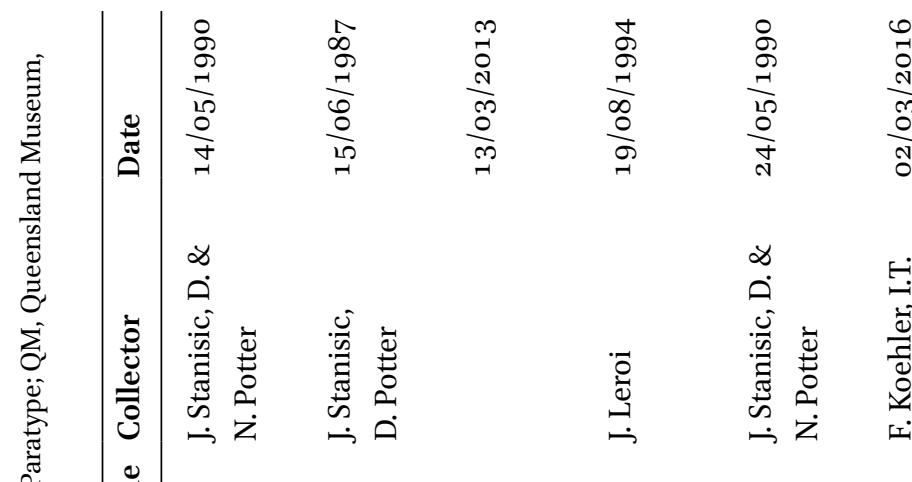

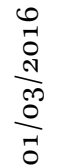

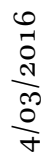

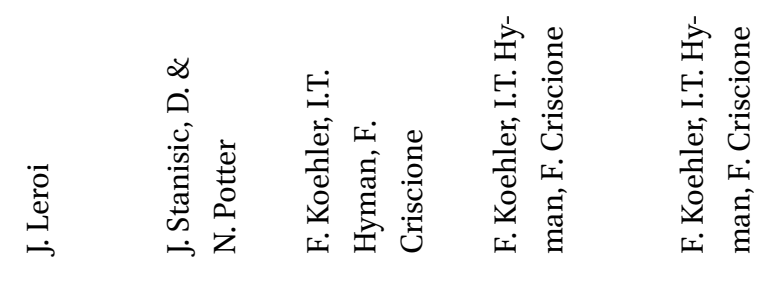

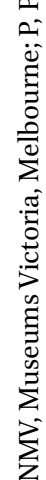

苛
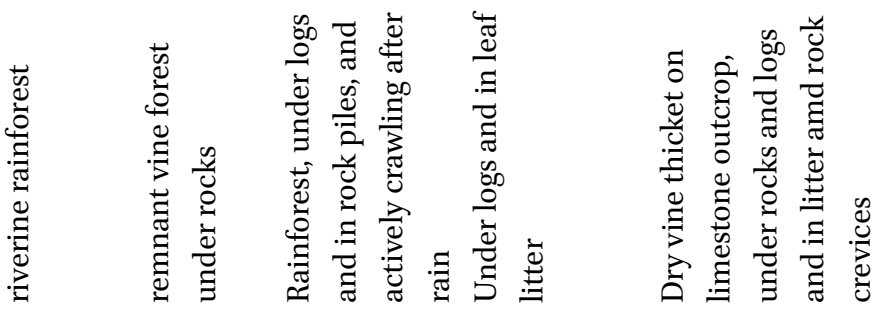

\section{(1)}

莺

i.

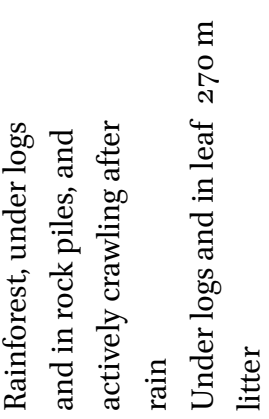

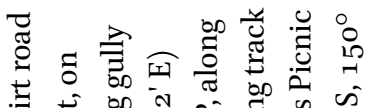
की 藏

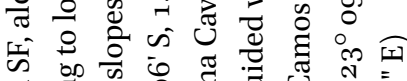
क क क

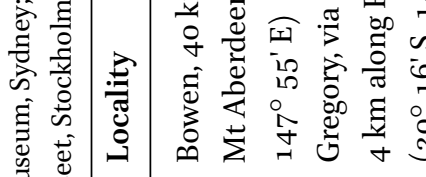

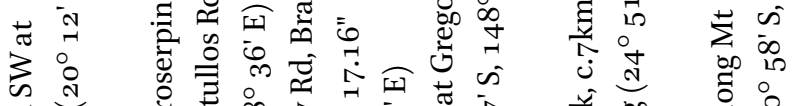

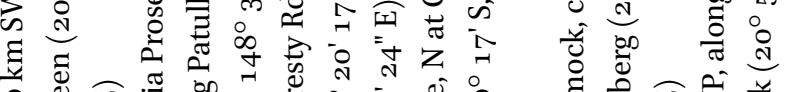
क 27<smiles>C=[13CH]</smiles>

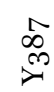

$\stackrel{9}{7}$

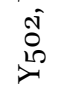

$\stackrel{1}{\sqrt{0}}$

$\underset{\substack{n \\ \text { in }}}{\substack{0 \\ 0}}$

艺

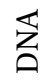

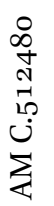

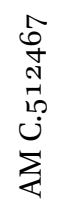




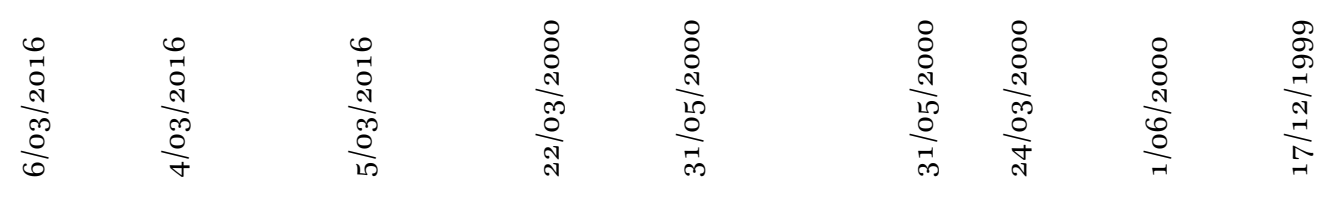

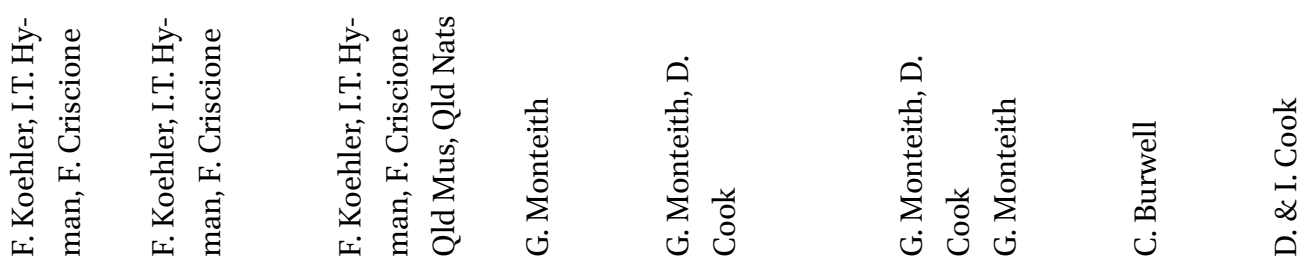

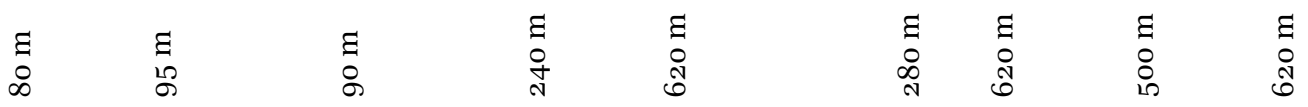
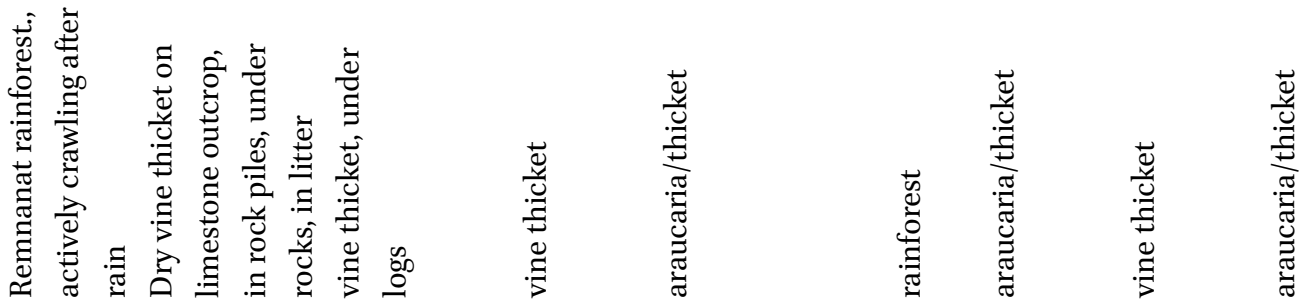

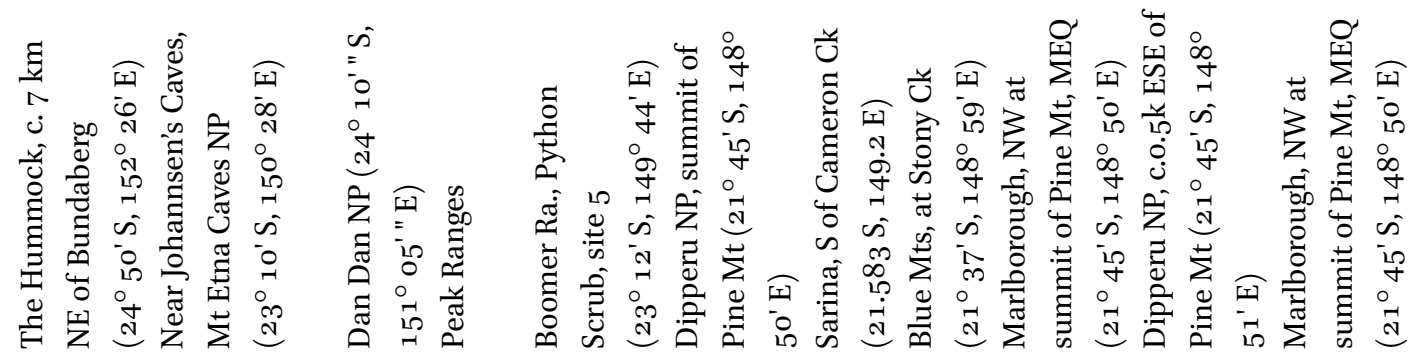

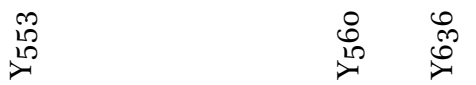

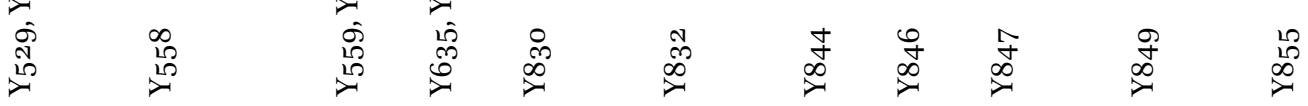

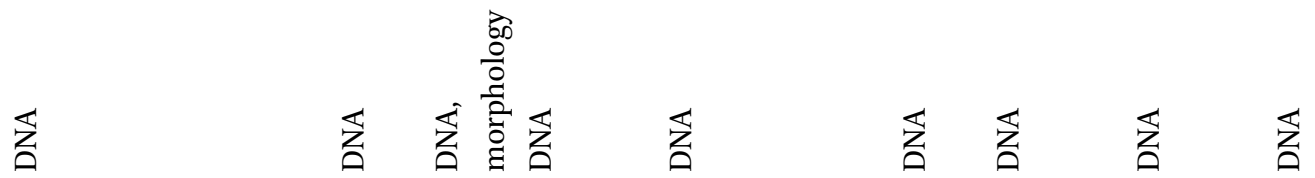

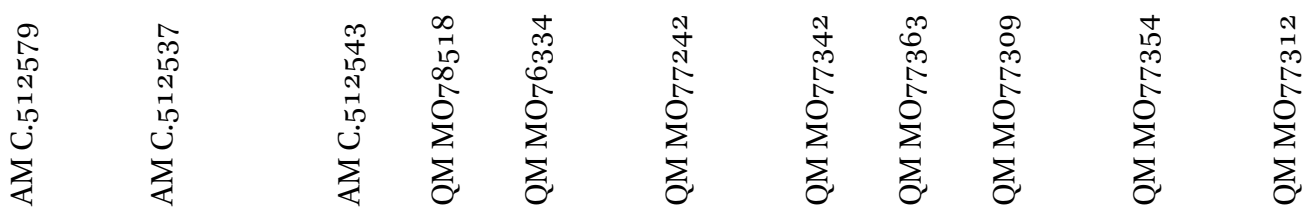




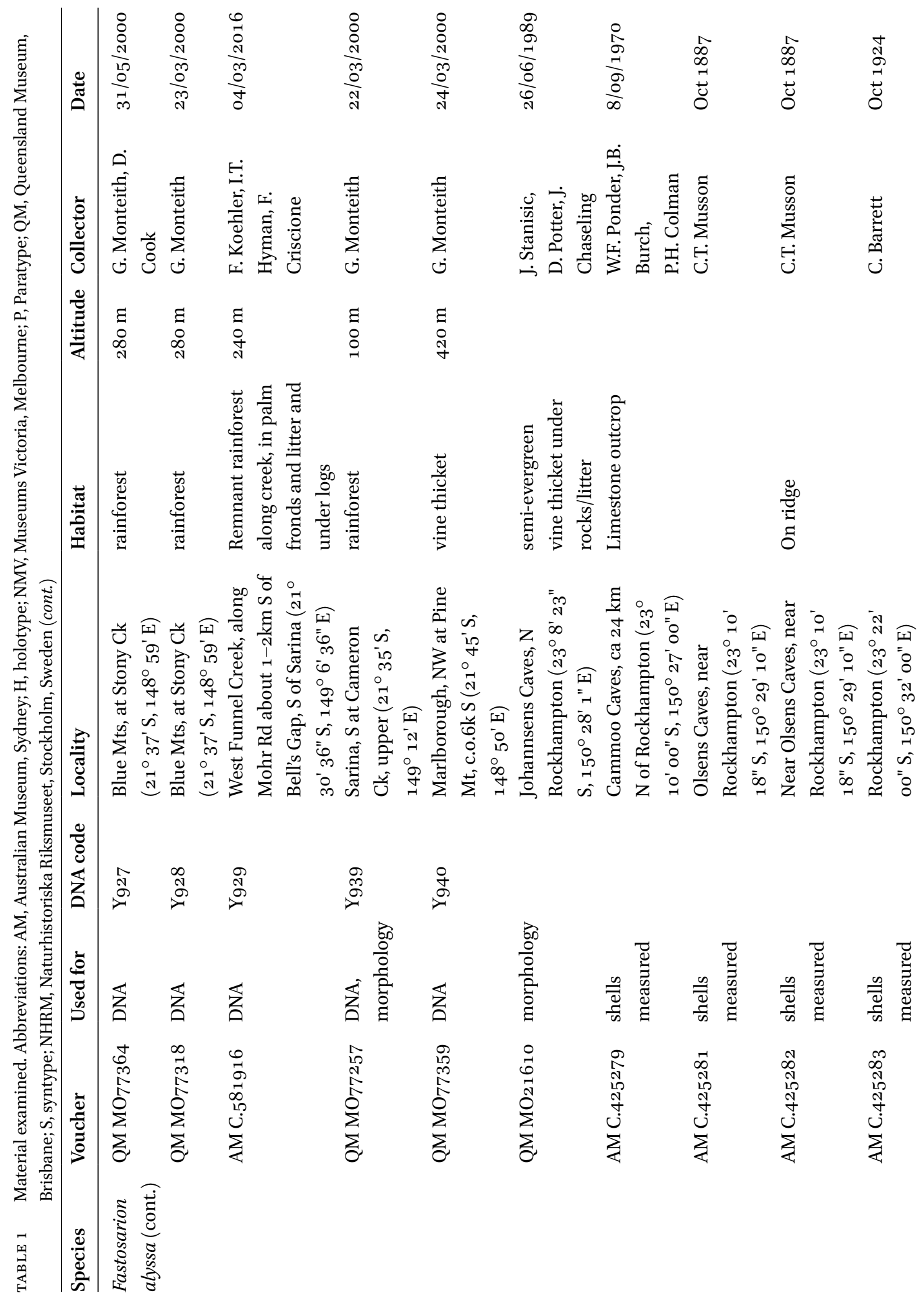




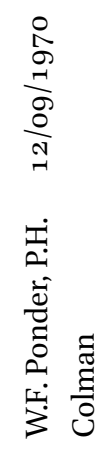

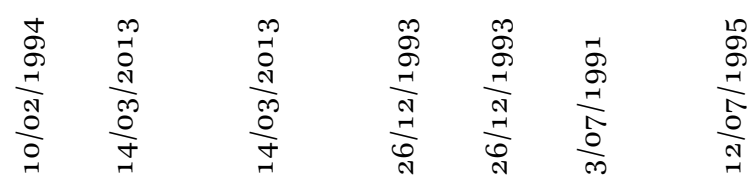

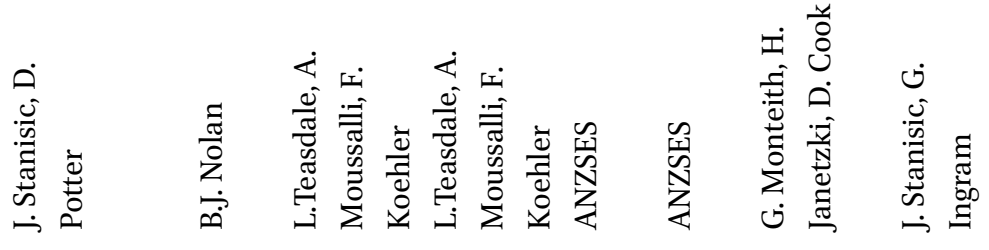

$\underset{1}{1}$

ב
$\vdots$
0
10

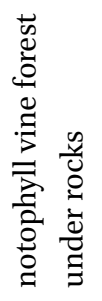

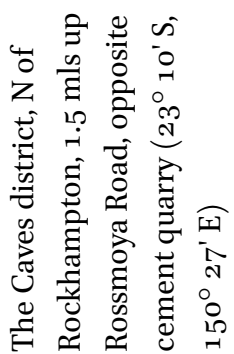

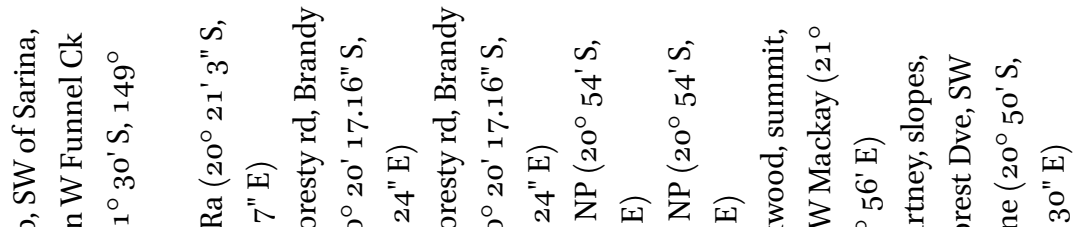

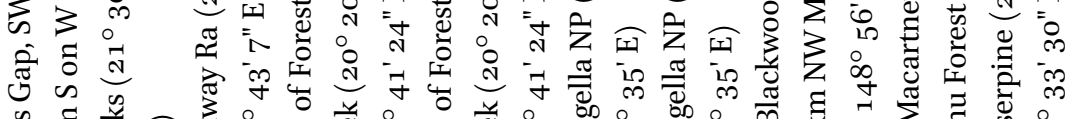
至 ๓

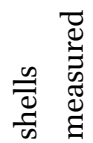

$\stackrel{8}{\nearrow}$

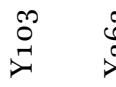

$\stackrel{\infty}{\infty} \underset{\substack{\infty}}{\infty}$

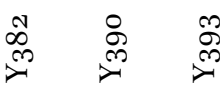

产

这

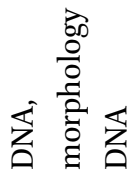

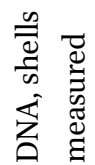

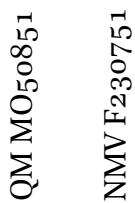

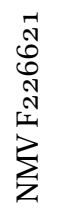

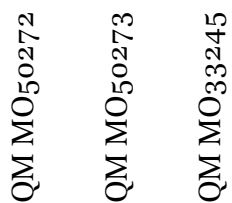

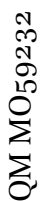

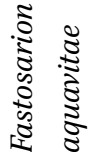




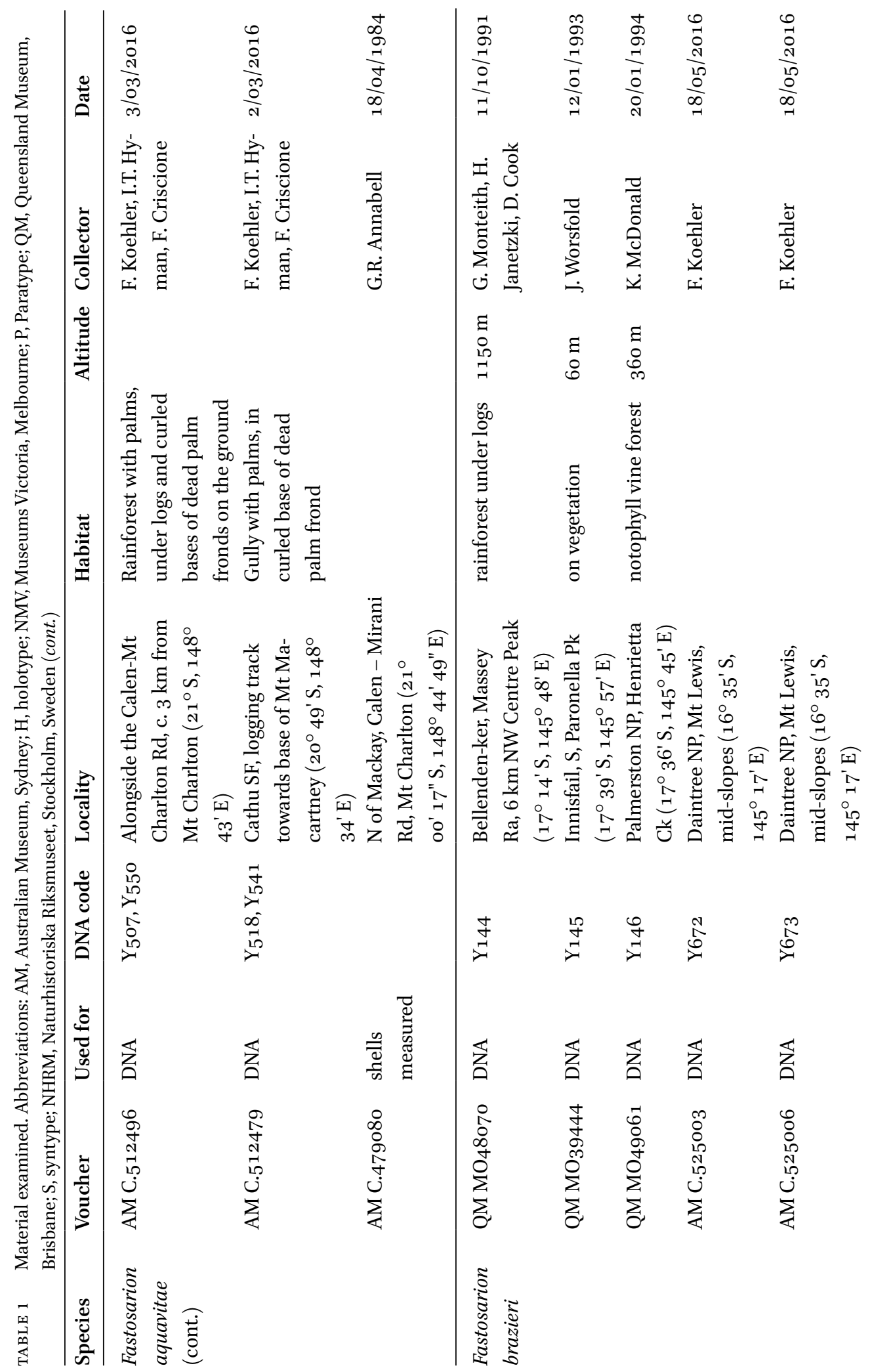




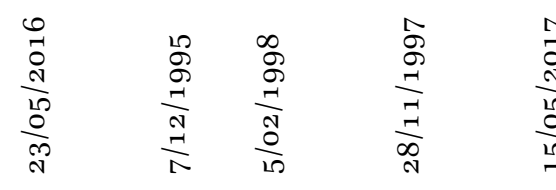

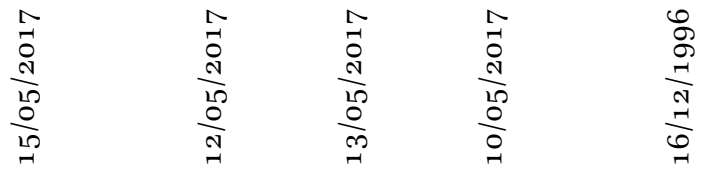

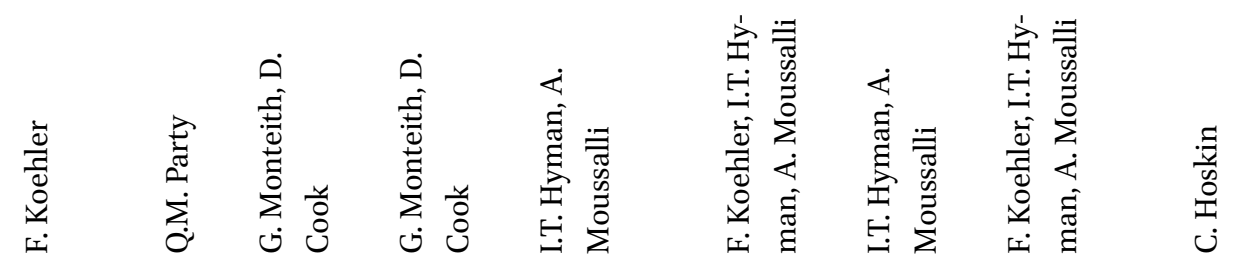

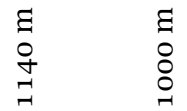

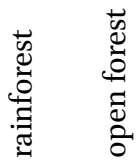

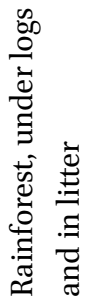

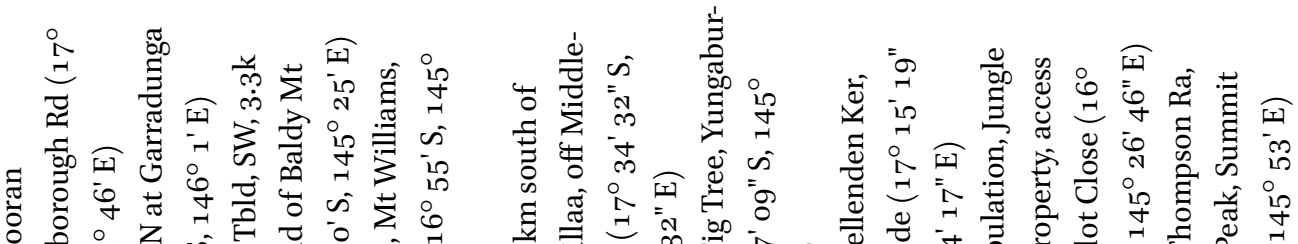

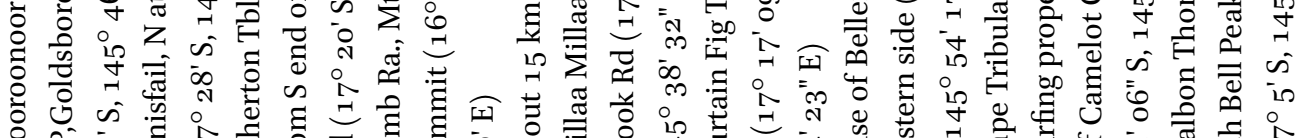

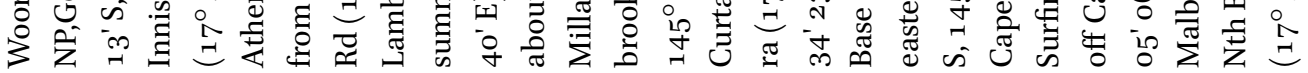

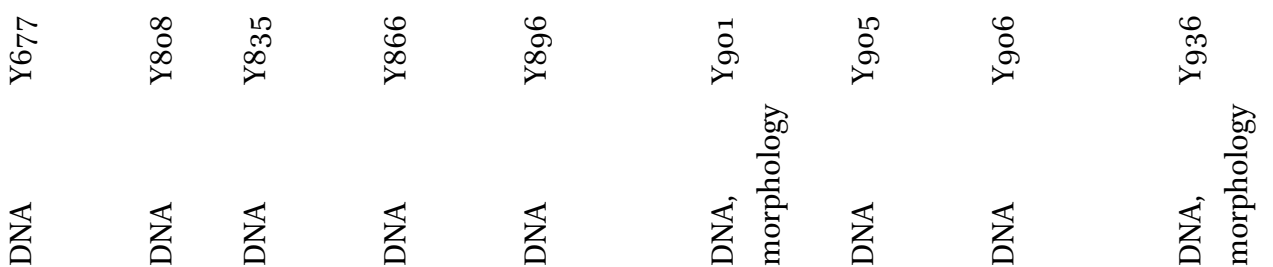

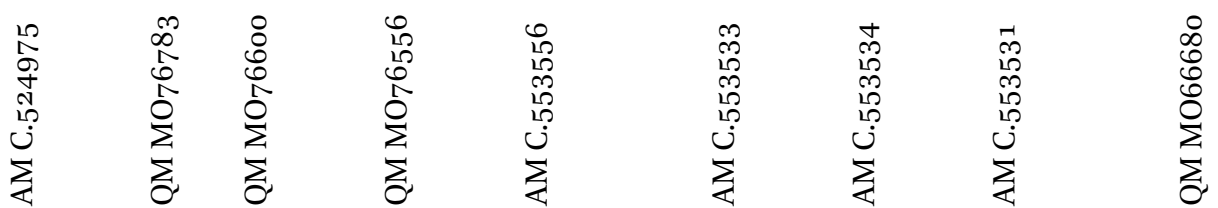




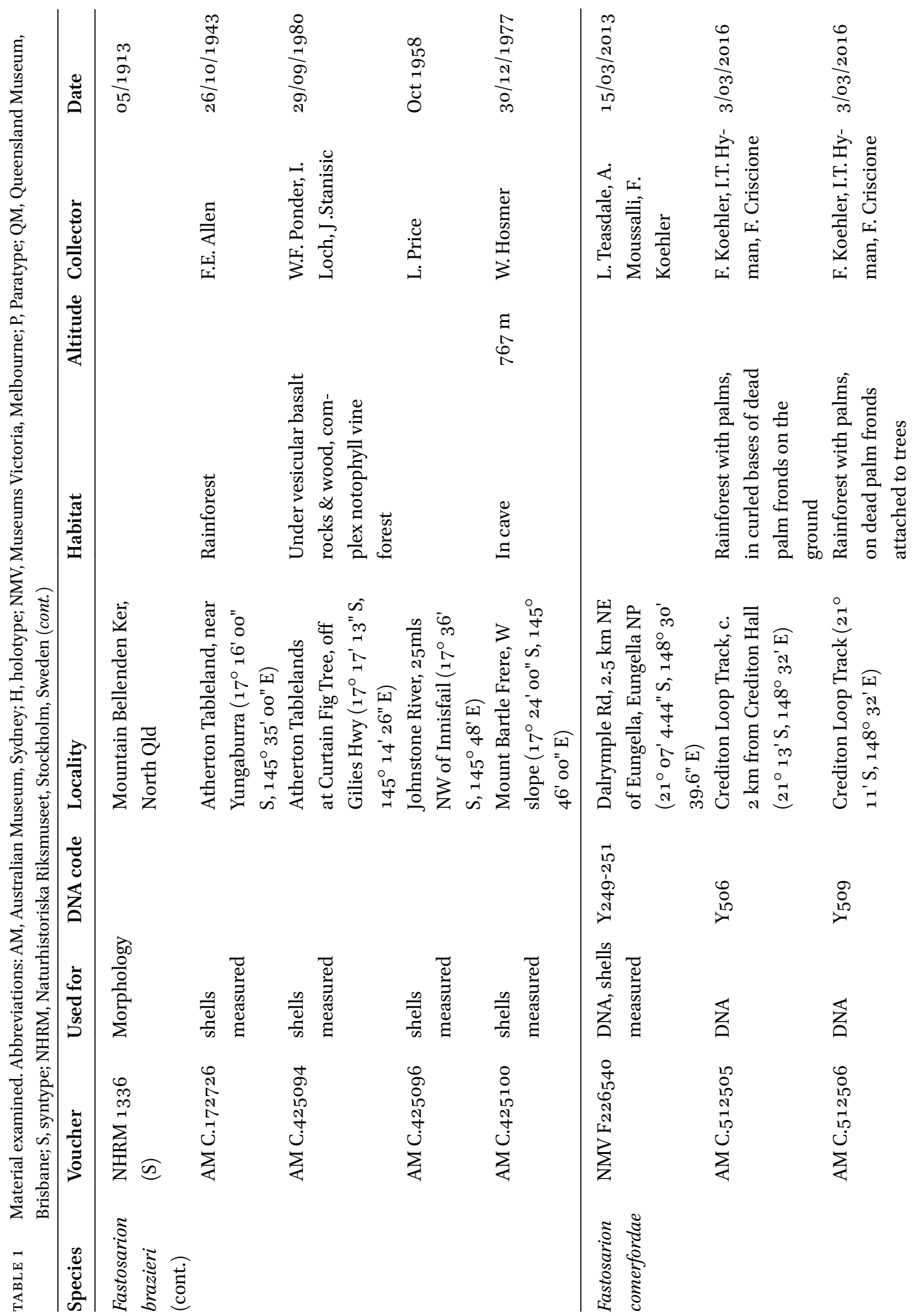




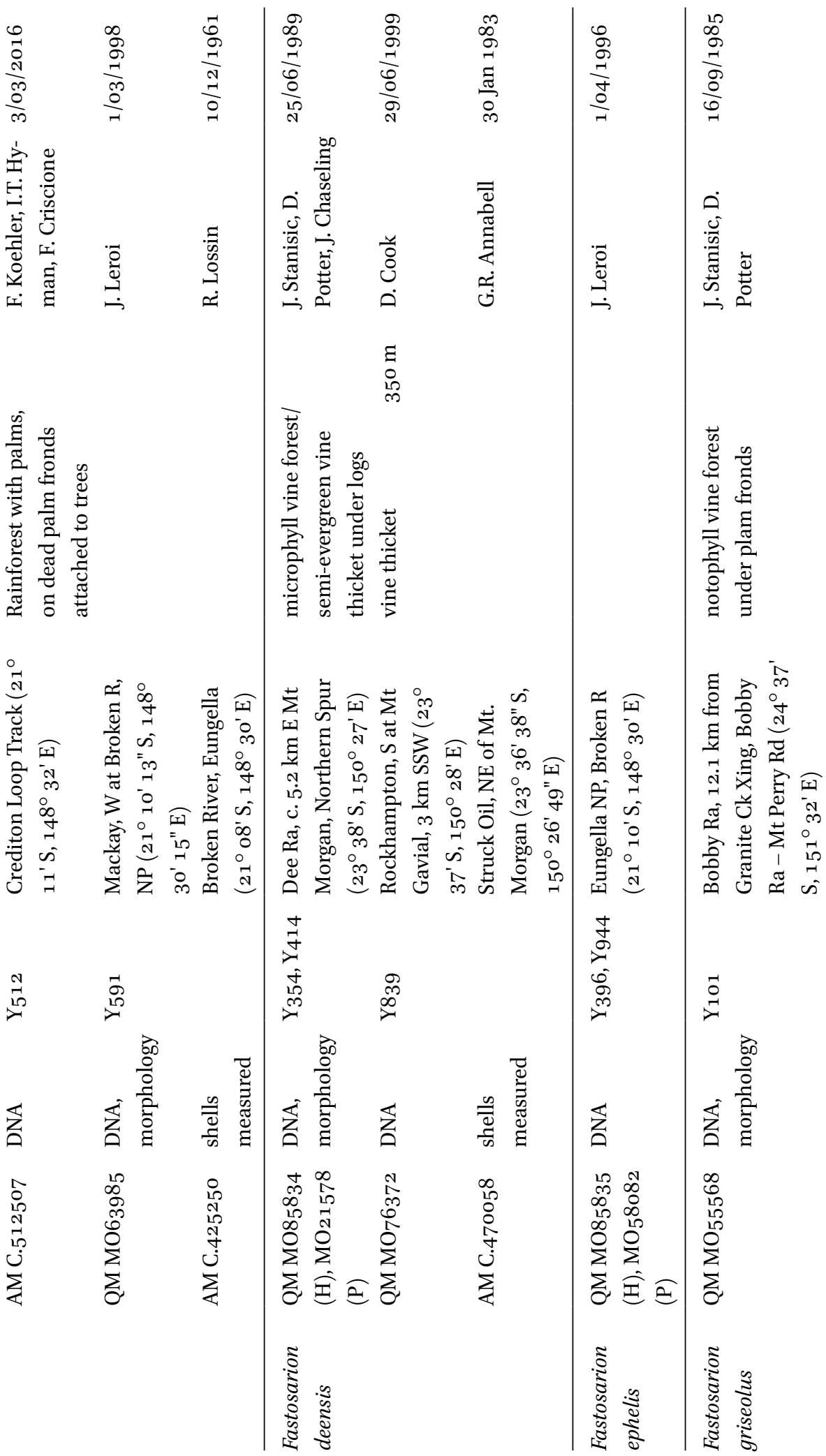




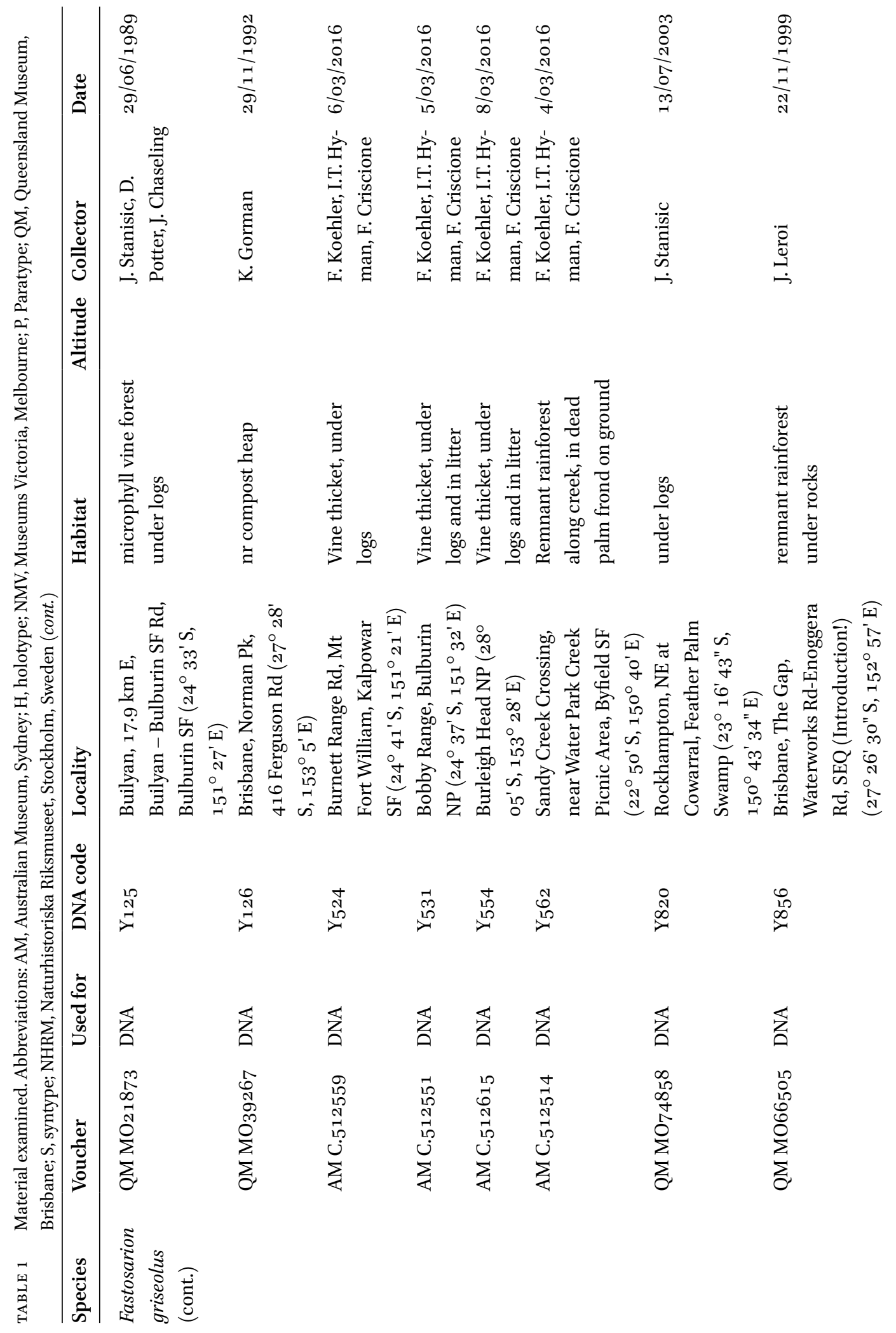


$\underset{\substack{\infty \\ \infty}}{\frac{1}{N}}$

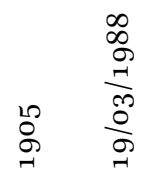

$\begin{array}{ll}\infty & \infty \\ \infty & \infty \\ \frac{1}{10} & \frac{1}{1} \\ \frac{1}{1} & \frac{5}{0}\end{array}$

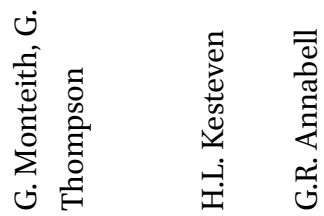

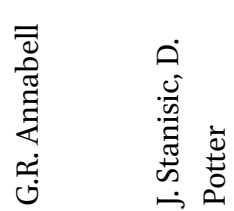

$\Xi$
8
$\infty$

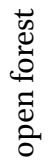

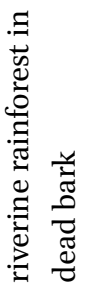

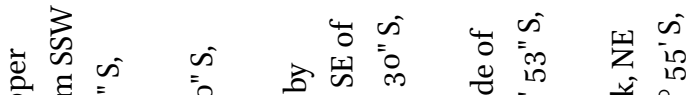

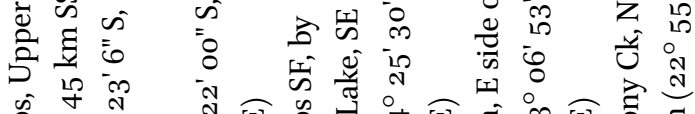

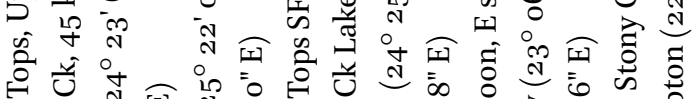

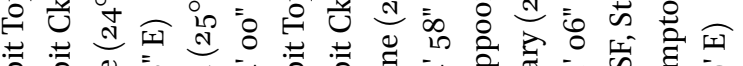
है है

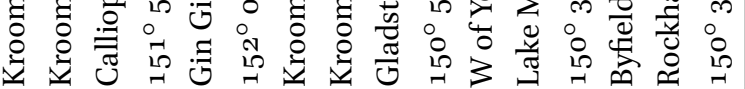

$\stackrel{\infty}{\infty}$

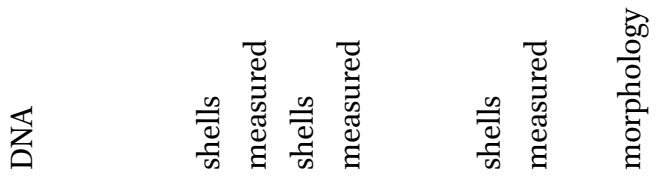

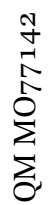

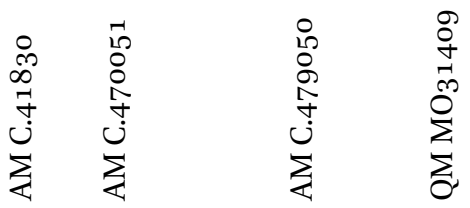

$\infty$
$\infty$
O
$\frac{1}{N}$
$\frac{1}{0}$

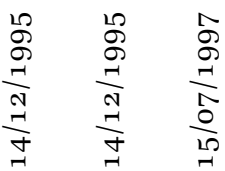

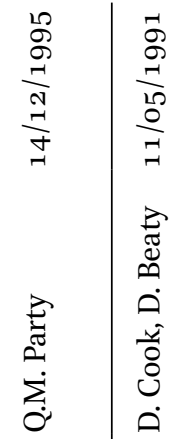

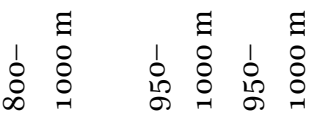

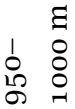

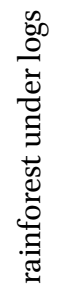

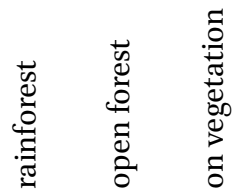

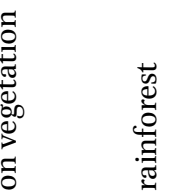

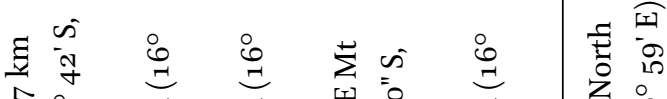
No

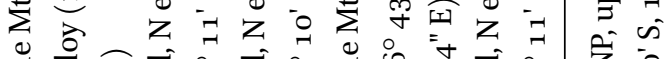

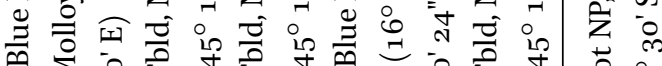

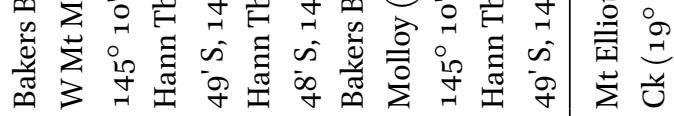




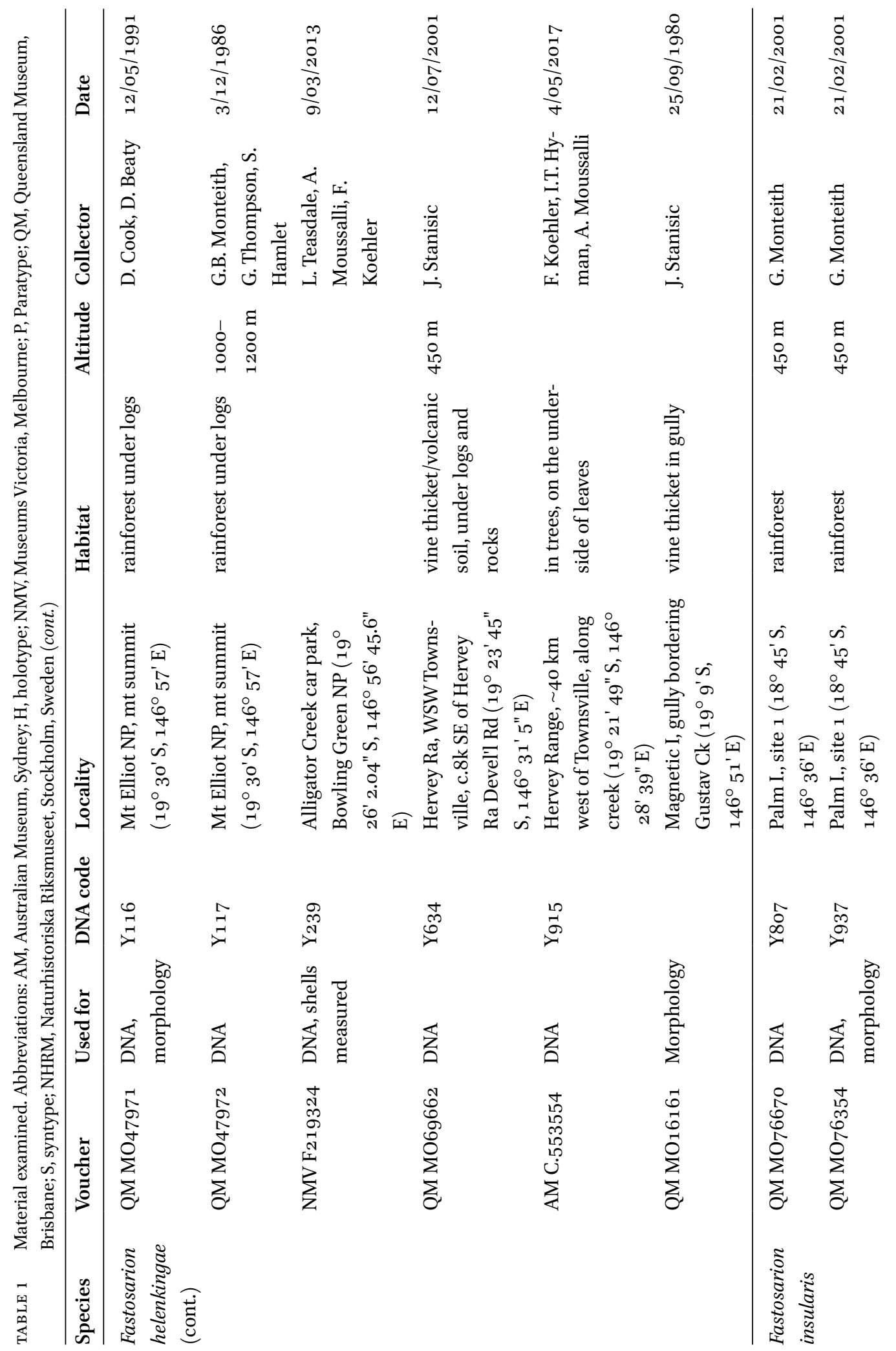




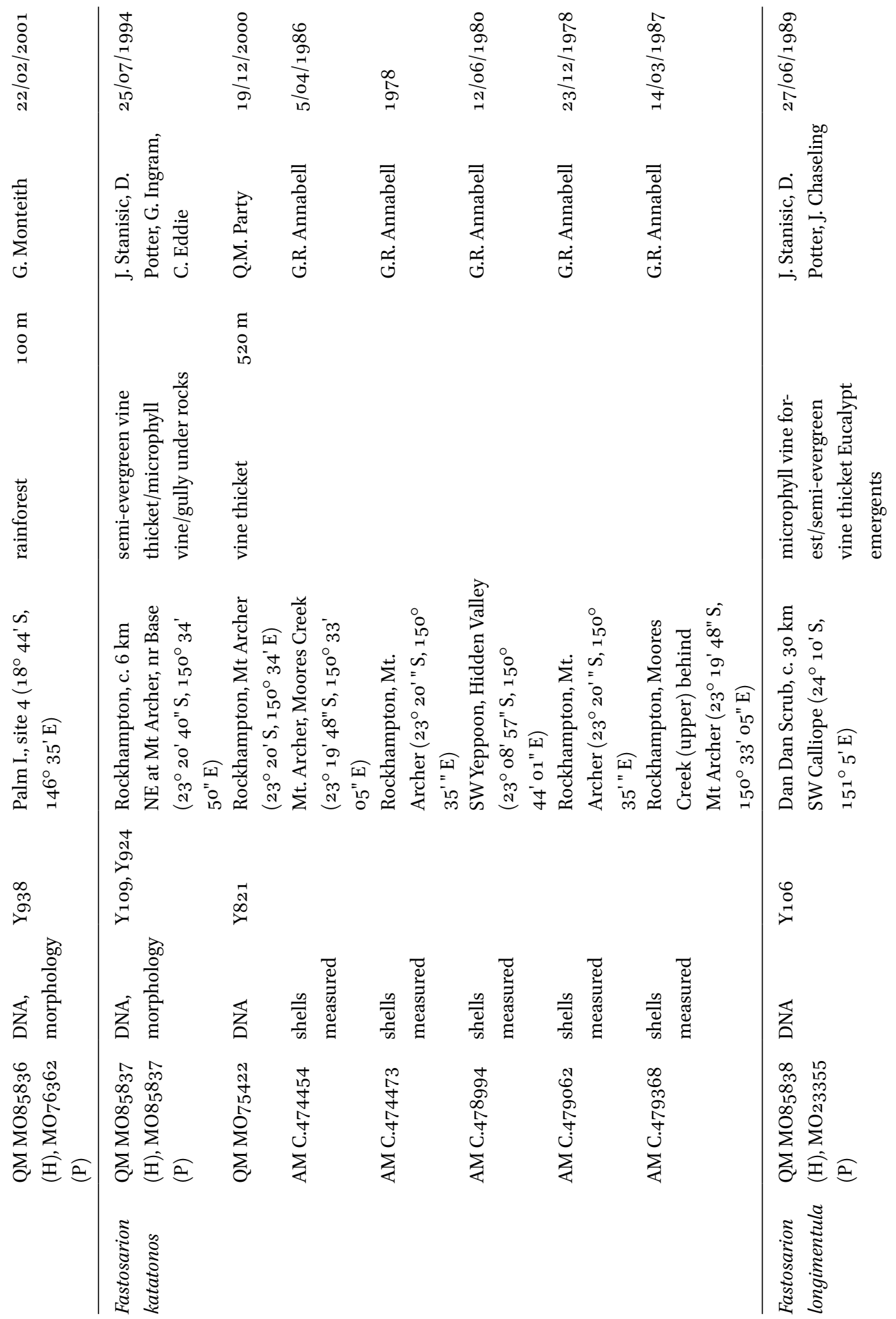




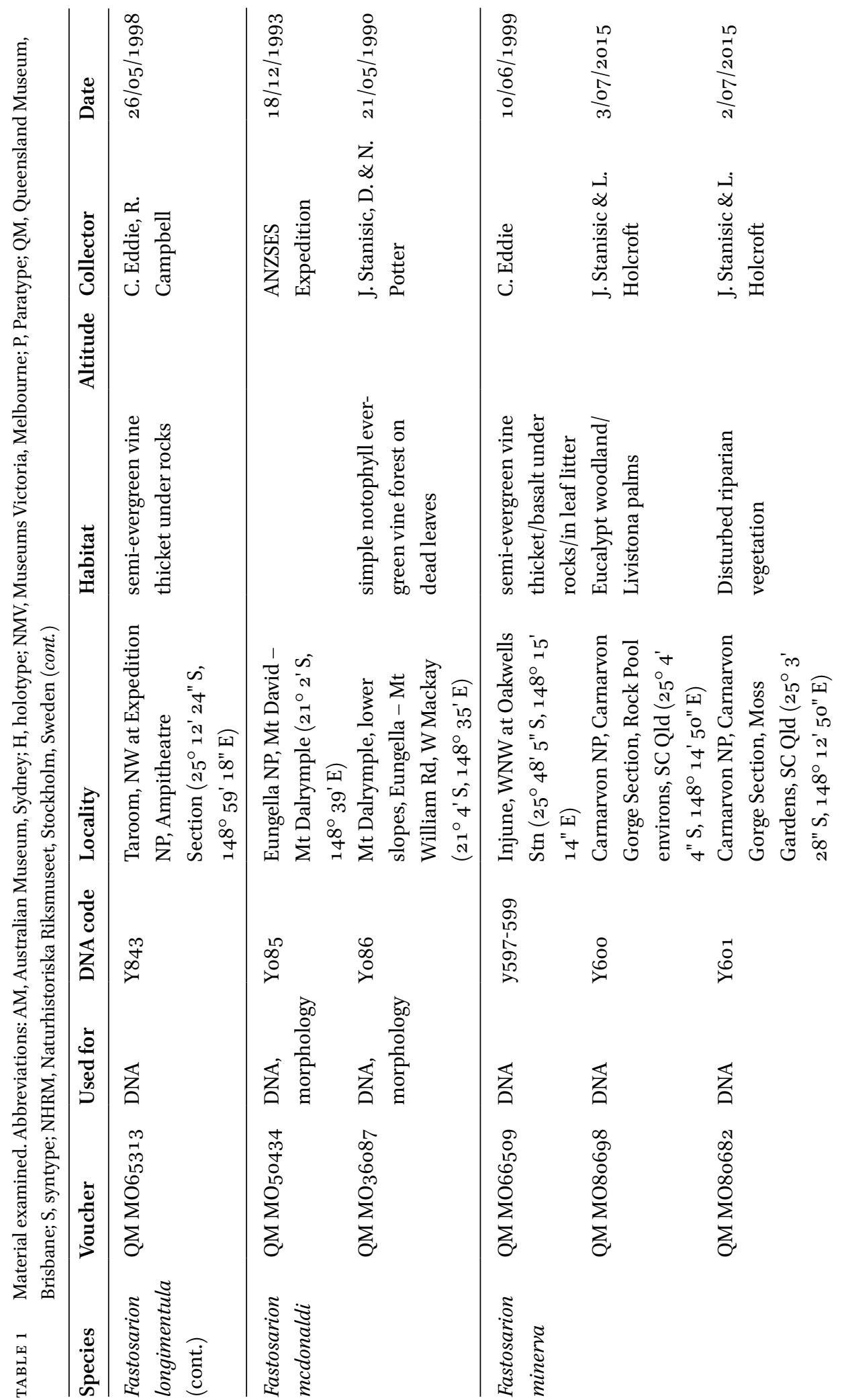




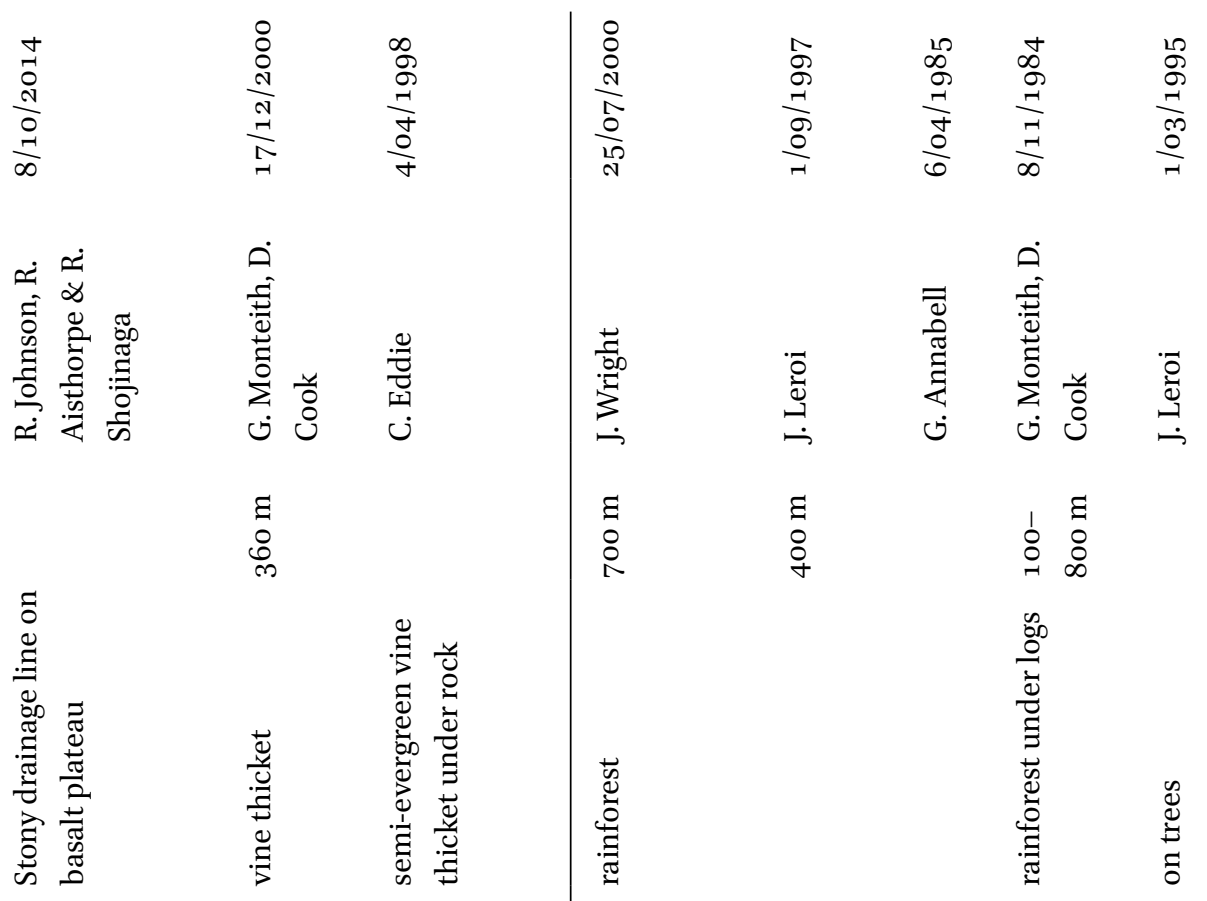

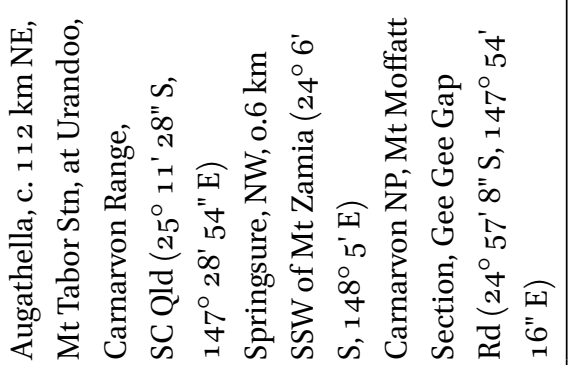

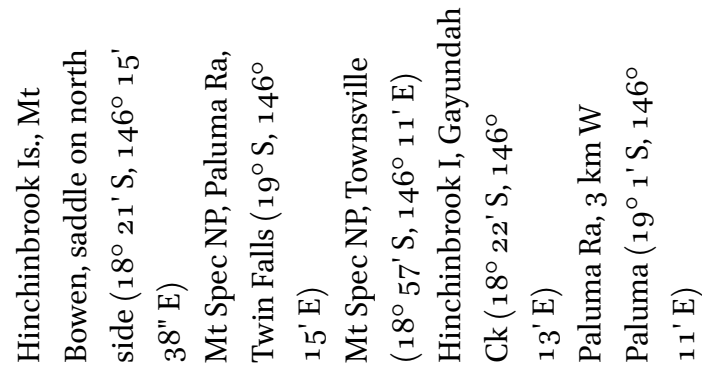

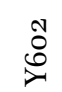

$\stackrel{\infty}{\infty} \quad \stackrel{0}{0}$

芯

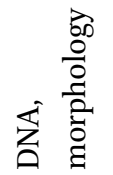

2
$\infty$
$\infty$

$\infty$

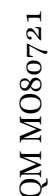

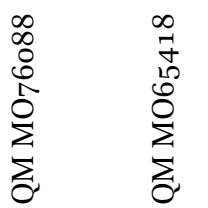

它

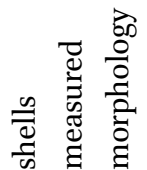

하

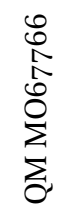

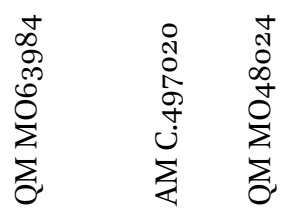

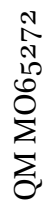

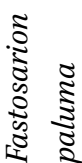



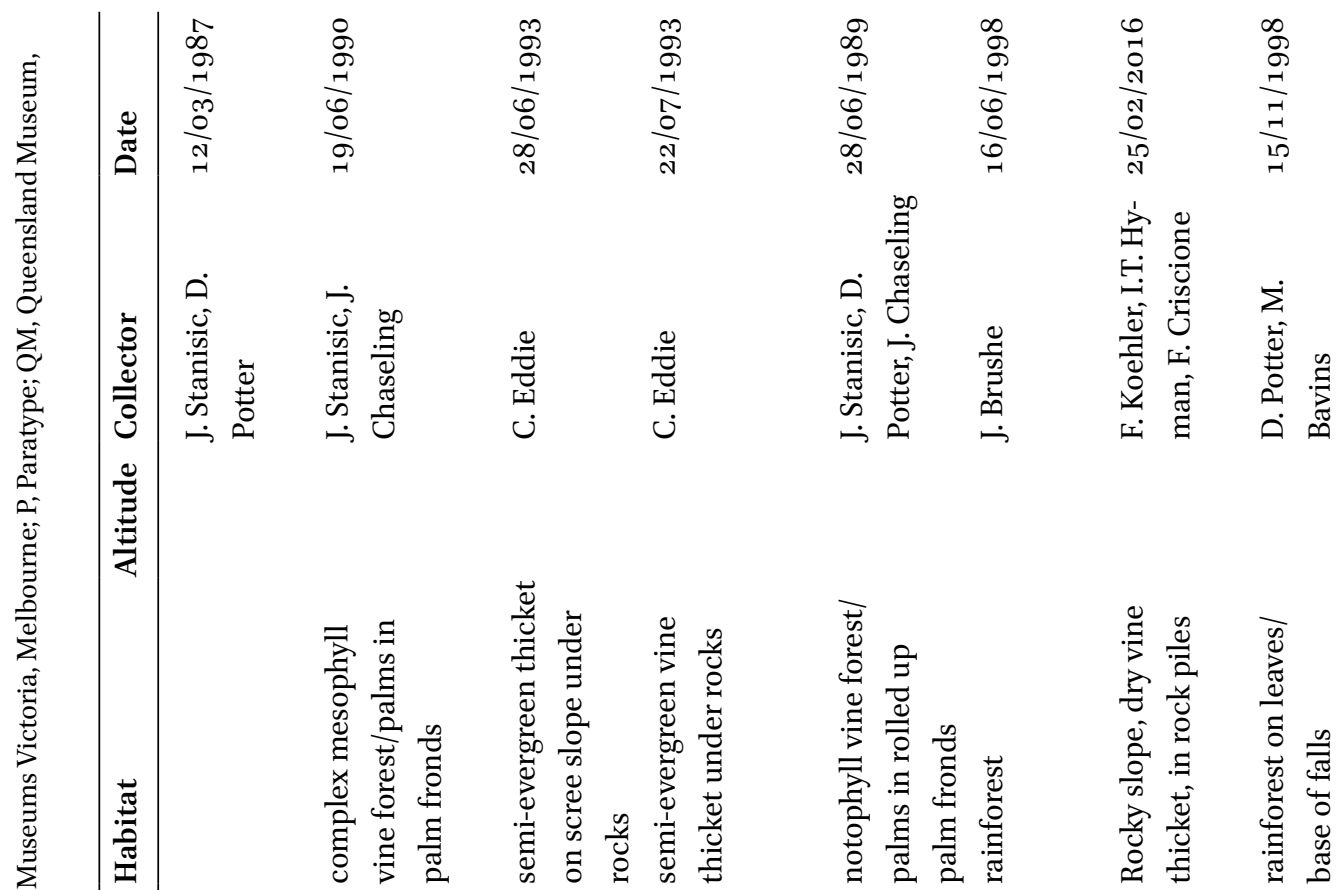

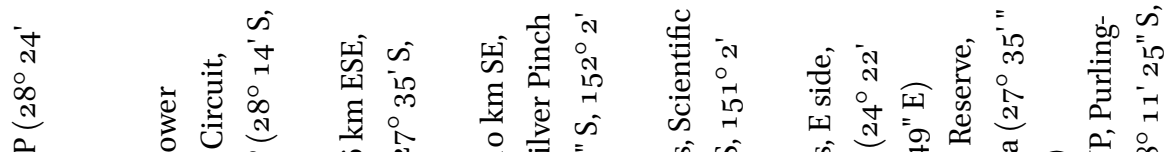

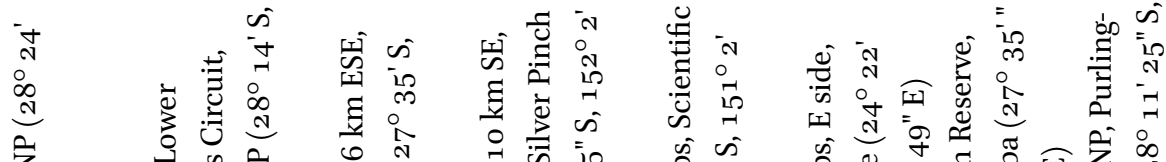

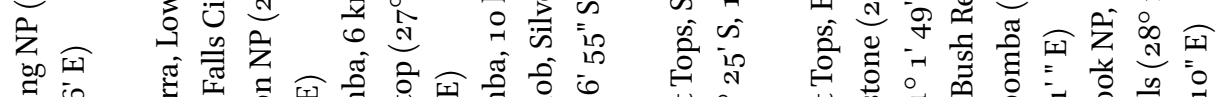

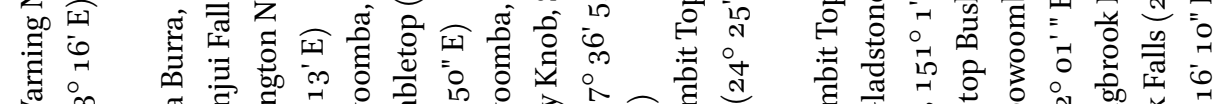

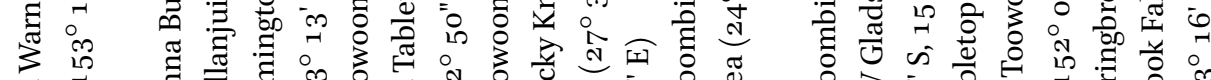
芝

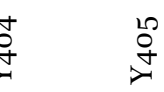

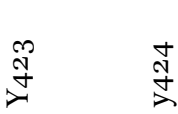

$\infty$
Dै
हो
$\infty$
0

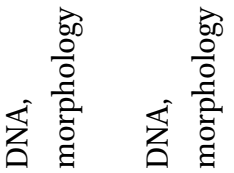

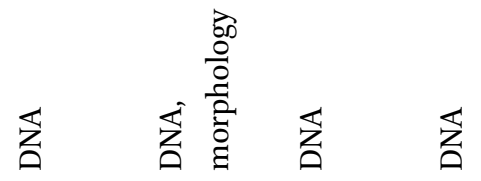

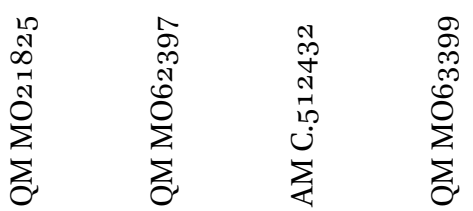




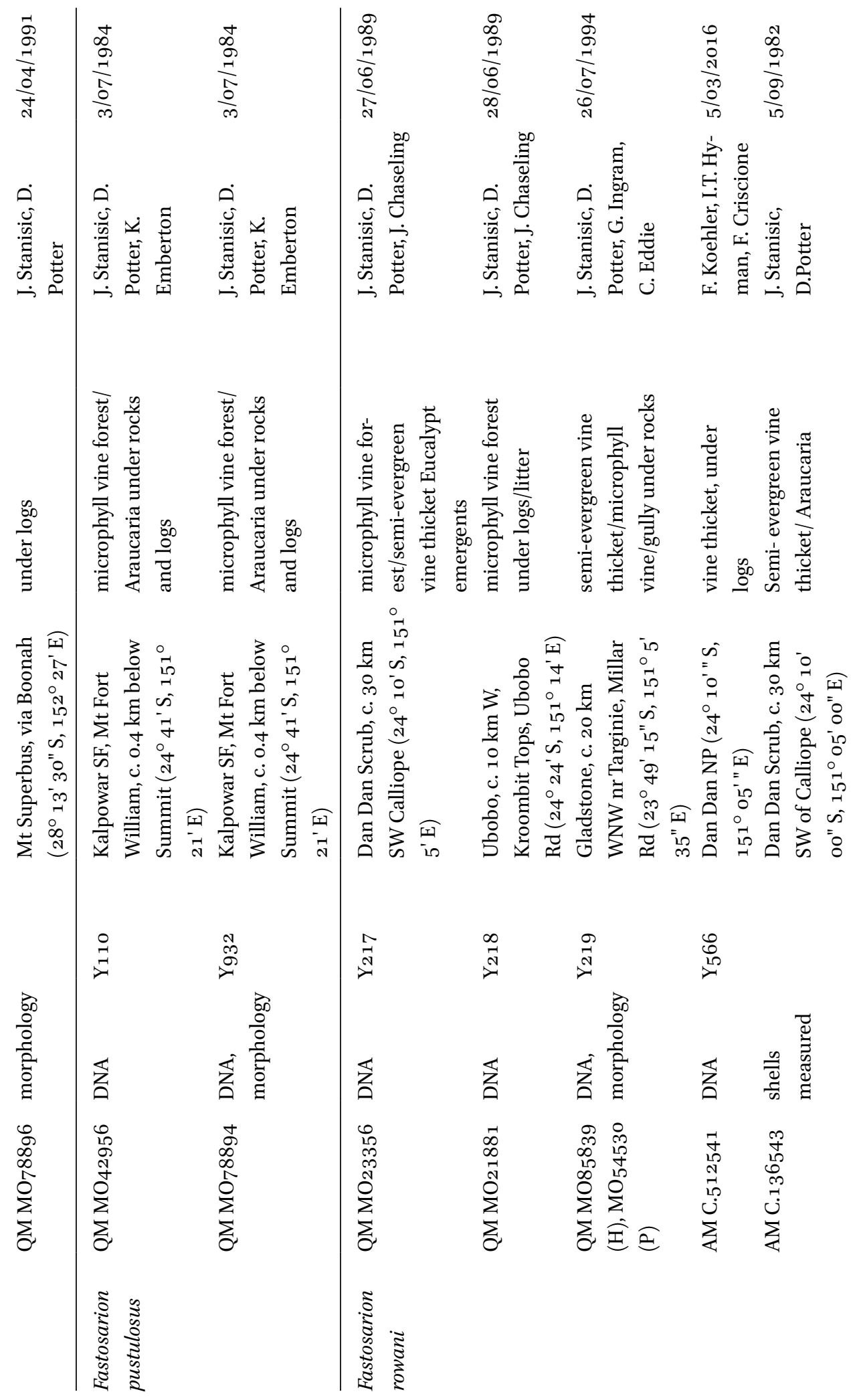




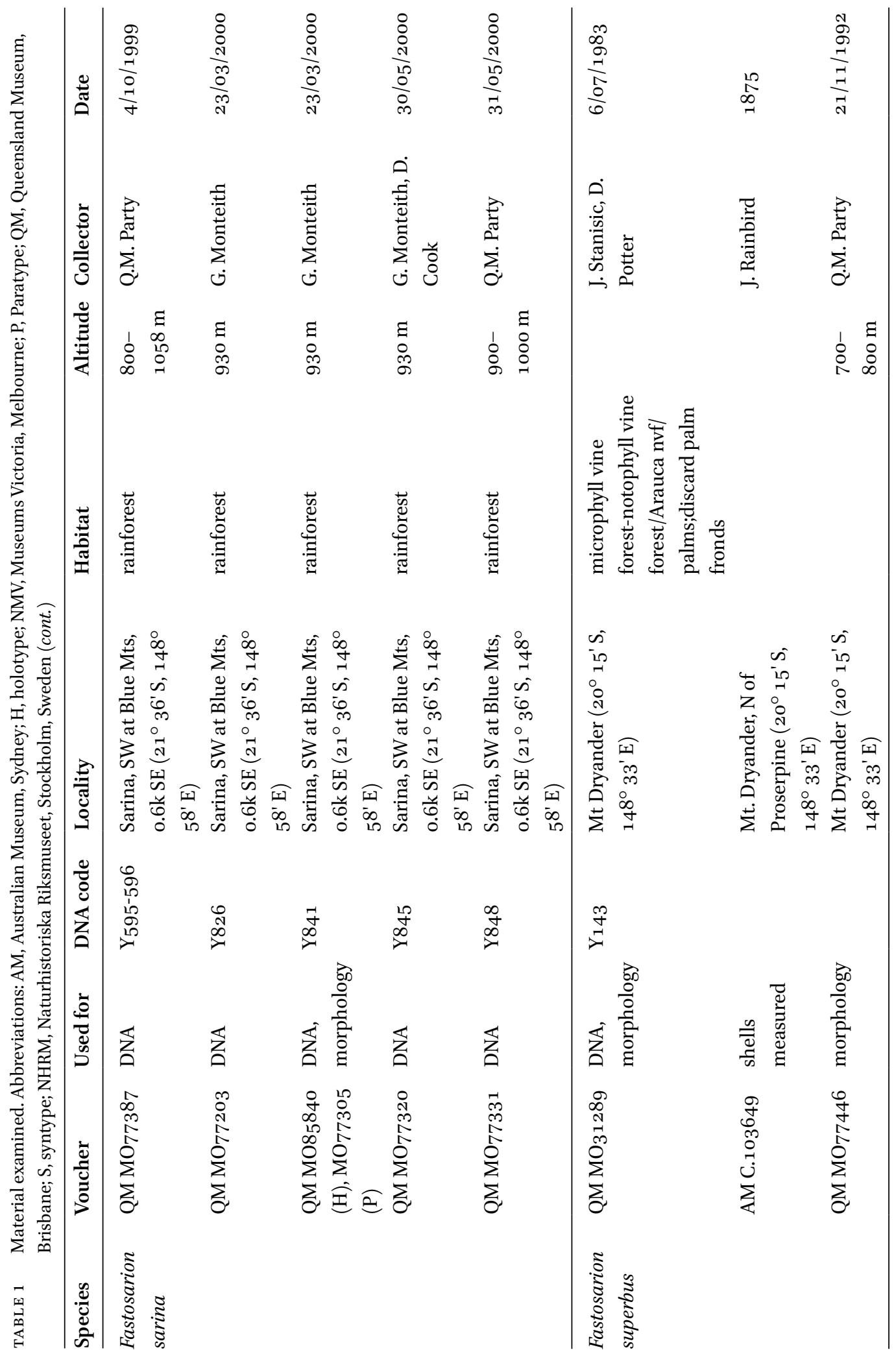




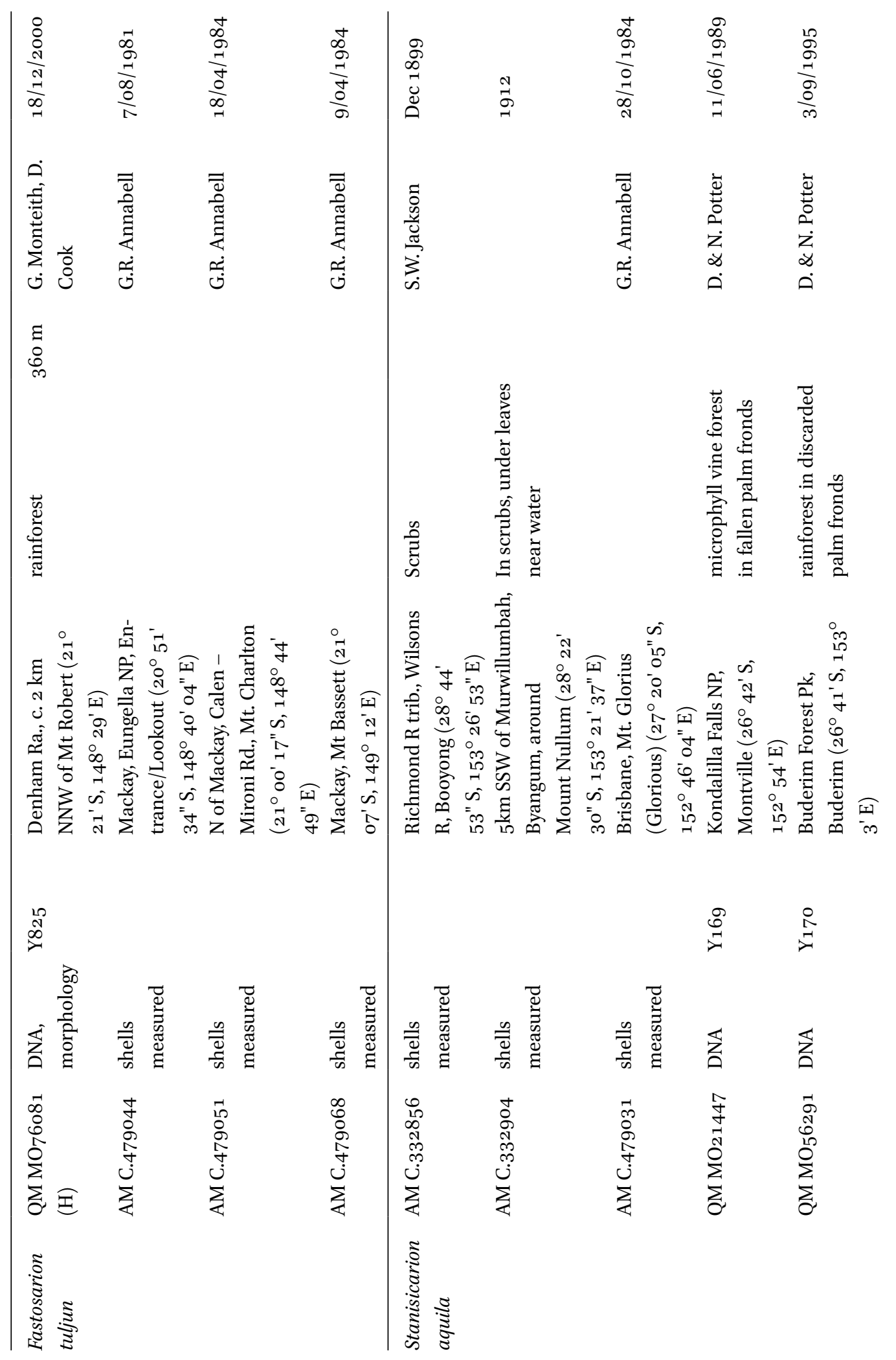




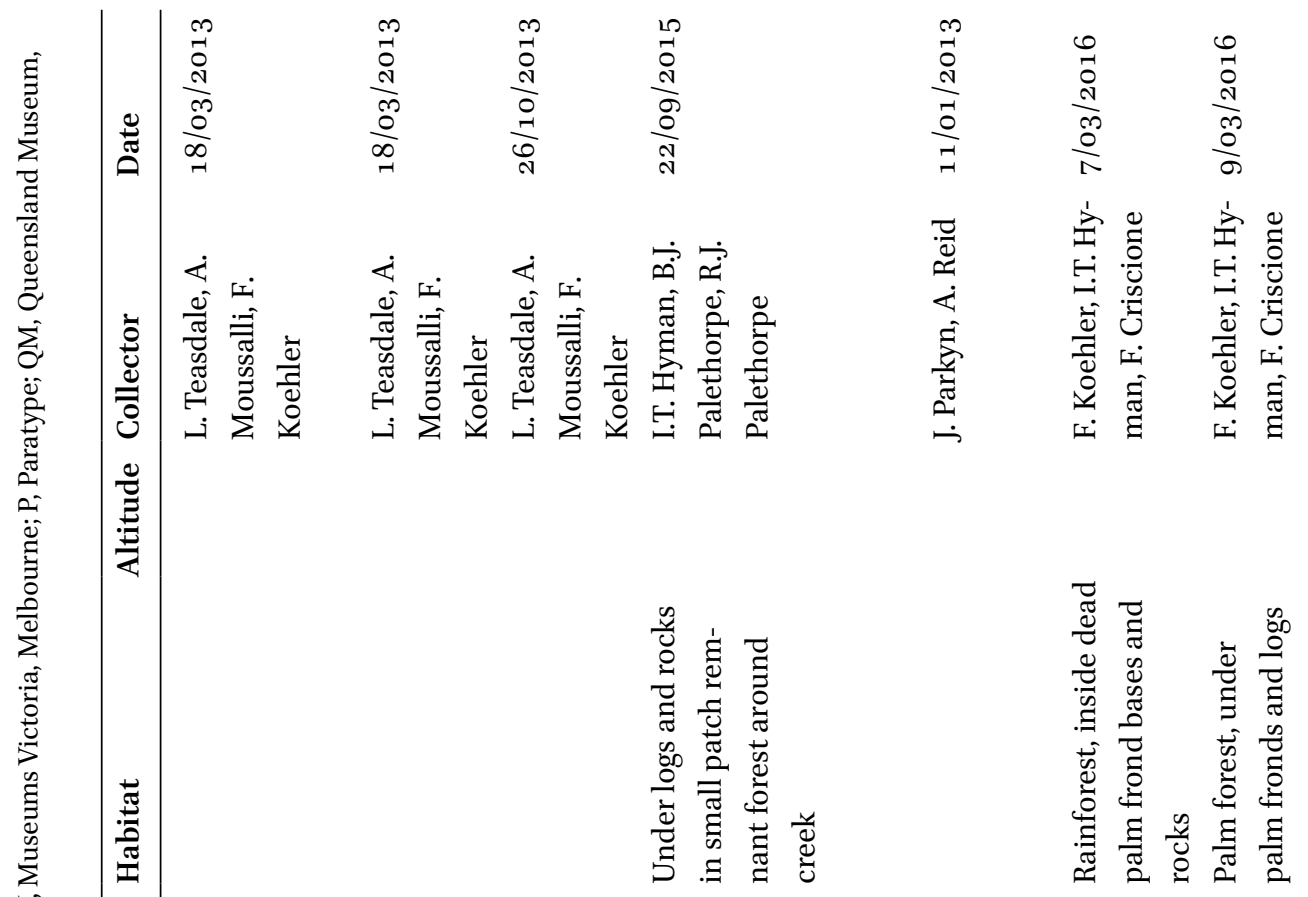

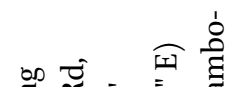

है

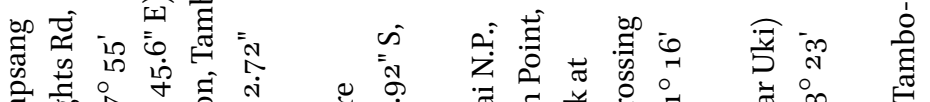

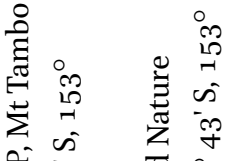

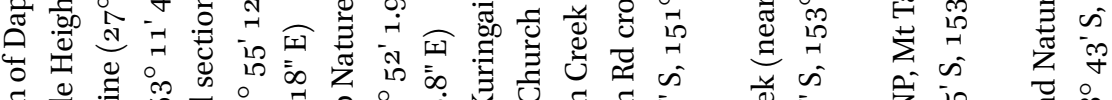

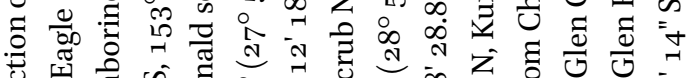

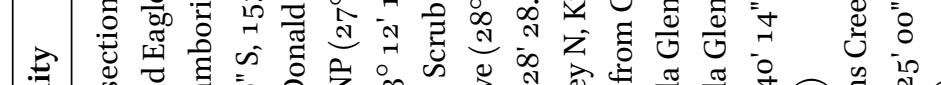

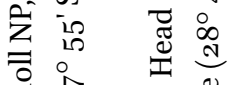

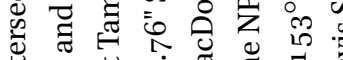
$\stackrel{\Xi}{\Xi} \sum^{\circ}$

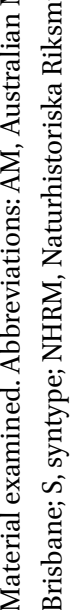

苑 齐

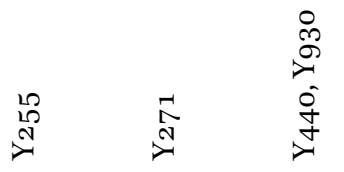

in

$\underset{\infty}{\infty}$

$\underset{10}{\sqrt{6}}$

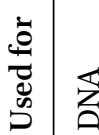

艺 点 至

芒

范

范

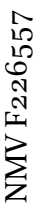

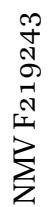

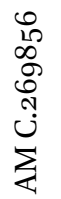

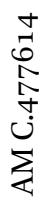

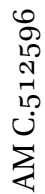

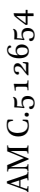




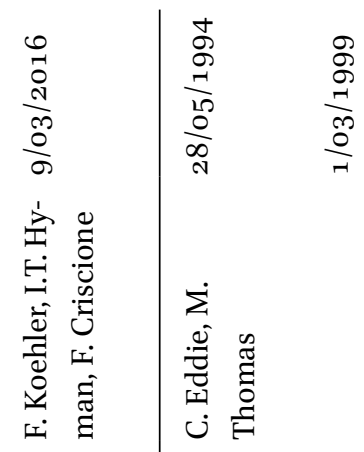

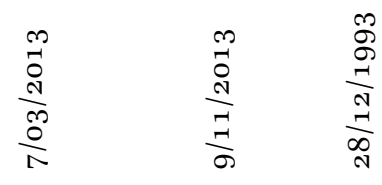

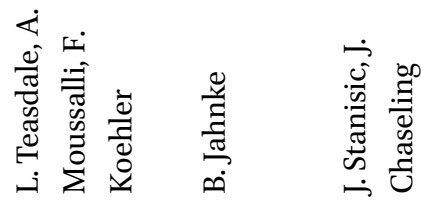

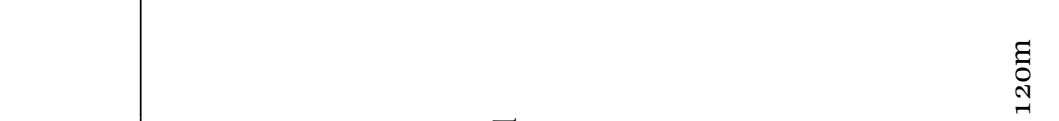

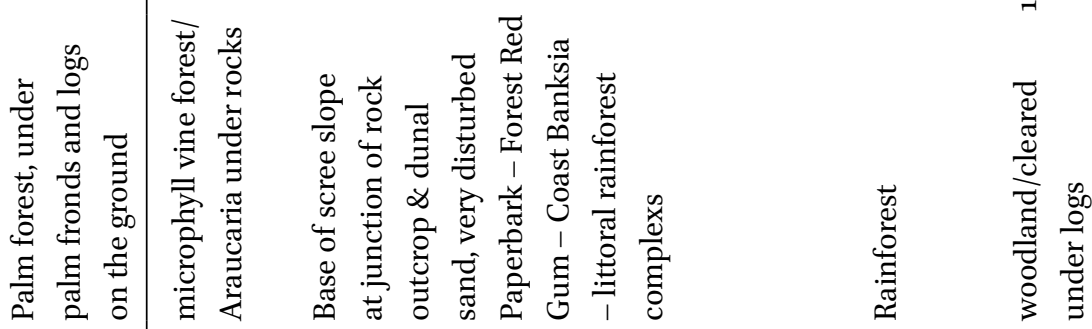

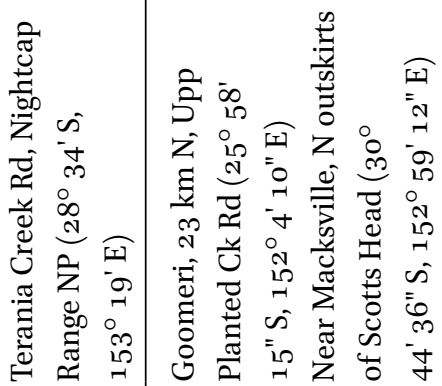

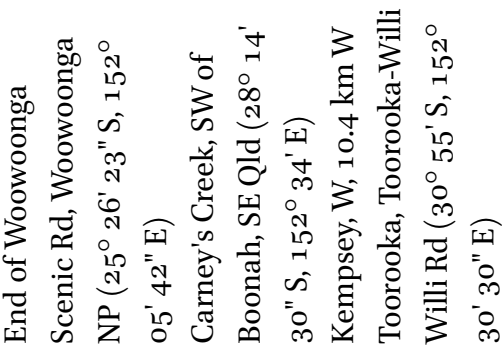

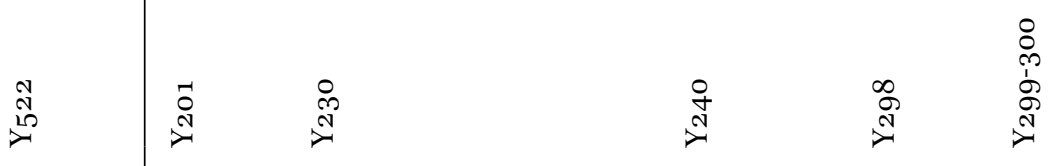

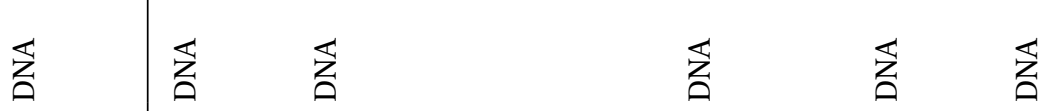

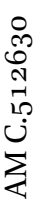

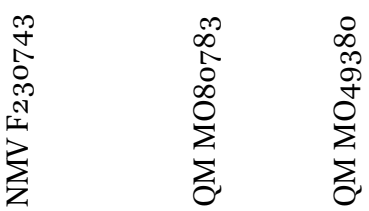

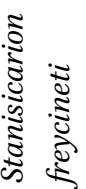




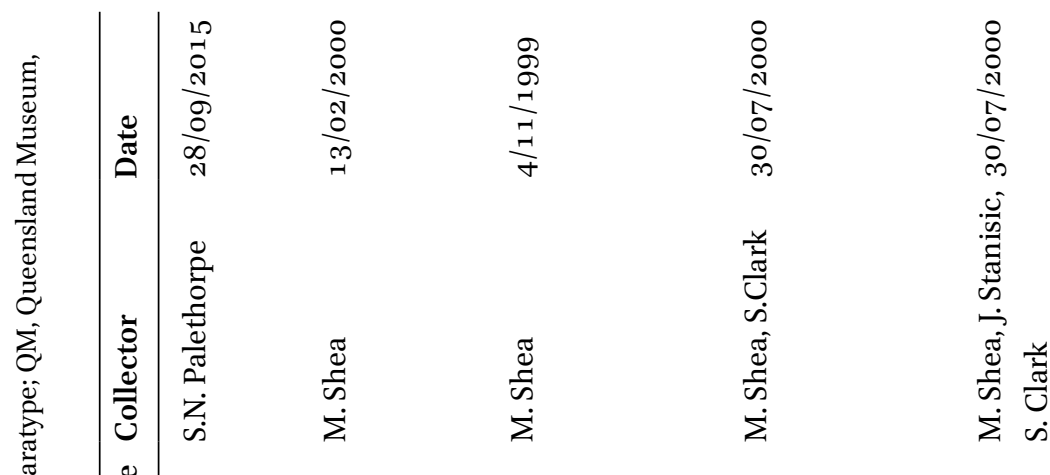

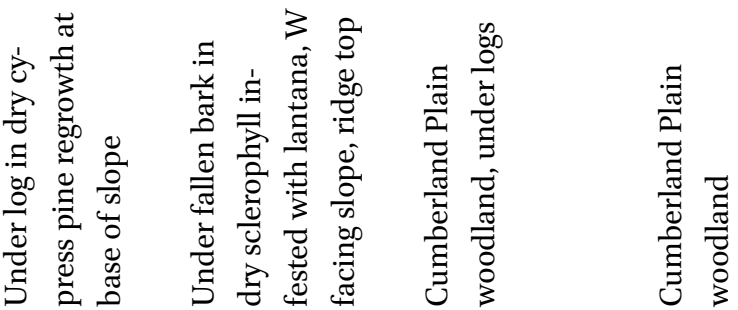

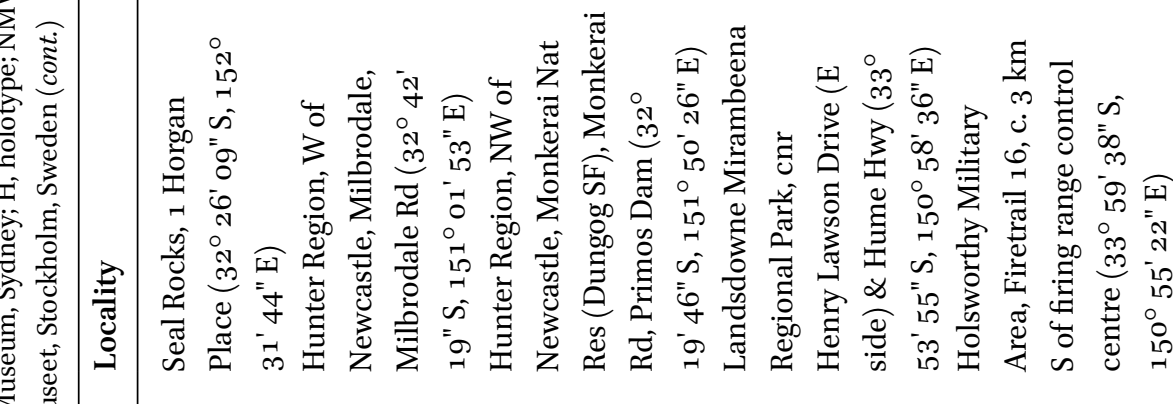

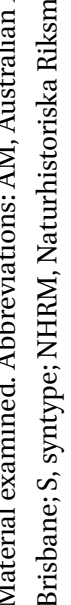

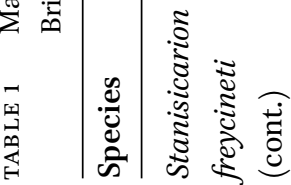




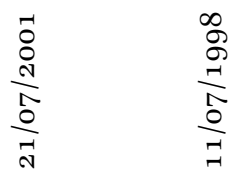

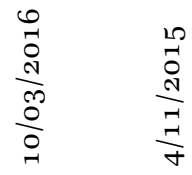

$\frac{0}{0} \frac{1}{0}$

$\frac{a}{0}$

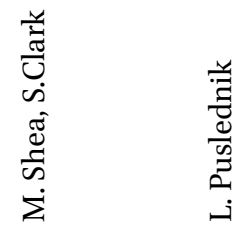

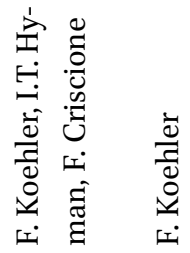

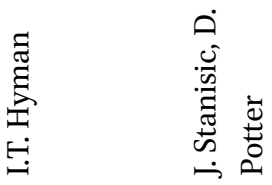

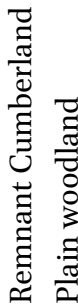
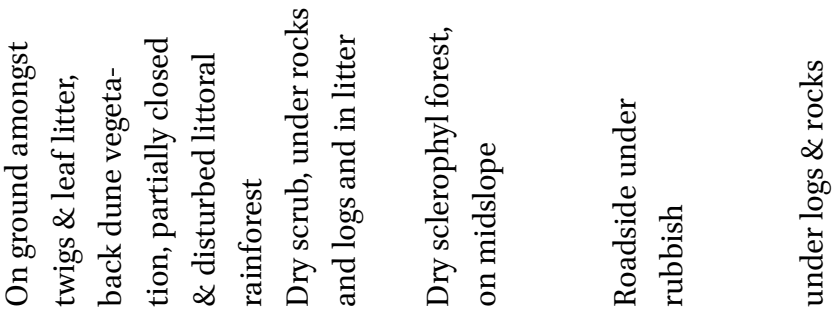

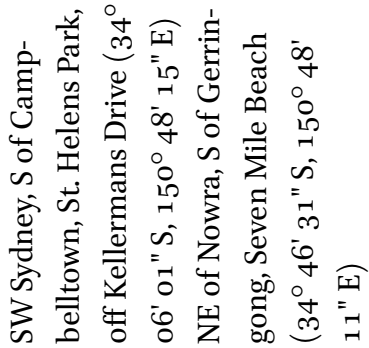

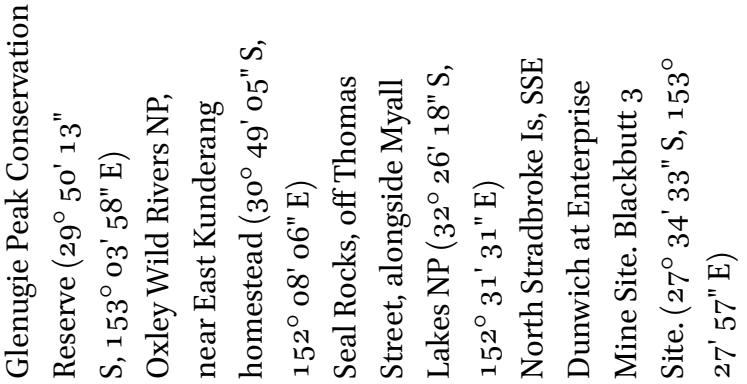

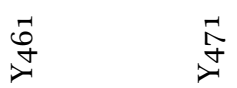

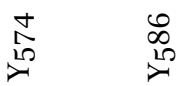

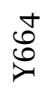

$\underset{\infty}{\infty}$

岁芯

范芯

岁

$\overleftrightarrow{\vdots}$

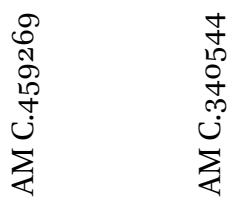

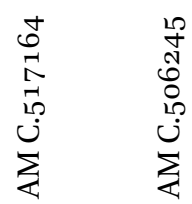

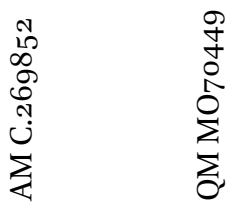




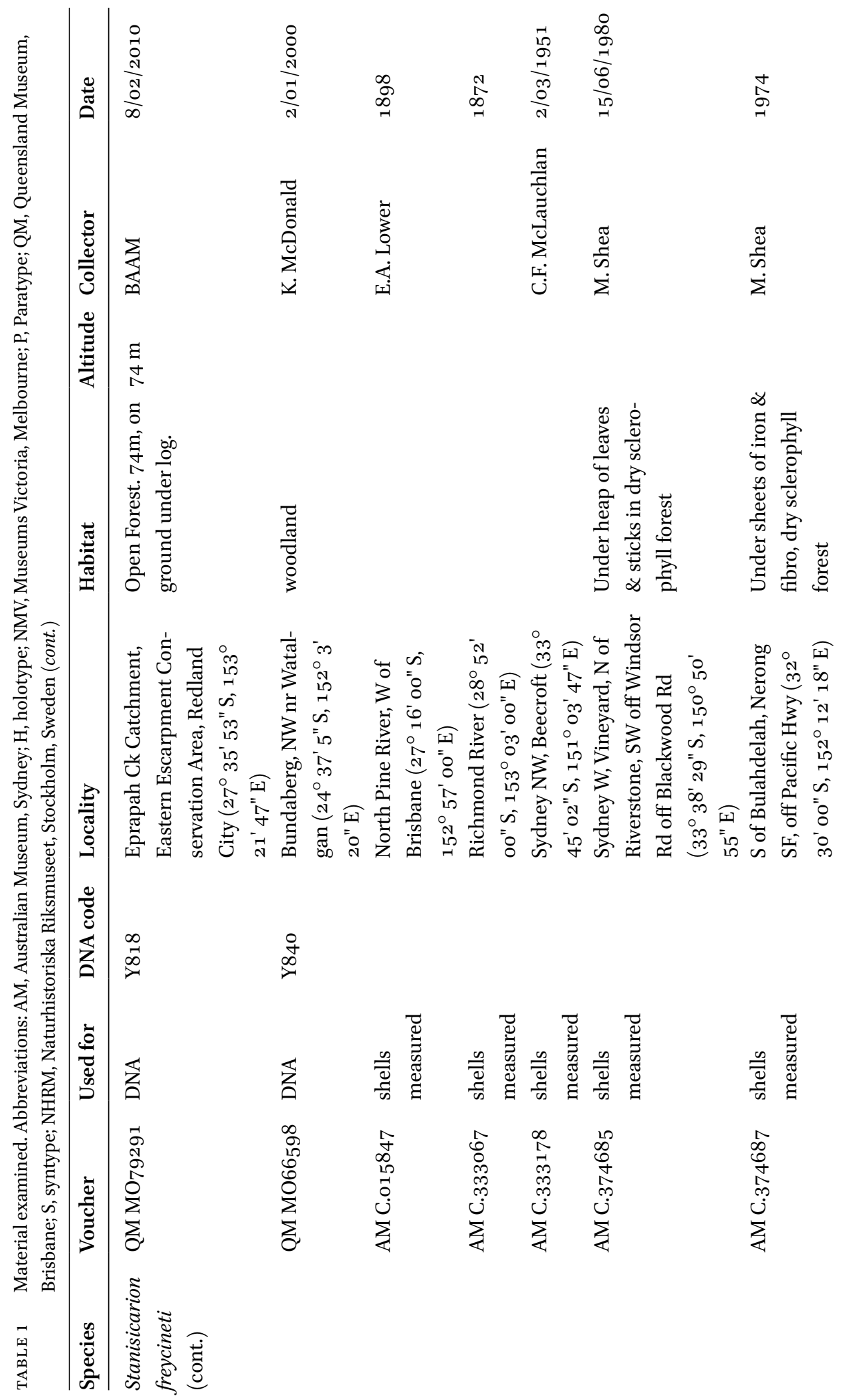



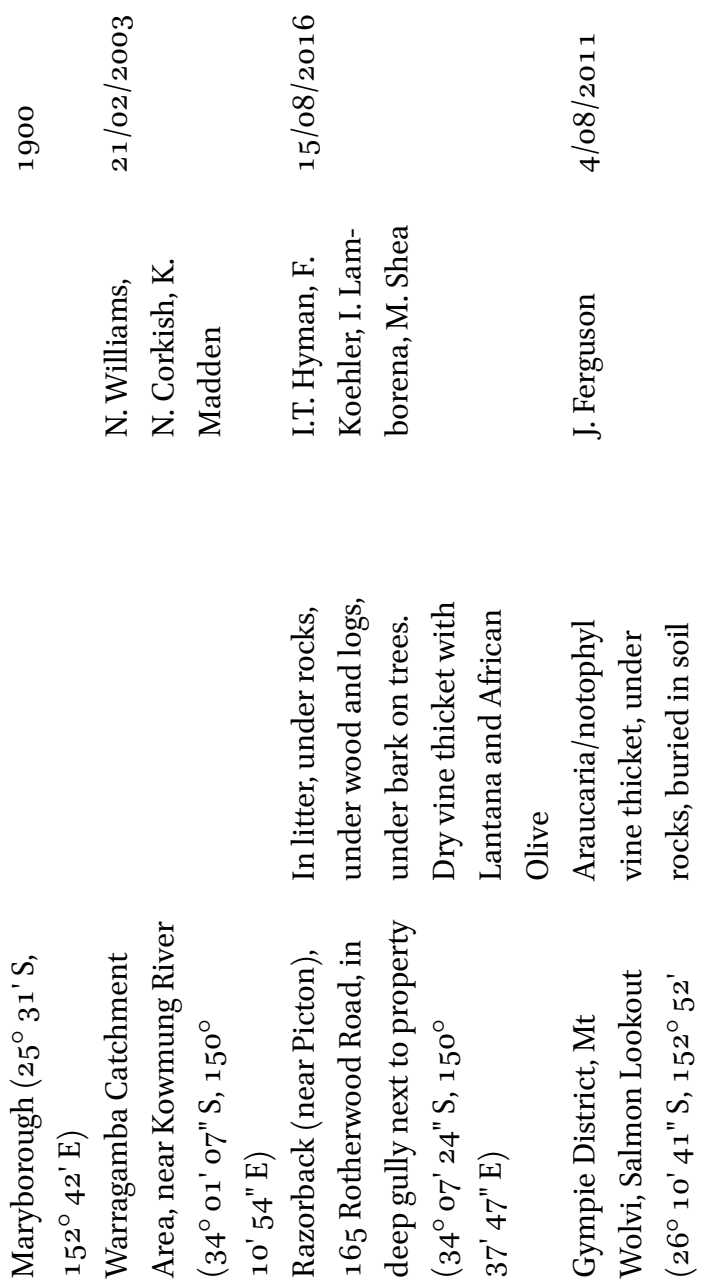

党

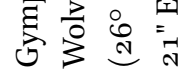

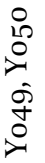

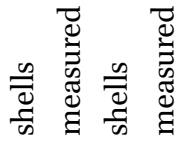

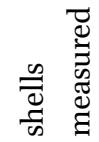

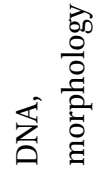

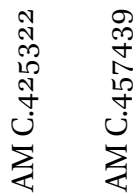

\begin{tabular}{l}
\multirow{2}{n}{} \\
0 \\
10 \\
$i$ \\
$i$ \\
$ن$ \\
$\sum$ \\
$\sum$
\end{tabular}
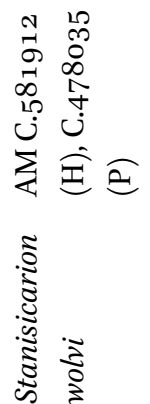
as Bayesian Inference. Maximum Likelihood (ML) phylogenies were reconstructed by using the program RAxML 8.o.o (Stamatakis, 2014) available on the Cipres Science Gateway (Miller et al., 2010). The model GTR $+\mathrm{G}$ was used for all partitions. Nodal support of the best ML tree was estimated by performing 10 independent runs each with 200 thorough bootstrap replicates. A second ML analysis was performed using the software IQ-TREE 1.6 (Nguyen et al., 2015). This analysis was performed using the integrated modelfinder function (Kalyaanamoorthy et al., 2017). Nodal support was estimated by performing 10,000 ultrafast bootstrap repeats as well as by employing Shimodaira-Hasegawa's (1999) approximate Likelihood Ratio Test ('SH-aLRT'). Bayesian posterior probabilities of phylogenetic trees were estimated by running 50,000,00o generations Metropolis-coupled Markov chains Monte Carlo (4 runs each with 4 chains, of which one was heated) as implemented by MrBayes 3.2.2 (Ronquist \& Huelsenbeck, 2003). A data partition was applied that allowed all parameters to be estimated separately for each partition. Sampling rate of the trees was 1,000 generations. Generations sampled before the chain reached stationary were discarded as burn-in. Stationarity was reached when the average standard deviation of split frequencies was lowerthan o.o1and the loglikelihood of sampled trees reached a stationary distribution (Ronquist \& Huelsenbeck, 2003).

\section{Morphological studies}

Genital anatomy was examined through dissection of ethanol-preserved specimens using a Leica MZ8 stereo microscope with a drawing apparatus. Prior to dissection, the shell was removed, cleaned and mounted on carbon tabs for scanning electron microscopy (SEM). The reproductive system was examined in situ in order to retain the folding of the spermoviduct. Spermatophores were removed from the bursa copulatrix and prepared for drawing and SEM by rinsing and the removal of extraneous tissue with fine forceps.

Shells were measured with calipers with a precision of $0.1 \mathrm{~mm}$. Dimensions measured were height $(\mathrm{SH}=$ maximum dimension parallel to axis of coiling), width (SW = maximum dimension perpendicular to $\mathrm{SH}$ ) and number of whorls $(\mathrm{NW}=$ whorl count using method shown by Köhler (2011)). Body length (BL) was measured in ethanol-preserved specimens that had been relaxed before preservation. Analyses of covariance (ANOVA) of morphometric parameters were performed using XLStatistics (Rodney Carr 1997-2011, Deakin University).

\section{Species identification and delineation}

Our operational criterion for the delimitation of species was to test whether candidate species were phenotypically and genotypically distinct from each other (Sites \& Marshall, 2004). Candidate species were initially delimited by grouping specimens into genetically distinct clades using phylogenetic analyses of mitochondrial gene sequences (= so-called molecular operational units, 'MOTUs'). We then assessed whether such MOTUs represented anatomically and morphologically coherent groups, distinguishable from each other. In such cases we considered the MOTUs to be independent species and assigned available taxon names to them based on morphological similarity and concurrent distribution with types. Subsequently, we employed basic statistics of morphometric characters and comparative reproductive anatomy to assess the amounts of phenotypic differentiation within and between the so recognized species.

\section{Ancestral state reconstruction}

We employed the Maximum Likelihood-based ancestral character estimation implemented in the functions fastAnc and contMap in the R package phytools (Revell, 2012) to estimate and visualize phenotypic trait values for body 
length, number of whorls and altitude of habitat for ancestral nodes in the tree.

\section{Abbreviations}

Geographic: NP, National Park; NR, Nature Reserve; NSW, New South Wales; Qld, Queensland; SF, State Forest.

Institutional: AM, Australian Museum, Sydney; MNHP, Muséum National d'Histoire Naturelle, Paris, France; NHMUK, Natural History Museum, London, UK; NHRM, Naturhistoriska Riksmuseet, Stockholm, Sweden; NMV, Museums Victoria, Melbourne; QM, Queensland Museum, Brisbane.

Anatomical: alb, albumen gland; bc, bursa copulatrix; ca, caecum; cap, capsule of spermatophore; cg, capsular gland; ep, epiphallus; ep1, epiphallus 1 (situated between epiphallic flagellumandepiphalliccaecum);ep2,epiphallus 2 (situated between epiphallic caecum and penis) fl, flagellum; fov, free oviduct; her; hermaphrodite duct; ov, ovotestis; p, penis; pl, penial lamellae; pp, penial pilasters; pr, prostate; prm, penis retractor muscle; ppu, penial pustules;ps, penial stimulator; pt, penial tunica;pv, penialverge; $r$, penial ridges; tp, tail-pipe of spermatophore;ut,uterus;v,vagina;vd,vasdeferens.

\section{Results}

\section{Mitochondrial phylogenetics}

The final concatenated sequence dataset contained sequences of 156 ingroup specimens and 20 outgroup representatives used to root the trees (table 1). The outgroup representatives were selected based on a molecular phylogeny of Australian Helicarionidae (Hyman et al., 2007) and an ongoing revision of Helicarionidae (Hyman \& Köhler, 2017, 2018a; Hyman et al., 2017). In particular, we included all available sequences of helicarionid semislugs from Qld. One Stanisicarion sequence and several outgroup sequences were obtained from GenBank while all other sequences were produced in the present study. Some samples were represented by just one sequence fragment as $4416 \mathrm{~S}$ and $10 \mathrm{COI}$ sequences were missing from the sequence dataset. However, all but two species (i.e., F. superbus and 'Helicarionidae sp. Mt Morgan' (=F. deensis sp. nov.)) were represented by at least one specimen with complete sequence data.

The final $16 \mathrm{~S}$ alignment had a total length of 665 aligned nucleotide positions after removal of 756 ambiguous alignment positions. The COI sequences had a length of 655 base pairs.

The best-fit nucleotide substitution models for each data partition were: $\mathrm{K}_{3} \mathrm{P}$ with empirical base frequencies (Kimura, 1981) for $16 \mathrm{~S}$ and $1^{\text {st }}$ codon positions of COI, Tamura \& Nei's (1993) model with empirical base frequencies and invariant sites for $2^{\text {nd }}$ codon positions of $\mathrm{COI}$, and $\mathrm{K}_{2} \mathrm{P}$ with empirical base frequencies and invariant sites (Kimura, 1980) for $3^{\text {rd }}$ codon positions of COI, respectively.

Both ML and BI analyses of the concatenated data set showed that Fastosarion, Stanisicarion, Macularion, Eungarion, Dimidarion and Hymanarion together formed a monophyletic clade ('the moderate Qld semislugs'), albeit with weak nodal support, in both the ML and BI phylogenies. All other semislug genera included in the analysis, including the northern Qld genera Parmacochlea and Thularion, could be excluded from this group, as could all snail genera.

Among the moderate Qld semislugs, our analyses revealed three moderately well differentiated (in terms of basal branch lengths) and well to moderately well supported (in terms of statistical support) mitochondrial clades: One consisting of Fastosarion as presently delineated except for F. papillosus and $F$. pustulosus (clade A), the second made up of Eungarion, Dimidarion, Hymanarion, F. papillosus, F. pustulosus, and several unnamed 
MOTUs (clade B), and the third consisting of Stanisicarion and Macularion (clade C). Two genera, Fastosarion and Dimidarion, as currently defined were polyphyletic in our mitochondrial phylogeny (figs. 1-3).

Each of these three major clades contained several generally well-supported and welldifferentiated subclades, which we treated as operational units for further taxonomic scrutiny through comparative analyses of morpho-anatomy. In the phylogenetic trees, individual specimens were labelled with a name based on their original identification, while clades were labelled with their final species name after detailed morpho-anatomical examination. It is apparent from the discrepancies between these names that the original identifications of many samples were erroneous. This demonstrates that external morphology and coloration, features emphasized for the initial identification of samples, are often unsuitable to correctly identify or delimit semislug species.

Our operational taxonomic units (subclades) exhibited within-group genetic distances of up to $5.6 \%$ in COI and $4.8 \%$ in $16 \mathrm{~S}$, and between-group distances of $5.6-15.1 \%$ in COI and $3.9-15.9 \%$ in $16 \mathrm{~S}$ (tables $2-3$; fig. 4). There is some degree of overlap between the mean within-group and mean between-group distances for $16 \mathrm{~S}$ (table 3 ). This is primarily due to high within-group variation in a single widespread species, Fastosarion brazieri.

We found that Stanisicarion freycineti and $S$. virens could not be distinguished from one another based on phylogenetic analyses of mtDNA sequences, and nor could the congeners Dimidarion alyssa, D. slatyeri and D. peterbrocki. In the $\mathrm{BI}$ tree (fig. 2), the MOTU 'Helicarionidae sp. Palm Island' (=F. insularis sp. nov.) nested within the Dimidarion clade.

Fourwell-differentiated and well-supported subclades were consistently recovered within clade B (figs. 1-2): B1 (consisting of Dimidarion alyssa, 'Helicarionidae sp. Palm Island' (= F. insularis sp. nov.) and Hymanarion hannianus), B2 (F. papillosus and F. pustulosus), B3 (D. minerva, 'Helicarionidae sp. Mt Morgan' (=F. deensis sp. nov.), 'Helicarionidae sp. SQ7' (= F. rowani sp. nov.)) and $\mathrm{B}_{4}$ ('Helicarionidae sp. Sarina' (=F. sarina sp. nov.), 'Helicarionidae sp. Taroom' (=F. longimentula sp. nov.), 'Helicarionidae sp. Denham Range' (=F. tuljun sp. nov.)). Three species did not consistently form part of any group. Eungarion mcdonaldi diverged basally in the ML tree (fig. 1) but formed part of clade B1 in the BI tree (fig. 2). 'Helicarionidae MQ16' (=F. ephelis sp. nov.) formed part of clade $\mathrm{B}_{1}$ in the ML tree (fig. 1) but its position was unresolved in the BI tree (fig. 2). Finally, 'Helicarionidae sp. Mt Archer' (=F. katatonos sp. nov.) grouped with clade $\mathrm{B}_{3}$ in the ML tree (fig. 1) but its position was unresolved in the BI tree (fig. 2).

Finally, primarily in order to reduce the number of ambiguously aligned nucleotide positions in the $16 \mathrm{~S}$ fragment, we produced a second sequence dataset with a more restricted taxon sampling that contained only in-group sequences. The $16 \mathrm{~S}$ sequences of all in-group taxa were re-aligned and ambiguous alignment positions were removed as described above for the more comprehensive dataset. The cleaned $16 \mathrm{~S}$ alignment in the restricted dataset had a length of 1,000 nucleotides (about $35^{\circ}$ more than in the comprehensive dataset). The topology of the ML phylogram for the restricted dataset was largely consistent with that of the trees for the extended dataset in terms of the relationships and composition of the three main clades as well as with respect to the relationships among the leaves of the tree (fig. 3). It differed, however, in revealing different relationships among the sub-clades of Clade $\mathrm{B}$ and also lower support for each of these subclades. 


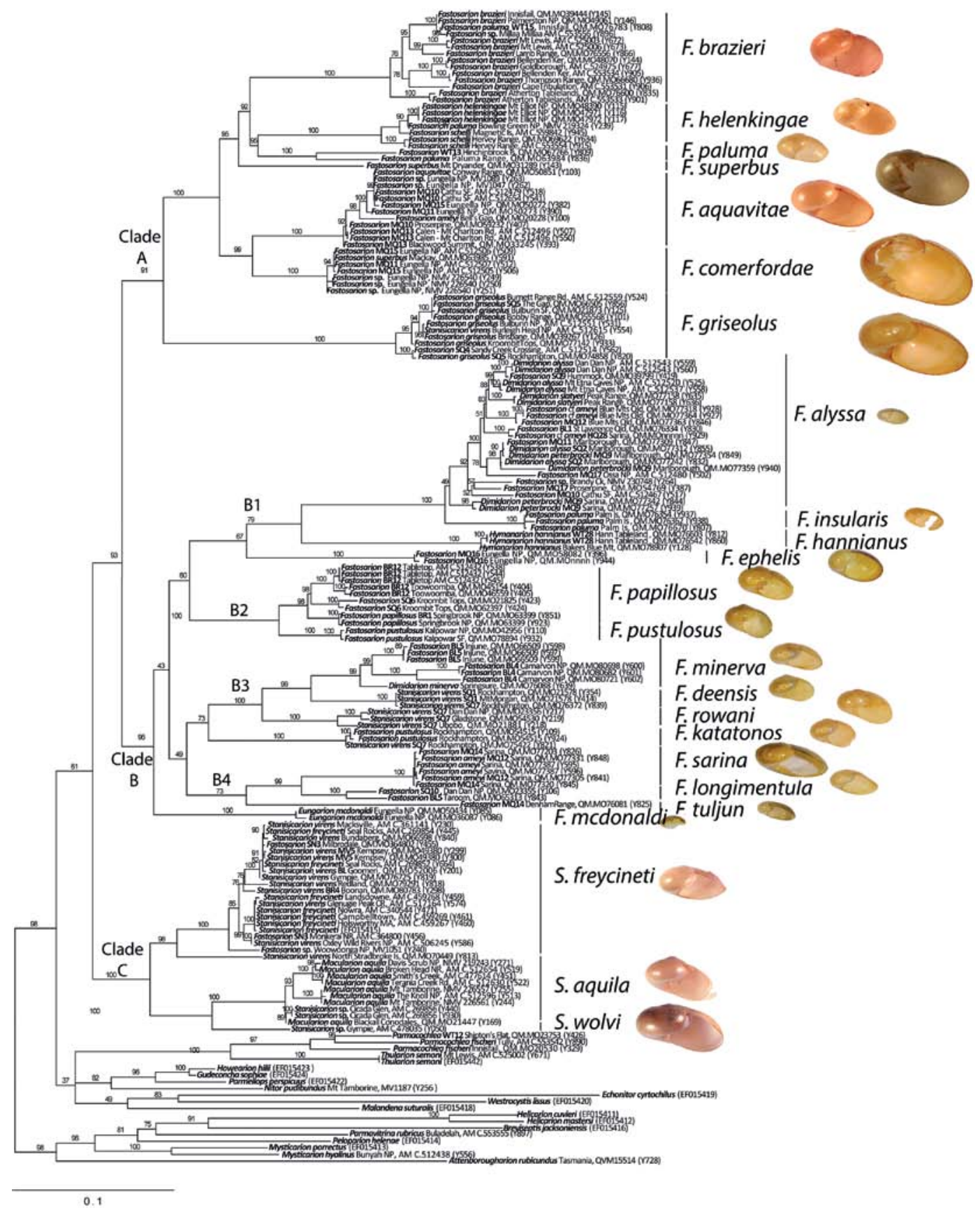

FIGURE 1 Best maximum likelihood tree based on analysis of the concatenated data set of fragments of the mitochondrial genes $16 \mathrm{~S}$ and COI using IQ-TREE. Ambiguous alignment sites in 16S removed using MAFFT. Numbers on branches indicate nodal support based on 10,000 ultra-fast bootstrap repeats as well as by employing Shimodaira-Hasegawa's (1999) approximate Likelihood Ratio Test ('SH-aLRT'). Scale bar indicating $10 \%$ of modelled sequence divergence. Shells shown to scale. 


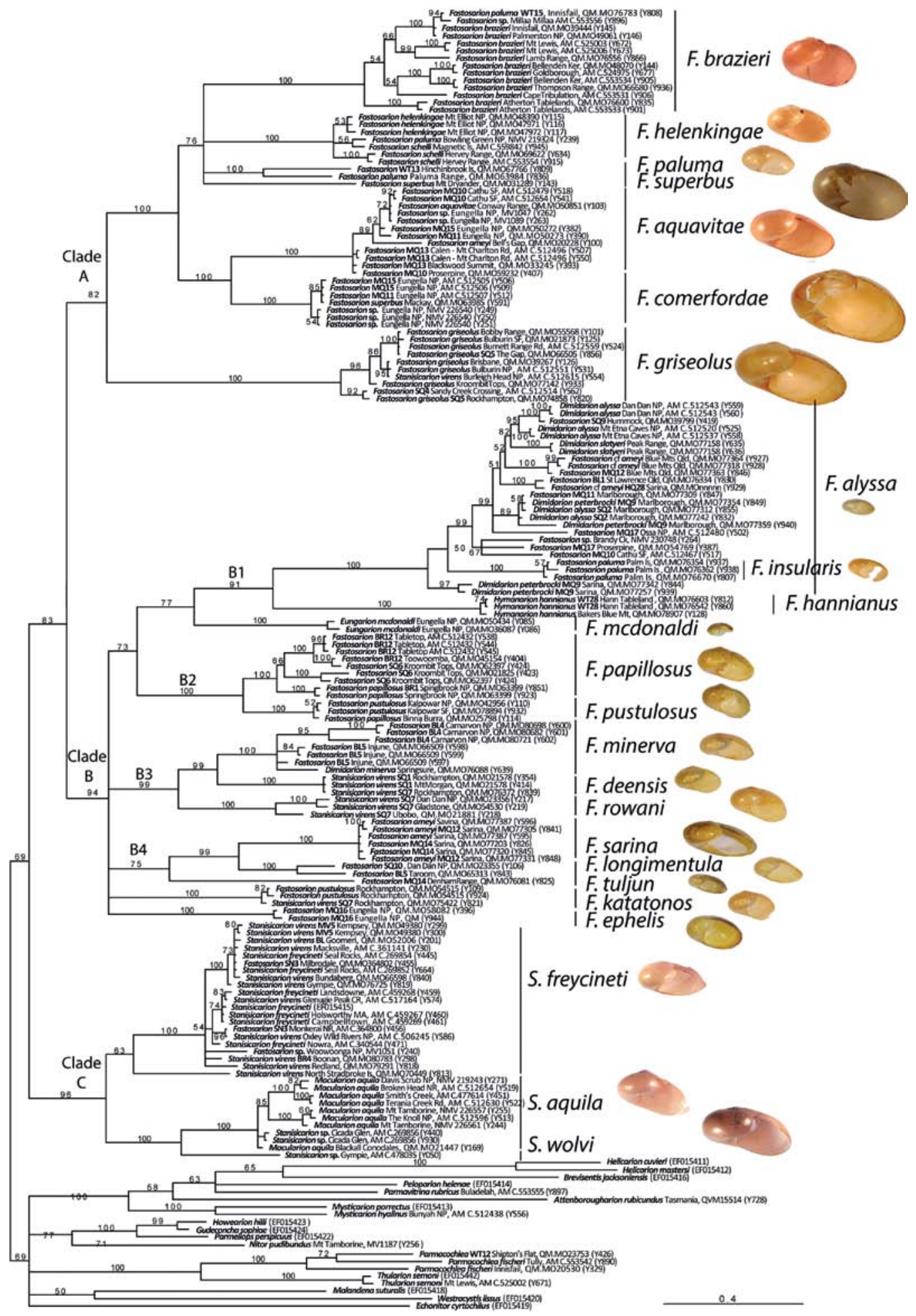

FIGURE 2 Majority-rule consensus tree based on Bayesian analysis of the concatenated data set of fragments of the mitochondrial genes $16 \mathrm{~S}$ and COI. Ambiguous alignment sites in 16S removed using MAFFT. Numbers on branches indicate posterior probabilities. Scale bar indicating $40 \%$ of modelled sequence divergence. Shells shown to scale. 


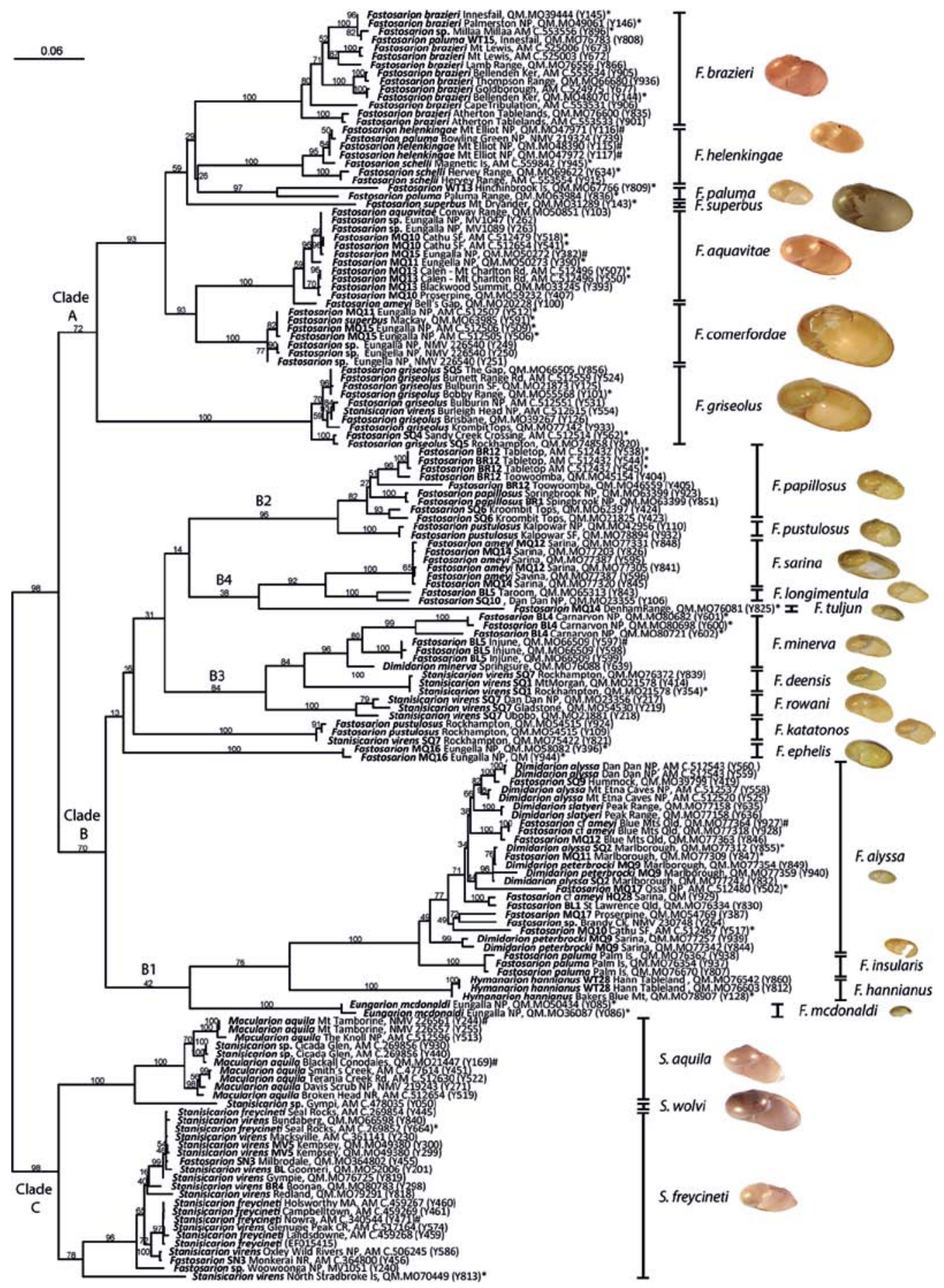

FIGURE 3 Best maximum likelihood tree based on analysis of the concatenated data set of fragments of the mitochondrial genes 16 S and COI using IQ-TREE, with reduced taxon sampling (including only the ingroup). Ambiguous alignment sites in $16 \mathrm{~S}$ removed using Guidance2. Numbers on branches indicate nodal support based on 10,000 ultra-fast bootstrap repeats as well as by employing Shimodaira-Hasegawa's (1999) approximate Likelihood Ratio Test ('SH-aLRT'). Scale bar indicating $10 \%$ of modelled sequence divergence. Shells shown to scale. 


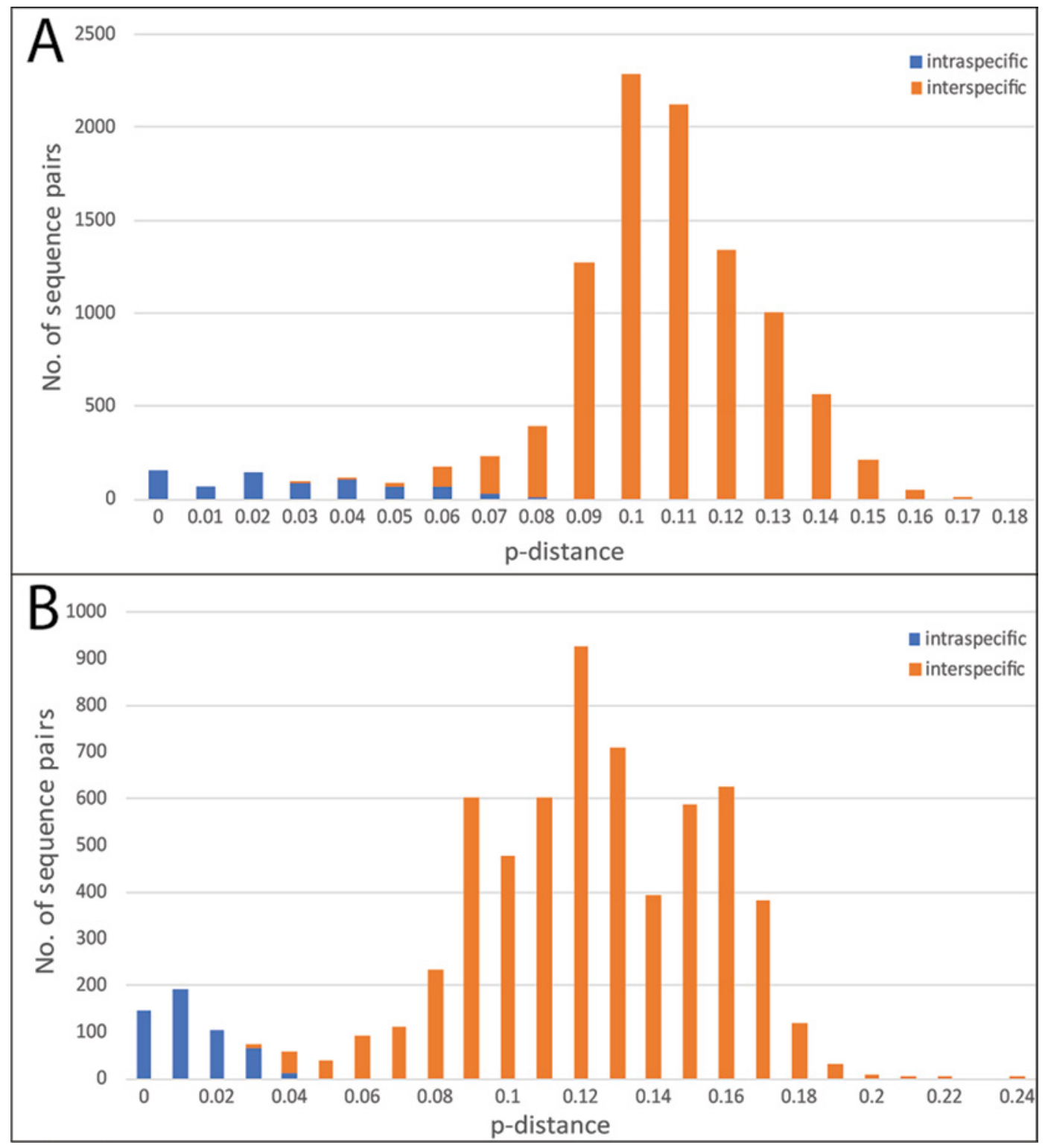

FIGURE 4 Comparison of intra- and interspecific genetic p-distances for the two mitochondrial fragments analysed. A. Frequency distributions of distances in COI. B. Frequency distributions of distances in $16 \mathrm{~S}$. 


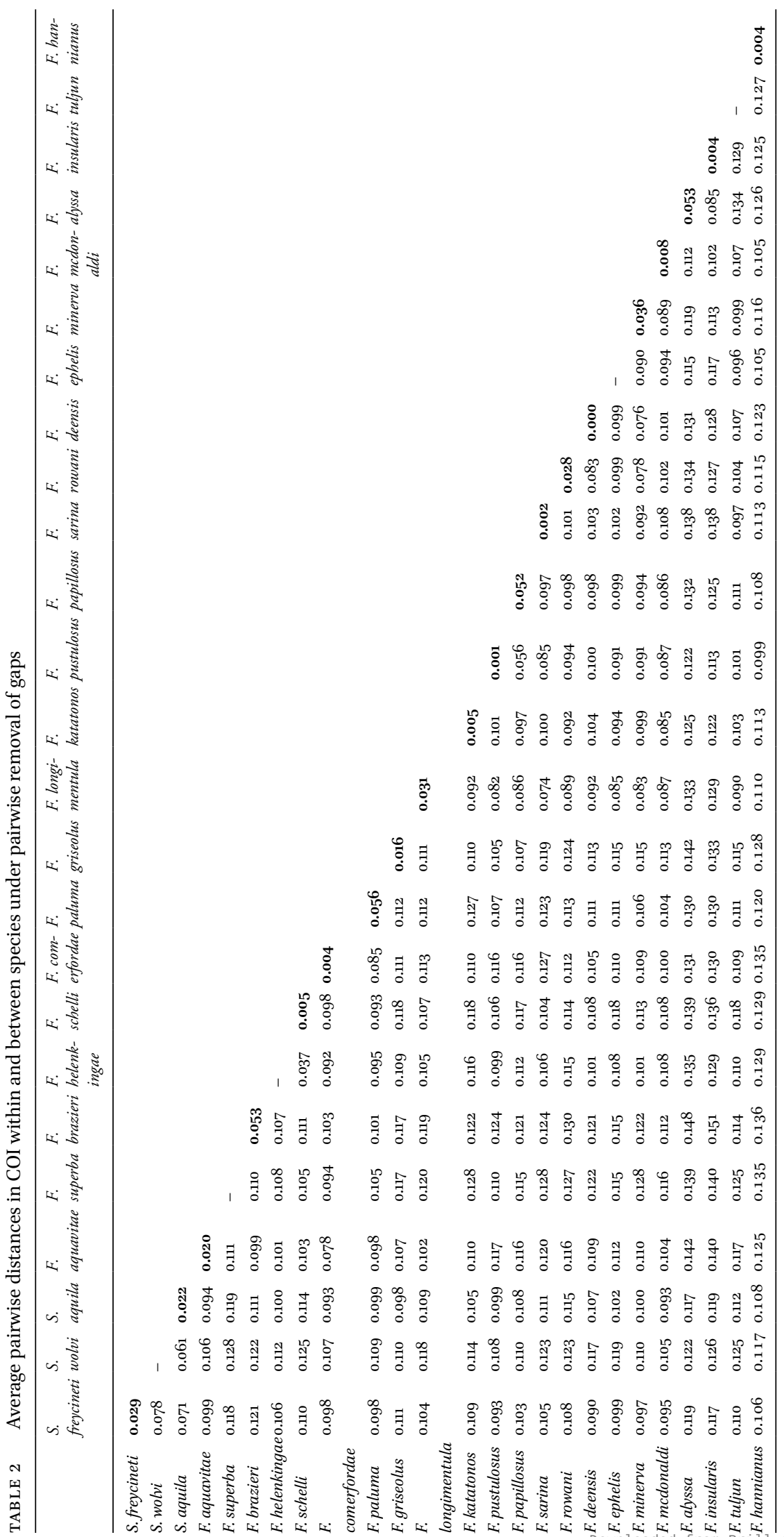




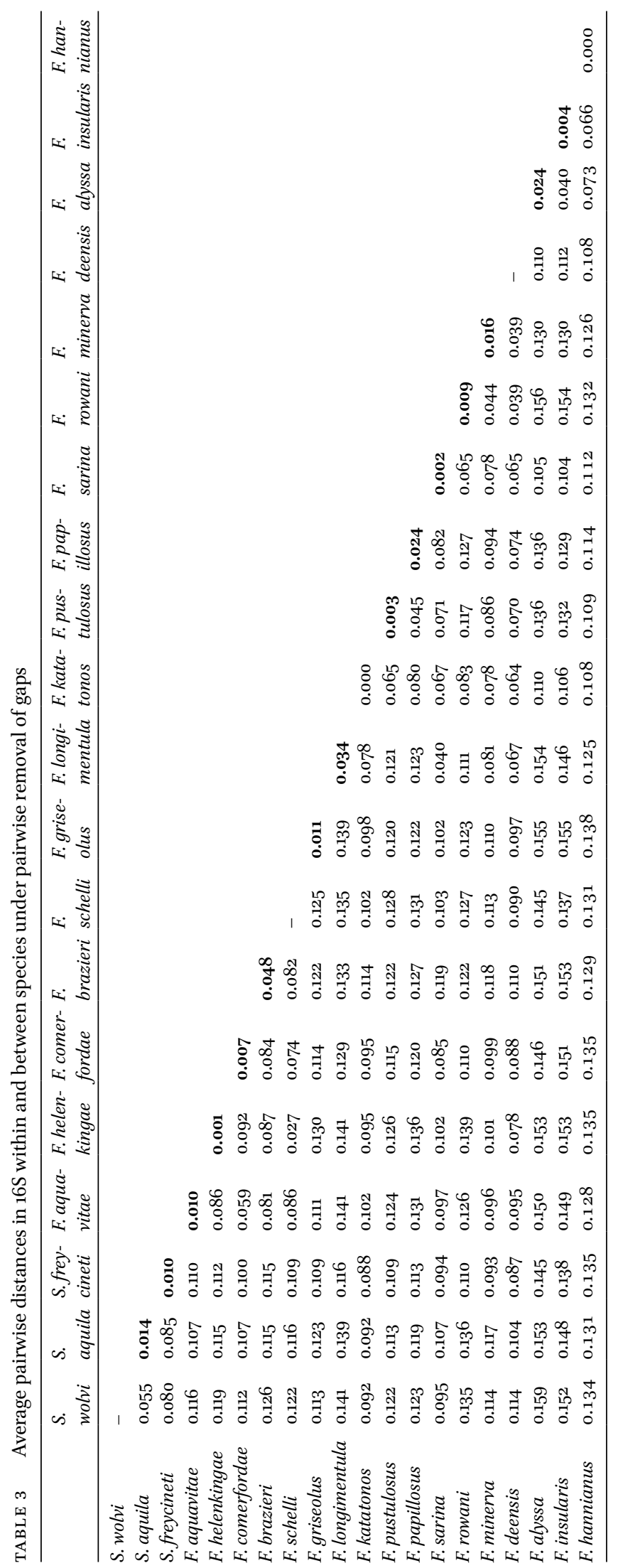




\section{Comparative morphology}

The majority of examined species and MOTUs shared certain features of the reproductive system, which distinguished them from all other Australian helicarionids. These species, presently assigned to the genera Fastosarion, Stanisicarion, Macularion, Eungarion, Dimidarion and Hymanarion, all had a moderately long to long vagina, an orange, elongate capsular gland taking up most of the free oviduct, an epiphallus with a relatively small caecum with the penial retractor muscle attached to the middle of the caecum, and a long, slender flagellum forming a simple spermatophore with a sculpture of at most small teeth or spines on the terminal end. Most of the variation among these species and MOTUs was observed in the penial complex, although differences also existed in the vagina, the bursa copulatrix and the folding of the spermoviduct, as well as characters of the shell, the shell lappets, and mantle lobes.

Fastosarion (comprising the type species, F. superbus, and other species $F$. ameyi, $F$. aquavitae, F. brazieri, F. comerfordae, F. griseolus, F. helenkingae, F. paluma, F. schelli; excluding F. papillosus and F. pustulosus and corresponding to Clade A in the phylogenetic analysis) contained medium-sized to large semislugs with globose to depressedly globose shells of around 3.5 whorls. Shell lappets were generally smooth and unicoloured, although a few species exhibited lappets with fine pustules and/or spots or mottling. The penis interior contained longitudinal pilasters and was sculptured with either pustules or diagonal ridges, forming a chevron-like pattern. Most species lacked a penial verge; however, a small verge was present in $F$. helenkingae and a large verge in F. griseolus. The spermatophore had a distinctive pattern of teeth followed by longer terminal spines on the tail-pipe.

Fastosarion papillosus and F. pustulosus (Clade B2 in the phylogenetic analysis) differed from other species of Fastosarion in their more highly whorled shells and the single row of large warts on each shell lappet. In both species the two arms of the epiphallus were fused together and the penis interior was sculptured with transversely ridged pilasters.

Eungarion, Dimidarion and Hymanarion were grouped together in Clade B, along with F. papillosus and F. pustulosus as well as several undescribed species. Monotypic genus Eungarion could be distinguished by its small, reduced shell with a membraneous base and its large mantle lobes and shell lappets sculptured with pigmented pustules. It had a swollen vagina and proximally swollen penis sculptured with pustulose longitudinal pilasters and a small penial verge.

Dimidarion (as currently defined) contains four species of small semislugs, D. alyssa, $D$. slatyeri, $D$. peterbrocki and $D$. minerva. The first three of these could not be distinguished from one another based on morphological data and are therefore synonymized in the Taxonomic Account below. All had small, reduced, flattened, very transparent shells of around 3 whorls with an expanded last whorl, a speckled cream to brown body and moderately large shell lappets with a pigmented ridge on the right lappet. Specimens identified as these three species also had a short vagina and a long, proximally swollen penis with a large, rounded pilaster and 1-3 minor longitudinal pilasters. A population from Palm Island (originally identified as Fastosarion palu$m a$ ) was similar, but these semislugs differed in the presence of white pustules on the shell lappets, and in its longer vagina and larger penis with no rounded pilaster. This population was treated as a potential new species, 'Helicarionidae sp. Palm Island' (=F. insularis sp. nov.).

In contrast, Dimidarion minerva differed from other members of Dimidarion in its slightly larger shell (see table 4; SD, SH: $\mathrm{p}<$ $0.05)$ with a higher whorl count $(\mathrm{p}<<0.005)$, finely pustulose shell lappets with multiple 
TABLE 4 Shell dimensions. Abbreviations: $\mathrm{n}=$ number of measured specimens, $\mathrm{SW}=$ shell width, $\mathrm{SH}=\mathrm{shell}$ height, AW = aperture width, NW = number of whorls

\begin{tabular}{|c|c|c|c|c|c|c|}
\hline Clade & Name & $n$ & SW & SH & AW & NW \\
\hline A & Fastosarion superbus & 9 & $\begin{array}{l}20.15-38 \\
(30.09 \pm 5.64)\end{array}$ & $\begin{array}{l}11.35^{-18.8} \\
(15.83 \pm 2.65)\end{array}$ & $\begin{array}{l}14.5^{-22.65} \\
(19.5 \pm 2.44)\end{array}$ & $\begin{array}{l}3.2-3.8 \\
\left(3.5^{1} \pm 0.18\right)\end{array}$ \\
\hline A & Fastosarion aquavitae & 5 & $\begin{array}{l}14-18.65 \\
(16.67 \pm 2.3)\end{array}$ & $\begin{array}{l}8.5^{-11.6} \\
(10.04 \pm 1.37)\end{array}$ & $\begin{array}{l}9-12.5 \\
(10.84 \pm 1.66)\end{array}$ & $\begin{array}{l}3.2-3 \cdot 7 \\
(3 \cdot 4 \pm 0.21)\end{array}$ \\
\hline A & Fastosarion brazieri & 17 & $\begin{array}{l}16.35^{-23.9} \\
(19.26 \pm 1.73)\end{array}$ & $\begin{array}{l}10.75^{-15.45} \\
(12.19 \pm 1.15)\end{array}$ & $\begin{array}{l}10.15^{-15} \\
(12.47 \pm 1.2)\end{array}$ & $\begin{array}{l}3 \cdot 5^{-4} \\
(3 \cdot 71 \pm 0.15)\end{array}$ \\
\hline A & Fastosarion comerfordae & 4 & $\begin{array}{l}21-24.4 \\
(23.1 \pm 1.47)\end{array}$ & $\begin{array}{l}12.5^{-14.4} \\
(13.5 \pm 0.9)\end{array}$ & $\begin{array}{l}12.8-15 \cdot 5 \\
(13.91 \pm 1.17)\end{array}$ & $\begin{array}{l}3.4-3.8 \\
(3.6 \pm 0.18)\end{array}$ \\
\hline A & Fastosarion griseolus & 5 & $\begin{array}{l}17-23.45 \\
(19.81 \pm 2.82)\end{array}$ & $\begin{array}{l}9.5^{-13.1} \\
(11.4 \pm 1.71)\end{array}$ & $\begin{array}{l}11.2-15 \cdot 75 \\
(13.47 \pm 1.87)\end{array}$ & $\begin{array}{l}3 \cdot 3-3 \cdot 5 \\
(3 \cdot 42 \pm 0.08)\end{array}$ \\
\hline A & Fastosarion helenkingae & 2 & $\begin{array}{l}14.3-18.5 \\
(16.4 \pm 2.97)\end{array}$ & $\begin{array}{l}8.6-11.2 \\
(9.9 \pm 1.84)\end{array}$ & $\begin{array}{l}9 \cdot 3-12.2 \\
(10.75 \pm 2.05)\end{array}$ & $\begin{array}{l}3.2-3 \cdot 4 \\
(3 \cdot 3 \pm 0.14)\end{array}$ \\
\hline A & Fastosarion paluma & 3 & $\begin{array}{l}11.9-13.65 \\
(12.58 \pm 0.94)\end{array}$ & $\begin{array}{l}7.2-7.6 \\
(7.43 \pm 0.21)\end{array}$ & $\begin{array}{l}7.8-9 \\
(8.23 \pm 0.67)\end{array}$ & $\begin{array}{l}3 \cdot 3-3 \cdot 5 \\
(3 \cdot 43 \pm 0.12)\end{array}$ \\
\hline B & Fastosarion alyssa & 12 & $\begin{array}{l}7 \cdot 5^{-9.8} \\
(8.31 \pm 0.6)\end{array}$ & $\begin{array}{l}4-5.25 \\
(4.72 \pm 0.33)\end{array}$ & $\begin{array}{l}5 \cdot 1-6.65 \\
(5 \cdot 53 \pm 0.44)\end{array}$ & $\begin{array}{l}2.8-3.1 \\
(2.96 \pm 0.08)\end{array}$ \\
\hline B & Fastosarion deensis sp. nov. & 2 & $\begin{array}{l}11.7-12.8 \\
(12.25 \pm 0.78)\end{array}$ & $\begin{array}{l}7.2-8.15 \\
(7.68 \pm 0.67)\end{array}$ & $\begin{array}{l}7.2-8.2 \\
(7 \cdot 7 \pm 0.71)\end{array}$ & 4 \\
\hline B & Fastosarion ephelis sp. nov. & 1 & 14.2 & 8.7 & $9 \cdot 4$ & 3.2 \\
\hline B & Fastosarion hannianus & 1 & 9.6 & 6.2 & 7.1 & 2.1 \\
\hline B & Fastosarion insularis sp. nov. & 2 & $\begin{array}{l}9.1-9 \cdot 4 \\
(9.25 \pm 0.21)\end{array}$ & $\begin{array}{l}4.7-5 \cdot 5 \\
(5.1 \pm 0.57)\end{array}$ & 6.55 & $\begin{array}{l}3.2-3.2 \\
(3.2 \pm 0)\end{array}$ \\
\hline B & Fastosarion katatonos sp. nov. & 6 & $\begin{array}{l}8.8-12.3 \\
(10.73 \pm 1.25)\end{array}$ & $\begin{array}{l}5.4-8.4 \\
(7.2 \pm 1.09)\end{array}$ & $\begin{array}{l}5 \cdot 6-8.15 \\
(7.18 \pm 1)\end{array}$ & $\begin{array}{l}3-3.9 \\
\left(3.5^{2} \pm 0.35\right)\end{array}$ \\
\hline B & $\begin{array}{l}\text { Fastosarion longimentula } \\
\text { sp. nov. }\end{array}$ & 2 & $\begin{array}{l}12.6-15.2 \\
(13.9 \pm 1.84)\end{array}$ & 8.15 & $\begin{array}{l}9-10.9 \\
(9.95 \pm 1.35)\end{array}$ & $\begin{array}{l}3-3.2 \\
(3.1 \pm 0.14)\end{array}$ \\
\hline B & Fastosarion mcdonaldi & 2 & $\begin{array}{l}11.3-11.6 \\
(11.45 \pm 0.21)\end{array}$ & $\begin{array}{l}7.2-8 \\
(7.6 \pm 0.57)\end{array}$ & $\mathrm{N} / \mathrm{A}$ & $\begin{array}{l}3.2-3 \cdot 5 \\
(3 \cdot 4 \pm 0.21)\end{array}$ \\
\hline B & Fastosarion minerva & 2 & $\begin{array}{l}8.55^{-12.8} \\
(10.68 \pm 3.01)\end{array}$ & $\begin{array}{l}5 \cdot 7-7 \cdot 55 \\
(6.63 \pm 1.31)\end{array}$ & $\begin{array}{l}5.4-8.4 \\
(6.9 \pm 2.12)\end{array}$ & $3 \cdot 4$ \\
\hline B & Fastosarion papillosus & 3 & $\begin{array}{l}14.3-15.8 \\
(14.97 \pm 0.76)\end{array}$ & $\begin{array}{l}9 \cdot 1-10 \\
(9 \cdot 47 \pm 0.47)\end{array}$ & $\begin{array}{l}8.95^{-10.4} \\
(9.78 \pm 0.75)\end{array}$ & $\begin{array}{l}3.8-4.1 \\
(3.97 \pm 0.15)\end{array}$ \\
\hline B & Fastosarion pustulosus & 2 & $\begin{array}{l}12.1-12.6 \\
(12.35 \pm 0.35)\end{array}$ & $\begin{array}{l}8.5^{-8.7} \\
(8.6 \pm 0.14)\end{array}$ & $\begin{array}{l}7 \cdot 7-7.8 \\
(7 \cdot 75 \pm 0.07)\end{array}$ & 4.1 \\
\hline B & Fastosarion rowani sp. nov. & 2 & $\begin{array}{l}10.2-13.5 \\
(11.85 \pm 2.33)\end{array}$ & $\begin{array}{l}6.75^{-8.8} \\
(7.78 \pm 1.45)\end{array}$ & $\begin{array}{l}6.4-9 \cdot 5 \\
(7 \cdot 95 \pm 2.19)\end{array}$ & 3.6 \\
\hline B & Fastosarion sarina sp. nov. & 1 & $17 \cdot 7$ & $9 \cdot 45$ & 12.5 & 3.2 \\
\hline B & Fastosarion tuljun sp. nov. & 4 & $\begin{array}{l}8.7-10.2 \\
(9 \cdot 45 \pm 0.65)\end{array}$ & $\begin{array}{l}4.1-5.1 \\
(4.7 \pm 0.45)\end{array}$ & $\begin{array}{l}5 \cdot 75^{-7} \\
\left(6.3^{6} \pm 0.68\right)\end{array}$ & $\begin{array}{l}2.6-3 \\
(2.83 \pm 0.17)\end{array}$ \\
\hline
\end{tabular}




\begin{tabular}{|c|c|c|c|c|c|c|}
\hline Clade & Name & $n$ & SW & $\mathrm{SH}$ & AW & NW \\
\hline $\mathrm{C}$ & Stanisicarion aquila & 13 & $\begin{array}{l}13.95^{-18.3} \\
(16.13 \pm 1.33)\end{array}$ & $\begin{array}{l}8.6-10.65 \\
(9.56 \pm 0.62)\end{array}$ & $\begin{array}{l}8.65^{-11.7} \\
(10.19 \pm 0.96)\end{array}$ & $\begin{array}{l}3.9-4.2 \\
(4.05 \pm 0.12)\end{array}$ \\
\hline $\mathrm{C}$ & Stanisicarion freycineti & 21 & $\begin{array}{l}12.8-16.65 \\
(14.59 \pm 0.88)\end{array}$ & $\begin{array}{l}7.1-10 \\
(8.57 \pm 0.71)\end{array}$ & $\begin{array}{l}7.85^{-11.55} \\
(10.05 \pm 0.84)\end{array}$ & $\begin{array}{l}3.2-3.8 \\
\left(3 \cdot 5^{1 \pm 0.16)}\right.\end{array}$ \\
\hline $\mathrm{C}$ & Stanisicarion wolvi sp. nov. & 2 & $\begin{array}{l}20.5^{-20.7} \\
(20.6 \pm 0.14)\end{array}$ & $\begin{array}{l}11.1-11.35 \\
(11.23 \pm 0.18)\end{array}$ & 12.2 & $4 \cdot 3$ \\
\hline
\end{tabular}

rows of large black warts, a short vagina and a moderately sized, cylindrical penis internally with fine diagonal ridges and sculptured with one raised longitudinal pilaster and three small irregular pilasters.

Hymanarion (containing a single species, H. hannianus), another small semislug with a very reduced shell of 2.6-3.0 whorls, had moderately large, smooth mantle lobes and shell lappets with some dark markings. This species had a moderately short vagina, a moderate sized, cylindrical penis with diagonal to transverse ridges and a single ridged pilaster. The penis had a short, conical verge.

In addition, there were another seven candidate taxa belonging to Clade B: 'Helicarionidae sp. Denham Range' (= F. tuljun sp. nov.), 'Helicarionidae sp. Taroom' ( = F. longimentula sp. nov.), 'Helicarionidae sp. Sarina' (= F. sarina sp. nov.), 'Helicarionidae sp. Mt Archer' (=F.katatonos sp. nov.),'Helicarionidae sp.SQ7' (=F. rowani sp. nov.), 'Helicarionidae sp. $\mathrm{Mt}$ Morgan' (=F. deensis sp. nov.) and 'Helicarionidae sp. MQ16' (= F. ephelis sp. nov.). Each could be distinguished by a unique combination of characters including the shell shape and size, mantle lobes and lappets, and the terminal genitalia. Some of these species grouped together based on morphological characters; for example, 'Helicarionidae sp. Sarina' (= F. sarina sp. nov.), 'Helicarionidae sp. Taroom' ( $F$. longimentula sp. nov.) and 'Helicarionidae sp. Denham Range' ( $=$ F. tuljun sp. nov.) all had a moderately long vagina and bursa copulatrix, and a penis with a small verge and sculptured internally with transverse ridges and longitudinal pilasters. Seven Clade B species had rows of large warts on the shell lappets (including 'Helicarionidae sp. Mt Morgan' ( $F$. deensis sp. nov.), 'Helicarionidae sp. Sarina' (=F. sarina sp. nov.), 'Helicarionidae sp. Mt Archer' (= F. katatonos sp. nov.), Fastosarion papillosus, F. pustulosus and Dimidarion minerva).

Macularion and Stanisicarion (comprising Clade $\mathrm{C}$ in the phylogenetic analysis) are medium-sized to large semislugs with subglobose, low-spired shells of around 3.5-4 whorls and pustulose, spotted or speckled shell lappets. Macularion was found to be significantly larger than Stanisicarion (SD, SH: $\mathrm{p}<0.0005$ ) with a higher whorl count $(\mathrm{p}<<0.0005)$. Both genera had a pustulose penis interior with a moderately short, slender verge partially fused to the penial wall. The epiphallic caecum was short and the spermatophore simple, with a small hook at the terminal end. The eggs of both genera had a rounded base and a spiraling top.

Stanisicarion contains two species, S. freycinetiand $S$. virens, which could not be separated anatomically in the present study. Macularion contains a single species, $M$. aquila, but specimens from Mt Wolvi were significantly larger (SH, SD: p < 0.005) and anatomically distinct and are here referred to as 'Helicarionidae sp. Mt Wolvi' (= S. wolvi sp. nov).

While some diagnostic morphological characters could be identified for Clades A and C, Clade B contained considerably more 
morphological variation and no single unique character was shared by every species.

All additional genera included in this study could be clearly excluded from the moderate Qld semislugs based on morphological characters (unpubl. data). Colmanarion burchi Stanisic, 2010 differed in its swollen vagina, the presence of cryptae in the epiphallus and flagellum and the large branching spines on the spermatophore. Colmanarion thorntonianus Stanisic, 2010, in contrast, had no vagina, a slender flagellum and epiphallus, and a spermatophore with only tiny hair-like spines. It appears unlikely that the two species are congeneric; however, neither groups with the moderate Qld semislug radiation.

Extreme semislugs Antiquarion collinsae Stanisic, 2010 and Fenestrarion brianna Stanisic, 2010 showed little morphological similarity to the moderate Qld semislugs (unpubl. data). Both lacked a vagina and had a reduced flagellum with no axial filament, producing a soft-walled spermatophore with no tail-pipe. Moreover, Fenestrarion brianna lacked a caecum and Antiquarion collinsae had a very long, coiled caecum with basal attachment of the penial retractor muscle.

Of the snail groups examined, Nitor Gude, 1911 showed the greatest anatomical resemblance to the moderate Qld semislugs, sharing many of the key genital characters (Hyman \& Köhler, 2018a) and differing primarily in the attachment of the penial retractor muscle to the tip rather than the middle of the caecum, the presence of a more rounded capsular gland lacking orange colouration, and the fine sculpture of the spermatophore. Echonitor Iredale, 1937, Malandena Iredale, 1937 and Westracystis Iredale, 1939 differed in each having a very short or absent vagina and in the accessory structures of the epiphallus; Echonitor has no epiphallic caecum or flagellum, Malandena has a slender flagellum but lacks a caecum, and Westracystis has both caecum and flagellum but exhibits a clearly basal attach- ment of the penial retractor muscle (Hyman \& Ponder, 2010).

\section{Ancestral state reconstruction}

We undertook ancestral state reconstructions using three characters: body size, number of whorls (as a measure of degree of shell reduction) and altitude (fig. 5). Mapping body size onto the tree indicated that the ancestral state of the moderate Qld semislugs is likely to be a moderate body size. This size is maintained in Clade C, with a slight size increase in 'Helicarionidae sp. Mt Wolvi' (= S. wolvi sp. nov.) and a slight decrease in Stanisicarion freycineti. Similarly, in Clade A most ancestral species are inferred to be of moderate length, with size increases or decreases in single species only (although F. paluma and F. helenkingae may share a slightly smaller ancestor). However, the common ancestor of Clade B is postulated to have been moderately small, and the genera Hymanarion and Dimidarion are predicted to share a small ancestor.

Mapping of altitude showed considerable variation, with not much similarity in altitude between sister taxa. However, the ancestral state reconstruction indicated that members of Clade $\mathrm{C}$ shared a moderately low altitude ancestor, as did members of Dimidarion.

Ancestral reconstruction of whorl count allowed us to track the likely evolution of shell reduction. The outgroup taxon used, Nitor pudibundus (Cox, 1868), is a snail with a high whorl count of around six whorls. In the reconstruction the most recent common ancestor of the ingroup had a whorl count of around 4.4 whorls. Moderate shell reduction (to a shell of fewer than 3.8 whorls) was shown independently three times (in Stanisicarion freycineti; in the common ancestor of most of the Fastosarion group, excluding only F. griseolus; and in the common ancestor of Eungarion, Hymanarion and Dimidarion). Extreme shell reduction (to a shell of fewer than three whorls) also occurred independently 


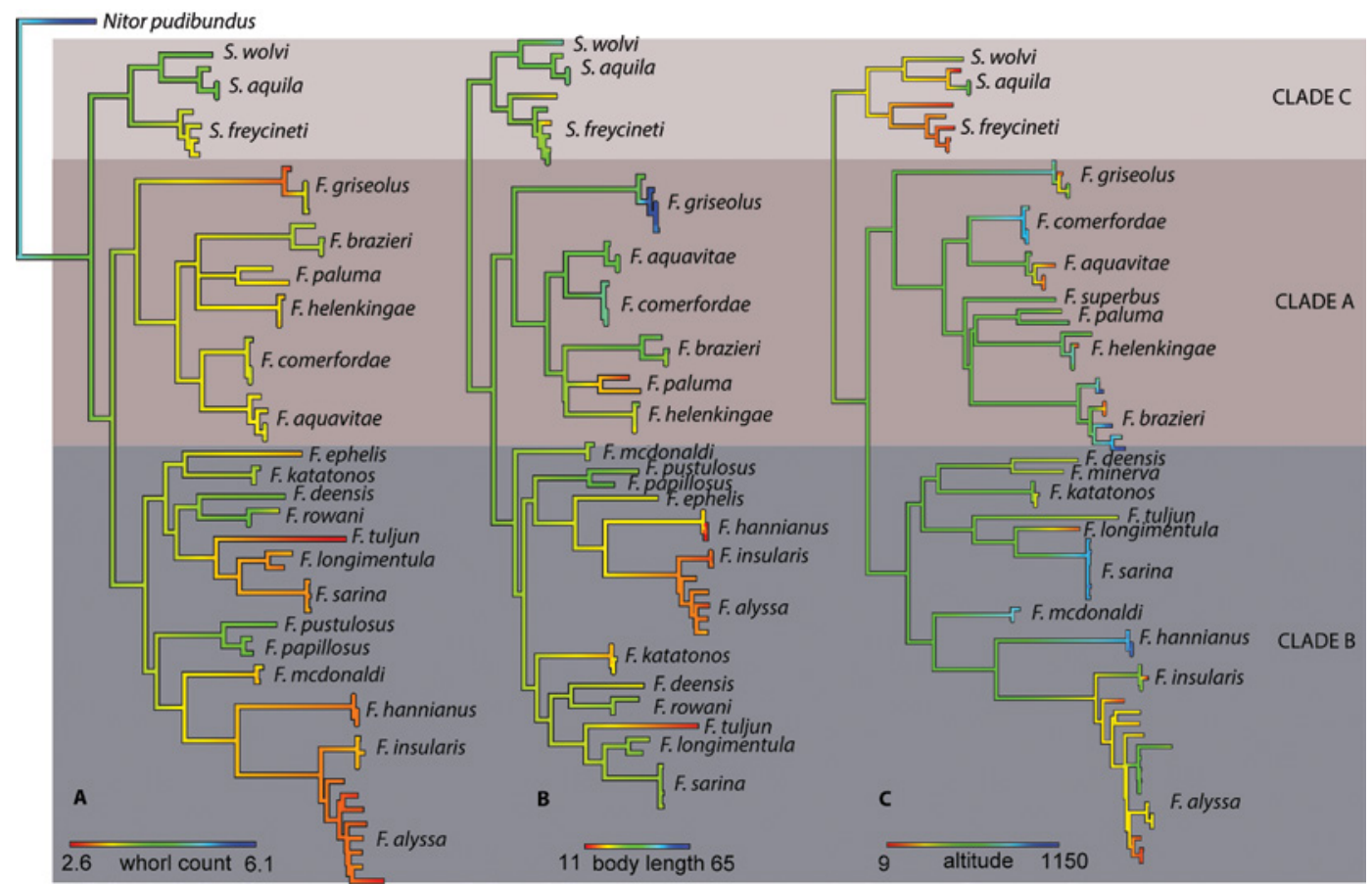

FIgURE 5 Ancestral state reconstructions. A. Whorl count. B. Body length. C. Altitude.

three times: firstly, in the ancestor of Dimidarion and Hymanarion; secondly, in the most recent common ancestor of 'Helicarionidae sp. Taroom' ( $=F$. longimentula sp. nov.), 'Helicarionidae sp. Sarina' (=F. sarina sp. nov.) and 'Helicarionidae sp. Denham Range' ( $=F$. tuljun sp. nov.); and thirdly, in 'Helicarionidae sp. MQ16' (= F. ephelis sp. nov.). The algorithm used allows reversals, so slight whorl count increases were seen in a number of groups.

\section{Discussion}

\section{Phylogenetic relationships}

Combined morphological and molecular evidence corroborates the monophyly of the mid-Qld moderate semislug radiation, which includes the currently accepted genera Fastosarion, Stanisicarion, Macularion, Eungarion, Dimidarion and Hymanarion. Morphologi- cal features characteristic of this group include the presence of a long vagina, a slender epiphallic flagellum forming a simple spermatophore with at most tiny teeth or spines on the tail-pipe, an epiphallic caecum with penial retractor muscle attachment to the middle, near the base, and the distinct orange colouration of the large capsular gland.

Other major groups previously identified among the Australian Helicarionidae include the southeastern Australian radiation $(\mathrm{He}$ licarion, Attenborougharion, Parmavitrina, Peloparion, Ubiquitarion, Mysticarion, Cucullarion; Hyman et al., 2017) and the Nitor / Lord Howe Island (LHI) radiation (Nitor, Epiglypta, Gudeoconcha, Howearion, Parmellops; Hyman \& Köhler, 2018a). Correspondingly, these two groups are defined each by a combination of genital characters: the presence or absence of a vagina, the flagellum and spermatophore type, the presence or absence of an epiphallic 
caecum and the attachment of the penial retractor muscle. These characters appear to be diagnostic in the identification of major lineages among the Australian Helicarionidae. The mid-Qld moderate semislugs exhibit a similar pattern of key genital characters to the Nitor / LHI clade, differing primarily in their medial to basal attachment of the penial retractor muscle, their more rounded capsular gland lacking orange colouration, and the fine sculpture of the spermatophore.

\section{Shell reduction}

In contrast to the southeastern Australian radiation and the Nitor / LHI radiation, which both contain snails as well as semislugs, the moderate Qld semislugs contain just a single body type. This suggests that the move from snail to semislug occurred just once in the ancestry of this group (fig. $5^{\mathrm{B}}$ ). The sister group of the moderate Qld semislugs in both trees (figs. 1-2) is an unresolved clade that contains representatives of at least 3-4 different radiations and contains both snails and semislugs. Under the assumption that shell reduction is unlikely to be reversed, the most recent common ancestor of these two lineages is probably a snail. If this is the case, shell reduction has evolved in the moderate Qld semislugs independently from other helicarionid semislugs.

Shell reduction is relatively slight in the basal Clade $\mathrm{C}$ and in some members of Clade $\mathrm{B}$, with whorl counts of around four, but more advanced in Clade A (whorl counts around 3.5) and some members of Clade B (whorl counts of around 3 ), indicating ongoing limacisation in these clades. Semislugs with whorl counts of fewer than three whorls have independently evolved twice within Clade B.

\section{Biogeographic origins and species distribution}

The moderate Qld semislugs inhabit a wide geographic area stretching from southern NSW to northern Qld and to Carnarvon Gorge in the west and are found primarily in rainforest or vine thicket, in regions classified by the Köppen climate classification (Stern et al., 200o) as tropical, subtropical with no dry season or temperate.

From the late Miocene, eastern Australia experienced progressive aridification (Martin, 2006). While continued climatic changes resulted in many contractions and expansions of mesic habitats, the general shift was from rainforest towards drier sclerophyllous vegetation. This resulted in the fragmentation of once widespread rainforest into an archipelago of isolated refugia (Byrne et al., 2011). Broad corridors of dry habitat or physical barriers such as mountain ranges or rivers have been shown to form significant barriers to gene flow in numerous mesic plant and animal groups (including mammals, birds, reptiles, amphibians, freshwater fish and invertebrates; e.g., Joseph \& Moritz, 1994; Schauble \& Moritz, 2001; Brown et al., 2006; Chapple et al., 2011). Two such barriers within the range of the moderate Qld semislugs are the Burdekin Gap (dry woodland and savanna separating rainforests in northeastern Qld and mideastern Qld) and the St Lawrence Gap (a dry habitat corridor separating mideastern Qld and southeastern Qld) (Ford, 1987a, b; Cracraft, 1991).

These biogeographical barriers may be relevant for some helicarionid semislugs, as they are for other organismal groups: of the three most widespread species in Clade A, F. brazieri is only found north of the Burdekin Gap, F. aquavitae between the Burdekin Gap and St Lawrence Gap and F. griseolus south of the St Lawrence Gap, indicating the presence of genetic breaks along these barriers. However, the widespread species $D$. alyssa (Clade B) is found both north and south of the St Lawrence Gap with little geographic structuring. This species manages to occupy drier habitats than any other member of this radiation (see fig. 18), and is also distinguished by a very long branch on the phylogenetic tree, 
which may be indicative of its comparatively early evolutionary divergence from other species. This could indicate that this species is a biogeographical relic from past times when more mesic habitats spread further inland than today.

The basally diverging Clade C comprises species from northern NSW and southern Qld, while species from Clades A and B are generally found further north, in southern to mideastern Qld. Within clade A, the wellsupported phylogeny closely matches the geographic distribution of the mostly allopatric species, with the most basal group (F. griseolus) found furthest to the south and more recently diverged groups $F$. brazieri, F. helenkingae and $F$. paluma furthest to the north. This, along with the distribution of the most likely sister clade Nitor / LHI (northern NSW / southern Qld), suggests that Fastosarion may have originated in northern NSW or southern Qld and subsequently radiated further north.

Many species examined herein were found to have broader ranges than previously understood; for example, Stanisicarion freycineti, Fastosarion brazieri and Dimidarion alyssa, and to a lesser extent, F. aquavitae, Macularion aquila, F. papillosus and D. minerva. In each case, the extended distributions are a result of taxonomic changes suggested herein as we either synonymised species names or amalgamated candidate species that were previously identified based on curatorial work with existing species names. Such large ranges are unusual in helicarionid semislugs and to date have been seen primarily in arboreal species (Hyman et al., 2017). However, in the southeastern semislug Helicarion cuvieri, recent work has shown that populations from southern Tasmania to north of Sydney (NSW) all belong to the same species (although in this case, there is some indication of incipient speciation in some more isolated populations) (Hyman \& Köhler, 2018b). Our findings that at least some semislugs are capable dispersers that are able to maintain gene flow across relatively large distances and with intervening dry areas is a reminder that a one-fits-all approach is not an appropriate predisposition in land snail systematics and ecology.

\section{Queensland helicarionids}

This clade of over 20 species dominates the helicarionid fauna of southeastern and mideastern Qld. Three species extend into the Wet Tropics and one extends into NSW. Other semislugs in southeastern Qld include Cucullarion, Peloparion and Mysticarion from the southeastern helicarionid radiation (Hyman et al., 2017) and Fenestrarion (of unknown affiliation). In the Wet Tropics or further north are found Antiquarion, Colmanarion, Thularion and Parmacochlea, all of which differ considerably from the moderate semislugs in both body form and anatomy (Stanisic, 1993b; Hyman \& Ponder, 2010; Hyman \& Köhler, unpubl. data).

There are relatively few helicarionid snails in southern Qld (compared to the diverse semislug fauna); those that are found in this area are to date known almost entirely from their shells (e.g., Tarocystis, Dendronitor, Delinitesta, Burnettia and Eddiella; Stanisic et al., 2010). An exception is Nitor, which is found in northern NSW and southern Qld (Hyman \& Köhler, 2018a). The two radiations share several morphological characters, including the presence of a distinct vagina, a slender flagellum producing a relatively simple spermatophore and a distinct epiphallic caecum (although with a different attachment of the penial retractor muscle) (Hyman \& Köhler, 2018a).

Despite the extensive land snail collections held by the Queensland Museum in particular, it is clear that numerous species of moderate Qld semislugs are heavily under-represented in Museum collections. In particular, four new species were described from near Rockhampton, three new species from just west 
of Mackay and one new species from Palm Island near Townsville, all of them with narrow ranges and known from only a few specimens. It is highly likely that more collecting in southeastern Qld will reveal range extensions and the existence of additional species belonging to this group.

\section{Systematic significance of morphological characters}

Helicarionid semislugs have extensive shell lappets and mantle lobes, and their size, shape, degree of fusion and ornamentation can be used to differentiate both species and genera (e.g., Nitor, Hyman \& Köhler, 2018a; Helicarion, Hyman \& Köhler, 2018b).

Within the moderate semislugs of Qld, shell lappets and mantle lobes were moderately well developed and the left and median mantle lobes were almost always fused to form a cephalic shield. The shell lappets were sometimes joined by a narrow collar. Ornamentation was much more variable. In Clade A, some species had finely pustulose shell lappets but large, discrete warts were only observed in one species, F. brazieri (although warts are also recorded in $F$. comerfordae; Stanisic, 2018). In Clade C, all species had pustulose shell lappets (although pustules were not always visible in active Stanisicarion freycineti) and the sister taxa M. aquila and 'Helicarionidae sp. Mt Wolvi' (= S. wolvi sp. nov.) had larger pigmented warts or ridges as well.

Shell lappet ornamentation was most prevalent and variable in Clade $\mathrm{B}$, where seven of the 13 species exhibited large warts on the shell lappets, in most cases arranged in one or several rows. Close sister taxa often shared the same pattern (e.g., multiple rows of warts on each lappet in D. minerva and 'Helicarionidae sp. Mt Morgan' (=F. deensis sp. nov.); single row of warts on each lappet in F. pustulosus and F. papillosus). However, within both subclades $\mathrm{B}_{2}$ and $\mathrm{B}_{3}$, warts were present in some species and absent in others, so this character could not be used to define subgroups within clade $\mathrm{B}$.

Most of the variation between species was found in the penial complex. The sculpture of the inner penial wall is usually species-specific in land snails (Gómez, 2001) and as expected, varied considerably among species. Previous studies within Helicarionidae, primarily on genera of fewer than six species, have generally found a consistent penial type within a genus: for example, diagonal papillose ridges are present in all members of Helicarion (Hyman \& Köhler, 2018b), just as longitudinal pilasters and a penial verge are present in all Mysticarion (Hyman et al., 2017). However, in snail genera Nitor and Sigaloeista, more than one penial type is found (e.g., pustules or longitudinal pilasters in Nitor; Hyman \& Köhler, 2018a, 2019). Each of these represents a larger radiation: there are ten species in Nitor and seven in Sigaloeista.

A similar pattern was seen in the current study. While the three members of Clade C had the same penial type, in each of the larger clades a mix of penial types was observed, and overall there is no feature of the penial interior that unites all members of the radiation of the Qld moderate semislugs or indeed the members of clades A or B.

\section{Systematic significance of the mitochondrial phylogeny}

The mitochondrial trees presented herein are to date the only available phylogenetic hypothesis for the moderate Qld semislugs and inform our interpretation of the comparative morpho-anatomy as well as systematic conclusions. However, the statistical support for some major clades indicates a certain degree of potential instability of the shown topology, which we also take into account. In particular, the phylogenetic relationships among the members of Clade B must be interpreted with 
caution as different analytical methods and differing treatment of molecular evidence affect the branching patterns in this part of the tree (figs. 1-3). To improve the robustness of the molecular phylogeny, it will be critical to sample additional DNA sequences, and where possible, also additional lineages. This is currently impossible due to lack of funding and the generally poor quality of DNA yielded from museum samples. Alternatively, the rather weak statistical support of the most basal relationships could result from a a phenomenon called a 'hard polytomy', which implies that the basal splits are indeed very narrow as a result of rapid lineage diversification in the past. In this case, moderate amounts of additional sequence data are unlikely to significantly improve the basal resolution of the shown trees.

Despite these limitations, which we incorporated into our systematic assessments, the molecular trees provided strong support for the monophyly of the entire radiation of the moderate Qld semislugs as well as reasonable support for the monophyly and nestedness of clades A, B and C. The trees also provided generally strong to maximum support for the monophyly of the species-level clades, here considered as MOTUs. The general agreement of the well-supported parts of our trees with comparative morpho-anatomy provides critical corroboration of these relationships. This corroboration from an independent source of evidence increases the probability of our phylogenetic hypothesis (Faith et al., 2011).

The amount of mitochondrial differentiation of the delineated MOTUs (tables 2-3) is generally comparable with interspecific genetic distances observed in other Australian helicarionids: For example, we observed a transition from intra- to interspecific pdistances in COI between four and six percent in Nitor (Hyman \& Köhler, 2018a), five and six percent in Helicarion (Hyman \& Köhler, 2018b), and three and seven percent in Sigaloeista (Hyman \& Köhler, 2019).

\section{Taxonomic divisions within the moderate Qld semislugs}

The radiation of moderate Qld semislugs encompasses six currently accepted genera (Stanisic et al., 2010). Three of these are monotypic (Eungarion, Hymanarion, Macularion) and one is effectively monotypic because its members are shown to be synonymous (Stanisicarion; see below). The remaining genera, Fastosarion and Dimidarion, are nonmonophyletic in our molecular tree. Even when considering that the branching patterns in Clade B are somewhat unstable, it is still improbable that Fastosarion or Dimidarion as currently encompassed would become monophyletic in future, more robust phylogenies. The reason for their non-monophyly is that nearly all genera were described without an understanding of the phylogenetic relationships in this group, rendering assessments of character evolution in this group of moderate Qld semislugs hypothetical. The current classification emphasizes readily accessible external morphology and shell features, which are here found to be subject to convergent evolution (fig. 5). We demonstrate that reductions in shell and body size have occurred independently in each major clade and conclude that both characters viewed in isolation are no suitable indicators for systematic relationships.

To reconcile the current classification with the new evidence presented here, taxonomic re-arrangements are necessary. Our aim is to create a robust and evidence-based classification in which genera are delimited so that they represent natural groups that are characterized by shared diagnostic features. In addition, we consider practicality (ease of identification), continuity (consistent use of names), and simplicity (avoidance 
of unwarranted taxonomic proliferation) as important aspects to ensure that the classification fulfils its main purpose: to enable unequivocal communication among biologists across disciplines and through time.

In principal, there are several possible solutions to maintain monophyletic genera, but not all of them ensure that genera so delimited are also readily identified by diagnostic features: First, if preference was given to the continued use of available taxonomic names, the evidence presented here would require the description of three additional genera bringing their total number to nine, of which four were monotypic. However, we do not consider such a proliferation of generic names as justified with respect to the overall amount of evolutionary differentiation within this clade. Moreover, the relationships among the species in Clade B in particular are not well-resolved and the addition of more data and/or taxa may cause changes in the topology of the trees, thereby potentially creating the need for further taxonomic splitting in the future. Because the subclades B1-4 are not well-supported by morphological characters and some species cannot be confidently assigned to a subclade based on their morphoanatomy, including Eungarion mcdonaldi, this solution would also perpetuate uncertainty as to how to delineate genera into the future.

Second, one could recognize the three comparatively well-supported mitochondrial clades A-C as distinct genera. However, the only clade that is well-characterized in terms of its morpho-anatomy is clade $\mathrm{C}$, which contains medium-to-large semislugs with shells of around 4 whorls, pustulose lappets, a pustulose penis interior, a verge partly fused to the penial wall, and distinctly spiraling eggs. By contrast, Clade A contains species with 3.5 whorls, usually smooth lappets, a broad epiphallus (equal in diameter to the penis), a distinctive penial sculpture of regularly spaced diagonal or longitudinal ridges or pustules with a single large longitudinal pilaster, and a distinctive spermatophore with a spiraling, toothed ridge and a feathered tip. However, there are no diagnostic features to consistently distinguish members of Clade B from Clade A because the range of morphoanatomical variation among its members (containing Eungarion, Dimidarion and Hymanarion as well as eight undescribed species) encompasses nearly the entire range of variation observed within clade $A$.

Alternatively, we prefer a more conservative assessment of the available evidence at the expense of the continuous use of some generic names: We propose to maintain Stanisicarion as an accepted genus. It was originally described in a phylogenetic context (Hyman \& Ponder, 2010) and its evolutionary distinctiveness is confirmed herein both in terms of statistical support and basal branch length in the mtDNA trees (Clade C; figs. 1-3). In addition, all members of the genus share key diagnostic characters that distinguish them from all other moderate Qld semislugs (penial verge partly fused to the penial wall, distinctly spiraling eggs). The monotypic Macularion falls within the range of morphoanatomical variation of Stanisicarion and is therefore treated as a junior synonym of the former.

Furthermore, we propose to unify all other species in a single genus because there is only modest to weak basal branch support in the phylogenetic tree for further subdivisions in the mtDNA tree and because we failed to identify any morpho-anatomical characters that consistently distinguish smaller subdivisions beyond the recognition of a larger number of monophyletic genera. The earliest applicable name for this genus combining clades A and B is Fastosarion while Eungarion, Hymanarion and Dimidarion become junior synonyms of the former (refer to taxonomic account for details). 


\section{Taxonomic account and species descriptions}

\section{ZooBank:}

lsid:zoobank.org:pub:1935CAD4-4BD5-450D92AC-63D1A5D84CD9.

Helicarionidae Bourguignat, 1877

Diagnosis: see Hyman \& Köhler (2018a).

\section{Fastosarion Iredale, 1933}

Fastosarion Iredale, 1933: 37. Type species Vitrina superba Cox, 1871 (by original designation); masculine.

Vercularion Iredale, 1933: 38 (name unavailable, no description). Intended type species Helicarion bullaceus Odhner, 1917 (by original designation); masculine.

Eungarion Stanisic, 1993: 27. Type species Eungarion mcdonaldi Stanisic, 1993 (by original designation); masculine.

Dimidarion Stanisic, 2010 in Stanisic et al., 2010: 314. Type species Dimidarion alyssa Stanisic, 2010 (by original designation); masculine.

Hymanarion Stanisic, 2010 in Stanisic et al., 2010: 318. Type species Hymanarion hannianus Stanisic, 2010 (by original designation); masculine.

\section{Remarks}

The gender of none of the genus names treated herein has been explicitly specified in the relevant original descriptions. However, all these names are compound words ending with the noun '-arion', which determines the gender of these names to be masculine in correspondence with the gender of the name Arion Férussac, 1819. Accordingly, we here correct any previously incorrect gender assignment of species names.

The genus Fastosarion was originally described as a monotypic subgenus of Helicarion by Iredale (1933), who later elevated it to full genus rank (Iredale, 1937). The name is of masculine gender as evident from Iredale's (1937) use of the species name $F$. superbus.
Iredale (1933) also proposed the name Vercularion for the type species V.bullaceus; however this name is unavailable because it was introduced without a description. It has not been made available subsequently by Iredale (1937: 8) nor Iredale (1941: 6) (no description). The simultaneously published name Fastosarion was later given precedence over Vercularion by First Reviewer's choice by Smith (1992: 231). Smith (1992) listed eight species in the genus.

Scott (1995) revised Fastosarion, redescribing $F$. superbus and describing two new species, F. helenkingae Scott, 1995 and F. aquavitae Scott, 1995. Hyman \& Ponder (2010) moved two species to the new genus Stanisicarion and Stanisic et al. (2010) moved an additional species to Macularion while also describing six new species and placing two in synonymy. Subsequently, a single species was synonymized with Mysticarion hyalinus (Pfeiffer, 1855) by Hyman et al. (2017), bringing the total number of accepted species in the genus to ten.

In the current study we uphold Fastosarion as an accepted genus, but treat the genus names Eungarion, Dimidarion and Hymanarion as its subjective junior synonyms.

Eungarion was described as a monotypic genus for new species E. mcdonaldi, a small semislug with a very thin, flattened, reduced shell with degenerate lower whorls (Stanisic, 1993a). Dimidarion was originally introduced for four new species of small to very small semislugs from southeastern to mideastern Qld, while the monotypic Hymanarion was described for a small semislug found in northeastern Qld (Stanisic et al., 2010). Five of these six species were described based only on their shell and external appearance. These genera all have small, thin, low-spired shells of $7 \cdot 5^{-}$ $12 \mathrm{~mm}$, but range in shape from flattened to globose. They share some anatomical characters, including a relatively short vagina, equal length arms of the epiphallus and a penis with longitudinal pilasters that often contains a Downloaded from Brill. come4/26/2023 02:27:14PM 
proximal rounded pilaster, but other aspects of their genital anatomy differ considerably. However, all share the diagnostic morphoanatomical characters seen in Fastosarion, Stanisicarion and Macularion (distinct vagina, elongate capsular gland, slender flagellum, distinct epiphallic caecum with a medial attachment of the penial retractor muscle, simple spermatophore with at most short teeth or spines) and hence we synonymise these three genera with Fastosarion.

We demonstrate in the current study that many Fastosarion species have larger ranges than previously thought, resulting in the synonymy of several existing species. In particular, we synonymise $F$. schelli with $F$. helenkingae, $F$. ameyi with $F$. aquavitae, $F$. virens with $F$. freycineti, and F. slatyeri and F. peterbrocki with $F$. alyssa. We also introduce eight new species, bringing the total number of accepted species in this genus to 21 .

The genus as delineated herein comprises Clades $\mathrm{A}$ and $\mathrm{B}$ in the mtDNA phylogeny (figs. 1-3).

\section{Differential diagnosis}

External appearance: Shell small to large (6-25 mm), amber, glossy, ear-shaped, 2.6-4.1 whorls, globose to flattened with an expanded last whorl, whorls rounded. Protoconch and teleoconch with very fine spiral grooves, sometimes becoming obsolete on the teleoconch. Body colour ranging from cream to dark reddish grey or brown, dark green or black, sometimes speckled or spotted, sole often contrasting in colour and sometimes with vertical stripes. Mantle lobes and shell lappets well-developed, completely covering shell when extended, often speckled, spotted or mottled, either smooth or sculptured with pustules or ridges, sometimes with rows of larger warts on shell lappets; median and left lobes always fused to form a cephalic shield. Slime network well developed; tail sometimes keeled. Caudal horn small to prominent.
Genital anatomy: Spermoviduct of $2-6$ lobes, embedded in digestive gland. Talon and carrefour embedded in albumen gland. Spermoviduct folded several times in zigzag fashion. Free oviduct with a large, oval, orange capsular gland medially; free oviduct internally smooth or sculptured with longitudinal pilasters or very fine transverse ridges. Vagina short to moderately long, sometimes swollen, internally smooth or with longitudinal pilasters. Bursa copulatrix short to moderately long, with slender duct and oval to elongate sac, inserted on the vagina, base of duct sometimes swollen. Penis long, cylindrical or proximally swollen, with variable internal sculpture of pustules or ridges (transverse, longitudinal or diagonal); longitudinal and/or rounded pilasters sometimes present. Penis tunica attached by muscle fibres to middle of epiphallus; epiphallus enters penis through simple pore or verge, verge never fused to penial wall; epiphallus 2 longer than or equal in length to epiphallus 1; epiphallic caecum present, penial retractor muscle attached to middle of caecum (near base). Long, slender epiphallic flagellum with axial filaxment present; internal cryptae minor and not visible externally. Spermatophore a soft-walled capsule with hard tail-pipe; tail-pipe mostly smooth, towards terminal end sometimes sculptured a single ridge with or without small teeth; spermatophore tip simple, or with hair-like spines, or expanded into a bell.

\section{Fastosarion superbus (Cox, 1871)}

Figs. 6, 7A, 8A, 9

Vitrina superba Cox, 1871: 54; Pfeiffer, 1876: 23; Cox, 1887: 1063, pl. 21, figs. 8-9.

Helicarion superbus: Tryon, 1885: 172; Hedley, 1888: 49; Cox, 1909: 5 .

Helicarion (Fastosarion) superbus: Iredale, 1933: 37 .

Fastosarion superbus: Iredale, 1937: 9.

Fastosarion superba: Smith, 1992: 232; Scott, 1995:71-74, figs. 1a-b, 3, 4, 5a; Hyman \& Ponder, 
2010: 47-49, figs. $6 \mathrm{H}-\mathrm{I}, 7 \mathrm{~L}, 8 \mathrm{~L}, 9 \mathrm{~L}, 12 \mathrm{I}, 13 \mathrm{H}, 17 \mathrm{~A}-$ C; Stanisic et al., 2010: 306-307; Stanisic, 2018: fig. $4 \mathrm{C}$.

\section{Material examined}

Types: Holotype: Status unknown, whereabouts unknown, presumed lost (Smith et al., 2002, Mt Dryander, Port Denison, QLD).

Non-type material: See table 1.

\section{Diagnosis}

External morphology: Shell (fig. $7 \mathrm{~A}$ ) large (20.2-38.0 mm), golden amber, 3.2-3.8 whorls, subglobose with a very low spire, protoconch slightly raised. Body (fig. 8A) 6o-75 mm long, dark speckled greenish brownish grey, sole slightly paler with narrow with indistinct dark vertical stripes, faint spots on sides of tail. Mantle lobes moderately large; shell lappets large, finely pustulose, each with a single ridge; lobes and lappets darker than body with a pale border. Tail strongly keeled, slime network moderately strong.

Genital anatomy: Genitalia (fig. 9) with swollen vagina, internally with faint longitudinal pilasters; bursa copulatrix short, duct indistinct, internally with longitudinal pilasters, bursa internally with transverse ridges. Penis very large, internally with one longitudinal pilaster, internal wall sculptured with fine diagonal lamellae arranged in a chevron pattern; approx. $60 \%$ contained in penial tunica. Penis longer than epiphallus; two arms of epiphallus approx. equal in length; epiphallus 2 equal in diameter to penis; epiphallus 1 narrower than penis; flagellum moderate length, slender.

\section{Remarks}

Fastosarion superbus has been reported from Mt Dryander to Clarke Range in mid-eastern Qld (Stanisic et al., 2010). However, both the results of Stanisic (2018) and the present work have demonstrated that specimens attributed to $F$. superbus from the Clarke Range belong to $F$. comerfordae, limiting the range of
F. superbus to just the type locality, Mt Dryander (fig. 6). This means that specimens figured by Scott (1995) for F. superbus actually belong to $F$. comerfordae.

Fastosarion superbus can be distinguished from its congeners by its large size and dark (often greenish) colouration, and its finely pustulose shell lappets. Anatomically, it is most similar to F. comerfordae, F. brazieri and F. paluma, sharing with all three species a similar internal penial anatomy. Specimens of Fastosarion comerfordae have often been misidentified as F. superbus; however, while similar in size and body colour, they can be distinguished by their more orange brown coloration, the absence of a ridge on the left shell lappet, and the very dark vertical stripes along the edge of the sole.

\section{Fastosarion aquavitae Scott, 1995}

Figs. $6,{ }_{7} \mathrm{~B}-\mathrm{C}, 8 \mathrm{~B}, 10$

Fastosarion aquavitae Scott, 1995: 77, figs. 1d, 2, 5c, 6; Stanisic et al., 2010: 306-307, 328.

Fastosarion ameyi Stanisic, 2010 in Stanisic et al., 2010: 306-307, 328.

Helicarionidae MQ 10: Stansic, 2018: fig. 4D.

Material examined

Types: Holotype: QM MO55782 (Conway Range, Brandy Creek Road, $20^{\circ} 20^{\prime} 30^{\prime \prime S}$, 148 39 '30"E).

Paratype: QM MO35370 (same data as holotype).

Holotype of F. ameyi: QM MO20228 (1 km S of Bell's Gap on banks of Funnel Ck, via Sarina, MEQ, $21^{\circ} 30^{\prime}$ S, $148^{\circ} 08^{\prime}$ E, 17 June 1987, J. Stanisic, D. Potter).

Paratypes of F. ameyi: QM MO78892 (same data as holotype).

Non-type material: See table 1.

Diagnosis

External morphology: Shell (fig. ${ }_{7} \mathrm{~B}-\mathrm{C}$ ) medium-sized to large $(14.0-18.7 \mathrm{~mm})$, orange Downloaded Prom Brill. come4/26/2023 02:29:14PM 


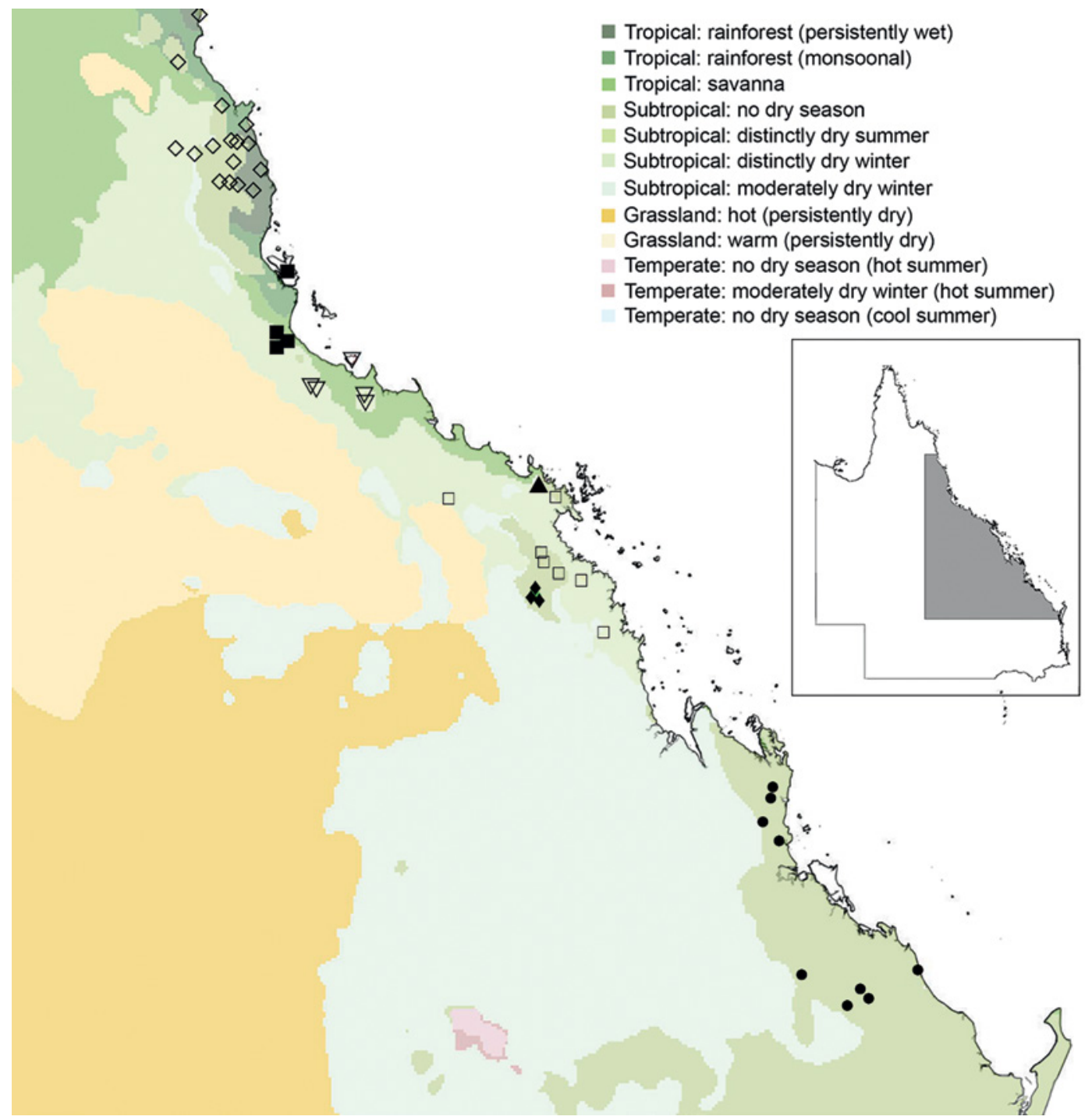

FIgURE 6 Distribution of Clade A species. $\mathbf{\Delta}=$ F. superbus, $\square=$ F. aquavitae, $\diamond=$ F. brazieri,

$\boldsymbol{\bullet}=$ F. griseolus, $\nabla=$ F. helenkingae, $\mathbf{\square}=$ F. paluma .

amber, 3.2-3.7 whorls, depressedly subglobose with a low spire. Body (fig. 8B) 35-40 mm long, pinkish grey-brown, pink deepening on tail tip, sole reddish. Shell lappets and mantle lobes large, brown, mottled with black; edge of mantle collar lined with black. Tail strongly keeled, slime network moderately strong.

Genital anatomy: Genitalia (fig. 10) with medium length vagina, slender; bursa copulatrix moderately short, duct distinct, bursa oval. Penis very long, slender, internally with one partial longitudinal pilaster proximally, internal wall sculptured with pustules; $30 \%$ of penis contained in penial tunica. Penis longer than epiphallus, slightly narrower in diameter; epiphallic caecum medium length; flagellum medium length, slender, terminal portion fused into a loop. 


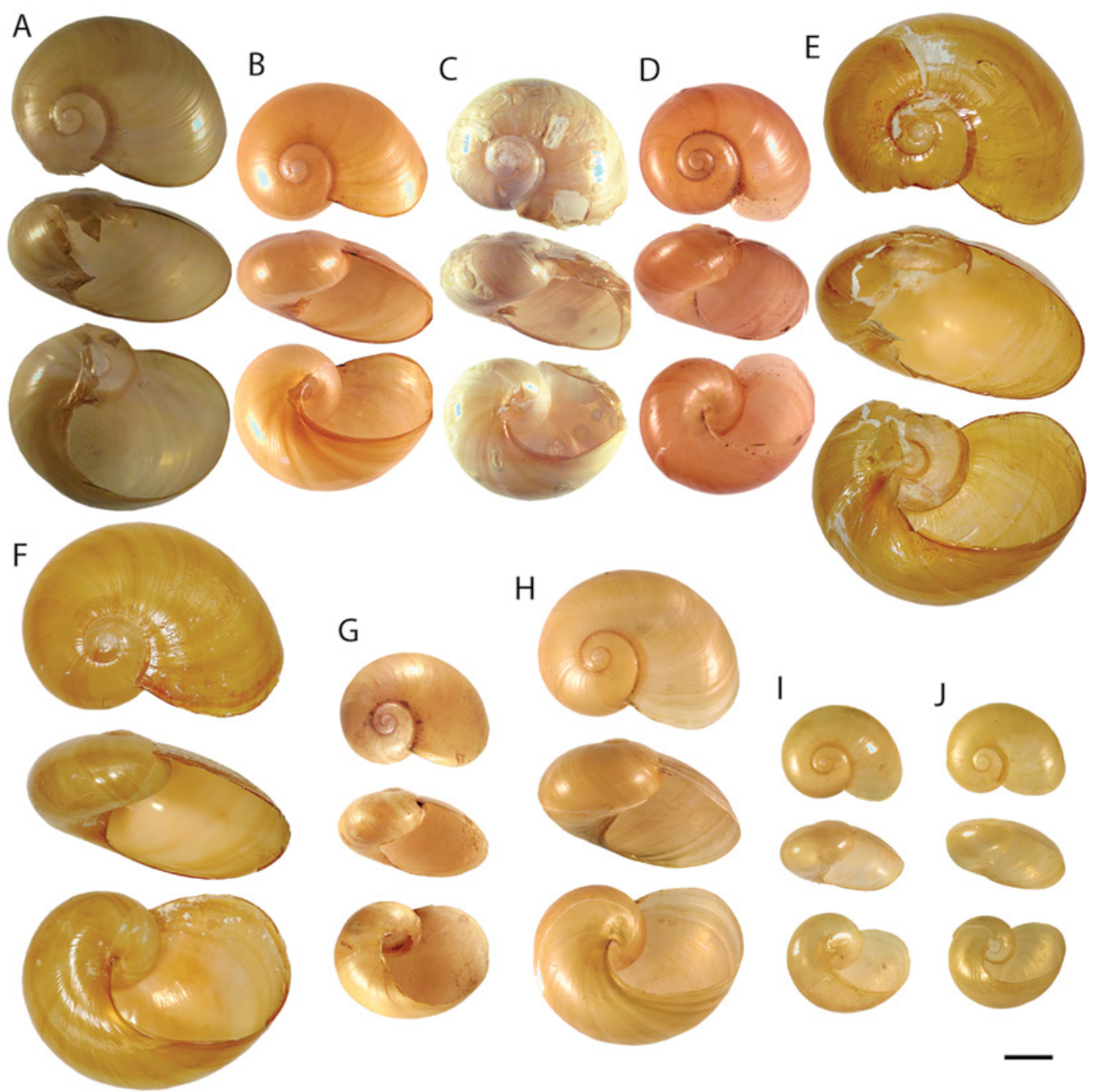

FIGURE 7 Shells of Clade A species. A. Fastosarion superbus, MO77446. B. Fastosarion aquavitae, MO50851. C. Fastosarion aquavitae, MO20228 (type locality of F. ameyi). D. Fastosarion brazieri, AM C.553533. E. Fastosarion comerfordae, MO63985. F. Fastosarion griseolus, MO55568. G. Fastosarion helenkingae, NMV F219324. H. Fastosarion helenkingae, AM C.559842 (type locality of F. schelli). I. Fastosarion paluma, MO63983. J. Fastosarion paluma, MO48024 (Hinchinbrook Is). Scale bar $5 \mathrm{~mm}$.

\section{Remarks}

Fastosarion aquavitae has previously been recorded only from the Conway Range (Stanisic et al., 2010). However, we treat $F$. ameyi as a junior synonym based on examination of the type material, and also allocate to this species the candidate taxa Helicarionidae MQ1o and
MQ13 (originally identified through curatorial work), expanding the known range to include Eungella NP, Cathu SF, Mt Blackwood and Sarina (fig. 6). Differences previously noted between $F$. ameyi and $F$. aquavitae include shell and body colour and also the more subglobose, less flattened shell shape of $F$. ameyi. 


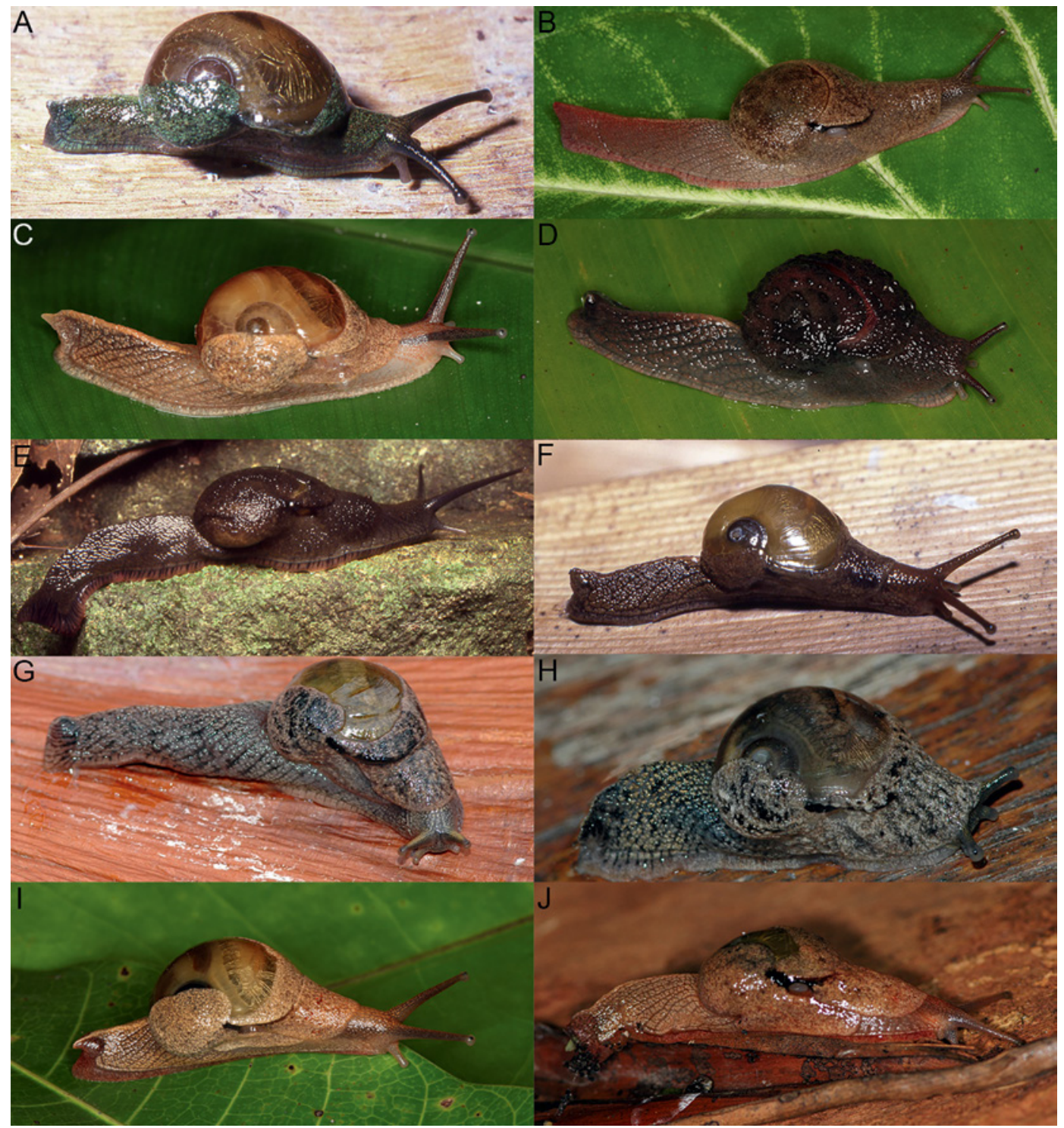

FIGURE 8 Fastosarion live images (Clade A). A. Fastosarion superbus, MO46340, Mt Dryander (QM image). B. F. aquavitae, NMV F230751, Brandy Creek (A. Moussalli, NMV). C. F. brazieri, AM C.553531, Cape Tribulation (A. Moussalli, NMV). D. F. brazieri, AM C.525003, Mt Lewis. E. F. comerfordae, Broken River NP (Kackland). F. F. paluma, Paluma (QM image). G. F. griseolus, AM C.512514, Byfield SF. H. F. griseolus, AM C.512615, Burleigh Head NP. I. F. helenkingae, NMV F219324, Bowling Green NP (A. Moussalli, NMV). J. F. helenkingae, AM C.559842, Magnetic Island (type locality of F. schelli).

The only spirit-preserved specimens of Fastosarion ameyi from Sarina were the paratypes; the specimens were 30 years old with fragile shells and faded body colouration, making comparisons of shell shape and shell / body colour problematic, but anatomically and genetically were a close match for $F$. aquavitae. All other material from Sarina was found to 


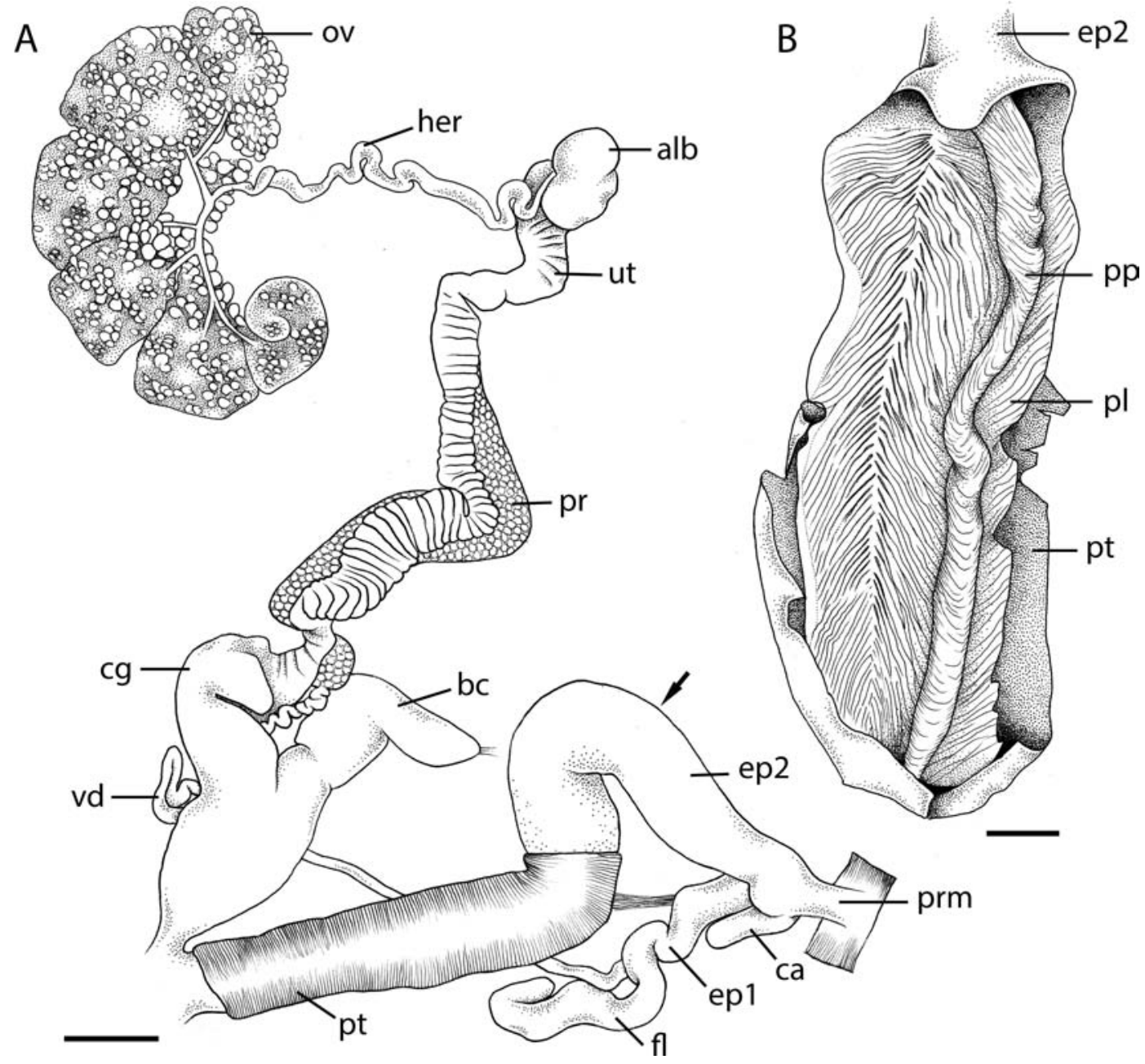

FIGURE 9 Genitalia of F. superbus. A. Reproductive system, MO77446, Mt Dryander. Arrow shows the junction of the penis and epiphallus. B. Penis interior, MO31289, Mt Dryander. Scale bars 1 mm (B), 2 mm (A).

belong to either Fastosarion alyssa or Fastosarion sarina.

This species can be distinguished from its congeners by its relatively large size, pinkish body colouration and relatively more flattened shell.

\section{Fastosarion brazieri (Cox, 1873)}

Figs. 6 , $7 \mathrm{D}, 8 \mathrm{C}-\mathrm{D}, 11,12 \mathrm{~A}-\mathrm{B}$

Helicarion brazieri Cox, 1873: 151.

Vercularion bullaceus Odhner, 1917: 77.
Vercularion brazieri: Iredale, 1937: 9.

Fastosarion brazieri: Smith, 1992: 231; Stanisic et al., 2010: 308-309; Stanisic, 2018: fig. 4G.

Fastosarion bullaceus: Smith, 1992: 231.

Material examined

Holotype: Status unknown, whereabouts unknown presumed lost (Fitzroy Is, Qld). Syntype of V. bullaceus: NHRM 1336 (Bellenden Ker Mts, Qld).

Non-type material: See table 1. 
A

A
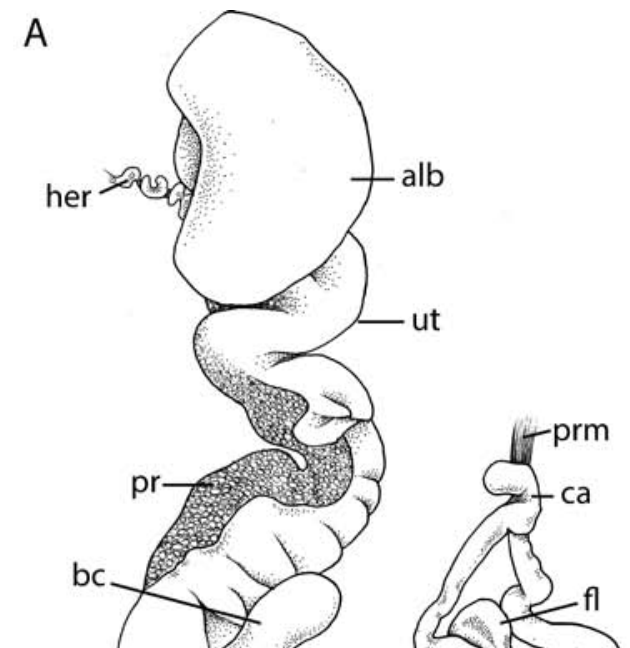

B

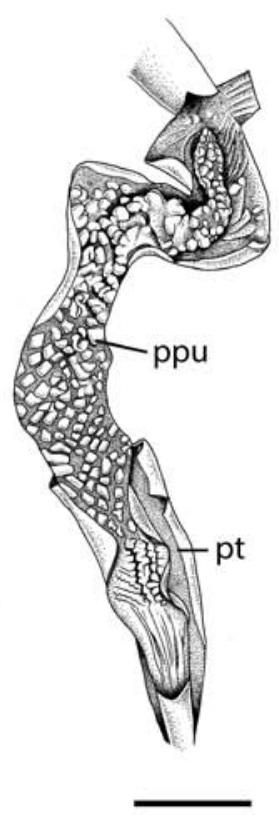

C

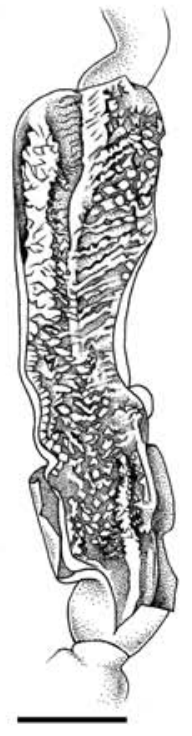

pt

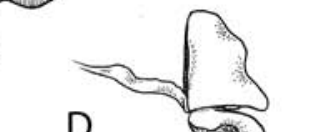

$\mathrm{D}$

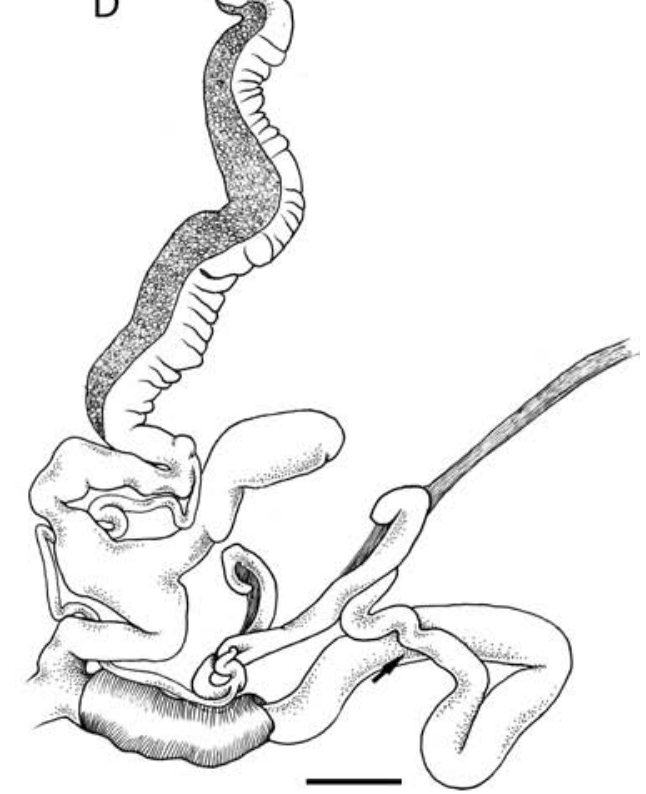

FIGURE 10 Genitalia of F. aquavitae. A, C. MO50851, Conway Range. B, D. MO20228, West Funnel Ck (type locality of $F$. ameyi). A-B, Reproductive system. Arrow shows the junction of the penis and epiphallus. C-D, Penis interior. Scale bars $2 \mathrm{~mm}$. 


\section{Diagnosis}

External morphology: Shell (fig. 7D) mediumsized to large (16.4-23.9 mm), golden amber, 3.5-4.0 whorls, subglobose with a moderately low spire. Body (fig. 8C-D) 30-45 mm long, colour variable, ranging from light greybrown to black, pale specimens with cream and brown specking, dark specimens with orange pustules on mantle lobes and shell lappets. Mantle lobes and shell lappets large, sculptured with pustules and small ridges. Tail strongly keeled, keel white or cream, slime network prominent.

Genital anatomy: Genitalia (figs. 11, 12A-B) with long, slender vagina; bursa copulatrix short, duct distinct, bursa spherical. Penis large, cylindrical, internally with one longitudinal pilaster, internal wall sculptured with fine diagonal lamellae arranged in a deep chevron pattern; all of penis and part of epiphallus contained in penial tunica. Penis equal in length to epiphallus, slightly narrower in diameter; epiphallic caecum long, with a small terminal bulb; flagellum moderately short, slender.

\section{Remarks}

Fastosarion brazieri is the northernmost species in this genus and has a broader range than its congeners, being currently recorded from Cardwell Range to Mossman in northeastern Qld (fig. 6). This species shows considerable variation in body colour and is also genetically rather diverse. However, different populations did not differ significantly in their reproductive anatomy, and the intraspecific variation is consistent with that seen in other widespread helicarionid species (e.g., Fastosarion alyssa, Fastosarion papillosus).

This species can be distinguished from its congeners by its relatively large size (only F. superbus is larger) and its pustulose and ridged shell lappets and mantle lobes.

In the current study we synonymise $F$. bullaceus with F. brazieri, following Iredale (1937).
The type localities of the two species are Bellenden Ker and Fitzroy Island respectively. Both points lie within the range of $F$. brazieri and there are no other large semislugs known to occur in this area. While the type material of F. brazieri is lost, the species descriptions of the two species agree and a comparison of the syntypes of $F$. bullaceus with topotype material of $F$. brazieri shows no anatomical difference (Hyman \& Ponder, 2010, this study). Stanisic et al. (2010) synonymized F. bullaceus with $F$. superbus; however, this was in error and it was intended to be synonymized with F. brazieri (Stanisic, pers. comm.).

\section{Fastosarion comerfordae Stanisic, 2018}

Figs. 6, $7 \mathrm{E}, 8 \mathrm{E},{ }_{12} \mathrm{C}-\mathrm{D}, 13$

Fastosarion comerfordae Stanisic, 2018: 61, figs. 1, 2, 3, 4A-B, 6A-C.

\section{Material examined}

Types: Holotype: QM M085406, Broken River, Granite Belt Track, Eungella NP $\left(20^{\circ} 10^{\prime}\right.$ S, $\left.148^{\circ} 30^{\prime} \mathrm{E}\right)$, nvf, under log, 17.xi.2016, J. Stanisic, L. Holcroft.

Paratypes: QM MO20221, 0.5 km along Diggings $\mathrm{Rd}$, Eungella NP $\left(21^{\circ} 10^{\prime} \mathrm{S}, 148^{\circ} 24^{\prime} \mathrm{E}\right)$, 16.vi.1987, J. Stanisic, D. Potter; QM MO 36086 , lower slopes of Mt Dalrymple, Eungella- Mt William Rd, Eungella NP (21 $\left.04^{\circ} \mathrm{S}, 148^{\circ} 35^{\prime} \mathrm{E}\right)$, nvf, in discarded palm fronds, 16.v.199o, J. Stanisic, D. \& N. Potter; QM MO50272, Eungella NP, Eungella NP $\left(20^{\circ} 54^{\prime} \mathrm{S}, 148^{\circ} 36^{\prime} \mathrm{E}\right), 26 . x i i .1993$, ANZSES; MO76946, Mt William trig station saddle, Eungella NP $\left(21^{\circ} 01^{\prime} \mathrm{S}, 148^{\circ} 36\right.$,'E), 8.iii.1994. ANZSES; QM MO19792, Broken River, Eungella NP $\left(20^{\circ} 10^{\prime} \mathrm{S}, 148^{\circ} 30^{\prime} \mathrm{E}\right)$, nvf, $800 \mathrm{~m}$, xi.1976, M. J. Bishop; QM MO59653, Dalrymple Heights, Eungella NP $\left(21^{\circ} 02^{\prime} \mathrm{S}, 148^{\circ} 36^{\prime} \mathrm{E}\right)$, nvf, $1000 \mathrm{~m}, \mathrm{xi} .1976$, M. J. Bishop.

Non-type material: See table 1.

Diagnosis

Externalmorphology: Shell (fig. $7 \mathrm{E}$ ) large (21.0$24.4 \mathrm{~mm}$ ), amber, $3.4-3.8$ whorls, subglobose 

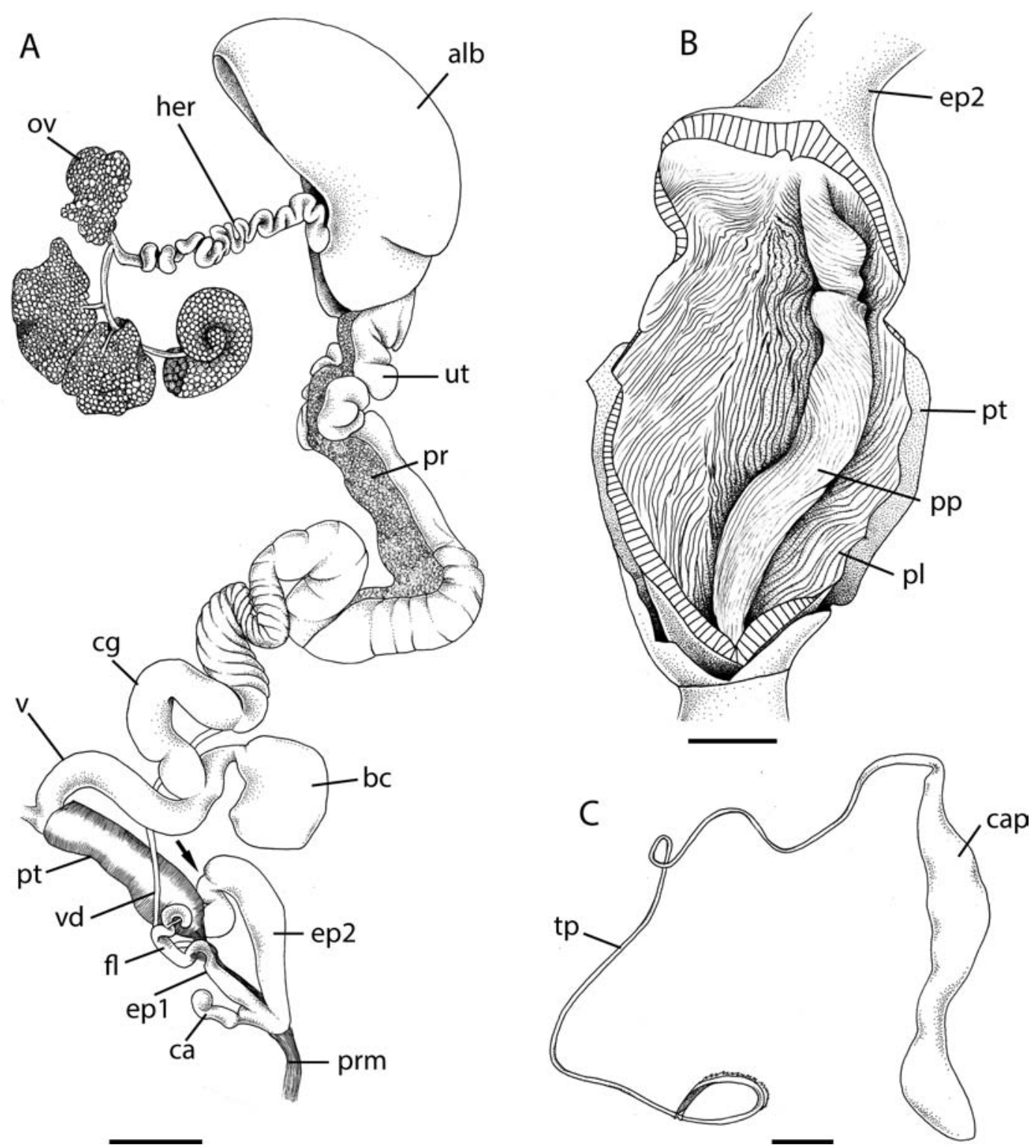

FIGURE 11 Genitalia of F. brazieri, MO66680, Malbon Thompson Range. A. Reproductive system. Arrow shows the junction of the penis and epiphallus. B. penis interior. C. Spermatophore. Scale bars $1 \mathrm{~mm}(\mathrm{~B}, \mathrm{C})$, $2 \mathrm{~mm}(\mathrm{~A})$. 

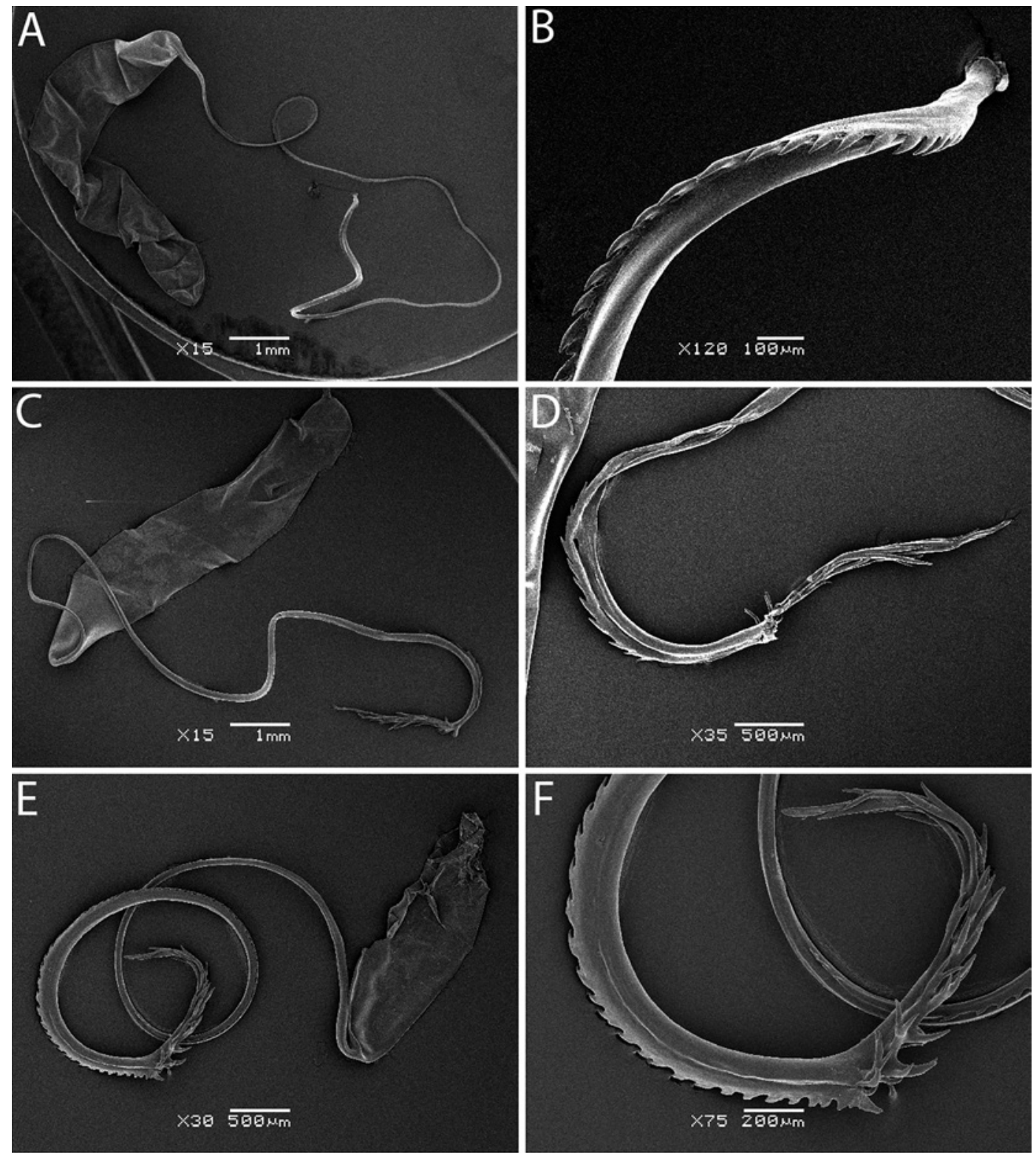

FIGURE 12 Spermatophores of Clade A species. A-B. Fastosarion brazieri, MO6668o. C-D. Fastosarion comerfordae, MO63985. E-F. F. helenkingae, MO47971. 
with a low spire. Body (fig. 8E) 45-55 mm long, orange brown to black, sole paler with narrow with very distinct dark vertical stripes. Shell lappets and mantle lobes large, darker than body, right lappet with a single ridge. Tail strongly keeled, slime network moderately strong.

Genital anatomy: Genitalia (figs. $12 \mathrm{C}-\mathrm{D}$, 13) with rounded vagina, internally smooth; bursa copulatrix moderately long, duct distinct, internally smooth. Penis short, slender, internally with one longitudinal pilaster and two rounded pilasters distally, internal wall sculptured with fine diagonal lamellae arranged in a chevron pattern; all of penis and part of epiphallus contained in penial tunica. Penis shorter than epiphallus, approx. equal in diameter; epiphallic caecum short; flagellum moderately short, slender.

\section{Remarks}

Fastosarion comerfordae was described by Stanisic (2018) for a large semislug from Eungella NP (Qld) on the basis of external animal features and reproductive anatomy. Previous studies had assumed this population was part of F. superbus (e.g., Scott, 1995; Hyman \& Ponder, 2010). Fastosarion comerfordae differs from $F$. superbus in its slightly smaller size, its brown to black body colouring with reddish markings (compared to the greenish-brown body colouration of $F$. superbus) and the presence of black, dart-like markings on the sides of the sole, its coarser penial lamellae and shorter longitudinal penial pilaster. We also show that it has a relatively shorter, narrower penis than F. superbus, and a correspondingly longer epiphallus 2.

This species is found living in moist notophyll vine forest in the Clarke Range of Eungella $\mathrm{NP}$ at altitudes above $800 \mathrm{~m}$, or along drainage lines at slightly lower elevations (Stanisic, 2018). It is sympatric with F. ephelis n. sp. and F. mcdonaldi, but can be distinguished from both by its larger size. It also comes into close proximity with congeners $F$. aquavitae, $F$. superbus and F. tuljun n. sp.

\section{Fastosarion griseolus Stanisic, 2010}

Figs. 6, $7 \mathrm{~F}, 8 \mathrm{G}-\mathrm{H},{ }_{14} \mathrm{~A}-\mathrm{C}, 15$

Fastosarion griseola [sic!] Stanisic, 2010 in Stanisic et al., 2010: 304-305, 327.

Material examined

Types: Holotype: QM MO51554 (Bobby Ra., c.12.1 km from Granite Ck Crossing on Bobby Ra.-Mt Perry Rd, SEQ, $24^{\circ} 37^{\prime}$ S, $15^{\circ}{ }^{\circ} 2^{\prime} \mathrm{E}$, nvf, under palm fronds, 16 Sept 1985, J. Stanisic, D. Potter).

Paratypes: QM MO12152, QM MO13275, QM MO21873, QM MO38962, QM MO43550, QM MO5556o, QM MO55568, AM C.425285, AM C.425286.

Non-type material: See table 1.

\section{Diagnosis}

External morphology: Shell (figs. $7 \mathrm{~F},{ }_{14} \mathrm{~A}-\mathrm{C}$ ) medium-sized to large $(17.0-23.5 \mathrm{~mm})$, amber, $3.3-3.6$ whorls, subglobose with a low, prominent spire. Body (fig. 8G-H) 50-65 mm, colour grey to pink, darker grey on neck, tail with grey or black spots. Shell lappets and mantle lobes large, spotted, lappets joined by a narrow collar. Dark line along mantle collar. Tail keeled towards tip, slime network prominent.

Genital anatomy: Genitalia (fig. 15) with medium length vagina, very swollen; bursa copulatrix moderately long, duct distinct, bursa elongate oval. Penis moderately short, slender, swollen proximally, internally with two complete longitudinal pilasters, internal wall sculptured with fine, sometimes wavy longitudinal ridges; $20-60 \%$ of penis contained in penial tunica. Epiphallus enters penis through a large verge; penis shorter than epiphallus; epiphallus 2 slightly longer than epiphallus 1; epiphallic caecum of moderate 


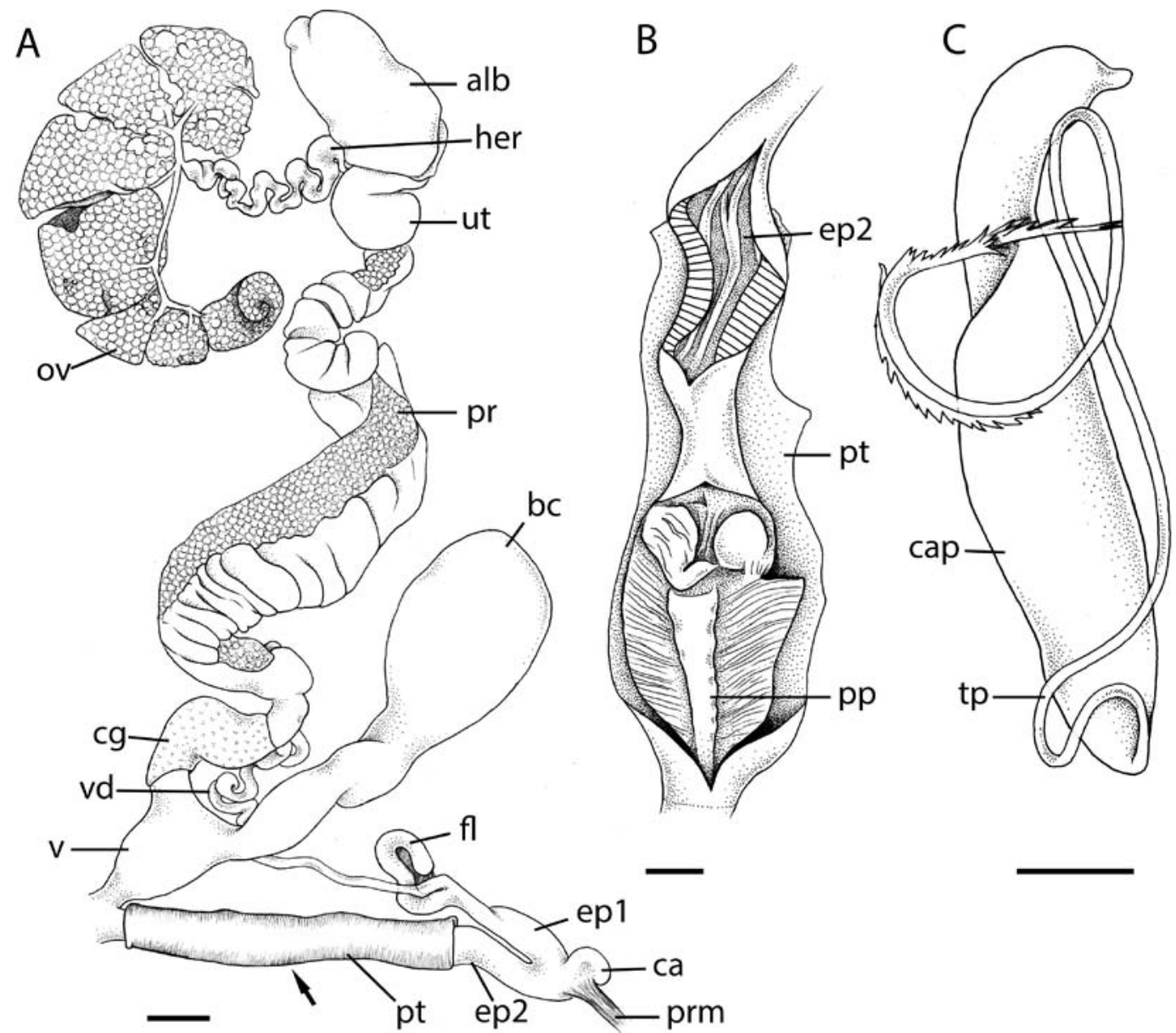

FIGURE 13 Genitalia of F. comerfordae, MO63985, Broken River NP. A. Reproductive system. Arrow shows the junction of the penis and epiphallus. B. Penis interior. C. Spermatophore. Scale bars $1 \mathrm{~mm}(\mathrm{~B}, \mathrm{C})$, $2 \mathrm{~mm}(\mathrm{~A})$.

length; flagellum short, slender, terminal portion fused into spiral. Spermatophore simple (based on fragment only).

\section{Remarks}

The spelling of the species name is adapted herein to agree with the masculine gender of the genus name. This large semislug is found from Bundaberg to Miriam Vale and has been introduced into Brisbane (fig. 6; Stanisic et al., 2010). Fastosarion griseolus has a somewhat different genital anatomy to other members of Clade A, being the only species with a large penial verge and with longitudinal ridges in the penial interior. It is the most basal species in Clade A and is genetically also rather distinct. However, it shares with other members of Clade A its large size, subglobose to globose shell of around 3.5 whorls, large, smooth shell lappets, and the ridged penial interior is similar to the diagonal ridges found in most Clade A species.

\section{Fastosarion helenkingae Scott, 1995}

Figs. 6, $7 \mathrm{G}-\mathrm{H}, 8 \mathrm{I}-\mathrm{J},{ }_{12} \mathrm{C}-\mathrm{D}, 16$

Fastosarion helenkingae Scott, 1995: 75, figs. 1c, 2, 5b, 6; Stanisic et al., 2010: 306-307, 329.

Fastosarion schelli Stanisic, 2010 in Stanisic et al., 2010: 306-307, 328. 

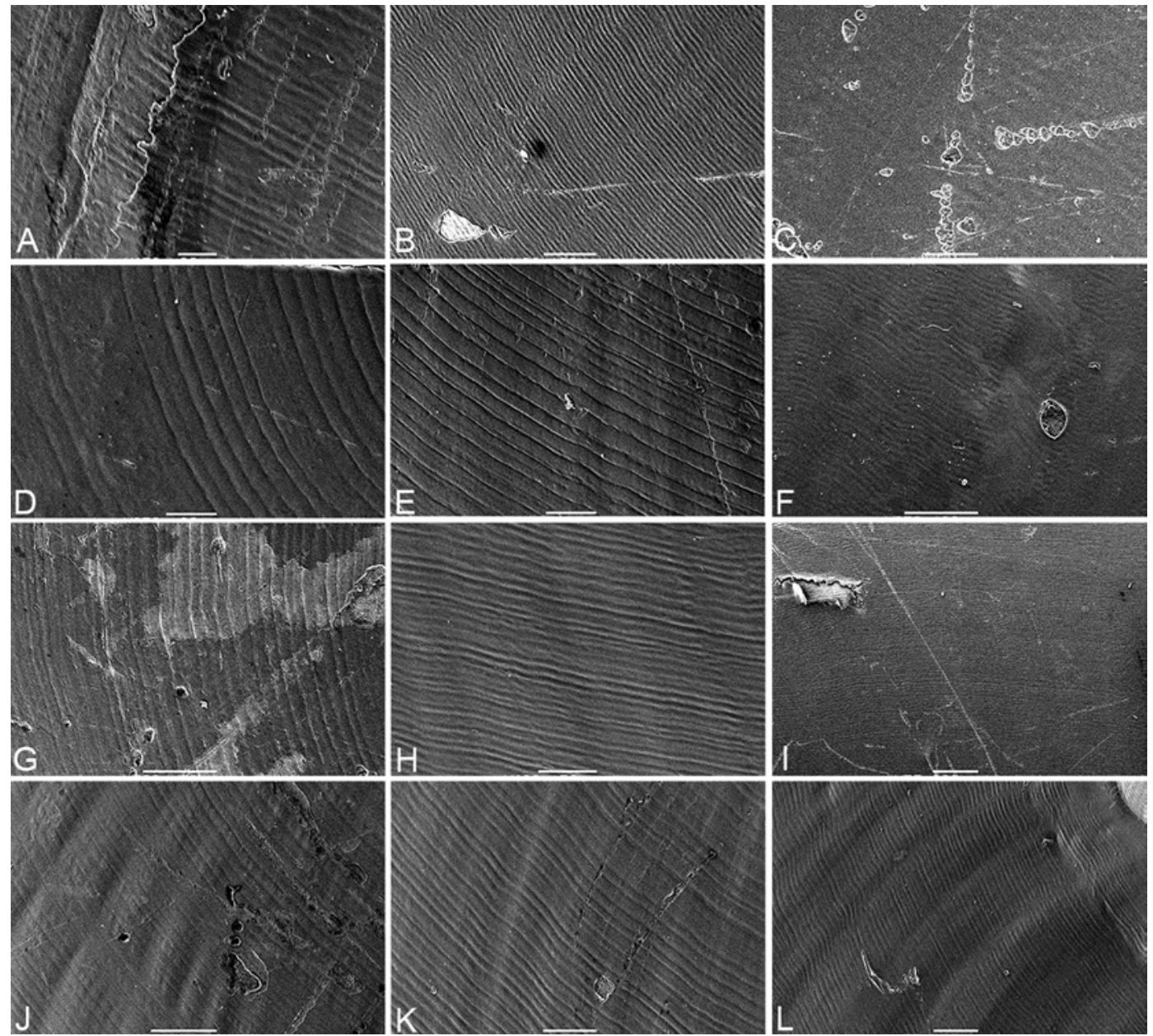

FIGURE 14 Shell microsculpture. A-C. Fastosarion griseolus, MO55568 (A = protoconch, B = early teleoconch, $\mathrm{C}=$ late teleoconch). D. Fastosarion alyssa, F230784 (protoconch). E-F. Fastosarion minerva, MO65418 (E = protoconch, $\mathrm{F}=$ teleoconch). G-I. Fastosarion papillosus, $\mathrm{MO} 78896$ ( $\mathrm{G}=$ protoconch, $\mathrm{H}=$ early teleoconch, I = late teleoconch). J-L. Stanisicarion aquila, MO49825 ( J = protoconch, K = early teleoconch, L = late teleoconch). Scale bars $20 \mu \mathrm{m}(\mathrm{A}, \mathrm{D}, \mathrm{E}, \mathrm{I}), 100 \mu \mathrm{m}(\mathrm{B}, \mathrm{F}, \mathrm{L}), 5^{0} \mu \mathrm{m}(\mathrm{C}, \mathrm{G}-\mathrm{H}, \mathrm{J}-\mathrm{K})$.

Material examined

Types: Holotype: MTQ MO40184 (Bowling Green Bay NP, Mt Elliot, $\left.19^{\circ} 30^{\prime} \mathrm{S}, 146^{\circ} 5^{8} \mathrm{E}\right)$.

Paratypes: MTQ MO40185-40191 (same data as holotype).

Holotype of F. schelli: QM MO14106 (Magnetic I., MEQ, $19^{\circ} 08^{\prime} \mathrm{S}, 146^{\circ} 51^{\prime} \mathrm{E}, 200 \mathrm{~m}, 23$ Sept 1980, J. Stanisic).

Paratypes of F. schelli. QM MO16161, QM MO78893, AM C.125918.
Non-type material: See table 1.

Diagnosis

External morphology: Shell (fig. $7 \mathrm{G}-\mathrm{H}$ ) medium-sized (14.3-18.5 mm), amber, transparent, 3.2-3.7 whorls, depressedly subglobose with a low spire. Body (fig. 8I-J) $30 \mathrm{~mm}$ long, speckled brownish cream to grey, darker on head and tail; sometimes with a reddish sole. Shell lappets and mantle lobes large, each lappet 


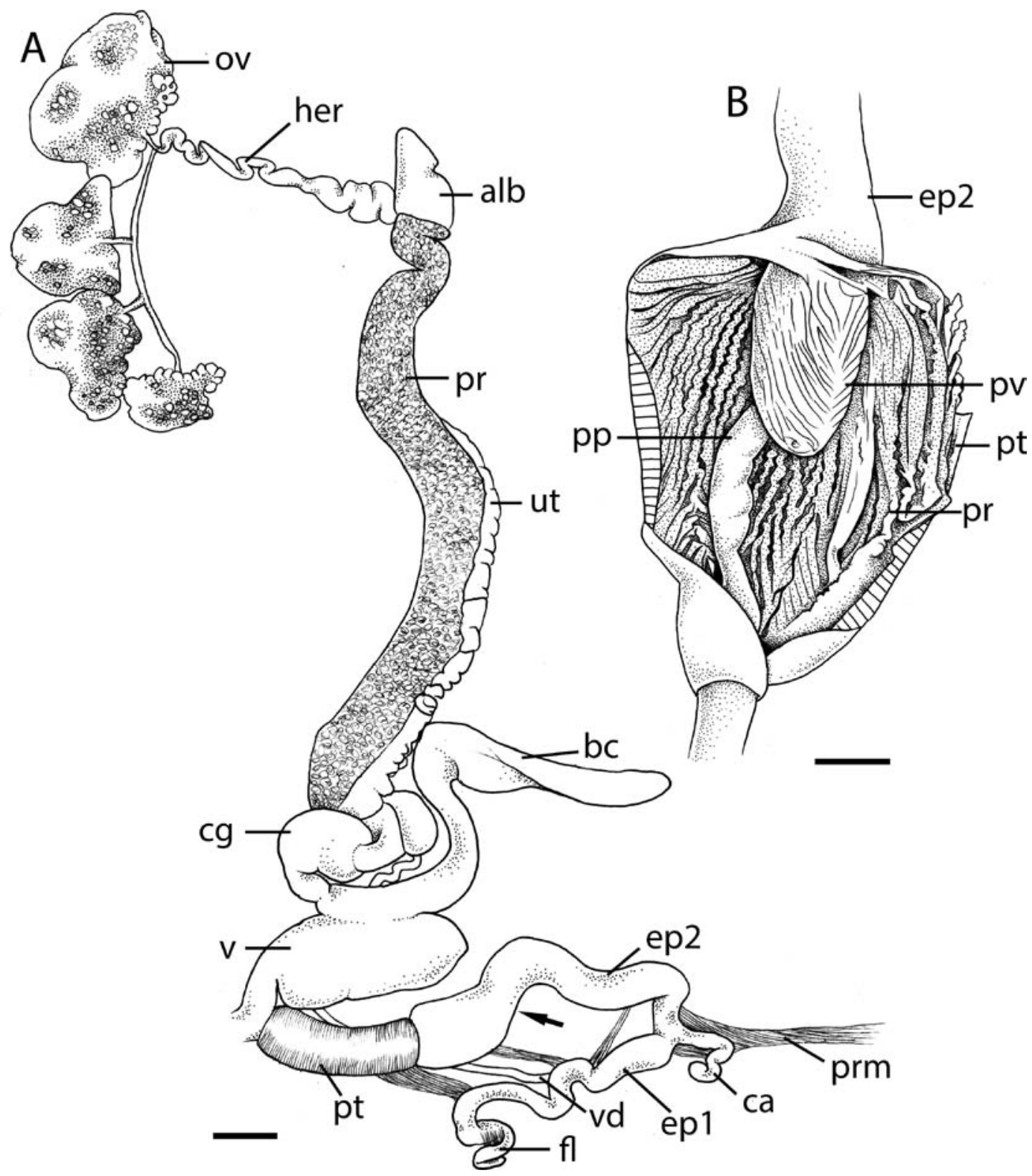

FIGURE 15 Genitalia of F. griseolus, MO55568, Bobby Range. A. Reproductive system. Arrow shows the junction of the penis and epiphallus. B. Penis interior. Scale bars $1 \mathrm{~mm}(\mathrm{~B}), 2 \mathrm{~mm}(\mathrm{~A})$.

with a ridged dark line close to and parallel with lower edge. Dark line along mantle collar. Tail weakly keeled, keel paler, slime network moderately strong.

Genital anatomy: Genitalia (figs. 12C-D, 16) with medium length vagina; bursa copulatrix moderately short, duct distinct, bursa spherical to oval. Penis long, slender, slightly swollen proximally, internally with one complete longitudinal pilaster and one short longitudinal pilaster proximally, internal wall sculptured with pustules; $60-80 \%$ of 
penis contained in penial tunica. Penis slightly longer than epiphallus, slightly narrower in diameter; epiphallus enters penis through a swollen ring; epiphallus 2 much longer than epiphallus 1; epiphallic caecum short; flagellum short, slender, terminal portion fused into loop. Spermatophore simple, tail-pipe mostly smooth, towards terminal end sculptured with small teeth pointing towards capsule, followed by hair-like spines pointing away from capsule on terminal portion.

\section{Remarks}

Fastosarion helenkingae is only known from the type locality, Mt Elliot NP near Townsville. Fastosarion schelli has been reported from the Townsville area, including Hervey Range, Magnetic Island and Mt Stuart (Stanisic et al., 2010). The two taxa are very similar in external appearance, differing primarily in size, shell shape and colouration: F. schelli is larger, with a more globose shell and paler body colour (Stanisic et al., 2010). There is also a possible ecological difference: $F$. helenkingae has only been found under logs in the high altitude mesophyll rainforest on the summit of Mt Elliot, while $F$. schelli is found semi-arboreally in dry vine thicket on granite, in the foothills of the Hervey Range and on Magnetic Island.

We have found that the two species agree very closely in reproductive anatomy, the only difference being slightly coarser pustules in the penis interior of $F$. schelli. They are also genetically very similar. Also, additional material examined herein includes $F$. helenkingae from the foothills of Mt Elliot and specimens of $F$. schelli from under logs. We do not believe that the minor genetic or morpho-anatomical differences warrant maintaining these taxa as separate species and we therefore treat the two names as synonyms.

Fastosarion helenkingae is allopatric with respect to its congeners. It can be distinguished from other members of Clade A by its generally smaller size and by the presence of a pigmented ridge on the shell lappets.

\section{Fastosarion paluma Stanisic, 2010}

Figs. 6, 7I-J, 8F, 17

Fastosarion paluma Stanisic, 2010 in Stanisic et al., 2010: 308-309, 329.

Material examined

Types: Holotype: QM MO55707 (Paluma Ra., $3 \mathrm{~km}$ W Paluma, NEQ, $19^{\circ} \mathrm{o}{ }^{\prime} \mathrm{S}, 146^{\circ} 11^{\prime} \mathrm{E}$, in grass, March 1995, J. Leroi).

Paratypes: QM MO34956, QM MO47981, QM MO55704, QM MO55706,

QM MO55763, QM MO58087, QM MO 63984, QM MO78897, AMSC106771.

Non-type material: See table 1.

\section{Diagnosis}

External morphology: Shell (fig. 7I-J) mediumsized (11.9-13.7 mm), pale amber, transparent, 3.3-3.5 whorls, subglobose with a low spire. Body (fig. 8F) 20-25 mm long, speckled grey to brown, darker on end of tail and neck, sometimes with a red tail tip. Shell lappets and mantle lobes moderately small, lobes mottled dark grey, lappets with black spots and markings forming a discontinuous border, each lappet with a strong ridge. Tail slightly keeled at tip, keel paler, slime network moderately strong.

Genital anatomy: Genitalia (fig. 17) with medium length vagina, slightly swollen; bursa copulatrix moderately short, duct distinct, bursa spherical. Penis moderately long, slender, slightly swollen proximally, internally with one longitudinal pilaster and one oval pilaster proximally, internal wall sculptured with coarse diagonal lamellae arranged in a deep chevron pattern; $60-100 \%$ of penis contained in penial tunica. Penis approx. equal in length to epiphallus, slightly narrower in diameter; epiphallic caecum long, with a small terminal bulb; flagellum moderately short, bumpy, terminal portion sometimes fused. 


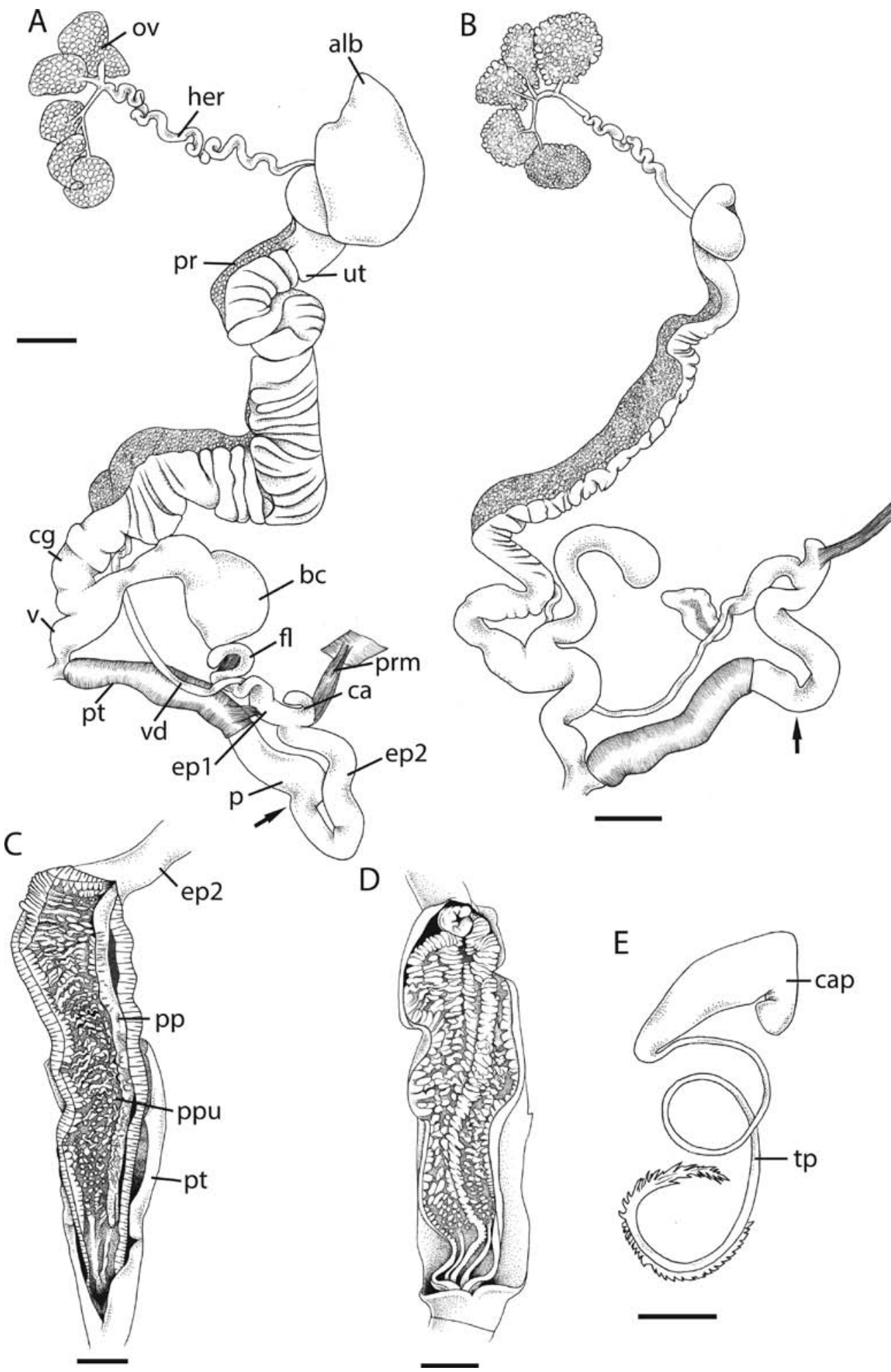

FIGURE 16 Genitalia of F. helenkingae. A, C, E. MO47971, Mt Elliot. B, D. MO16161, Magnetic Is. A-B, Reproductive system. Arrows show the junction of the penis and epiphallus. C-D, Penis interior. E. Spermatophore. Scale bars $1 \mathrm{~mm}(\mathrm{C}-\mathrm{E}), 2 \mathrm{~mm}(\mathrm{~A}-\mathrm{B})$. 


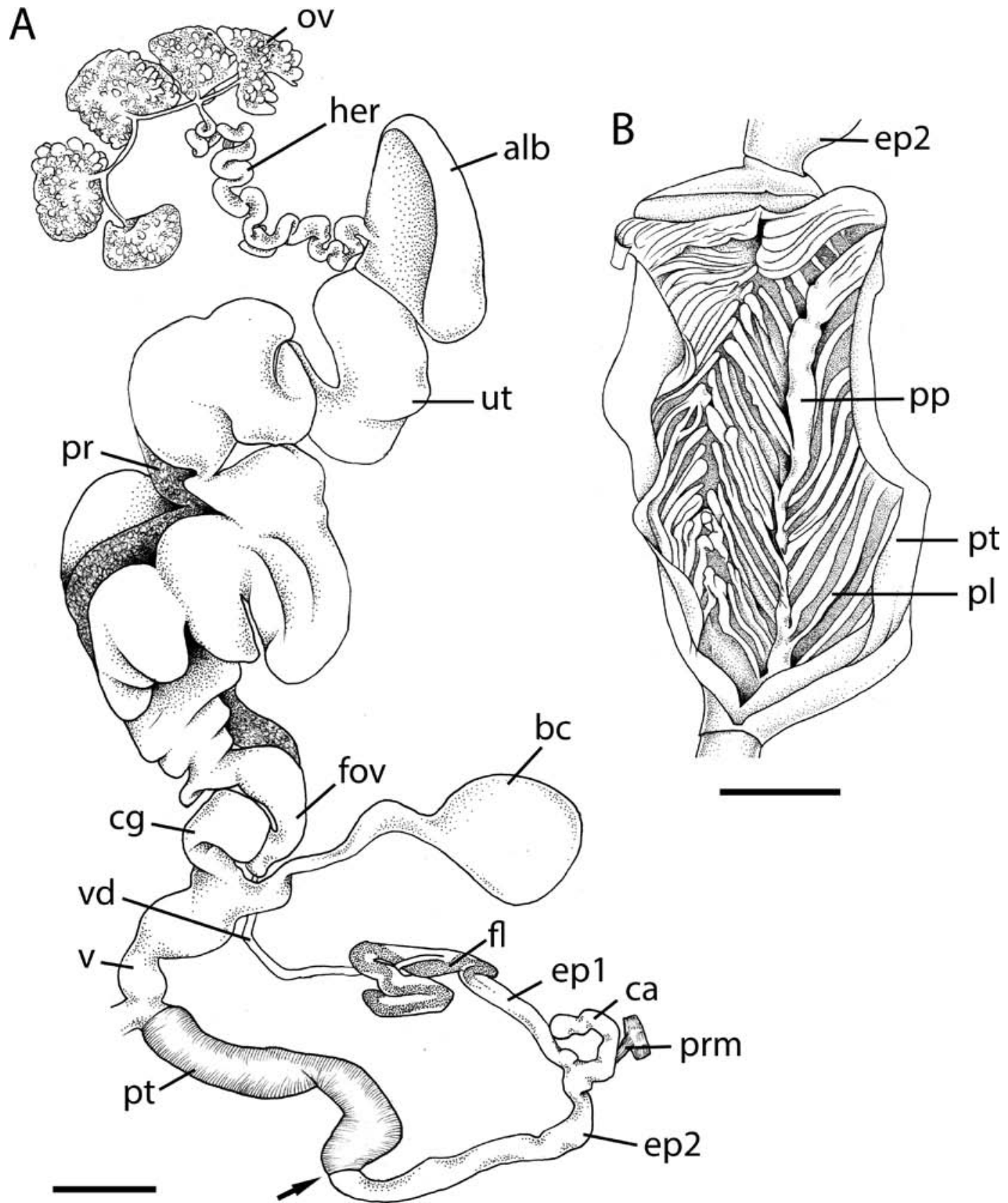

FIGURE 17 Genitalia of F. paluma, MO63984, Paluma Range. A. Reproductive system. Arrow shows the junction of the penis and epiphallus. B. penis interior. Scale bars $1 \mathrm{~mm}(\mathrm{~B}), 2 \mathrm{~mm}(\mathrm{~A})$. 
Spermatophore simple (based on fragment only).

\section{Remarks}

This species was described from the Paluma Range in northeast Qld (fig. 6). In the current study, specimens from Hinchinbrook Island were genetically and anatomically similar to those from the Paluma Range. Only a single sequence from each locality was available and the genetic distance between them was $5.6 \%$ (COI), higher than the intraspecific variation seen in any other species (see table 2). There was slight variation present in the genital anatomy: one specimen from Paluma Range lacked the oval penial pilaster, while a separate specimen from Paluma Range lacked any fusion in the flagellum tip; however, since these differences do not correspond with the genetic differentiation observed, we currently treat the Hinchinbrook population as conspecific with F. paluma. Further studies incorporating a greater number of samples would be of benefit in confirming this placement.

Fastosarion paluma is allopatric with respect to its congeners. It can be distinguished from $F$. brazieri (found to the north) and $F$. helenkingae (found further south) by its smaller size. Specimens from Palm Island that were originally identified as F. paluma have herein been shown to belong to new species Fastosarion insularis, which can be distinguished by its smaller size and more reduced and flattened shell.

\section{Fastosarion alyssa (Stanisic, 2010)}

Figs. 14D, 18, 19A, 10A-D, 21, 22A-B

Dimidarion alyssa Stanisic, 2010 in Stanisic et al., 2010: 314-315, 332.

Dimidarion peterbrocki Stanisic, 2010 in Stanisic et al., 2010: 316-317, 333 .

Dimidarion slatyeri Stanisic, 2010 in Stanisic et al., 2010: 316-317, 333.
Material examined

Types: Holotype of D. alyssa: QM $\mathrm{MO}_{433} 87$ (Johannsens Caves, Fitzroy Caves NP, MEQ, $23^{\circ}$ og'S, $150^{\circ} 27^{\prime} \mathrm{E}$, sevt/limestone outcrop, under rocks and logs, 4 July 1984, J. Stanisic, D. Potter, K. Emberton).

Paratypes of D. alyssa: QM MO21610, QM $\mathrm{MO}_{34264,} \mathrm{QM} \mathrm{MO62566,} \mathrm{QM} \mathrm{MO62569,}$ QM MO62571, QM MO62572, QM MO78900, AMSC425279, AMSC425281, AMSC425282.

Holotype of D. peterbrocki: QM MO19923 ( $4.5 \mathrm{~km}$ along Brandy $\mathrm{Ck} \mathrm{Rd}$, Conway SF, MEQ, $22^{\circ} 40^{\prime} 15^{\prime \prime}$ S, $148^{\circ} 00^{\prime} 55^{\prime \prime}$ E, 15 June 1987 , J. Stanisic, D. Potter).

Paratypes of D. peterbrocki: QM MO11678, QM MO11697, QM MO35541, QM MO54769, QM MO60707, QM MO 78899 , AMSC425256, AMSC425257, AMSC425259.

Holotype of D. slatyeri: QM MO78022 (Peak Range, via Clermont, SE slope Lords Table Mtn, MEQ, $22^{\circ} 40^{\prime} 15^{\prime \prime}$ S, $148^{\circ} 05^{\prime} 00^{\prime \prime}$ E, vine thicket, under rocks, 9.i.2006, J. Stanisic, T. Carless).

Paratypes of D. slatyeri: QM MO78898.

\section{Diagnosis}

External morphology: Shell (figs. 14D, 19A) small $\left(7.5^{-9} .8 \mathrm{~mm}\right)$, pale golden amber, transparent, 2.9-3.1 whorls, flattened, thin, last whorl large. Body (fig. 10A-D) 18-28 $\mathrm{mm}$, speckled cream to brown, darker along sides of tail; shell lappets and mantle lobes moderately large, right lappet rounded, with horizontal dark brown ridge near lower edge; black line along mantle edge. Tail not keeled, slime network prominent. Internal organs show clearly through transparent shell: yellow-coloured kidney fills most of last whorl; curved orange-brown finger of digestive gland lies on first half of last whorl.

Genital anatomy: Genitalia (figs. 21, 22A-B) with short vagina; bursa copulatrix moderately short, duct distinct, bursa spherical to oval. Penis long, swollen proximally, internally with 1-3 minor longitudinal pilasters and one large 
rounded pilaster proximally; internal wall smooth or pustulose; $75^{-90} \%$ of penis contained in penial tunica. Epiphallus approx. 1.5 times length of penis; epiphallic caecum long, usually lying alongside epiphallus 1 ; flagellum short, slender. Spermatophore simple, with a small spiraling row of teeth at tail tip.

\section{Remarks}

Dimidarion was introduced for four species, newly described on the basis of slight differences in their external morphology: D. alyssa, D. slatyeri, D. peterbrocki and D. minerva. The fourth species (minerva) is anatomically distinct from the others and is addressed further below. The first three species were originally distinguished from one another by slight differences in size and body colour as well as geographical separation (Stanisic et al., 2010). Material from the type localities of all three species was included in the current study, as well as material of additional candidate species Helicarionidae BL1, MQ17, MQ10 and MQ12 identified through curatorial work. Most locations were represented by 2-3 specimens and most formed monophyletic clusters (e.g., Dan Dan NP, Mt Etna Caves, Peak Range, Blue Mountain NP, Marlborough), but the differences between them were very slight. Dissections showed correspondingly very slight anatomical differences. We consider these differences to be consistent with intraspecific variation between relatively isolated populations and hereby synonymise the three names. One population was genetically more divergent and showed clear anatomical differences; this is described below as separate species $F$. insularis.

The range of $F$. alyssa as so delimited stretches from the Caves north of Rockhampton in southeastern Qld to Bowen in mideastern Qld (fig. 18). The species is found in dry vine thickets, often on limestone outcrops, living under logs, rocks and leaf litter. It cooccurs with several of its congeners, includ- ing $F$. papillosus, F. longimentula, F. sarina, F. superbus, F. aquavitae and F. griseolus, but can be distinguished from these species by its smaller body and more flattened shell.

\section{Fastosarion deensis sp. nov.}

Figs. 18, 19B, 22C-D, 23A-C

Etymology

For Dee Range, the type locality; noun in apposition.

\section{Material examined}

Types: Holotype: QM MO85834 (Dee Ra, c. $5.2 \mathrm{~km}$ E Mt Morgan, Northern Spur, $23^{\circ} 38^{\prime} \mathrm{S}$, $150^{\circ} 27^{\prime}$ E, coll. 25 Jun 1989, J. Stanisic, D. Potter, J. Chaseling).

Paratypes: QM MO 21578 (same data as holotype).

Non-type material: See table 1.

\section{Diagnosis}

External morphology: Shell (fig. 19B) medium-sized (11.7-12.8 mm), golden amber, very transparent, 4.0 whorls, subglobose with a low spire. Body 24-25 mm long, colour (in ethanol) beige, darker grey on tail and head. Mantle lobes large, finely pustulose, shell lappets moderately large, finely pustulose, each with several rows of larger unpigmented warts; some smaller pustules have brown pigmentation. Tail not keeled, slime wrinkles weak.

Genital anatomy: Genitalia (figs. 22C-D, $23 \mathrm{~A}-\mathrm{C}$ ) with moderately short vagina; bursa copulatrix moderate length; duct broad, long, bursa small, oval shaped. Penis moderate size, cylindrical, inner penial wall sculptured with coarse pustules arranged in irregular transverse rows, penis interior with one proximal penial stimulator; $55 \%$ of penis contained in penial tunica. Epiphallus approx. same length as penis, entering through simple pore; epiphallus 2 longer than epiphallus 1 ; epiphallic caecum short, hooked; flagellum moderately long, slender, coiled. Spermatophore 


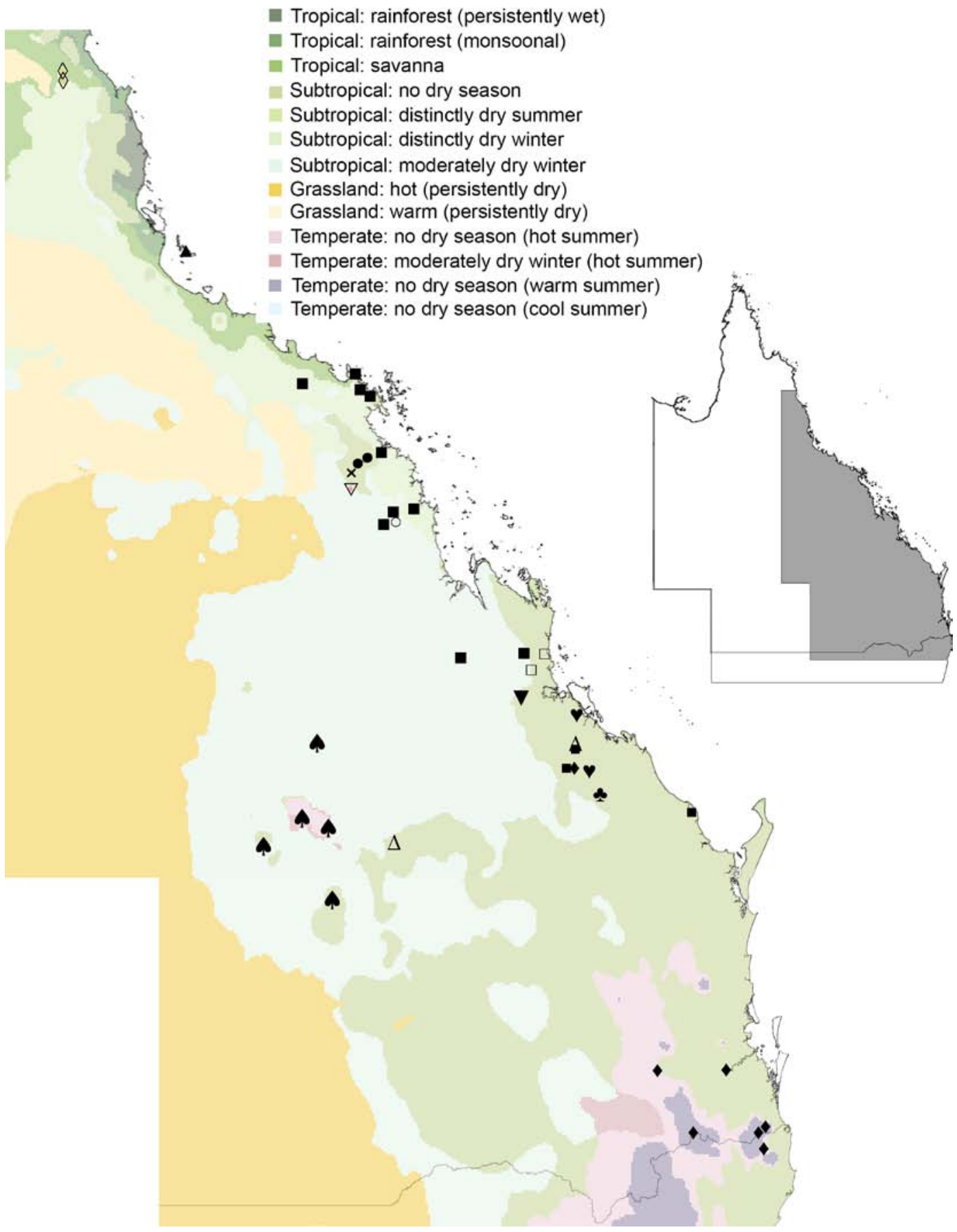

FIGURE 18 Distribution of Clade B species. $\boldsymbol{\square}=$ F. alyssa, $\boldsymbol{\nabla}=$ F. deensis, $x=$ F. ephelis, $\diamond=$ F. hannianus, $\boldsymbol{\Delta}=F$. insularis, $\square=$ F. katatonos, $\Delta=$ F. longimentula, $\boldsymbol{\bullet}=$ F. mcdonaldi, $\boldsymbol{\phi}=$ F. minerva, $\boldsymbol{\nabla}$. F. papillosus, $\boldsymbol{\bullet}=$ F. pustulosus, $\boldsymbol{\nabla}=$ F. rowani, $\mathrm{O}=$ F. sarina, $\nabla=$ F. tuljun . 
A

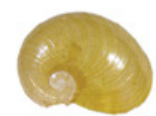

B
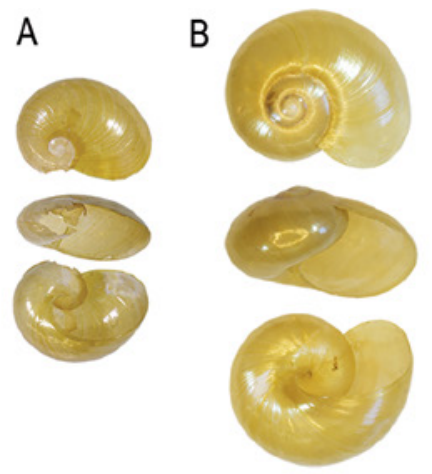

$\mathrm{F}$
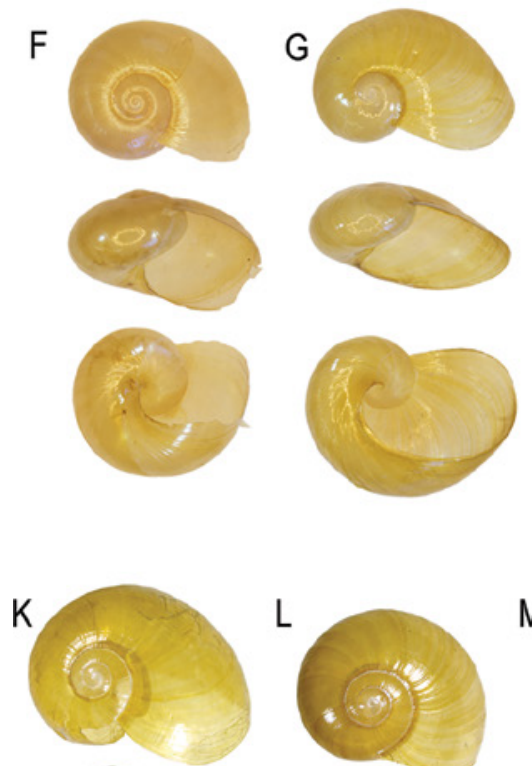

$\mathrm{L}$

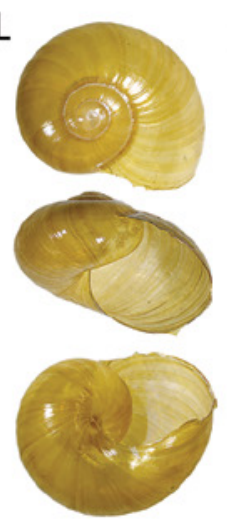

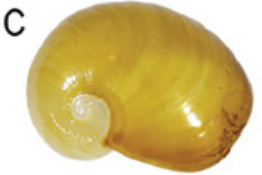
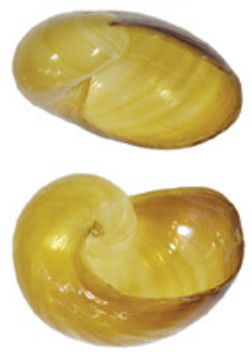

D
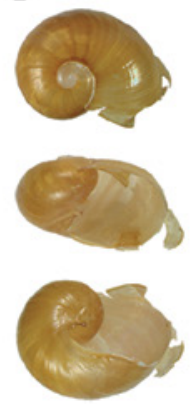

E
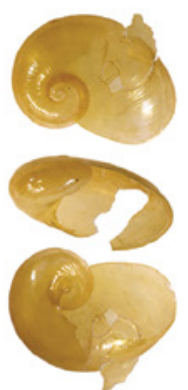

$\mathrm{H}$
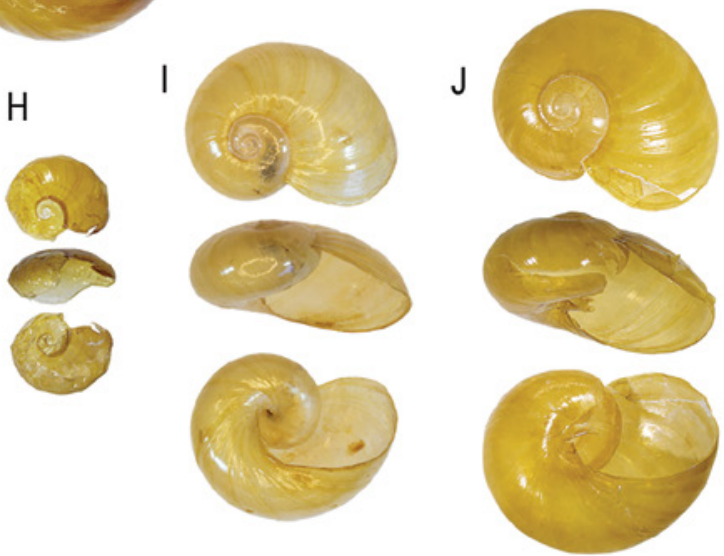

M
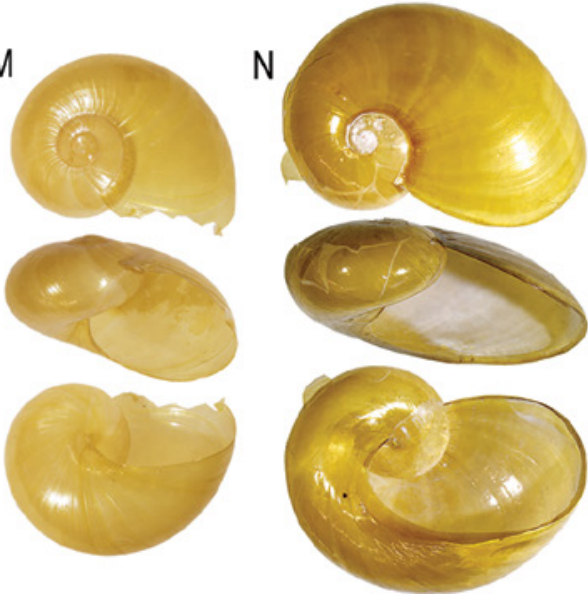

0
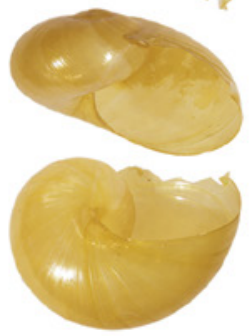
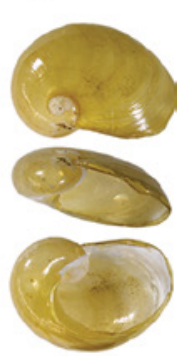

FIGURE 19 Shells of Clade B species. A. Fastosarion alyssa (type locality of D. peterbrocki), NMV F230748. B. Fastosarion deensis, MO85834 (holotype). C. Fastosarion ephelis, MO85835 (holotype). D. Fastosarion hannianus, MO56684. E. Fastosarion insularis sp. nov., MO76354. F. Fastosarion katatonos, M085837 (holotype). G. Fastosarion longimentula, MO65313. H. Fastosarion mcdonaldi, MO50434. I. Fastosarion minerva, $\mathrm{MO}_{78358}$. J. Fastosarion papillosus, $\mathrm{MO}_{78896}$ (Mt Superbus). K. Fastosarion papillosus, MO62397 (Kroombit Tops). L. Fastosarion pustulosus, MO78894 (Kalpowar SF). M. Fastosarion rowani, M085839 (holotype). N. Fastosarion sarina, MO85840 (holotype). O. Fastosarion tujun (Denham Range), $\mathrm{MO}_{76081}$ (holotype). Scale bar $5 \mathrm{~mm}$. 
with a single, finely toothed, spiraling ridge only on terminal half of tail-pipe.

\section{Remarks}

Fastosation deensis (referred to above as 'Helicarionidae sp. Mt Morgan') is known from a single population $5 \mathrm{~km}$ east of Mt Morgan (south of Rockhampton), living under logs in semi-evergreen vine thicket (fig. 18). This population was previously included in F. pustulosus by Stanisic et al. (2010) but is both genetically and anatomically distinct from this species, having a flatter shell and pustulose shell lappets with more numerous rows of warts as well as a distinct genital anatomy. Several other congeners live in close proximity, including Fastosarion katatonos and F. rowani, but none are recorded in sympatry. Fastosarion deensis can be distinguished from the sympatric $S$. freycineti by its smaller size and the warts on its shell lappets.

\section{Fastosarion ephelis sp. nov.}

Figs. $18,19 \mathrm{C}, 20 \mathrm{E}, 23 \mathrm{D}-\mathrm{E}$

Helicarionidae MQ16: Stanisic, 2018: figs. $4 \mathrm{E}, 6 \mathrm{D}$.

\section{Etymology}

From ephelis (Greek, meaning freckle), referring to the speckled appearance of the animal; noun in apposition; noun in apposition.

\section{Material examined}

Types: Holotype: QM MO85835 (Broken River, Eungella NP, MEQ, coll. Apr 1996, J. Leroi).

Paratypes: QM MO58082 (same data as holotype).

Non-type material: See table 1.

\section{Diagnosis}

External morphology: Shell (fig. 19C) medium-sized (14.2 mm), amber, darkening along aperture, 3.2 whorls, globose, flattened, thin, last whorl very large. Body (fig. $2 \mathrm{oE}$ ) at least $25 \mathrm{~mm}$ long, pale orange-brown speckled with cream, head and sole paler, outer field of sole slightly darker than inner fields. Mantle lobes and shell lappets large, pale brown, smooth, very finely speckled. Tail not keeled, slime grooves weak.

Genital anatomy: Genitalia (fig. 23D-E) moderately long; bursa copulatrix of moderate length, duct distinct, bursa oval. Penis long, cylindrical, internally with one ridged longitudinal pilaster, inner penial wall sculptured with rather large, diamond-shaped pustules; $80 \%$ of penis contained in penial tunica. Epiphallus approx. 1.5 times penis length; entering penis through a short verge; epiphallus arms equal in length; epiphallic caecum of moderate length; flagellum of moderate length, slender.

\section{Remarks}

This species was previously identified through curatorial work as Helicarionidae MQ16. Despite frequent collecting in the Eungella region, F. ephelis is only known from two lots of material from Eungella NP (fig. 18). It seems likely that this species is much rarer than other semislugs from the same area, including F. comerfordae, F. aquavitae and F. mcdonaldi. It can be distinguished from all of these by its intermediate size (smaller than the first two and larger than the latter). Fastosarion comerfordae and $F$. aquavitae have a more robust, globose shell, while $F$. mcdonaldi has a much thinner, more reduced shell. Moreover, this species is easily distinguished by its pale, speckled appearance.

\section{Fastosarion hannianus (Stanisic, 2010)}

Figs. 18, 19D, 20F, 22E-F, 24

Hymanarion hanniana [sic!] Stanisic, 2010 in Stanisic et al., 2010: 318-319, 334. 


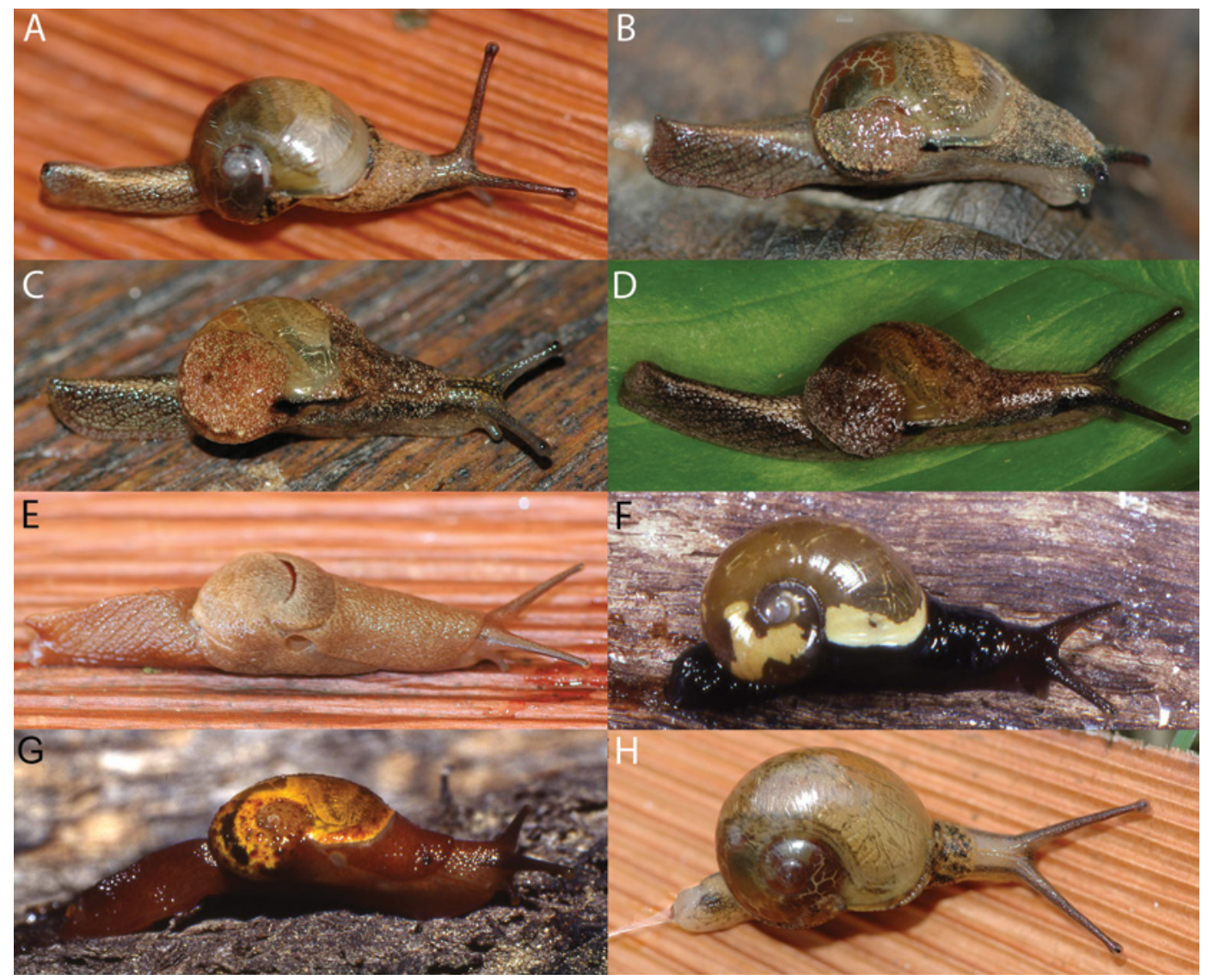

FIGURE 20 Fastosarion live images (Clade B). A-D. Fastosarion alyssa, A: AM C.512537, Mt Etna Caves; B: AM C.512480, Mt Ossa; C: AM C.512579, The Hummock. D: NMV F230748, Brandy Creek (Type locality of F. peterbrocki; A. Moussalli, NMV). E. Fastosarion ephelis (J. Stanisic). F. Fastosarion hannianus (QM image). G. Fastosarion mcdonaldi, Mt Dalrymple (QM image). H. Fastosarion rowani, AM C.512541, Dan Dan NP.

Material examined

Types: Holotype: QMMO48176 (Bakers Blue Mtn, c. $17 \mathrm{~km} \mathrm{~W}$ of Mt Molloy, NEQ $16^{\circ} 42^{\prime} \mathrm{S}$, $145^{\circ}{ }^{10}$ 'E, rainforest, 800-100o $\mathrm{m}$, under logs, coll. 30 Dec 1989, ANZSES).

Paratypes: QM MO48167, QM MO78907.

Non-type material: See table 1.

\section{Diagnosis}

External morphology: Shell (fig. 19D) small (9.6 mm), golden amber, transparent, 2.1-3.0 whorls, subglobose, thin, last whorl large. Body (fig. 20F) 18-24 mm, dark reddish brown, darker on tail; dark bands on either side of neck. Mantle lobes and shell lappets moderately large, darker in colour, smooth. Tail not keeled, slime network weak. White pigmentation on visceral mass visible through shell.

Genital anatomy: Genitalia (figs. 22E-F, 24) with very short vagina; bursa copulatrix very short, duct distinct, bursa spherical. Penis 

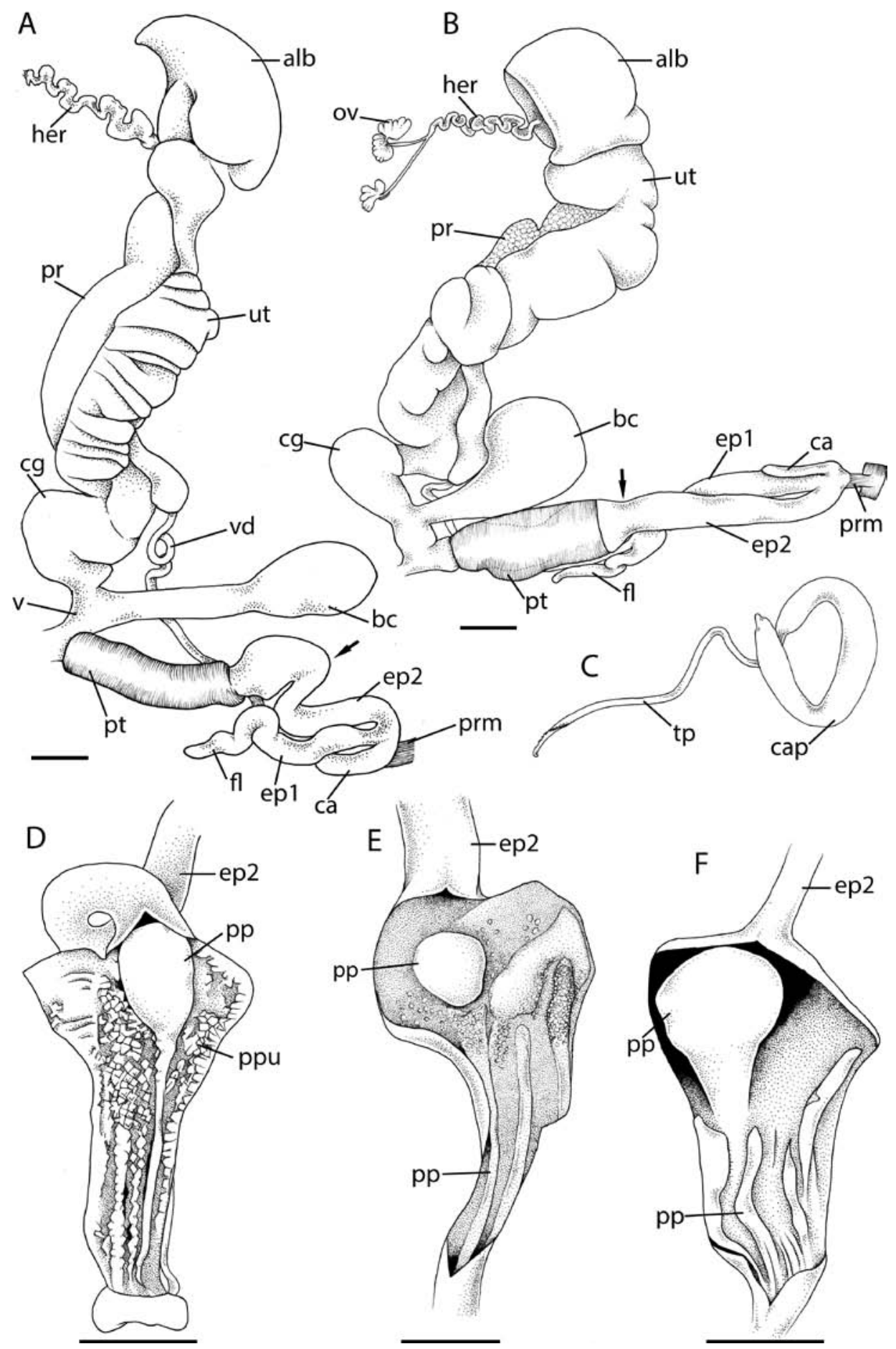

FIGURE 21 Genitalia of F. alyssa. A, D. MO21620, Johanssen's Caves. B-C, F. MO 77188 , Lords Table Mountain, Peak Range (type locality of $F$. slatyeri). D. F230748. Brandy Creek (type locality of $F$. peterbrocki). A-B: Reproductive system. Arrows show the junction of the penis and epiphallus. C: Spermatophore. D-F: Penis interior. Scale bars $1 \mathrm{~mm}$. 

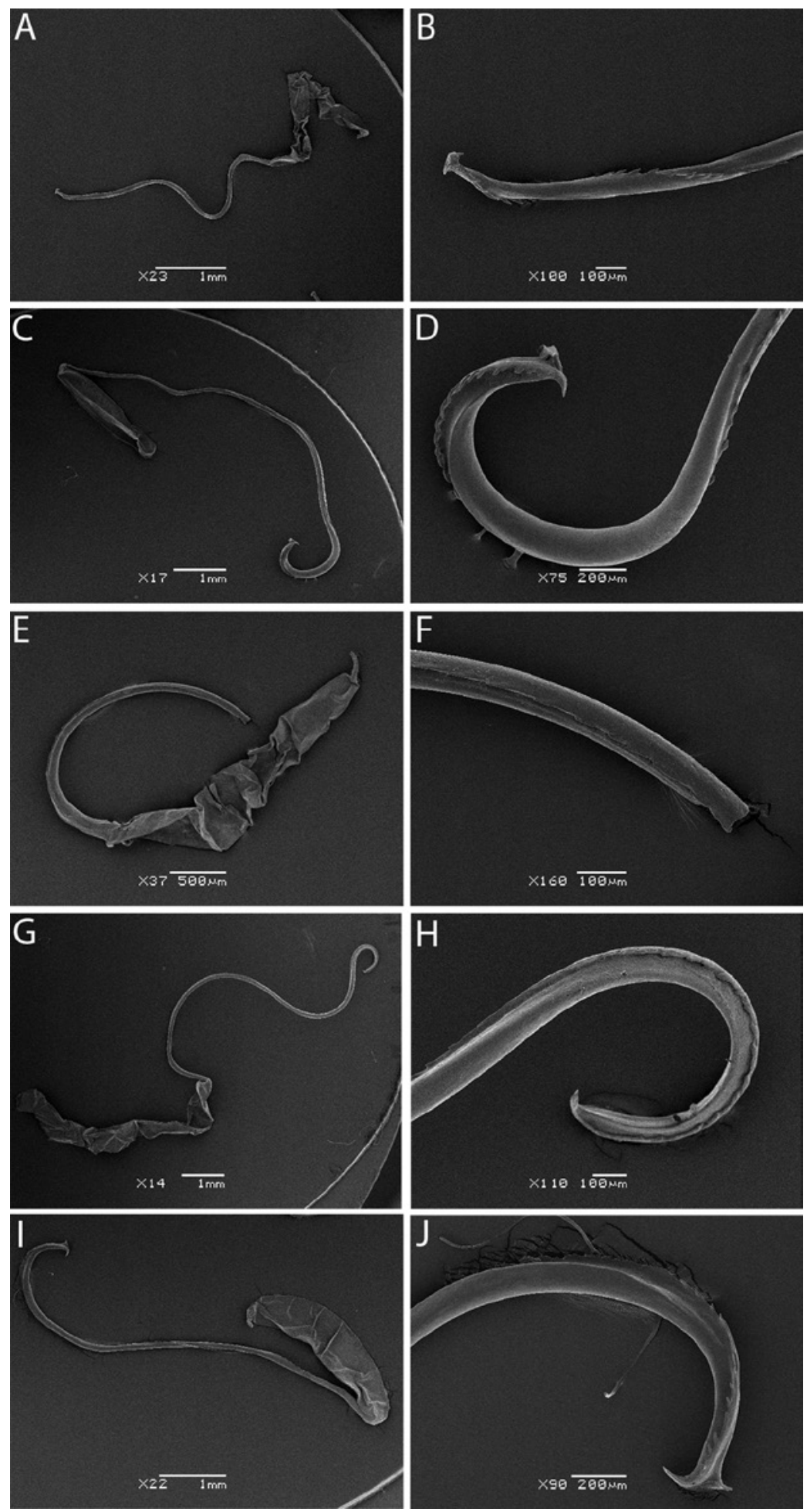

FIGURE 22 Spermatophores of Clade B species. A-B. F. alyssa, MO77158. C-D. F. deensis, MO85834. E-F. F. hannianus, $\mathrm{MO}_{72277}$. G-H. F. mcdonaldi, MO50434. I-J. F. minerva, $\mathrm{MO}_{7} 8358$. 


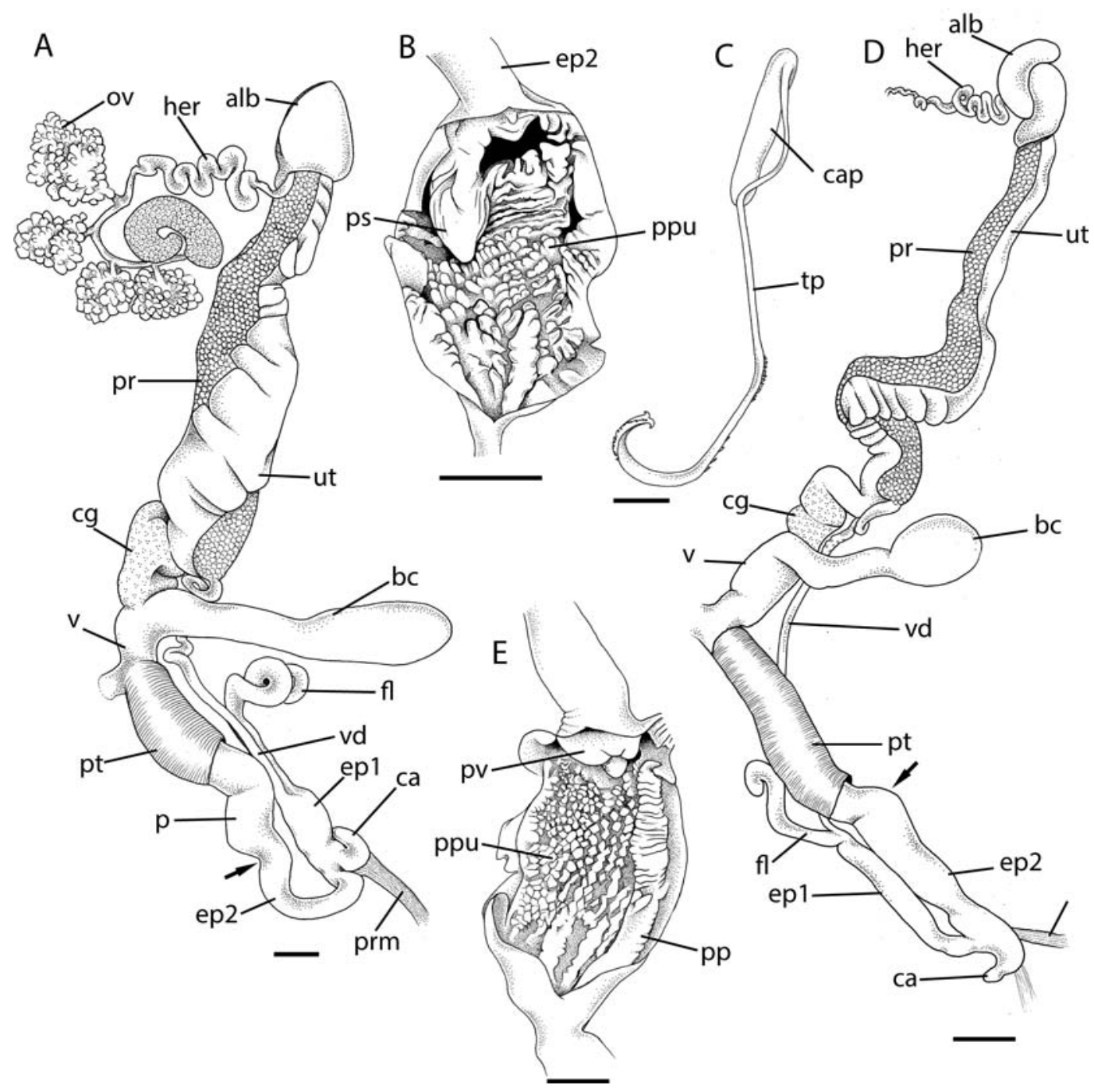

FIGURE 23 Genitalia. A-C. F. deensis, MO85834, Mt Morgan. D-E. F. ephelis, MO85835, Broken River. A, D. Reproductive system. Arrows show the junction of the penis and epiphallus. B, E. Penis interior. F. Spermatophore. Scale bars $1 \mathrm{~mm}(\mathrm{E}), 2 \mathrm{~mm}(\mathrm{~A}-\mathrm{D})$.

large, cylindrical, internally often with $3^{-4}$ short, narrow longitudinal pilasters basally, two narrow longitudinal pilasters proximally, and one stimulator and one rounded pilaster medially; internal wall pustulose distally and longitudinally ridged proximally; $50 \%$ of penis contained in penial tunica. Epiphallus approx. equal to penis length; epiphallus arms equal in length; epiphallic caecum short; flagellum moderately long, uncoiled, slender, slightly swollen towards tip. Spermatophore simple (based on a fragment).

\section{Remarks}

The spelling of the species name is adapted herein to agree with the masculine gender 
of the genus name. Fastosarion hannianus is only known from the Hann Tableland and Bakers Blue Mountain, SW of Mossman in northeastern Qld (fig. 18), where it is found in vine thicket on basalt. This species shares with F. alyssa, F. insularis and F. mcdonaldi its small size and low-spired shell no greater than three whorls with, a short vagina and bursa copulatrix, equal length arms of the epiphallus, and a penis with some rounded pilasters proximally. It differs from these species in its more globose shell. Fastosarion hannianus is genetically very distinct from its nearest relatives (F. alyssa and F. insularis).

\section{Fastosarion insularis sp. nov.}

Figs. 18, 19E, 25

\section{Etymology}

From insularis (Latin = of an island), referring to the island habitat of this species; adjective.

\section{Material examined}

Types: Holotype: QM MO85836 (Palm Island, site 4, NEQ, coll. 22 Feb 2001, G. Monteith).

Paratype: QM MO76362 (same data as holotype).

Non-type material: See table 1.

\section{Diagnosis}

External morphology: Shell (fig. 19E) small (9.1-9.4 mm), pale amber, transparent, 2.8-3.2 whorls, flattened, thin, last whorl large. Body 16-19 mm, colour (in alcohol) brown with tiny white specks; dark bands on either side of neck; sole pale. Mantle lobes and shell lappets moderately large, covered with small white pustules, both lappets with horizontal ridge near lower edge, left lappet only with dark band below ridge.

Genital anatomy: Genitalia (fig. 25) with long vagina; bursa copulatrix moderately short, duct distinct, bursa triangular. Penis very large, swollen proximally, internally with 3 longitudinal pilasters; internal wall smooth; $85-90 \%$ of penis contained in penial tunica. Epiphallus approx. 1.5-2 times length of penis; epiphallus 1 shorter than epiphallus 2; epiphallic caecum medium length; flagellum short, slender.

\section{Remarks}

Fastosarion insularis (referred to above as 'Helicarionidae sp. Palm Island') is only recorded from Palm Island in northeastern Qld (fig. 18) and is parapatric with respect to its congeners. It is most closely related to $F$. alyssa, which it greatly resembles, but can be distinguished by the presence of small white pustules covering the shell lappets and lobes, less distinct slime grooves, and a less transparent shell, as well as its distinct genital anatomy.

\section{Fastosarion katatonos sp. nov.}

Figs. 18, 19F, 26

\section{Etymology}

From katatonos (Greek: broader than high), referring to the wide aperture of the shell; noun in apposition.

\section{Material examined}

Types: Holotype: QM MO85837 (Rockhampton, c. $6 \mathrm{~km}$ NE at Mt Archer, nr base, $23^{\circ}{ }^{2} 0^{\prime}$ 40" S, $150^{\circ} 34^{\prime} 50^{\prime \prime}$ E, coll. 25 Jul 1994, J. Stanisic, D. Potter, G. Ingram, C. Eddie).

Paratypes: QM MO54515 (same data as holotype).

Non-type material: See table 1.

\section{Diagnosis}

External morphology: Shell (fig. $19 \mathrm{~F}$ ) small to medium-sized (8.8-12.3 $\mathrm{mm})$, pale golden, 3.0-3.9 whorls, subglobose with a low spire, last whorl very large. Body $25 \mathrm{~mm}$ long, colour (in ethanol) beige, darker on tail with a pale keel. Mantle lobes and shell lappets large, 


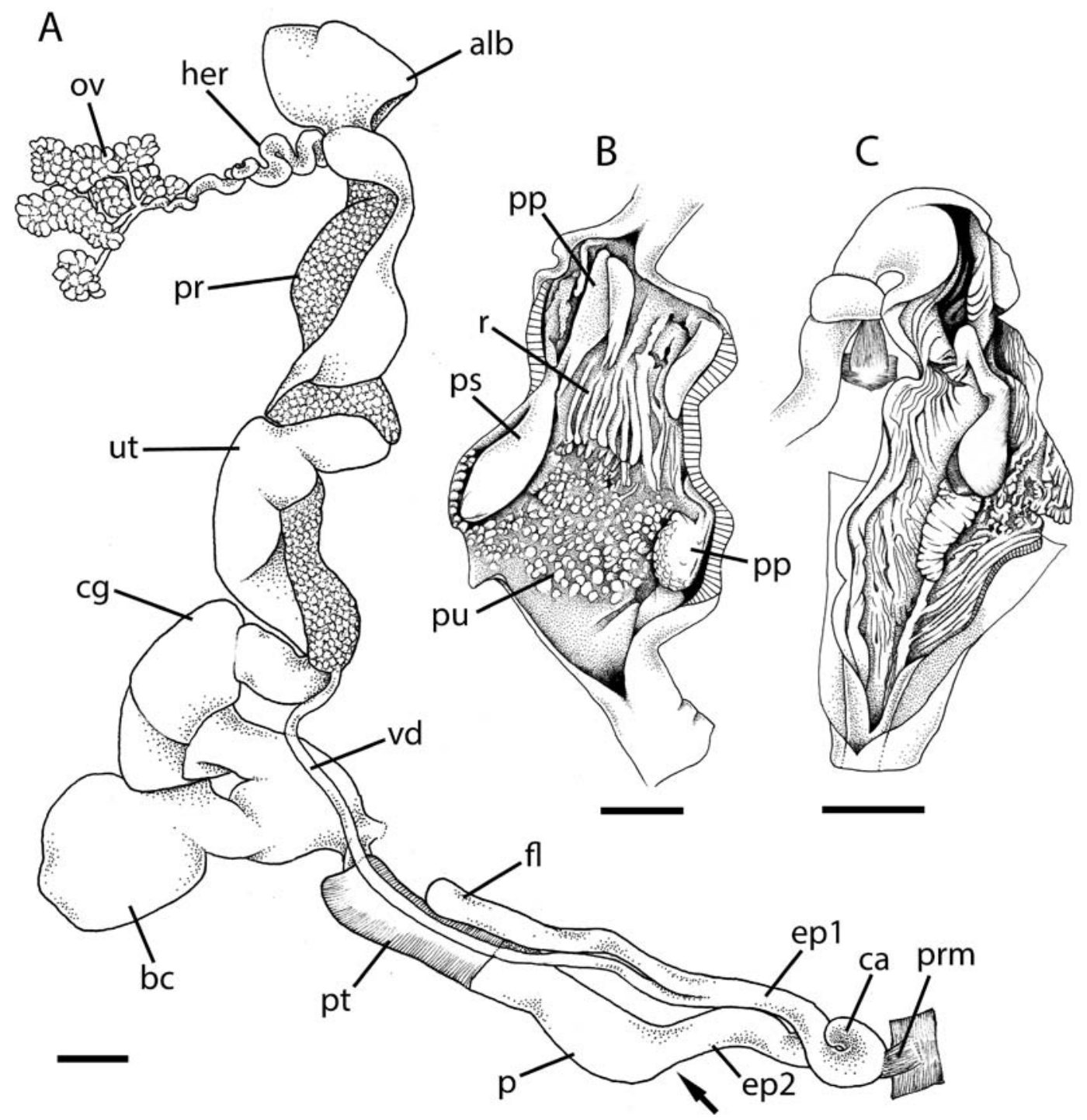

FIGURE 24 Genitalia of F. hannianus. A, B. MO72277, Bakers Blue Mountain. C. MO76564, Hann Tableland. A. Reproductive system. Arrow shows the junction of the penis and epiphallus. B-C. Penis interior. Scale bars $1 \mathrm{~mm}$.

lappets with dark streaks, right lappet with a row of five warts at base and few smaller pustules scattered randomly, left lappet with eight warts arranged in two rows.

Genital anatomy: Genitalia (fig. 26) with moderately short vagina; bursa copulatrix short; duct swollen, bursa spherical. Penis moderately large, mostly cylindrical, slender, swollen proximally, inner penial wall sculptured with very fine transverse lamellae, becoming coarser proximally; penis interior with two longitudinal pilasters, major pilaster branches distally, then proximally becomes swollen and irregular; $60 \%$ of penis 


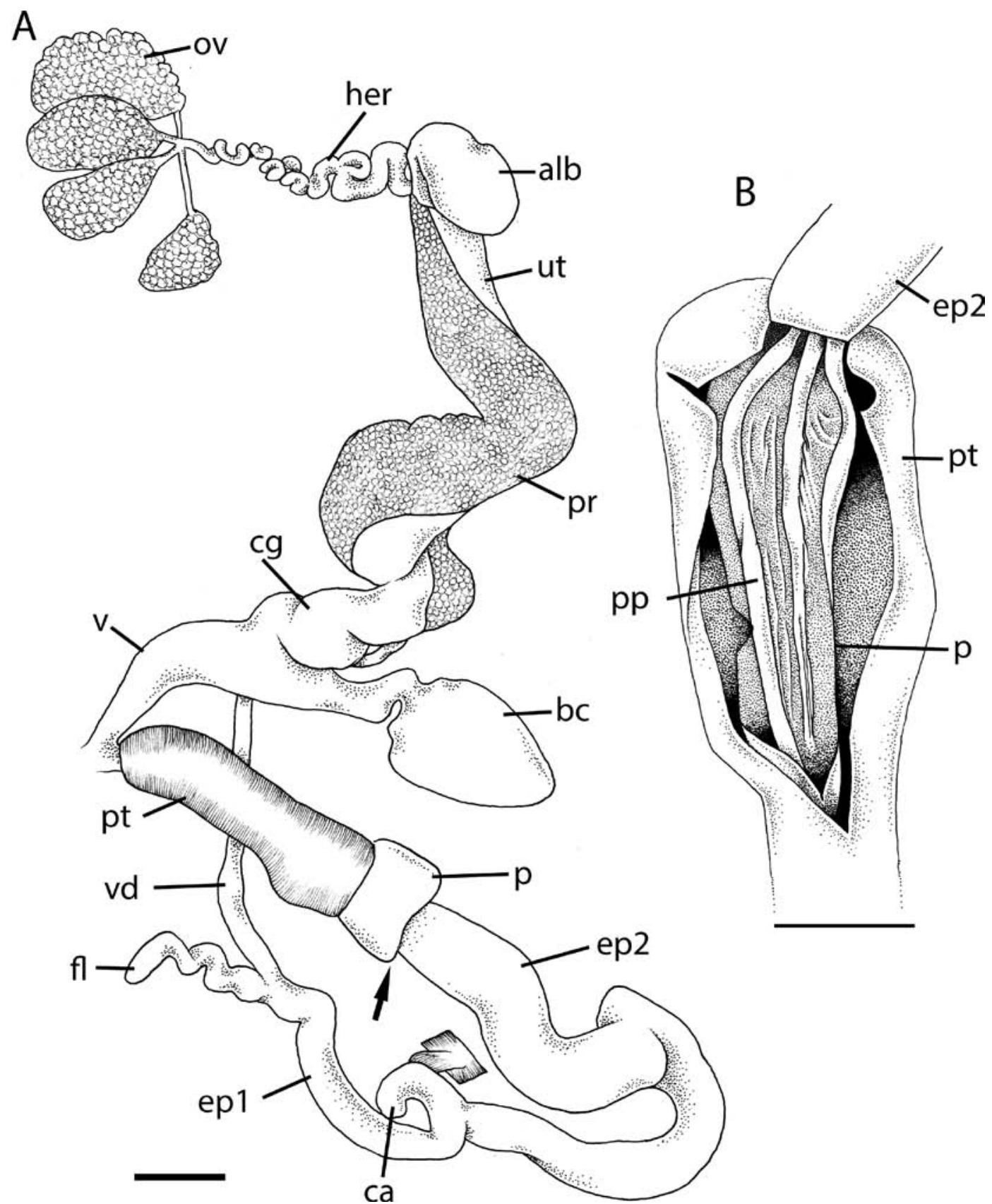

FIGURE 25 Genitalia of $F$. insularis, MO85836, Palm Island. A. Reproductive system. Arrow shows the junction of the penis and epiphallus. B. Penis interior. Scale bars $1 \mathrm{~mm}$. 
contained in penial tunica. Epiphallus approx. same length as penis, entering through simple pore; epiphallus 2 equal in length to epiphallus 1; epiphallic caecum moderate length, terminating with a swollen region consisting of multiple small outpocketings; flagellum short, slender.

\section{Remarks}

Fastosarion katatonos (referred to above as 'Helicarionidae sp. Mt Archer') is found in vine thickets at Mt Archer (northeast of Rockhampton) and also further to the northeast at Hidden Valley, near Yeppoon (fig. 18). It has been previously considered to be part of $F$. pustulosus (Stanisic et al., 2010), and shares with this species a very similar shell and the presence of warts and dark streaks on the shell lappets. However, F. katatonos has a slightly lower spire and more numerous warts on the shell lappets, and anatomically the two species can be very easily distinguished by their very different penial anatomy and the shape of the epiphallic caecum.

This species forms the sister taxon to $F$. minerva, F. deensis and F. rowani in our phylogenetic analysis. It shares some similarities with these species, in particular the subglobose shell with a relatively high whorl count and the presence of rows of warts on its shell lappets, but is smaller in size with a unique genital anatomy. This species is set apart by its distinctive epiphallic caecum shape and short flagellum, its proximally swollen penis with fine transverse lamellae, equal length epiphallus arms and its short bursa copulatrix with a swollen duct.

\section{Fastosarion longimentula sp. nov.}

Figs. 18, 19G, 27

\section{Etymology}

From longus (Latin, meaning long) and mentula (Latin, meaning penis), referring to the very long penis; noun in apposition.
Material examined

Types: Holotype: QM M085838 (Dan Dan Scrub, c. $30 \mathrm{~km} \mathrm{SW}$ Calliope, $24^{\circ} 10^{\prime} \mathrm{S}, 15^{\circ}$ 5 ' E, coll. 27 Jun 1898, J. Stanisic, D. Potter, J. Chaseling).

Paratypes: QM MO 23355 (same data as holotype).

Non-type material: See table 1.

\section{Diagnosis}

External morphology: Shell (fig. 19G) mediumsized (12.6-15.2 mm), golden, 3.0 whorls, flattened, last whorl very large. Body $30 \mathrm{~mm}$ long, colour (in ethanol) beige with a grey tail and neck, mantle lobes large, mottled grey; shell lappets moderately large, joined by narrow collar, right lobe rounded, left pointed; lappets smooth, without warts or pustules. Tail weakly keeled, slime network prominent.

Genital anatomy: Genitalia (fig. 27) with medium length vagina; bursa copulatrix of moderate length, duct broad, bursa elongate. Penis long, cylindrical, muscular, same diameter as epiphallus, inner penial wall sculptured with transverse, chevron-shaped ridges; 50\% of penis contained in thin penial tunica. Penis longer than epiphallus; epiphallus enters penis through a simple pore; epiphallus 2 much longer than epiphallus 1; epiphallic caecum of moderate length; flagellum moderately short, slender.

\section{Remarks}

This species (referred to above as 'Helicarionidae sp. Taroom') contains two populations originally identified as candidate taxa through curatorial work, Helicarionidae SQ10 from Dan Dan NP and $\mathrm{BL}_{5}$ to the west in Expedition NP near Taroom. Both populations are found in semi-evergreen vine thicket. The two sequenced specimens, one from each population, differ by around $3 \%$ in both COI and $16 \mathrm{~S}$ and it is possible that they represent separate species. The Taroom specimen was reproductively immature; however, despite Downloaded from Brill, como4/26/2023 02 27:14PM 


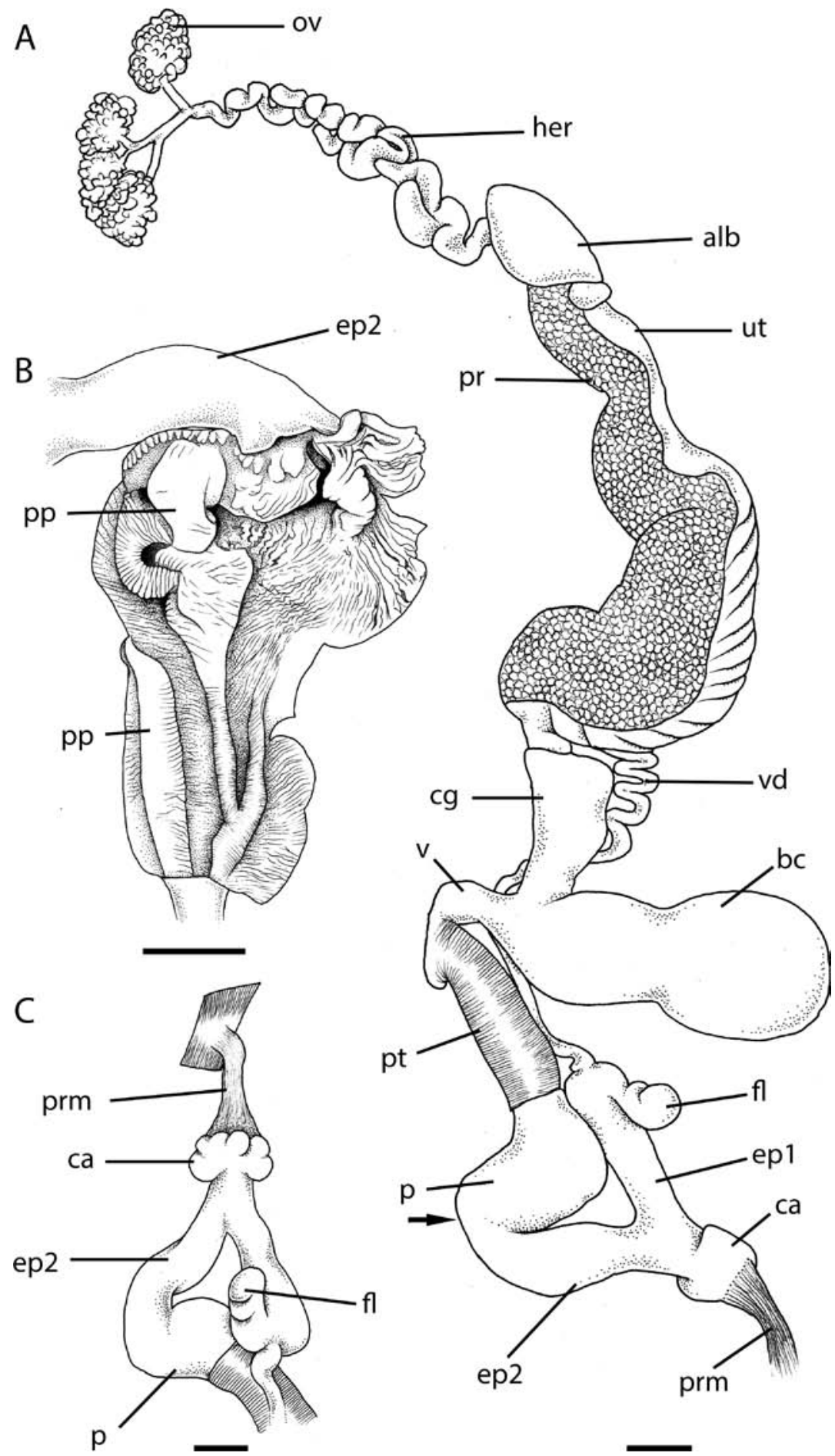

FIGURE 26 Genitalia of F. katatonos, MO85837, Mt Archer. A. Reproductive system. Arrow shows the junction of the penis and epiphallus. B. Penis interior. Scale bars $1 \mathrm{~mm}$. 


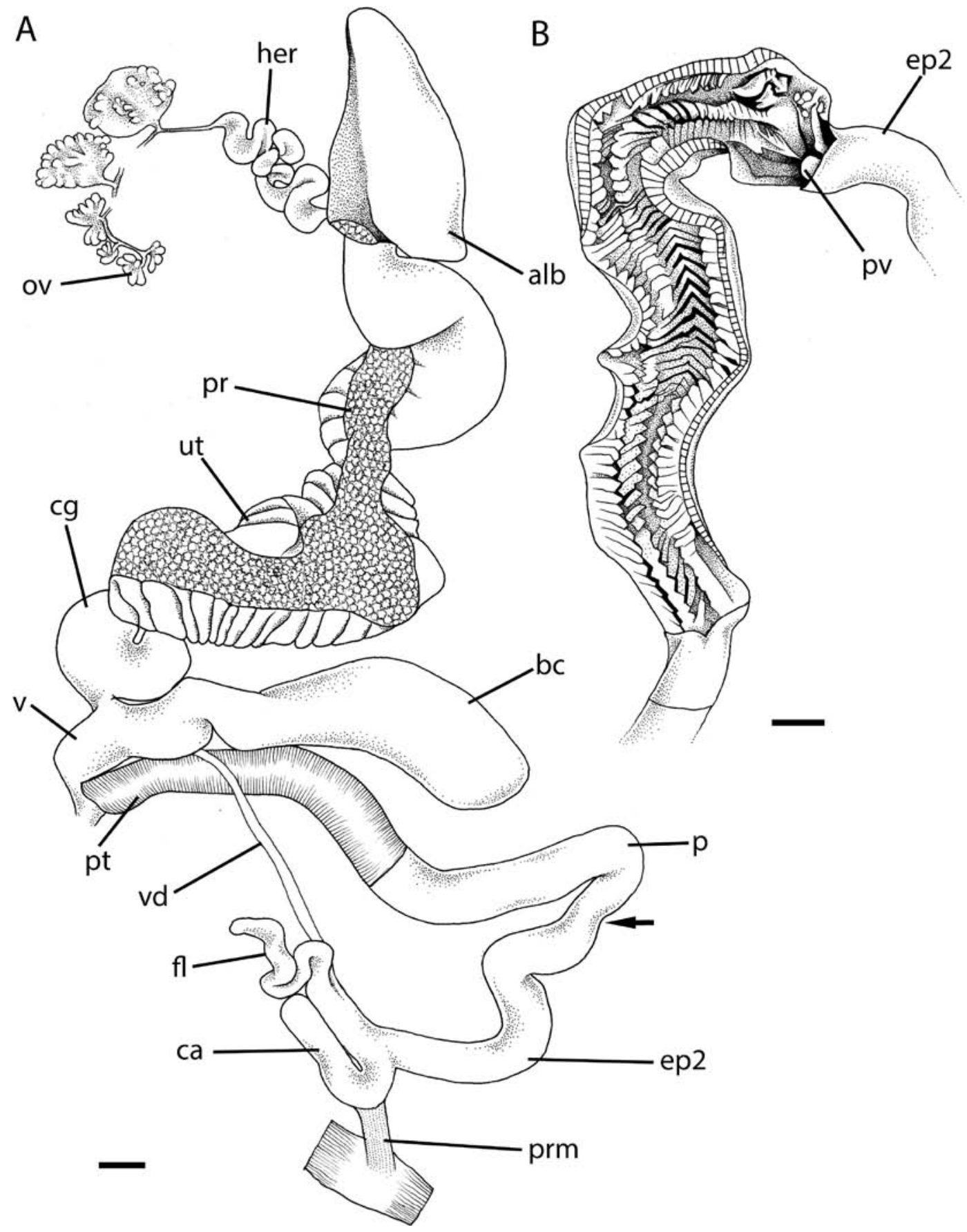

FIGURE 27 Genitalia of F. longimentula, M085838, Dan Dan Scrub. A. Reproductive system. Arrow shows the junction of the penis and epiphallus. B. Penis interior. Scale bars $1 \mathrm{~mm}$. 
this, the morpho-anatomical features were in agreement apart from a slight difference in the proportion of penis and epiphallus length (possibly due to immaturity) and a slightly more protruding protoconch in the Taroom specimen. Therefore, in the absence of further evidence, we retain both populations in Fastosarion longimentula (fig. 18).

Fastosarion longimentula is sympatric with F. rowani and F. alyssa in Dan Dan NP, but can be distinguished from the former species by its more flattened shell with a larger aperture, its more distinct slime network and by the lack of black pustules on the shell lappets, and from the latter species by its larger size. Both species also have a very different genital anatomy.

\section{Fastosarion mcdonaldi Stanisic, 1993}

Figs. 18, 19H, 20G, 22G-H, 28

Eungarion mcdonaldi Stanisic, 1993: 28, figs. 1a-b, 2, 3a-f, 4a-c; Hyman \& Ponder, 2010: 56, figs. $6 \mathrm{~L}-\mathrm{M},{ }_{13} \mathrm{~K}, 14 \mathrm{E}-\mathrm{F}, 18 \mathrm{C},{ }_{19} \mathrm{C},{ }_{21} \mathrm{C}$; Stanisic et al., 2010: 316-317, 333; Stanisic, 2018: fig. $4 \mathrm{~F}$.

\section{Material examined}

Types: Holotype: QM MO43309 (Dalrymple Heights, Eungella National Park, 1000 m, ME QLD).

Paratypes: QM MO43310.

Non-type material: See table 1.

\section{Diagnosis}

External morphology: Shell (fig. $19 \mathrm{H}$ ) small (11.3-11.6), orange amber, 3.2-3.5 whorls, flattened, thin, base uncalcified, membraneous. Shell sculpture very faint on protoconch, obsolete on teleoconch. Body (fig. 2oG) 28-32 $\mathrm{mm}$, reddish brown. Shell lappets and mantle lobes large with pigmented pustules, lappets joined on both sides by a narrow collar.

Genital anatomy: Genitalia (figs. $22 \mathrm{G}-\mathrm{H}$, 28) with medium length vagina, very swollen; bursa copulatrix moderately short, duct distinct, bursa elongate oval. Penis long, swollen proximally, internally with 2-4 longitudinal pilasters, internal wall pustulose; $60 \%$ of penis contained in penial tunica. Epiphallus approx. equal length to penis, enters penis through small rounded verge; epiphallic caecum of moderate length; flagellum short, slender. Spermatophore simple.

\section{Remarks}

Fastosarion mcdonaldi is restricted to the Clarke Ranges in Mideastern Qld, usually found above $900 \mathrm{~m}$ altitude (fig. 18). Several other semislugs are found in this region, including F. aquavitae, F. comerfordae, F. ephelis and F. tuljun. Fastosarion mcdonaldi can be distinguished from $F$. aquavitae, F. comerfordae and $F$. ephelis by its more flattened, reduced shell and smaller size, and from $F$. tuljun by its larger size, pustulose shell lappets and more reduced shell with a membraneous base.

\section{Fastosarion minerva (Stanisic, 2010)}

Figs. 18, 15E-F, 19I, 22I-J, 29

Dimidarion minerva Stanisic, 2010 in Stanisic et al., 2010: 316-317.

\section{Material examined}

Types: Holotype: QM MO56626 (Springsure, NW at Mt Zamia, Minerva Hills NP, MEQ, $24^{\circ} 05^{\prime} 55^{\prime \prime} \mathrm{S}, 148^{\circ} 00^{\prime} 55^{\prime} \mathrm{E}$, sevt, under rocks and logs, coll. 20 Sep 1995, J. Stanisic, D. Potter, C. Eddie).

Paratypes: QM MO76o88, QM MO76366, QM MO78901.

Non-type material: See table 1.

\section{Diagnosis}

External morphology: Shell (figs. 15E-F, 19I) small to medium-sized (8.6-12.8 mm), light golden amber, subglobose with a low spire, 3.2-3.5 whorls. Body 24-27 mm long, colour 


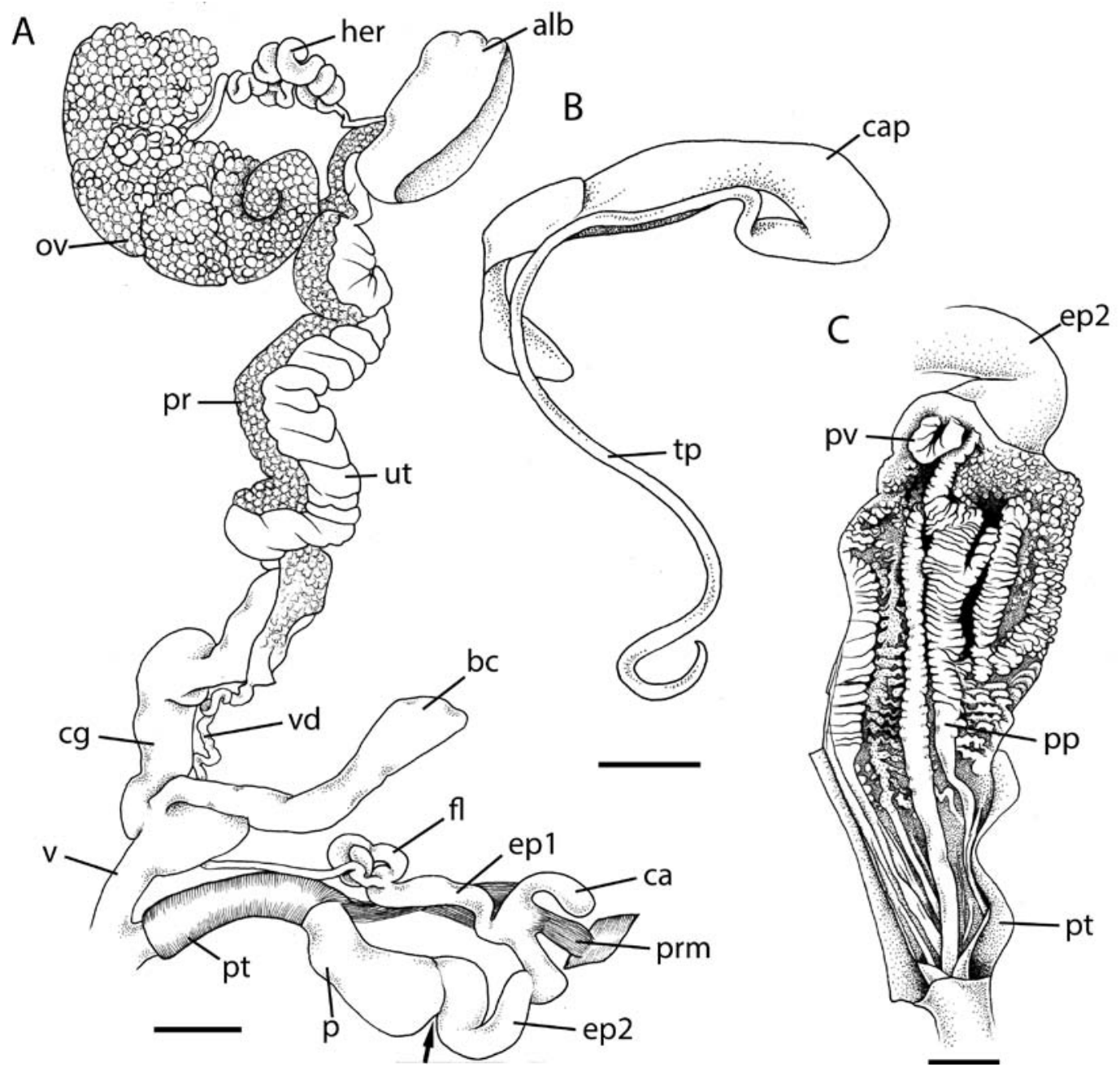

FIGURE 28 Genitalia of F. mcdonaldi, MO504354, Eungella NP. A. Reproductive system. Arrow shows the junction of the penis and epiphallus. B. Spermatophore. C. Penis interior. Scale bars $1 \mathrm{~mm}(\mathrm{~B}-\mathrm{C}), 2 \mathrm{~mm}(\mathrm{~A})$.

(in ethanol) beige, darker brown on tail, mantle lobes large with black spots and mottling, shell lappets moderately large to large, finely pustulose with multiple rows of larger black warts, joined by a narrow collar; dark line along mantle edge. Tail not keeled, slime network weak, caudal horn large.

Genital anatomy: Genitalia (figs. 22I-J, 29) with short vagina; bursa copulatrix moderately short; duct very short, bursa large, oval shaped. Penis moderate size, cylindrical, inner penial wall sculptured with very fine diagonal ridges, penis interior with one large, raised longitudinal pilaster and three small, irregularly shaped pilasters (two distal, one proximal); $75 \%$ of penis contained in penial tunica. Epiphallus slightly longer than penis, entering penis through a simple pore; epiphallus 2 longer than epiphallus 1; epiphallic caecum short; flagellum moderately long, slender, coiled. Spermatophore with a single, finely toothed, spiraling ridge. 


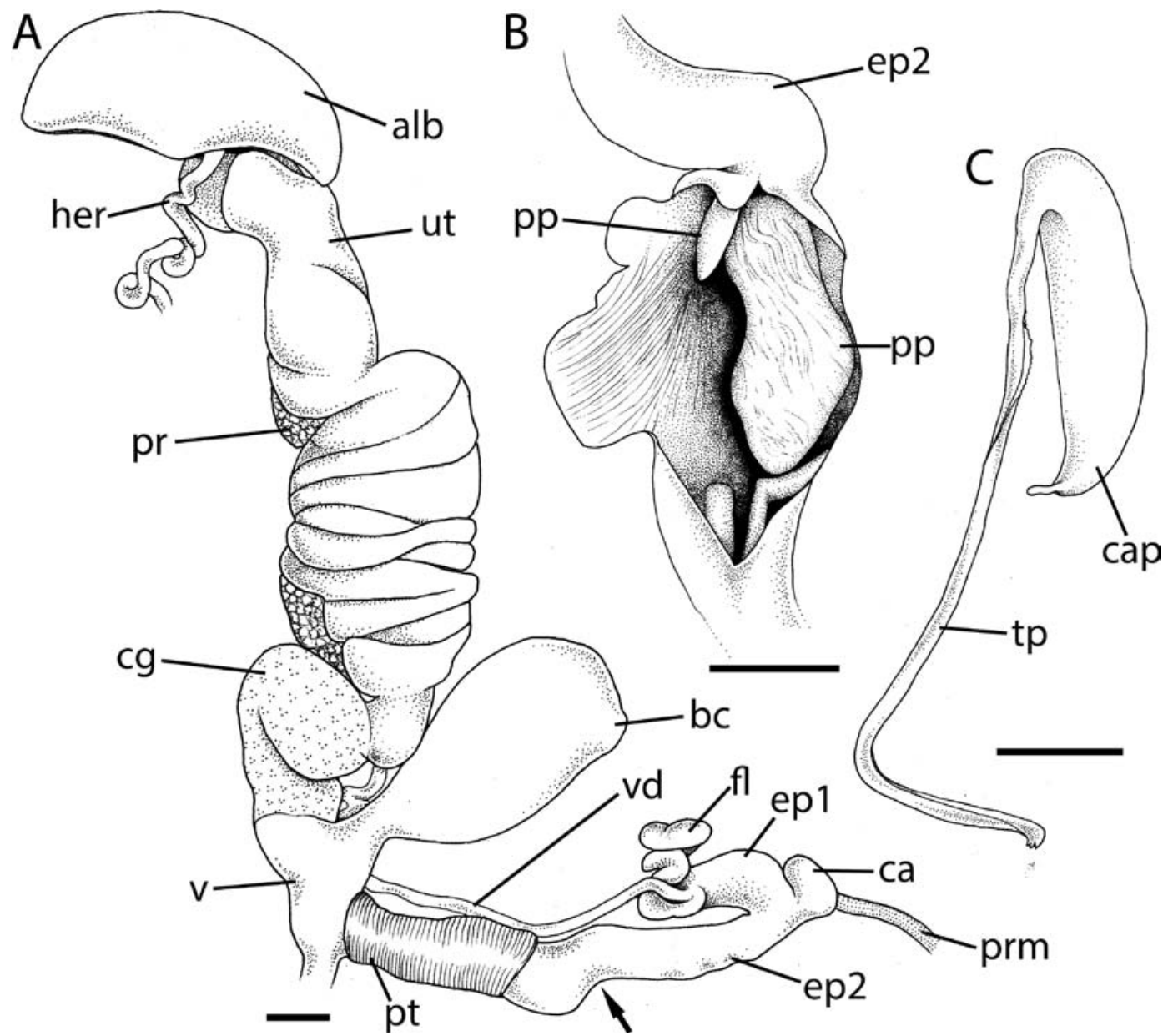

FIGURE 29 Genitalia of F. minerva, MO $7835^{8}$, Carnarvon NP. A. Reproductive system. Arrow shows the junction of the penis and epiphallus. B. Penis interior. C. Spermatophore. Scale bars $1 \mathrm{~mm}$.

\section{Remarks}

Fastosarion minerva (from Minerva Hills NP) was originally described as part of the genus Dimidarion, a group of small semislugs distributed in southern Qld, in habitats ranging from dry vine thicket to rainforest. Herein we show that F. minerva is not closely related to its former congeners (now synonymized to a single species, F. alyssa) but instead groups most closely with $F$. deensis and $F$. rowani, both of which are found near Rockhampton. A similar link between these distant locations is seen in helicarionid species Tarocystis toomba, which is distributed from Rockhampton to the Conway Range and west to Carnarvon Gorge (Stanisic et al., 2010), and camaenid genus Trachygenia Stanisic, 2010, which contains species ranging from from Dan Dan Scrub and Kroombit Tops (south of Rockhampton) to the Clarke Range and Conway Range, as well as one species from Carnarvon Gorge.

The type locality of $F$. minerva is $\mathrm{Mt}$ Zamia in Minerva Hills NP (see fig. 18). Populations from Carnarvon NP and Injune are 
genetically distinct from each other and from those from Mt Zamia. Material suitable for dissection was not available for the type locality, but specimens from Carnarvon NP and Injune did not differ anatomically despite their genetic differentiation. We include all populations within F. minerva, pending further investigation once more material is available.

\section{Fastosarion papillosus Stanisic, 2010}

Figs. 18, 15G-I, 19J-K, 30A-B

Fastosarion papillosa [sic!] Stanisic, 2010 in Stanisic et al., 2010: 304-305.

\section{Material examined}

Types: Holotype: QM MO32337 (Mt Superbus, via Boonah, SEQ, $28^{\circ} 13^{\prime} 30^{\prime \prime S}, 15^{2^{\circ}} 27^{\prime} \mathrm{E}$, under logs, coll. 24 May 1991, J. Stanisic, D. Potter).

Paratypes: QM MO23314, QM MO51156, QM MO55366, QM MO55410, QM MO55432, QM MO78896.

Non-type material: See table 1.

\section{Diagnosis}

External morphology: Shell (16G-I, 19J-K) medium-sized (14.3-14.8 mm), golden amber, very transparent, 3.8-4.0 whorls, subglobose with a flat spire. Body beige, sole cream. Mantle lobes and shell lappets moderately small, irregularly marked with black; each lappet with row of 4-5 warts (sometimes pigmented) near lower edge. Tail slightly keeled at tip, slime network weak, caudal horn large.

Genital anatomy: Genitalia (fig. 30A-B) with long bulging vagina; bursa copulatrix very short, duct distinct, bursa oval. Penis long, broad, cylindrical, proximally fused to epiphallus 2, inner penial wall smooth, with three transversely ridged longitudinal pilasters, two not reaching the distal end; $35-65 \%$ of penis contained in penial tunica. Epiphallus longer than penis; entering penis through a simple pore; epiphallus 2 much longer than epiphallus 1; half of epiphallus 2 fused to penis; epiphallic caecum of moderate length, penial retractor muscle attaching to the middle; flagellum of moderate length, slender.

\section{Remarks}

The spelling of the species name is adapted herein to agree with the masculine gender of the genus name. Fastosarion papillosus is recorded from Richmond Range in northeastern NSW to Lamington NP in southeastern Qld (Stanisic et al., 2010). In the present study we found that candidate taxa Helicarionidae BR12 from Tabletop Bush Reserve and SQ6 from Kroombit Tops, previously identified through curatorial work, also belong to this species. The Kroombit Tops population is approximately $400 \mathrm{~km}$ further north than the rest of the included populations; however, both morpho-anatomical and molecular data confirm its placement as part of F. papillosus.

The sister taxon to this species is the very similar F. pustulosus. A comparison of the original descriptions indicates that F. papillosus is slightly larger, with a row of black lappets on the right shell lappet and no pigmentation on the left lappet, and with pale pinkish grey body colouration, while $F$. pustulosus has unpigmented pustules on the right shell lappet and three black stripes on the left lappet, and dark body colouration. We found some of these reported differences to be erroneous (although observations were based only on preserved data): both species were found to have a row of around five large pustules or warts (sometimes pigmented in F. papillosus) on both left and right lappets, and both also had black markings on the shell lappets (particularly on the left). The most consistent external difference was the higher spire seen in F. pustulosus. The two species shared a unique genital character comprising fusion 


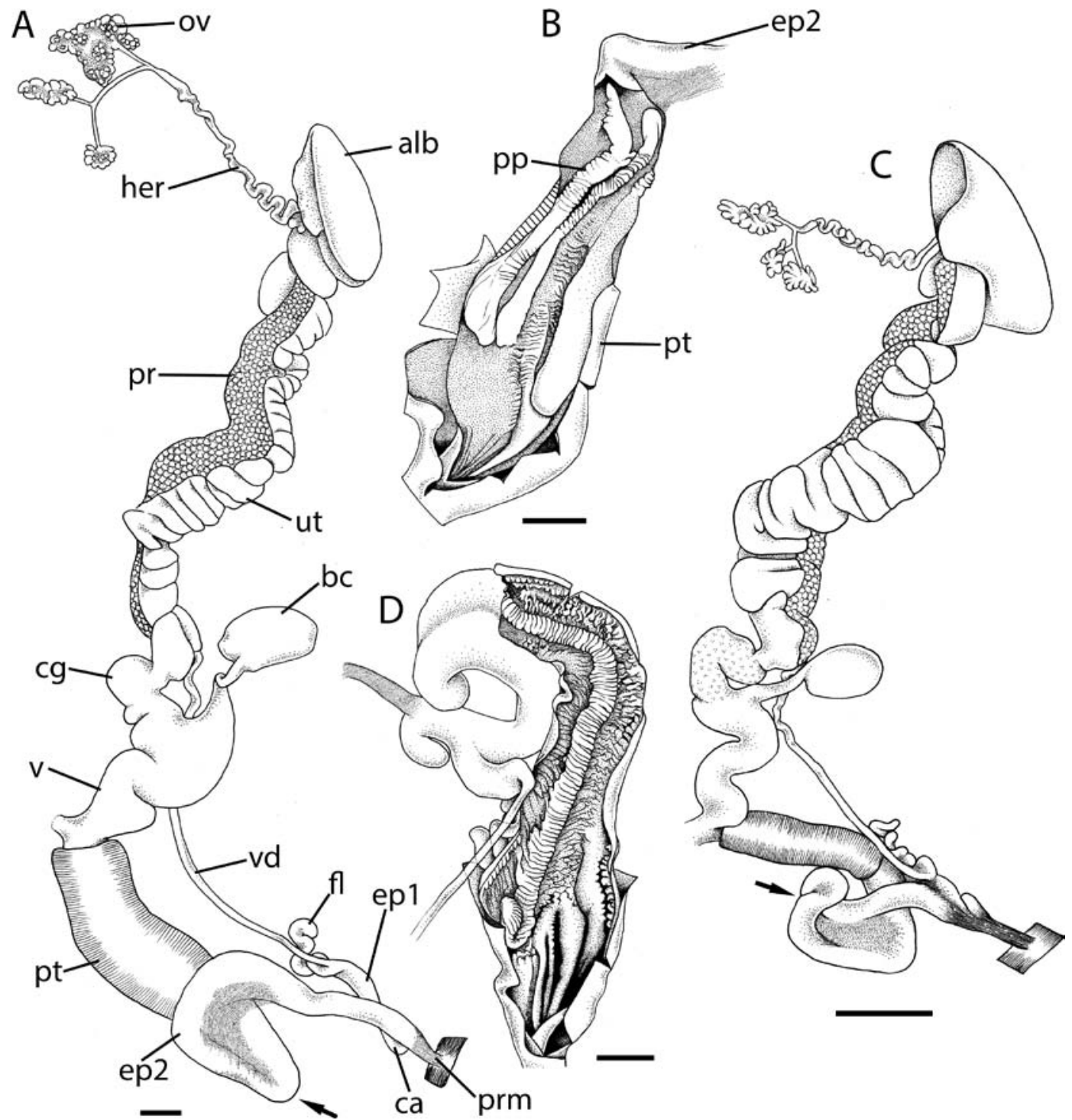

FIgURE 30 Genitalia. A-B. F. papillosus, MO78896, Mt Superbus. C-D. F. pustulosus, MO78894, Mt Fort William.

A, D. Reproductive system. Arrows show the junction of the penis and epiphallus. B-C. Penis interior. Scale bars $2 \mathrm{~mm}$.

of the two epiphallus arms and the proximal portion of the penis. However, in F. pustulosus the penis was longer and narrower, and approximately half of the penis was fused to the epiphallus, while in F. papillosus the penis was very broad and only the proximal quarter or third was fused to the epiphallus. Moreover, $F$. pustulosus has one major longitudinal pilaster while F. papillosus has three.

\section{Fastosarion pustulosus Stanisic, 2010}

Figs. $18,19 \mathrm{~L}, 30 \mathrm{C}-\mathrm{D}$

Fastosarion pustulosa [sic!] Stanisic, 2010 in Stanisic et al., 2010: 304-305. 


\section{Material examined}

Types: Holotype: QM MO4295 (c.4km below summit Mt Fort William, Kalpowar SF, SEQ, $24^{\circ} 41^{\prime} \mathrm{S}, 15^{\circ}{ }^{\circ} 21^{\prime} \mathrm{E}$, mvf/Araucaria, under logs and rocks, 3.vii.1984, J. Stanisic, D. Potter, K. Emberton).

Paratypes: QM MO43276, QM MO78894.

Non-type material: See table 1.

\section{Diagnosis}

External morphology: Shell (fig. 19L) mediumsized (12.1 $\mathrm{mm})$, dull amber, very transparent, 4.1 whorls, subglobose with a moderately low spire. Body (in ethanol) beige, sole paler. Mantle lobes and shell lappets moderately small, narrow, each lappet with a row of at least five unpigmented warts and with black streaks or markings. Tail weakly keeled at tip, slime network moderately strong, caudal horn large.

Genital anatomy: Genitalia (fig. 30C-D) with long vagina, with longitudinal pilasters; bursa copulatrix very short, duct distinct, bursa oval. Penis long, narrow, cylindrical, proximally fused to epiphallus 2, internally with pulstulose transverse ridges and one transversely ridged longitudinal pilaster, several smooth, minor pilasters basally; $35 \%$ of penis contained in penial tunica. Epiphallus longer than penis; entering penis through a simple pore; epiphallus 2 longer than epiphallus 1 ; at least half of epiphallus 2 fused to penis; epiphallic caecum of moderate length, penial retractor muscle attaching to middle; flagellum of moderate length, slender.

\section{Remarks}

The spelling of the species name is adapted herein to agree with the masculine gender of the genus name. Fastosarion pustulosus is recorded from Monto to Rockhampton in southeastern Qld (Stanisic et al., 2010); however, we demonstrate that specimens from around Rockhampton belong to congeners Fastosarion katatonos and Fastosarion deensis.
This restricts $F$. pustulosus to specimens from the type locality, Mt Fort William in Kalpowar State Forest (fig. 18). The three populations were previously grouped together based on the strong similarity between their shells, although F. pustulosus appears to be slightly smaller and higher spired. They are also very similar in their external morphology, with similar body colouration (only observed in ethanol) and pustulose shell lappets. However, they differ greatly in their genital anatomy and are also genetically distinct. Fastosarion pustulosus is most closely related to $F$. papillosus and shares with it the fused penis and epiphallus and a similar internal penial anatomy.

\section{Fastosarion rowani sp. nov.}

Figs. 18, 19M, 31A-B

Etymology

For Rowan Palethorpe.

Material examined

Types: Holotype: QM MO85839 (Gladstone, c. 20 km WNW near Targinie, Millar Rd, 23 ${ }^{\circ} 49^{\prime}$ 15" S, $151^{\circ} 5^{\prime} 35^{\prime \prime}$ E, coll. 26 Jul 1994, J. Stanisic, D. Potter, G. Ingram, C. Eddie).

Paratypes: QM MO54530 (same data as holotype).

Non-type material: See table 1.

\section{Diagnosis}

External morphology: Shell (fig. 19M) medium-sized (10.2-13.5 mm), pale golden amber, 3.6-3.7 whorls, subglobose with a low but prominent spire. Body 25-30 $\mathrm{mm}$ long, colour (in ethanol) beige, darker brown on tail with a pale keel, sole pale in midfield, darker with dark grey wrinkles in outer fields, sides of sole pale with black vertical stripes. Mantle lobes and shell lappets moderately large, pustulose, mantle lobes with black markings, shell lappets with few black pustules. 


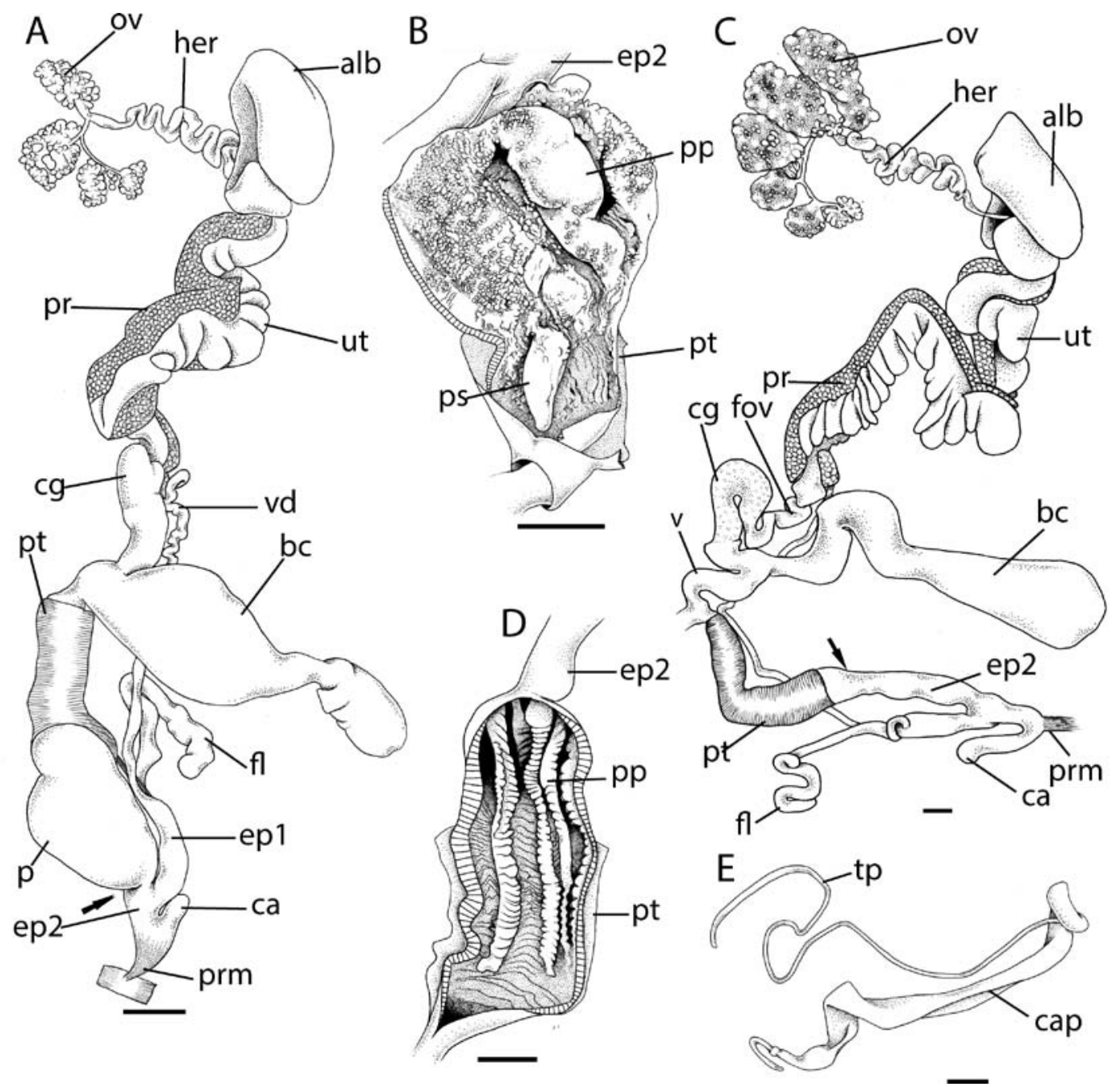

FIGURE 31 Genitalia. A-B. F. rowani, M085839, Gladstone. C-E. F. sarina, M085840, Sarina. A, C. Reproductive system. Arrows show the junction of the penis and epiphallus. B, D. Penis interior. E. spermatophore. Scale bars $1 \mathrm{~mm}(\mathrm{C}-\mathrm{E}), 2 \mathrm{~mm}(\mathrm{~A}-\mathrm{B})$.

Tail weakly keeled at tip, slime network moderate, caudal horn large. Genital anatomy: Genitalia (fig. $31 \mathrm{~A}-\mathrm{B}$ ) with very short vagina; bursa copulatrix moderately long; duct highly swollen distally with thick internal longitudinal pilsaters, bursa oval. Penis large, distally cylindrical, greatly swollen proximally, inner penial wall sculptured with fine pustules; penis interior with a stimulator distally, one minor rounded pilaster medially, and one major longitudinal pilaster proximally; $45 \%$ of penis contained in penial tunica. Epiphallus much shorter than penis, entering through simple pore; epiphallus 2 much shorter than epiphallus 1; epiphallic caecum moderate length; flagellum short, slender.

\section{Remarks}

Fastosarion rowani (previously identified by curatorial work as Helicarionidae SQ7) can be found in semi-evergreen vine thicket under logs in a few locations south of Rockhampton 
in southeastern Qld (Dan Dan NP, Kroombit Tops and Targinie) (fig. 18). In Dan Dan NP it is sympatric with $F$. alyssa and F. longimentula, but it can be distinguished from both by its more globose and highly whorled shell, from $F$. longimentula by the pustules (some pigmented) on the shell lappets, and its slenderer foot with a less obvious slime network, and from $F$. alyssa by its larger size.

\section{Fastosarion sarina sp. nov.}

Figs. 18, 19N, 31C-E

\section{Etymology}

For Sarina, the type locality; noun in apposition.

\section{Material examined}

Types: Holotype: QM MO85840 (Sarina, SW at Blue Mts, c. $0.6 \mathrm{~km} \mathrm{SE}, 21^{\circ} 36^{\prime} \mathrm{S}, 148^{\circ} 5^{8} \mathrm{E}$, coll. 23 Mar 2000, G. Monteith).

Paratypes: QM MO77305 (same data as holotype).

Non-type material: See table 1.

\section{Diagnosis}

External morphology: Shell (fig. 19N) medium-sized (17.7 mm), amber, 3.2 whorls, flattened, last whorl very large. Body $28-30 \mathrm{~mm}$ long, colour (in ethanol) light grey-brown, sole orange-brown, keel cream, right mantle lobe moderately large, left and median lobes used to form a large cephalic shield, shell lappets moderately large, dark brown, paler at tips, with black markings, left lappet with three rows of warts, right lappet smooth. Tail strongly keeled, slime network moderately strong.

Genital anatomy: Genitalia (fig. 31C-E) with medium length vagina; bursa copulatrix long, duct broad, bursa elongate. Penis moderately long, base narrow, increasing in diameter, inner penial wall sculptured with transverse ridges, penis interior with three transversely ridged longitudinal pilasters; $85 \%$ of penis contained in penial tunica. Epiphallus equal in length to penis, entering penis through a simple pore; epiphallus 2 longer than epiphallus 1; epiphallic caecum long; flagellum long, slender. Spermatophore with simple tail-pipe.

\section{Remarks}

This species (identified above as 'Helicarionidae sp. Sarina') is known only from a single location, in rainforest above $800 \mathrm{~m}$ altitude at Blue Mountain southwest of Sarina (fig. 18). Fastosarion alyssa and F. aquavitae are found nearby at Sarina. The former can easily be distinguished by its smaller size and the latter by its more globose shell; however, neither are recorded from Blue Mountain.

\section{Fastosarion tuljun sp. nov.}

Figs. 18, 19O, 32

\section{Etymology}

From tuljun (Wiri = hill or mountain), referring to the Tuljunburra (= mountain people) clan of the Wiri people whose traditional lands include the Denham Range; noun in apposition.

\section{Material examined}

Holotype. QM MO76081, Denham Range, ca $2 \mathrm{~km} \mathrm{NNW}$ of Mt Robert, MEQ. Coll. 18 Dec 2000, D. Cook. G. Monteith.

\section{Diagnosis}

External morphology: Shell (fig. 19O) small (8.7-10.2 mm), golden, transparent, ear-shaped, very reduced, 2.6-3.0 whorls, flattened, thin, last whorl large. Body at least $13 \mathrm{~mm}$, discoloured through immersion in pitfall trap; shell lappets and mantle lobes moderately large with some dark markings, smooth. Tail not keeled, slime network moderately strong.

Genital anatomy: Genitalia (fig. 32) with moderately short vagina; bursa copulatrix 


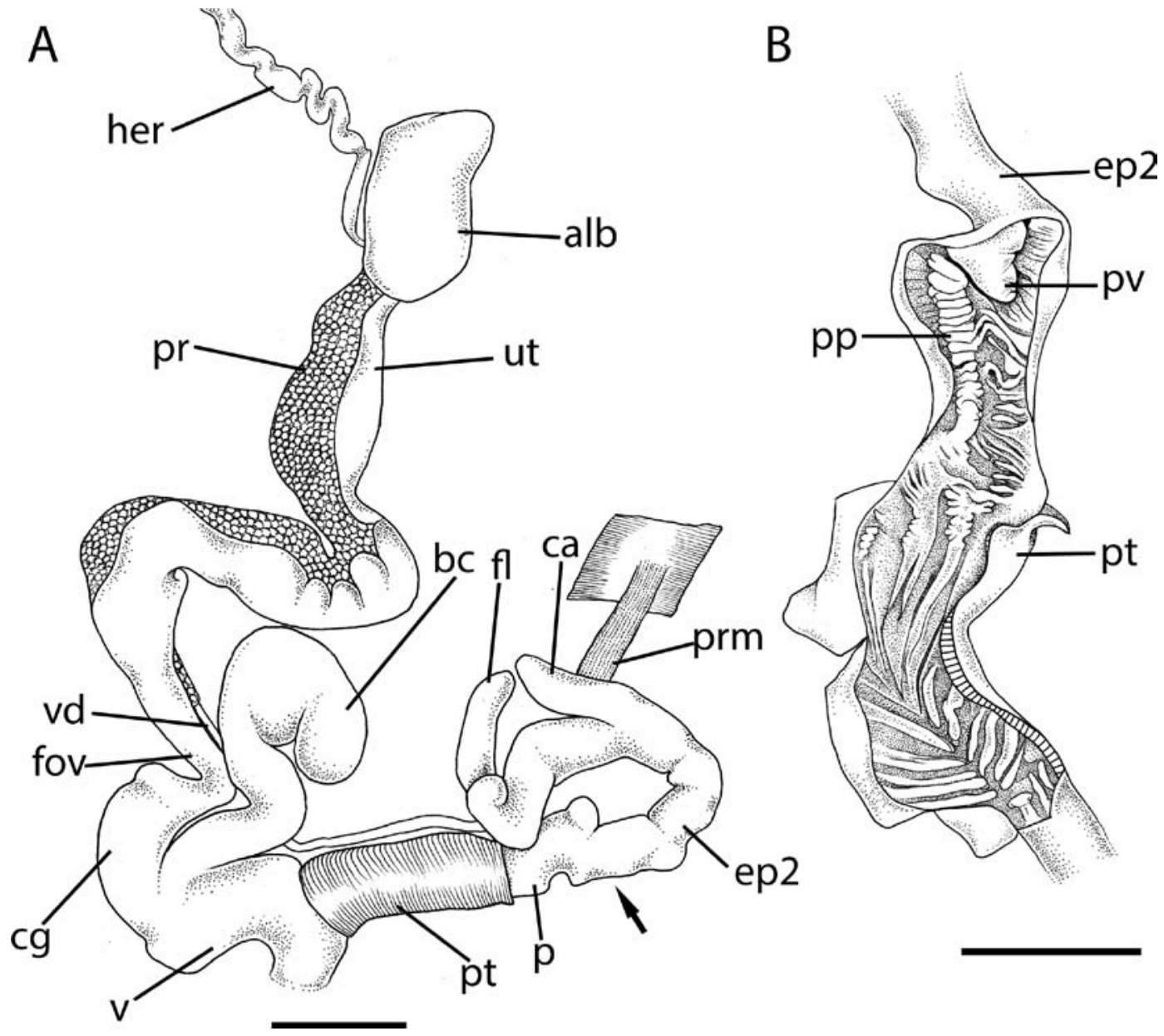

FIGURE 32 Genitalia of F. tuljun, MO76o81, Denham Range. A. Reproductive system. Arrow shows the junction of the penis and epiphallus. B. Penis interior. Scale bars $1 \mathrm{~mm}$.

short, duct distinct, bursa oval. Vagina, free oviduct and base of bursa copulatrix folded into foot. Penis cylindrical, internally with chevron-shaped diagonal ridges distally, a single ridged longitudinal pilaster medially to proximally, proximal portion of penial wall sculptured with transverse ridges; $70 \%$ of penis contained in penial tunica. Epiphallus approx. equal to penis length; entering penis through a short, conical verge; epiphallus arms equal in length; epiphallic caecum of moderate length; flagellum of moderate length, slender.

\section{Remarks}

This species (identified above as 'Helicarionidae sp. Denham Range') is only known from a single live specimen found in rainforest on the Denham Range, west of Mackay, and several shells from the surrounding region (Mt Bassett, Mt Charlton, Eungella NP) (fig. 18). In the phylogenetic analysis it grouped with 
F. longimentula and F. sarina. However, morpho-anatomically it is more similar to F. mcdonaldi, both in its small, flattened, reduced shell and in its genitalia (in particular, the presence of a penial verge and the equal length arms of the epipihallus). It can be distinguished from all other Qld semislugs by its unique penis interior.

\section{Stanisicarion Hyman \& Ponder, 2010}

Stanisicarion Hyman \& Ponder, 2010: 49. Type species Helixarion freycineti Férussac, 1821 (by original designation); masculine.

Macularion Stanisic, 2010 in Stanisic et al., 2010: 312. Type species Vitrina aquila Cox, 1868 (by original designation); masculine.

\section{Remarks}

Stanisicarion, which is of masculine gender, was originally introduced for Helixarion freycineti Férussac, 1821 and Vitrina virens Pfeiffer, 1849, both previously included in Fastosarion (Hyman \& Ponder, 2010). These two nominal species are distinguished from the rest of Fastosarion by their pustulose penis interior, the presence of a penial verge, the presence of only a short penial tunica, a less reduced shell, and less developed or fused shell lobes and lappets (Hyman \& Ponder, 2010). In the same year, the genus Macularion was described for another former member of Fastosarion, Vitrina aquila Cox, 1868, based on the more prominent spiral sculpture on its shell and the strongly textured body surface of the animal.

We show herein that Stanisicarion and Macularion are sister taxa, each containing just a single species. Together they represent Clade $\mathrm{C}$ in the mitochondrial phylogeny. They have less reduced shells with a higher whorl count than most moderate Qld semislugs, with strongly pustulose shell lappets (most easily visible in $S$. freycineti when the animal is at rest). The extent of the mantle lobes and shell lappets was difficult to compare, given the differing degrees of contraction present in preserved material; if there is a difference, it is very slight. The reproductive system had a vagina with deep internal pilasters (although pilasters were not always observed in the capsular gland) and where eggs could be observed, they always had deep spiralling grooves, in contrast to the smooth spherical eggs seen in Fastosarion. The epiphallic caecum was short and hooked with the penis retractor muscle attaching near its base, and the penis had primarily pustulose internal sculpture, a small, elongate verge partially fused to the penial wall, and a penial tunica that in most specimens covered around half of the penis. In addition, the two genera grouped closely in the phylogenetic tree.

The genus as delineated herein is consistent with Clade $\mathrm{C}$ in the mtDNA phylogenies (figs. 1-3).

\section{Differential diagnosis}

External appearance: Shell medium-sized to large $(14-20 \mathrm{~mm})$, golden to greenish amber, glossy, ear-shaped, 3.5-4.4 whorls, subglobose with a low spire, last whorl large, whorls rounded. Protoconch and teleoconch with very fine spiral grooves. Mantle lobes and shell lappets moderately large, completely covering shell when extended, pustulose, spotted; slime network prominent; tail keeled towards tip; caudal horn moderately small.

Genitalia: Spermoviduct of $3-5$ lobes, embedded in digestive gland. Talon and carrefour embedded in albumen gland. Spermoviduct folded in zig-zag pattern. Free oviduct with oval, orange-brown capsular gland; interior of free oviduct with deep longitudinal pilasters, interior of capsular gland with folds in the thickened, glandular walls. Vagina moderately short, internally with longitudinal pilasters. Bursa copulatrix long, with slender duct and oval to elongate sac, inserted on the 
vagina. Penis long, slender, internally pustulose with no pilasters. Penis tunica covering only distal half of penis, attached by muscle fibres to middle of epiphallus; epiphallus enters penis through a short, conical verge, partially fused to penial wall, tip free; epiphallus 2 longer than epiphallus 1; epiphallic caecum situated in middle of epiphallus, short to moderately short, curved, penis retractor muscle attached at or near base; long, slender epiphallic flagellum with axial filament present, coiled and twisted irregularly. Spermatophore a softwalled capsule with hard, smooth tail-pipe; tail-pipe mostly smooth, towards terminal end sculptured with a single spiraling toothed ridge.

\section{Stanisicarion freycineti (Férussac, 1821)}

Figs. 33, 34A, 35, 36A-B, 37

Helixarion freycineti Férussac, 1821: 20.

Helicarion freycineti: Quoy \& Gaimard, 1824.

Vitrina (Helicolimax) australasia Blainville, 1824: 255. [nom. nov. for Helicarion freycineti Quoy \& Gaimard, 1824].

Helix (Vitrina) helicarion Voigt, 1834: 76 [nom. nov. for Helicarion freycineti Quoy \& Gaimard, 1824].

Vitrina robusta Gould, 1846: 181.

Vitrina virens Pfeiffer, 1849:108; Reeve, 1962: pl. 3, sp. 14; Cox, 1868: 85-86, pl. 14, fig. 5, 5a; Pfeiffer, 1876: 26; Cox, 1909: 6.

Vitrina strangei Pfeiffer, 1850: 132; Pfeiffer, 1854: 17, pl. ii, figs. 9-12; Reeve, 1862: pl. vi, sp. 42; Cox, 1868: 85, pl. xiv, fig. 6.

Nanina (Helicarion) freycineti: Martens \& Albers, 1860: 47.

Vitrina freycineti: Reeve, 1862: pl. 6, sp. 40; Cox, 1868: 83, pl. 14, figs. 4, 4a; Pfeiffer, 1876: 23.

Vitrina inflata Reeve, 1862: sp. 64, pl. 9.

Helicarion virens: Tryon, 1885: 172, pl. 39, figs. 69-71; Hedley, 1888: 49; Gabriel, 1930: 85; Iredale, 1937c: 8.

Vercularion freycineti: Iredale, 1941: 6, fig. 8. Vercularion virens: Iredale, 1941: 6.
Fastosarion freycineti: Smith, 1992: 231; Stanisic et al., 2010: 302.

Fastosarion virens: Smith, 1992: 232; Stanisic et al., 2010: 304.

Stanisicarion freycineti: Hyman \& Ponder, 2010: 49 .

Stanisicarion virens: Hyman \& Ponder, 2010: 50 .

Synonymy of $V$. robusta, $V$. strangei and $V$. inflata follows Iredale $(1937,1941)$.

Material examined

Types: Lectotype of $H$. freycineti: MNHP no number (Port Jackson, NSW).

Paralectotypes: MNHP no number.

Syntypes of V. virens: NHMUK 19776 (Moreton Bay, QLD).

Non-type material: See table 1.

\section{Description}

External morphology: Shell (fig. 34A, 35) medium-sized (12.8-16.7 mm), amber, 3.2-3.8 whorls, subglobose with a low spire, reduced, ear-shaped with an expanded last whorl. Body (fig. 36A-B) 25-30 mm, grey-brown (often with a reddish tinge), darker on tail, with a red sole. Shell lappets and mantle lobes moderately large, pustulose, mottled with dark grey. Dark line along mantle edge. Tail keeled, keel often paler, slime network prominent.

Genital anatomy: Genitalia (fig. 37) with long vagina; bursa copulatrix moderately long, duct distinct, bursa spherical to oval. Penis long, slender, slightly swollen proximally, internally pustulose; $60 \%$ of penis contained in penial tunica. Penis longer than epiphallus; epiphallus enters penis through a short verge; epiphallus 2 much longer than epiphallus 1 ; epiphallic caecum very short; flagellum moderately long, slender.

\section{Remarks}

Stanisicarion freycineti was originally described as a member of southeastern Australian genus Helicarion (Férussac, 1821-1822); 


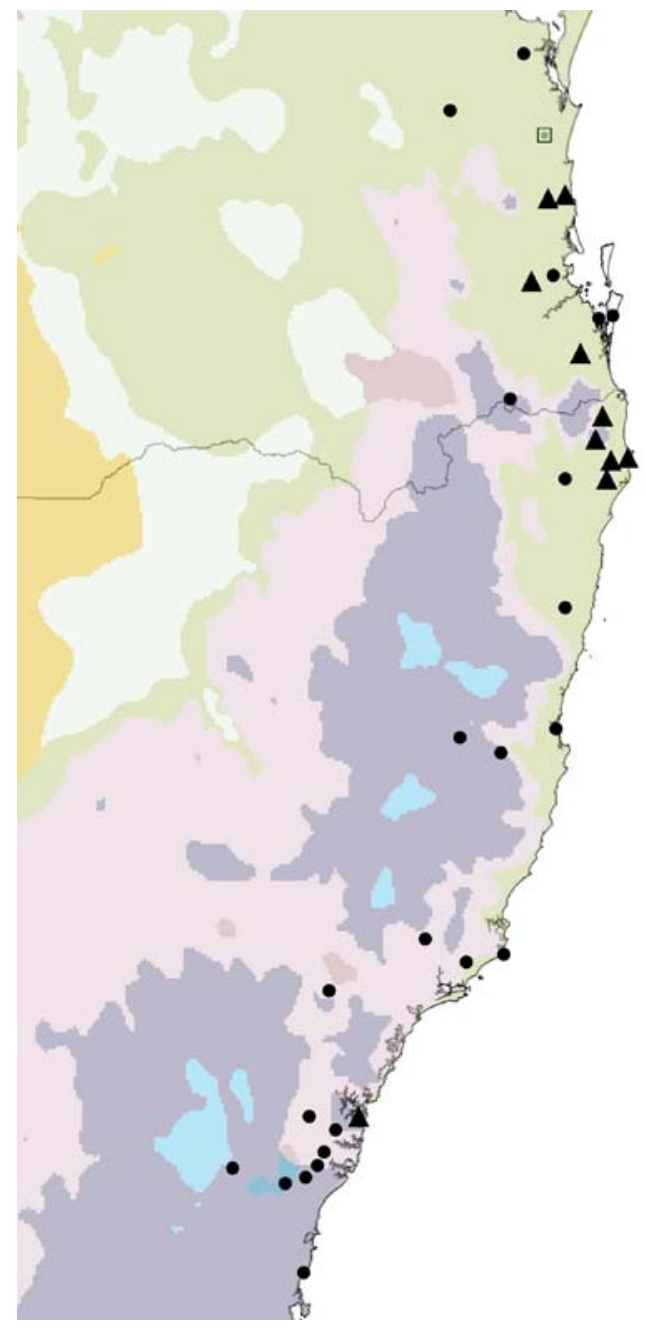

Subtropical: no dry season

Subtropical: distinctly dry summer

Subtropical: distinctly dry winter

Subtropical: moderately dry winter

- Grassland: hot (persistently dry)

Temperate: no dry season (hot summer)

Temperate: moderately dry winter (hot summer)

Temperate: distinctly dry (and hot) summer

Temperate: no dry season (warm summer)

Temperate: moderately dry winter (warm summer)

Temperate: distinctly dry (and warm) summer

Temperate: no dry season (mild summer)

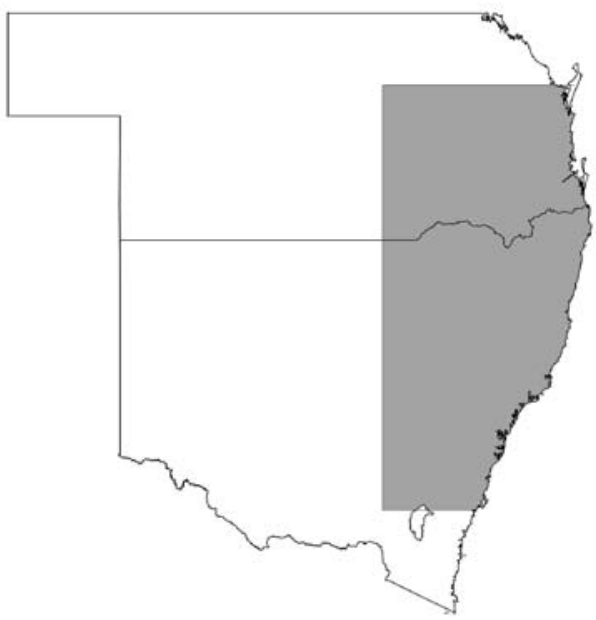

FIGURE 33 Distribution of Clade C species. $\mathbf{\Delta}=$ S. aquila, $\bullet=S$. freycineyti, $\square=S$. wolvi.

however, it has been clearly demonstrated that $S$. freycineti is not closely related to this genus (Hyman et al., 2007; Hyman \& Ponder, 2010; Hyman et al., 2017). In the current study we synomymise Vitrina virens with Helixarion freycineti. Previous authors have maintained the two species as distinct without specifically comparing them, but comparison of the species descriptions implies that discrimination was based on their disjunct ranges, slight differences in size and colouration, and anatomical characters such as the attachment of the penial retractor muscle and the presence or absence of longitudinal pilasters in the capsular gland (Hyman \& Ponder, 2010; Stanisic et al., 2010). We have sampled extensively throughout the range of both species and have found relatively low genetic variation (COI: $2.9 \%$; $16 \mathrm{~S}: 1 \%$ ), consistent with the variation found within other widespread helicarionid species (Hyman \& Köhler, 2018a, b). A single, basally diverging specimen from 


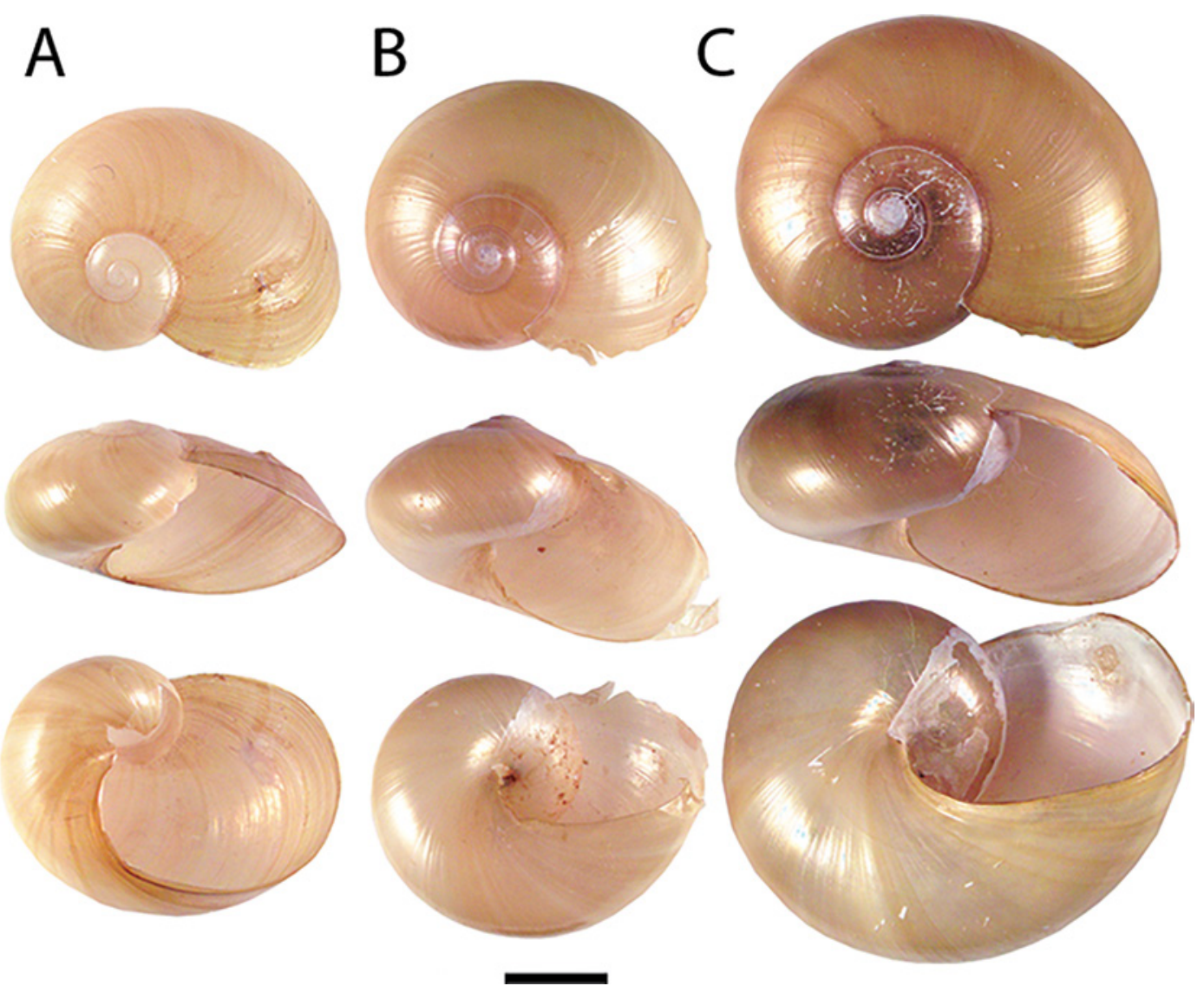

FIGURE 34 Shells of Stanisicarion. A. Stanisicarion freycineti, MO70449. B. Stanisicarion aquila, MO49825. C. Stanisicarion wolvi sp. nov., AM C.581912. Scale bar $5 \mathrm{~mm}$.

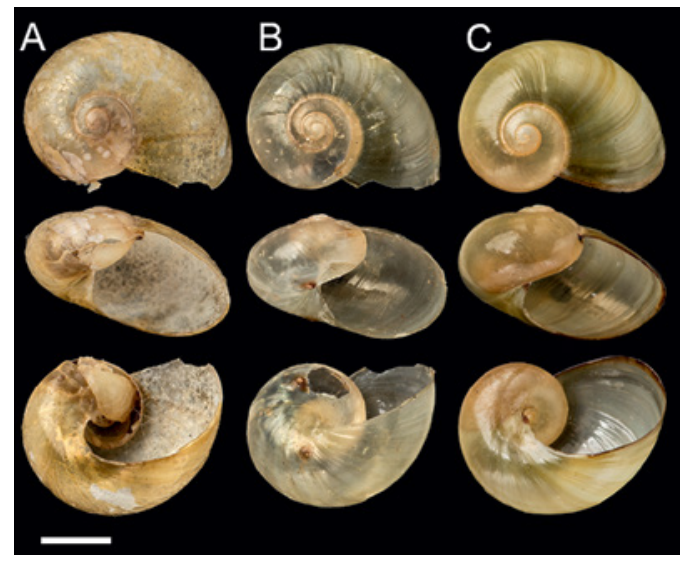

FIGURE 35 Shells of synonyms of Stanisicarion freycineti. A. Vitrina inflata, NHMUK 1977079 (syntypes). B. Vitrina strangei, NHMUK 1983076 (syntypes). C. Vitrina robusta, NHMUK 1926.9.1.63-73 (possible syntypes). All images NHMUK.
Stradbroke Island is genetically more distinct; however, no significant anatomical differences were observed.

The anatomical differences previously noted between $S$. freycineti and $S$. virens (Hyman \& Ponder, 2010) include a terminal rather than basal attachment of the penial retractor muscle to the caecum in $S$. freycineti. The caecum is very short and quite rounded in this species, making it difficult to categorize the position of attachment. However, additional dissections have confirmed that the attachment is the same in $S$. freycineti and $S$. virens, and is best described as medial, near the base.

Iredale $(1937,1941)$ recognized Vitrina robusta (type locality Parramatta near Sydney, NSW) and $V_{\text {inflata }}$ (type locality Sydney I $_{27: 14 \mathrm{PM}}$ 


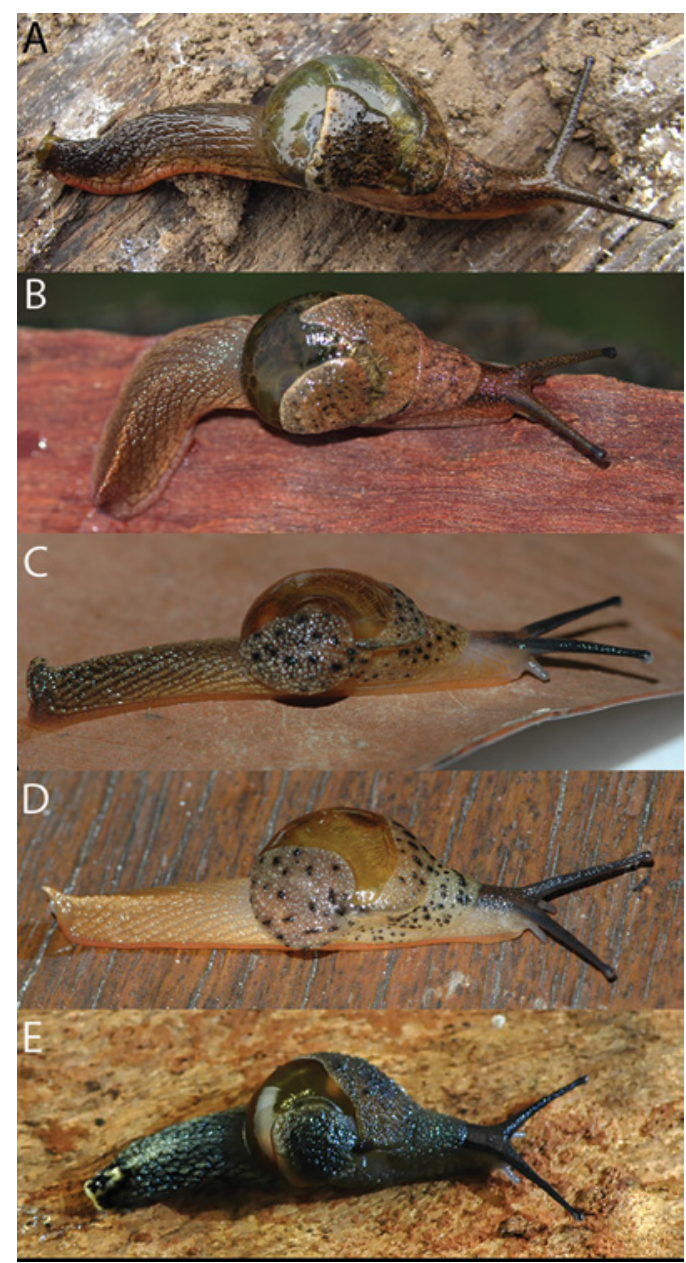

FIGURE 36 Stanisicarion live images (Clade C). A. Stanisicarion freycineti, Emu heights, Sydney (image J. Wradjan). B. Stanisicarion freycineti, AM C.506245, Oxley Wild Rivers NP. C. Stanisicarion aquila, C.512654, Broken Head. D. Stanisicarion aquila, C.512596, Mt Tamborine. E. Stanisicarion aquila, C.269856, Cicada Glen Creek.

NSW) as synonyms of $S$. freycineti, and $V$. strangei (type locality Brisbane, Qld) as a synonym of $S$. virens. However, this was disregarded by Smith (1992) and Smith et al. (2002), who listed $V$. robusta (with junior synonym $V$. inflata) and $V$. strangei as accepted members of Fastosarion. Stanisic et al. (2010) followed Iredale's (1941) lead regarding $V$. strangei, but

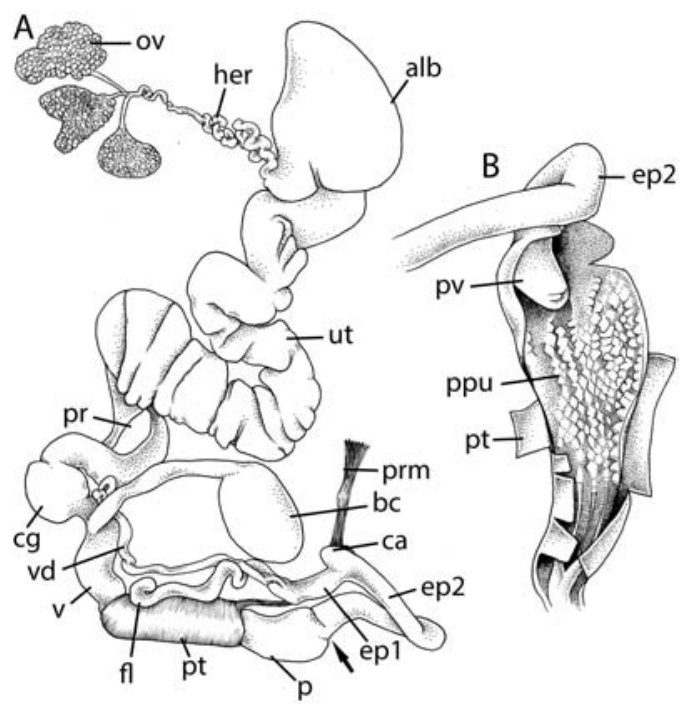

FIGURE 37 Genitalia of S. freycineti, $\mathrm{MO}_{71655}$, Ingleburn. A. Reproductive system. Arrow shows the junction of the penis and epiphallus. B. Penis interior. Scale bars $2 \mathrm{~mm}$.

did not include $V$. robusta or $V$. inflata either as synonyms or as valid species.

Each of these three nominal species are medium-sized semislugs with subglobose shells of $3.2-3.8$ whorls and each matches the dimensions of $S$. freycineti (based on photographs of the syntypes of $V$. inflata and $V$. strangei, and the original illustration of $V$. robusta; fig. 37). The type localities are also located within the known distribution of S. freycineti and therefore we treat all three names as synonyms of $S$. freycineti.

The range of $S$. freycineti now stretches from Sydney, NSW to Rockhampton in southeastern Qld (fig. 33). Stanisicarion freycineti co-occurs with congeners $S$. aquila and $S$. wolvi but can distinguished from these species by its smaller size and more reduced shell with a lower whorl count and more expanded last whorl. It also co-occurs with F. papillosus near the NSW / Qld border, but can be distinguished from this species by its reddish body colouration, its more expanded and rapidly 
descending last whorl and by the lack of a row of distinct pustules on the shell lappets. It can be distinguished from Helicarion, with which it also co-occurs, by its more globose shell and reddish foot-border.

\section{Stanisicarion aquila (Cox, 1868)}

Figs. 14J-L, 33, 34B, 36C-E, 38, 39A-D

Vitrina aquila Cox, 1868: 109.

Vercularion aquila: Iredale, 1941: 6-7.

Macularion aquila: Stanisic, 2010 in Stanisic et al., 2010: 312 .

\section{Material examined}

Types: Holotype: AM C.101185 (Eagle Scrub, Brisbane, Qld).

Non-type material: See table 1.

\section{Description}

External morphology: Shell (figs. 14J-L, 34B) medium-sized (14-18.3 mm), amber, 3.9-4.2 whorls, subglobose with a low spire. Body (figs. 36C-E) 40-45 mm long, light orangebrown to grey, tail often darker, depressions of slime network darker (giving tail a diagonally striped appearance), eyestalks dark grey, foot border sometimes orange. Mantle lobes and shell lappets moderately large, pustulose, with numerous, discrete, raised black spots or ridges. Dark line along mantle edge. Tail keeled at tip, keel paler, slime network prominent.

Genital anatomy: Genitalia (figs. 38, 39A-D) with moderately long vagina; bursa copulatrix moderately long, duct distinct, bursa oval. Penis long, slender, internally pustulose; $50-80 \%$ of penis contained in penial tunica. Epiphallus longer than penis; epiphallus enters penis through a short, pointed verge, partially fused to the penis wall; epiphallus 2 much longer than epiphallus 1; epiphallic caecum very short; flagellum moderately long, slender, irregularly coiled or twisted. Spermatophore a soft capsule with a simple tail-pipe; terminal end hooked with several small spines.

\section{Remarks}

Stanisicarion aquila is currently recorded from Mullumbimby in northeastern NSW to Kenilworth in southeastern Qld (Stanisic et al., 2010), where it is found in rainforest habitats under logs, rocks and fallen palm fronds (fig. 33). This relatively broad range and some variation in external morphology (Stanisic, pers. comm.) led Stanisic et al. (2010) to suggest that $S$. aquila may represent more than one species. Semislugs from northern NSW have brown bodies with orange markings and discrete raised spots on the shell lappets, while those from Mt Tamborine in southern Qld have cream bodies with orange markings and raised short ridges rather than spots on their shell lappets (fig. 34A-C). Further north still, semislugs from Conondale and the Sunshine Coast are grey rather than cream, with no orange colouring and much less visible spots on the shell lappets (fig. 34A-C). These three morphs form separate clades in the phylogenetic tree, but sampling across the entire range has revealed little anatomical variation and a degree of genetic variation consistent with other widespread species (COI: 1.4\%, 16S: 2.2\%).

A population of this species was also discovered in Cicada Glen in northern Sydney and is assumed to have been introduced, perhaps in plants being brought in to a nearby nursery. It matches the Conondale population in its body colour and genetics.

Both introduced and native populations of S. aquila occur within the range of congener $S$. freycineti, but $S$. freycineti is generally found in dry sclerophyll forest and open woodland rather than rainforest and the two species have not been recorded in sympatry. Stanisicarion aquila can be distinguished by its larger, more highly whorled but less globose shell and more highly pustulose shell lappets, usually with visible spots or ridges. It is also sympatric with arboreal semislug Fastosarion papillosus, but can be distinguished by its larger 


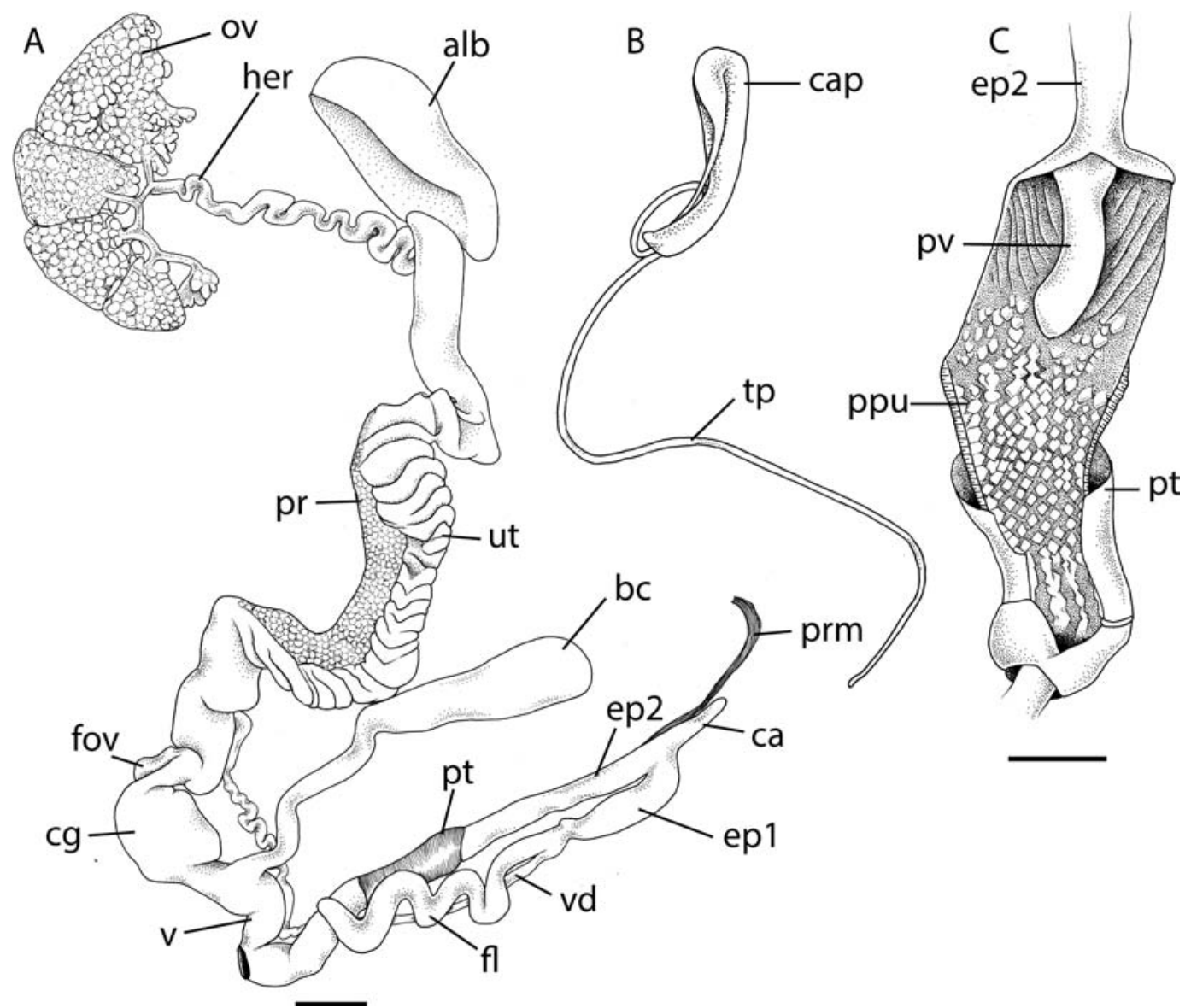

FIGURE 38 Genitalia of S. aquila, MO23337, McDonald NP. A. Reproductive system. Arrow shows the junction of the penis and epiphallus. B. Penis interior. C. Spermatophore. Scale bars $1 \mathrm{~mm}$.

size and evenly pustulose lappets, in contrast to the single row of papillae on the shell lappet of F. papillosus.

\section{Stanisicarion wolvi sp. nov.}

Figs. 33, 34C, 39E-F, 40

\section{Etymology}

For Mt Wolvi, the type locality; noun in apposition.

\section{Material examined}

Types: Holotype: AM C.581912 (Gympie District, Mt. Wolvi, Salmon Lookout, $26^{\circ} 10^{\prime} 41^{\prime \prime} \mathrm{S}$, $12^{\circ} 5^{\prime} 21 "$ E, coll. 04 Aug 2011, J. Ferguson).
Paratypes: AM C.478035 (same data as holotype).

Non-type material: See table 1.

\section{Description}

External morphology: Shell (fig. 34C) large $\left(20.5^{-20.7} \mathrm{~mm}\right)$, golden amber, 3.9-4.4 whorls, subglobose with a very low spire. Body 40-45 $\mathrm{mm}$, colour (in alcohol) uniform grey, mid field of sole white, shell lappets and mantle lobes grey with few black spots. Shell lappets and mantle lobes moderately large, lappets heavily pustulose, lobes finely pustulose. Dark line along mantle edge. Tail weakly keeled at tip, slime network prominent. 


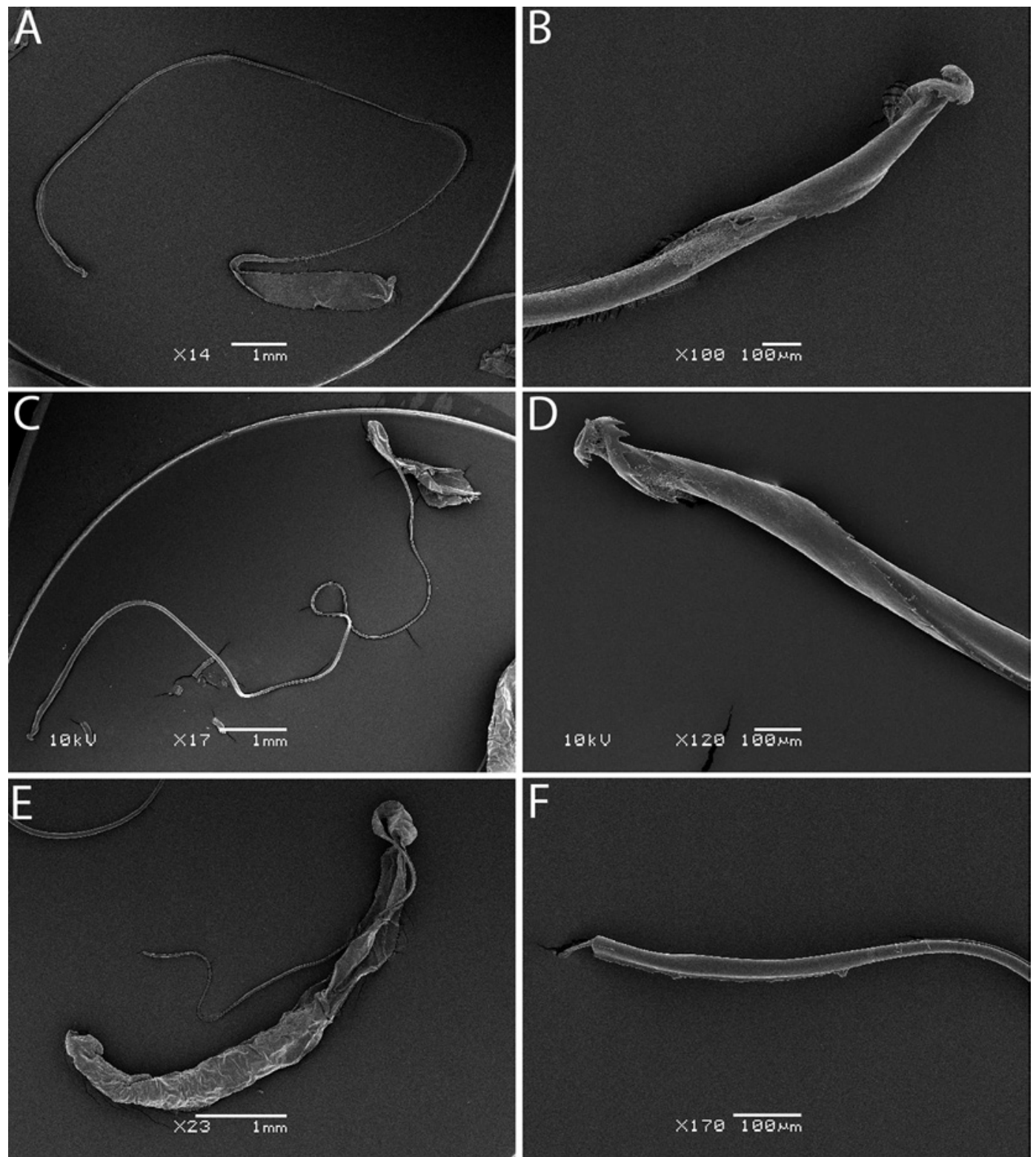

FIGURE 39 Stanisicarion spermatophores (Clade C). A-B. S. aquila, MO77158. C-D. S. aquila, AM C.269856. E-F. S. wolvi, AM C.581912.

Genital anatomy: Genitalia (figs. $39 \mathrm{E}-\mathrm{F}, 40$ ) with moderately long vagina, slightly swollen; bursa copulatrix moderately long, duct distinct, bursa elongate oval. Penis long, slender, narrowing distally, internally with fine, numerous pustules arranged in longitudinal rows; $40 \%$ of penis contained in penial tunica. Epiphallus slightly longer than penis; epiphallus enters penis through a very short, broad verge, pointed at tip; epiphallus 2 longer than epiphallus 1; epiphallic caecum of moderate length; flagellum moderately long, 
A

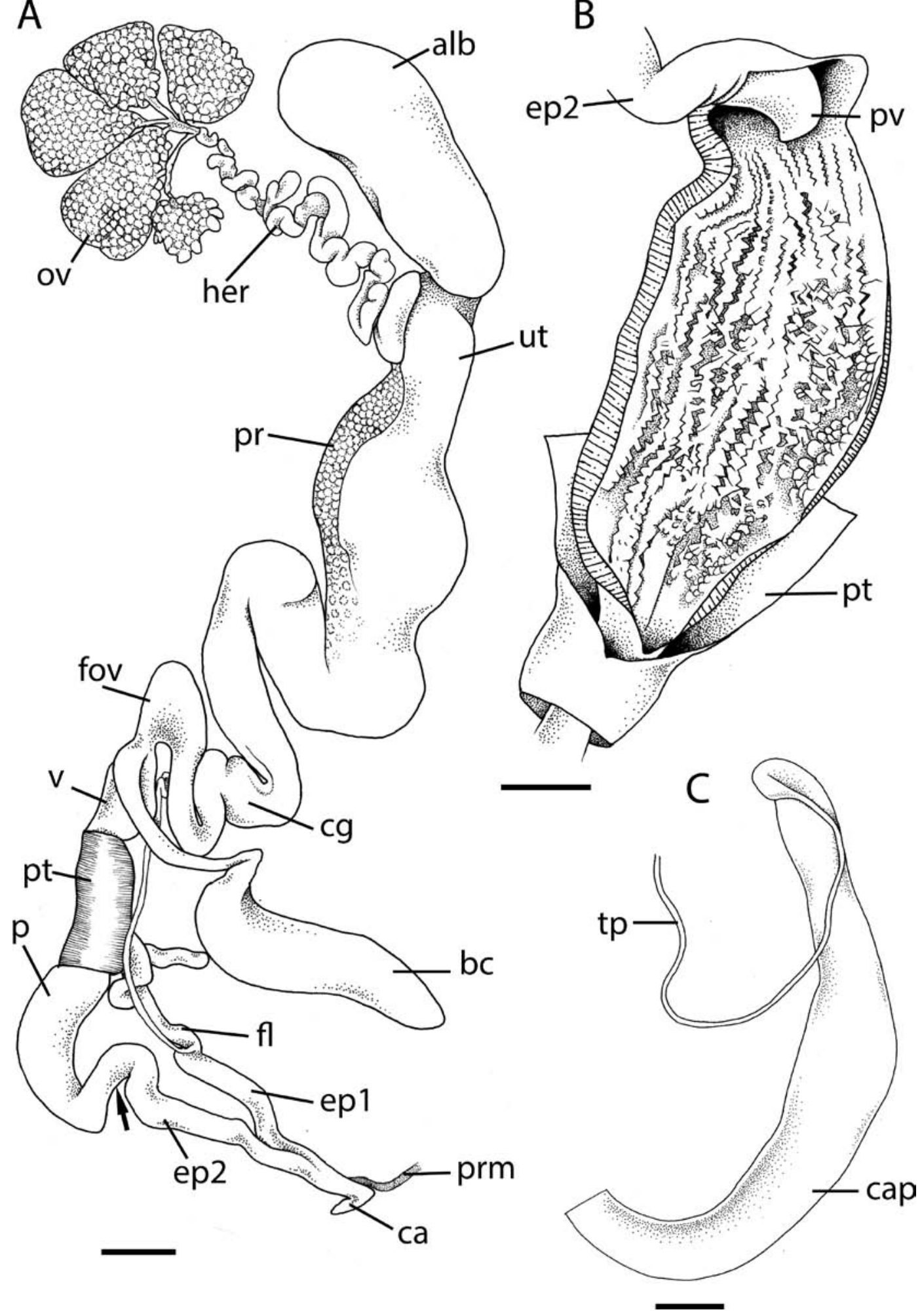

FIGURE 40 Genitalia of S. wolvi sp. nov., AM C.581912, Wolvi Lookout, Mt Salmon. A. Reproductive system. Arrow

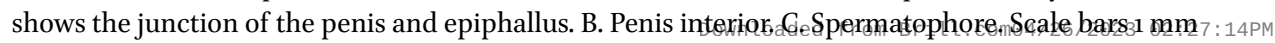
(A-B), $2 \mathrm{~mm}(\mathrm{C})$. 
slender. Spermatophore with a very long, narrow tail-pipe sculptured with a single spiraling row of small teeth.

\section{Remarks}

Stanisicarion wolvi (referred to above as 'Helicarionidae sp. Mt Wolvi') is known only from Mt Wolvi near Gympie in southeastern Qld (fig. 33). It is closely related to $S$. aquila, which is not recorded from Mt Wolvi but is found only a short distance to the south in Kenilworth. However, S. wolvi is larger than S. aquila and while it is only known from preserved specimens, appears to differ in its uniform grey colouration with fewer spots on the shell lappets. Stanisicarion wolvi was found buried in the soil under rocks in notophyll vine thicket.

\section{Acknowledgements}

This work has been made possible through financial support from the Australian Government (ABRS grant RF215-49), which is gratefully acknowledged. We extend our thanks to Adnan Moussalli and Chris Rowley (NMV), Darryl Potter and John Stanisic (QM), Jonathan Ablett (NHMUK), Anna Persson (NHRM) and Michael Shea, Mandy Reid and Alison Miller (AM) for providing material and photographs and for assistance with loans. We also thank three anonymous reviewers for constructive comments that greatly improved the manuscript. We are also grateful to Michael Shea for carrying out the anatomical drawings.

\section{References}

Bank, R. (2017) Classification of the recent terrestrial Gastropoda of the World. Last update: 16 July 2017. Accessed 3 February 2019.

Blainville, H. de. (1824) Mollusques, Mollusca (Malacoz.). In: F.G. Levrault (Ed.) Dictionaire des Sciences Naturelles, pp. 567. Levrault, Paris \& Strassburg.
Brown, M., Cooksley, H., Carthew, S.M. \& Cooper, S.J.B. (2006) Conservation units and phylogeographic structure of an arboreal marsupial, the yellow-bellied glider (Petaurus australis). Aust. J. Zool., 54, 305-317.

Byrne, M., Steane, D.A., Joseph, L., Yeates, D.K., Jordan, G.J., Crayn, D., Aplin, K., Cantrill, D.J., Cook, L.G., Crisp, M.D., Keogh, J.S., Melville, J., Moritz, C., Porch, N., Sniderman, J.M.K., Sunnucks, P. \& Weston, P.H. (2011) Decline of a biome: evolution, contraction, fragmentation, extinction and invasion of the Australian mesic zone biota.J. Biogeogr., 38, 1635-1656.

Chapple, D.G., Hoskin, C.J., Chapple, S.N. \& Thompson, M.B. (2011) Phylogeographic divergence in the widespread delicate skink (Lampropholis delicata) corresponds to dry habitat barriers in eastern Australia. BMC Evol. Biol., 11, 191.

Cox, J.C. (1868) A Monograph of Australian Land Shells. Maddock, Sydney.

Cox, J.C. (1871) Descriptions of seven new species of Australian land shells. Proc. Zool. Soc. Lond., 1871, 53-55.

Cox, J.C. (1873) Descriptions of new land-shells from Australia and the Solomon Islands. Proc. Zool. Soc. Lond., 1873, 146-152.

Cox, J.C. (1887) Contributions to conchology I. Proc. Linn. Soc. N. S. W., 2, 1061-1064.

Cox, J.C. (1909) A List of the Ssubclass Pulmonata Found in Australia, Part I., not Including Tasmania, Lord Howe's Island (under the NSW Government), or the New Guinea Mainland and Adjacent Islands. Frederick W. White, Sydney.

Cracraft, J. (1991) Patterns of diversification within continental biotas: heirarchial congruence among the areas of endemism of Australian vertebrates. Aust. Syst. Bot., 4, 211-227.

Faith, D.P., Köhler, F., Puslednik, L. \& Ballard, J.W.O. (2011) Phylogenies with corroboration assessment. Zootaxa, 2946, 52-56.

Férussac, A.E.J.P.J.F. d'Audebard de. (1821-1822) Deuxième partie: Tableau particuliers des mollusques terrestres et fluviatiles, tableau de la famille des Limaçons et tableau de la famille des Auricules. Didot, Baris.om Brill.com04/26/2023 02:27:14PM via free access 
Folmer, O., Black, M., Hoeh, W., Lutz, R. \& Vrijenhoek, R. (1994) DNA primers for amplification of mitochondrial cytochrome c oxidase subunit I from diverse metazoan invertebrates. $\mathrm{Mol} . \mathrm{Ma}$ rine Biol. Biotechnol., 3, 294-299.

Ford, J. (1987a) Minor isolates and minor geographical barriers in avian speciation in continental Australia. Emu, 87, 90-102.

Ford, J. (1987b) Hybrid zones in Australian birds. Eтu, 87, 158-178.

Gabriel, C.J. (1930) Catalogue of the land shells of Victoria. Proceedings of the Royal Society of Victoria, $43,62-88$.

Gómez, B.J. (2001) Structure and functioning of the reproductive system. In: G.M. Barker (Ed.) The Biology of Terrestrial Molluscs, pp. 307-330. CABI Publishing, Wallingford.

Gould, A. (1846) Descriptions of shells of the Exploring Expedition. Proc. Boston Soc. Nat. Hist., 2, 177-184.

Hausdorf, B. (1998) Phylogeny of the Limacoidea sensu lato (Gastropoda: Stylommatophora). J. Molluscan Stud., 64, 35-66.

Hedley, C. (1888) A list of the land shells recorded from Queensland. Proc. Royal Soc. Qld., 5, $45^{-70 .}$

Hyman, I.T., Ho, Y.W.S. \& Jermiin, L.S. (2007) Molecular phylogeny of Australian Helicarionidae, Euconulidae and related groups (Gastropoda: Pulmonata: Stylommatophora) based on mitochondrial DNA. Mol. Phylogenet. Evol., 45, 792-812.

Hyman, I.T. \& Köhler, F. (2017) Attenborougharion gen. nov. (Mollusca: Pulmonata: Helicarionidae): a likely case of convergent evolution in southeastern Tasmania. Rec. Aust. Mus., 69, $65^{-72 .}$

Hyman, I.T. \& Köhler, F. (2018a) A revision of eastern Australian land snails placed in Nitor Gude, 1911 (Helicarionidae, Stylommatophora). Invertebr. Syst., 32, 1171-1205.

Hyman, I.T. \& Köhler, F. (2018b). Reconciling comparative anatomy and mitochondrial phylogenetics in revising species limits in the Australian semislug Helicarion Férussac, 1821
(Gastropoda, Stylommatophora). Zool. J. Linn. Soc., 184, 933-968.

Hyman, I.T. \& Köhler, F. (2019) Revision of Sigaloeista Shea \& Griffiths, 2010 (Helicarionidae, Gastropoda, Stylommatophora) from eastern Australia.MolluscanRes., 39, 171-189. doi:10.1080/ 13235818.2018.1471973

Hyman, I.T., Lamborena, I. de la I. \& Köhler, F. (2017) Molecular phylogenetics and systematic revision of the south-eastern Australian Helicarionidae (Gastropoda, Stylommatophora). Contrib. Zool., 86, 51-95.

Hyman, I.T. \& Ponder, W.F. (2010) A morphological phylogenetic analysis and generic revision of Australian Helicarionidae (Gastropoda: Pulmonata: Stylommatophora), and an assessment of the relationships of the family. Zootaxa, 2462, 1-148.

Hyman, I.T. \& Ponder, W.F. (2016) Helicarionidae (Gastropoda: Heterobranchia: Stylommatophora) of Lord Howe Island. Molluscan Res., 36, 84-107.

Iredale, T. (1933) Systematic notes on Australian land shells. Rec. Aust. Mus., 19, 37-59.

Iredale, T. (1937) A basic list of the land Mollusca of Australia. Part II. Aust. Zool., 9, 1-39.

Iredale, T. (1941) Guide to the land shells of New South Wales - part III. Aust. Zool., 11, 1-8.

Joseph, L. \& Moritz, C. (1994) Mitochondrial DNA phylogeography of birds in eastern Australian rainforests: first fragments. Aust. J. Zool., 42, 385-403.

Kalyaanamoorthy, S., Minh, B.Q., Wong, T.K.F., von Haeseler, A. \& Jermiin, L.S. (2017) ModelFinder: fast model selection for accurate phylogenetic estimates. Nat. Methods, 14, 587-589.

Katoh, K., Misawa, K., Kuma, K. \& Miyata, T. (2002) MAFFT: a novel method for rapid multiple sequence alignment based on fast Fourier transform. Nucleic Acids Res., 30, 3059-3066.

Kimura, M. (1980) A simple method for estimating evolutionary rates of base substitutions through comparative studies of nucleotide sequences. J. Mol. Evol., 16, 111-120. 
Kimura, M. (1981) Estimation of evolutionary distances between homologous nucleotide sequences. Proc. Natl. Acad. Sci. U.S.A., 78, 454-458.

Köhler, F. (2011) The camaenid species of the Kimberley Islands, Western Australia (Stylommatophora: Helicoidea). Malacologia, 54, 203-406.

Kumar, S., Stecher, G. \& Tamura, K. (2016) MEGA7: Molecular Evolutionary Genetics Analysis version 7.o for bigger datasets. Mol. Biol. Evol., 33, 1870-1874.

Lanfear, R., Calcott, B., Ho, S.Y.W. \& Guindon, S. (2012) PartitionFinder: combined selection of partitioning schemes and substitution models for phylogenetic analyses. Mol. Biol. Evol., 29, 1695-1701.

Martens, E. von \& Albers, J.C. (1860) Die Heliceen nach natuerlicher Verwandtschaft systematisch geordnet. 2. Ausgabe. Engelmann, Leipzig.

Martin, H.A. (2006) Cenozoic climate change and the development of the arid vegetation in Australia. J. Arid Environ., 66, 533-563.

Miller, M.A., Pfeiffer, W. \& Schwartz, T. (2010) Creating the CIPRES Science Gateway for inference of large phylogenetic trees. In: 2010 Gateway Computing Environments Workshop (GCE), pp. 1-8.

Nguyen, L.-T., Schmidt, H.A., von Haeseler, A. \& Minh, B.Q. (2015) IQ-TREE: a fast and effective stochastic algorithm for estimating MaximumLikelihood phylogenies. Mol. Biol. Evol., 32, 268-274.

Odhner, N.H. (1917) Results of Dr. E. Mjöbergs Swedish Scientific Expeditions to Australia 1910-1913. XVII. Mollusca. K. svenska. VetenskAkad. Handl., 52, 1-115.

Pfeiffer, L. (1849) Description of a new Helix and Streptaxis, from the collection of H. Cuming, Esq. Proc. Zool. Soc. Lond., 1848, 108-109.

Pfeiffer, L. (1850) Descriptions of twelve new species of Vitrina and Succinea from the collection of H. Cuming, Esq. Proc. Zool. Soc. Lond., 1849, 132-134.
Pfeiffer, L. (1854) Die Gattungen Daudebardia, Simpulopsis, Vitrina und Succinea. In: Systematiches Conchylien-Cabinet von Martini und Chemnitz, Ersten Bandes, elfte Abtheilung, pp. 1-32. Bauer \& Raspe, Nürnberg.

Pfeiffer, L. (1876). Monographia heliceorum viventium: sistens descriptiones systematicas et criticas omnium huius familiae generum et specierum hodie cognitarum. Brockhaus, Lipsiae [Leipzig].

Quoy, J.R. \& Gaimard, J.P. (1832) Voyage de découvertes de l'Astrolabe exécuté par ordre du roi, pendant les années 1826-1827-1828-1829, sous le commandement de M.J. Dumont d'Urville. Zoologie. J. Tastu, Paris.

Reeve, L.A. (1862) Monograph of the genus Vitrina. In: L.A. Reeve (Ed.) Conchologia Iconica: or, Illustrations of the Shells of Molluscous Animals. Lovell Reeve, London.

Revell, L.J. (2012) Phytools: an R package for phylogenetic comparative biology (and other things). Methods Ecol. Evol., 3, 217-223.

Ronquist, F. \& Huelsenbeck, J.P. (2003) MrBayes 3: Bayesian phylogenetic inference under mixed models. Bioinformatics, 19, 1572-1574.

Schauble, C.S. \& Moritz, C. (2001) Comparative phylogeography of two open forest frogs from eastern Australia. Biol. J. Linn. Soc. Lond., 74, 157-170.

Scott, B. (1995) Redescription of Fastosarion super$b a(\mathrm{Cox}, 1871)$ with descriptions of two new species of Fastosarion from northern Queensland (Pulmonata: Helicarionidae). Molluscan Res., 16, 69-8o.

Sela, I., Ashkenazy, H., Katoh, K. \& Pupko, T. (2015) GUIDANCE2: accurate detection of unreliable alignment regions accounting for the uncertainty of multiple parameters. Nucleic Acids Res., 43, $\mathrm{W}_{7}-\mathrm{W}_{14}$.

Shimodaira, H. \& Hasegawa, M. (1999) Multiple comparisons of log-likelihoods with applications to phylogenetic inference. Mol. Biol. Evol., 16, 1114-1116. 
Sites, J.W. \& Marshall, J.C. (2004) Operational criteria for delimiting species. Annu. Rev. Ecol. Syst., 35, 199-227.

Smith, B.J. (1992) Non-marine Mollusca. In: W.W.K. Houston (Ed.), Zoological Catalogue of Australia, pp. 1-408. Australian Government Publishing Service, Canberra.

Smith, B.J., Reid, S. \& Ponder, W.F. (2002) Pulmonata. Australian Faunal Directory. Australian Biological Resources Study, Canberra. ABRS. Available online: http://www.environment.gov.au/ biodiversity/abrs/online-resources/fauna/afd/ taxa/pulmonata [Accessed on 28 August 2018].

Stamatakis, A. (2014) RAxML version 8: a tool for phylogenetic analysis and post-analysis of large phylogenies. Bioinformatics, 30, 1312-1313.

Stanisic, J. (1993a) Eungarion mcdonaldi gen. et sp. nov., a montane semi-slug from mideastern Queensland rainforests (Pulmonata: Helicarionidae). Mem. Queensl. Mus., 34, 27-34.

Stanisic, J. (1993b) The identity of Helicarion semoni Marten, 1894: a large semi-slug from the Wet Tropics, northeastern Queensland (Pulmonata: Helicarionidae). Mem. Queensl. Mus., 34, 1-9.

Stanisic, J., Shea, M., Potter, D. \& Griffiths, O. (2010) Australian Land Snails. 1. A Field Guide to Eastern Australian Species. Bioculture Press, Riviere des Anguilles, Mauritius.
Stanisic, J. (2018) Description of a new species of semi-slug, Fastosarion comerfordae sp.nov., from EungellaNationalPark,mid-easternQueensland (Gastropoda: Eupulmonata: Helicarionidae). Mem. Queensl.Mus. - Nature, 61, 43-51.

Stern, H. \& de Hoedt, G.J.E. (200o) Objective classification of Australian climates. Aust. Meteorol. Mag., 49, 87-96.

Tamura, K. \& Nei, M. (1993) Estimation of the number of nucleotide substitutions in the control region of mitochondrial DNA in humans and chimpanzees. Mol. Biol. Evol., 10, 512-526.

Tryon, G.W. (1885) Testacellidae, Oleacinidae, Streptaxidae, Helicoidea, Vitrinidae, Limacidae, Arionidae. In: Manual of Conchology, Structural and Systematic, with Illustrations of the Species. Second series, pp. 1-364, 36o pl. Conchological Section of the Academy of Natural Sciences of Philadelphia, Philadelphia.

Voigt, F.S. (1834) Das Thierreich, geordnet nach seiner Organisation als grundlage der Naturgeschichte der Tiere und einleitung in die vergleichende Anatomie. Vom Baron von Cuvier. F.A. Brockhaus, Liepzig.

RECEIVED: 8 FEBRUARY 2019 | REVISED AND

ACCEPTED: 27 JUNE 2019

EDITOR: A.J. DE WINTER 